Marcelo Cuadrado Marin

\title{
CONTRIBUIÇÃO À ANÁLISE DA ESTABILIDADE GLOBAL DE ESTRUTURAS EM CONCRETO PRÉ-MOLDADO DE MÚLTIPLOS PAVIMENTOS
}

Dissertação apresentada à Escola de Engenharia de São Carlos, da Universidade de São Paulo, como parte integrante dos requisitos para obtenção do título de Mestre em Engenharia de Estruturas.

Orientador: Prof. Titular Dr. Mounir Khalil El Debs

São Carlos 
AUTORIZO A REPRODUÇÃO E DIVULGAÇÃO TOTAL OU PARCIAL DESTE TRABALHO, POR QUALQUER MEIO CONVENCIONAL OU ELETRÔNICO, PARA FINS DE ESTUDO E PESQUISA, DESDE QUE CITADA A FONTE.

Ficha catalográfica preparada pela Seção de Tratamento da Informação do Serviço de Biblioteca - EESC/USP

Marin, Marcelo Cuadrado
M337c Contribuição à análise da estabilidade global de estruturas em concreto pré-moldado de múltiplos pavimentos / Marcelo Cuadrado Marin ; orientador Mounir Khalil El Debs. -- São Carlos, 2009.

Dissertação (Mestrado-Programa de Pós-Graduação e Área de Concentração em Engenharia de Estruturas) -- Escola de Engenharia de São Carlos da Universidade de São Paulo, 2009 .

1. Estruturas de concreto pré-moldado. 2. Estabilidade global. 3. Não-linearidade física. 4. Não-linearidade geométrica. 5. Ligações semi-rígidas. I. Título. 
FOLHA DE JULGAMENTO

Candidato: Engenheiro MARCELO CUADRADO MARIN.

Dissertação defendida e julgada em 04/12/2009 perante a Comissão Julgadora:

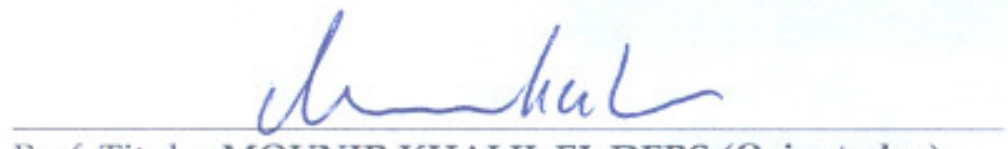

APRO VADO

Prof. Titular MOUNIR KHALIL EL DEBS (Orientador)

(Escola de Engenharia de São Carlos/USP)

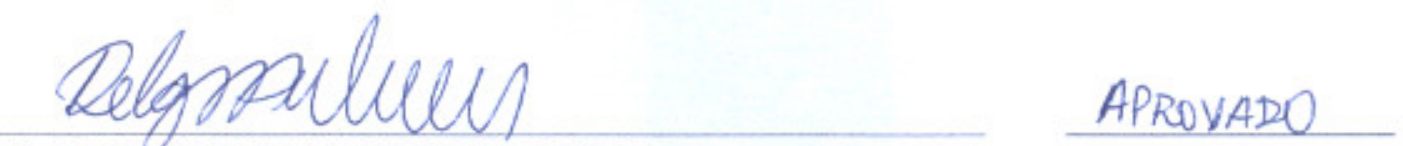

Dr. RODRIGO DE AZEVEDO NEVES

(Consultor)

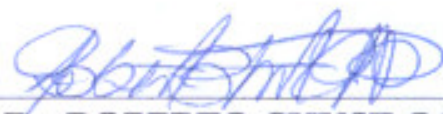

APROVADO

Prof. Dr. ROBERTO CHUST CARVALHO

(Universidade Federal de São Carlos/UFSCar)
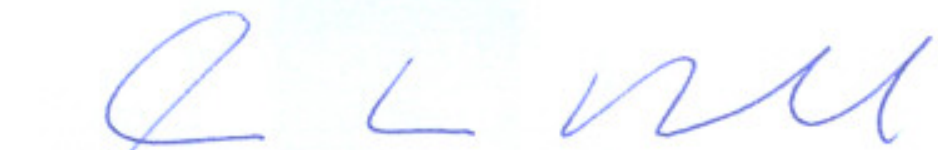

Prof. Associado MARCIO ANTONIO RAMALHO

Coordenador do Programa de Pós-Graduação em

Engenharia Civil (Engenharia de Estruturas)

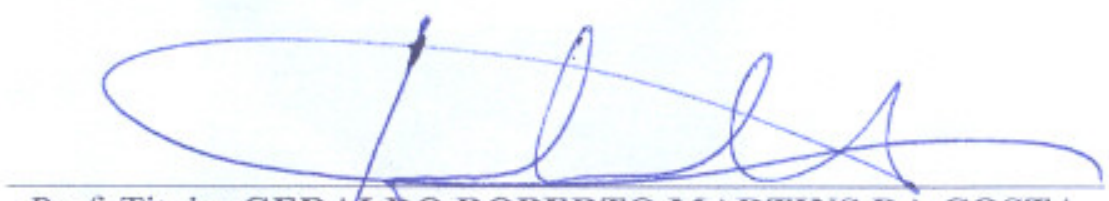

Prof. Titular GERALDO ROBERTO MARTINS DA COSTA

Presidente/da Comissão de Pós-Graduação 



\section{AGRADECIMENTOS}

À Deus, sem o qual este sonho não seria realizado.

Ao professor Mounir Khalil El Debs pela generosidade em conceder o privilégio de ser seu orientado, pela paciência e amizade demonstrada durante o desenvolvimento do trabalho.

À minha noiva Francini Cristiani Picon por me apoiar nos melhores e piores momentos nestes últimos anos. Por ter sido compreensiva nos muitos finais de semana em que não pudemos ficar juntos para que este projeto pudesse ser viabilizado.

Ao meu pai, minha irmã e em especial à minha mãe por ter zelado pela minha educação na infância.

À Leonardi Construção Industrializada Ltda, em especial ao Eng ${ }^{\circ}$ Edgar Fernandes Garcia Filho por flexibilizar a minha atuação profissional junto à empresa e apoiar este projeto.

Aos professores Ana Lúcia El Debs, Humberto Coda, Wilson Venturini e Samuel Giongo pelas contribuições.

À Universidade Federal de São Carlos pela excelente formação acadêmica.

Aos professores da Universidade Federal de São Carlos:

Roberto Chust Carvalho, por ser um excelente professor e ser responsável por grande parte da minha admiração pela engenharia de estruturas;

Marcelo de Araújo Ferreira por incentivar a minha inserção no segmento de pré-moldados;

Jasson Rodrigues de Figueiredo Filho por acreditar no meu potencial se disponibilizando a escrever a carta de recomendação ao programa de pós-graduação.

As simulações numéricas realizadas com o auxílio do programa ANSYS tiveram a contribuição do $\mathrm{Eng}^{\mathrm{o}}$ Luiz Lima da empresa ESSS, do professor Ernesto Massaroppi Junior e dos colegas do departamento de Engenharia de Estruturas, Eng ${ }^{\circ}$ Saulo Almeida e Eng ${ }^{\mathrm{o}}$ Fábio Sawasaki.

Aos amigos da graduação Neiton Fernandes, Igor Cotta e Paulo Lima que embora distantes continuaram próximos em pensamento.

Aos colegas com quem tive oportunidade de conviver e que de alguma forma contribuíram para a realização das disciplinas de pós-graduação e da dissertação de mestrado, Fábio Rocha, Marcela Filizola, Andreilton, Joaquim Mota, Rodrigo Barros, Dorival, Carlos 
Marek, Giovanni, Wagner, Socorro, Marcela Kataoka, Vanessa Lima, Gabriela, Rodrigo Paccola, Charles e tantos outros que embora não mencionados contribuíram para a realização deste trabalho.

Aos professores e funcionários do departamento de Engenharia de Estruturas da Escola de Engenharia de São Carlos da Universidade de São Paulo.

Por fim, a todas as pessoas com quem convivi e que acreditaram na realização deste trabalho. 


\section{RESUMO}

MARIN, M. C. Contribuição à análise da estabilidade global de estruturas em concreto pré-moldado de múltiplos pavimentos. 2009. 213f. Dissertação (Mestrado) - Escola de Engenharia de São Carlos, Universidade de São Paulo, São Carlos, 2009.

No presente trabalho são avaliados os principais parâmetros de projeto na análise da estabilidade global de estruturas em concreto pré-moldado de múltiplos pavimentos, considerando a não-linearidade física (NLF), não-linearidade geométrica (NLG) e ligações semi-rígidas. Os sistemas estruturais analisados são constituídos por pórticos com ligação viga-pilar semi-rígida e pilares engastados na fundação. As ligações viga-pilar têm sua tipologia definida por chumbadores retos e capa de concreto moldado in loco com armadura de continuidade. A NLF é avaliada segundo a construção dos diagramas $\mathrm{M}$ x N x 1/r, onde foi considerado de forma consistente o efeito da força normal, da armadura passiva, da armadura ativa e a reologia do concreto. São propostas funções e definidos coeficientes redutores de rigidez que foram comparados com valores apontados em expressões normativas que contemplam de forma aproximada a NLF. A NLG é avaliada com o auxílio do programa ANSYS e na forma aproximada segundo o coeficiente $\gamma_{z}$ e o método da carga lateral fictícia $(\mathrm{P}-\Delta)$. Apresentam-se modelos analíticos de caracterização de rigidez e resistência de ligações viga-pilar ao momento fletor negativo e positivo. $\mathrm{Na}$ análise numérica é feito um estudo de caso completo de uma estrutura típica de múltiplos pavimentos em concreto pré-moldado com o auxílio do programa ANSYS, avaliando-se diferentes formas de consideração da NLF e da NLG. É analisada a distribuição de esforços na estrutura frente às combinações de ações utilizadas e os modelos de comportamento das ligações, para algumas variações de geometria e carregamento. Dentre as conclusões, pode ser citado que os coeficientes redutores obtidos segundo o diagrama $\mathrm{M} \times \mathrm{N} \times 1 / \mathrm{r}$ divergem das indicações normativas para consideração simplificada de NLF. Quanto à consideração simplificada de análise NLG, o coeficiente $\gamma_{z}$ apresentou resultados melhores na previsão dos esforços de segunda ordem em relação aos obtidos por $0,95 \cdot \gamma_{\mathrm{z}}$.

Palavras-Chave: Estabilidade global, Concreto pré-moldado, Não-linearidade física, Nãolinearidade geométrica, Ligações semi-rígidas. 



\begin{abstract}
MARIN, M. C. Contribution in the analysis of global stability of multi-storey precast concrete framed structures. 2009. 213f. Dissertation (M.Sc) - Escola de Engenharia de São Carlos, Universidade de São Paulo, São Carlos, 2009.
\end{abstract}

In this research it was evaluated the main design parameters in the analysis of global stability of multi-storey precast concrete framed structures considering the physical nonlinearity (PNL), geometric nonlinearity (GNL) and semi-rigid connections behavior. The structural systems considered are those consisting of frames with beam-to-column semi-rigid connection and columns inset in the foundation. The beam-to-column connections are defined by two dowels and cast-in-place concrete cap with longitudinal reinforced bars. The PNL is evaluated according the $\mathrm{M} \times \mathrm{N} \times 1 / \mathrm{r}$ diagrams, where are considered the effect of normal force, the reinforcing steel, prestressing steel and creep. Functions are proposed and reducing stiffness coefficients are defined, with were compared with codes that include the approximated PNL. The GNL is evaluated according to ANSYS software by no approximate analisys and it's approximate according to the coefficient $\gamma_{\mathrm{z}}$ and $(\mathrm{P}-\Delta)$ method. This research presents an analytical model characterization of stiffness and strength of beam-to-column connections to the negative and positive bending moment. In the numerical analysis is made a full case study of a typical multi-storey precast concrete framed structure with the aid of the ANSYS software, evaluating different forms of consideration of the PNL and the GNL. It analysed the bending moment distribution according the combinations of actions used and the behavioral models of connections, for some variations at geometry and loading. The reduction coefficients of flexural rigidity obtained according the $\mathrm{M}$ x $\mathrm{N}$ x 1/r diagrams differ from normative indications for simplified account of PNL. In GNL simplified analysis, the coefficient $\gamma_{z}$ showed better results in predicting the second-order effects with respect to those obtained by the coefficient $0,95 . \gamma_{z}$.

Keywords: Global stability, Precast concrete structures, Physical nonlinearity, Geometric nonlinearity, Semi-Rigid connections. 



\section{LISTA DE FIGURAS}

Figura 1.1: Sistema estrutural formado por ligações viga-pilar articuladas. [EL DEBS (2000)].....

Figura 1.2: Sistema estrutural formado por ligações viga-pilar rígidas ou semi-rígidas. [EL DEBS (2000)]

Figura 1.3: Sistema estrutural formado por parede ou núcleo de contraventamento com ligações viga-

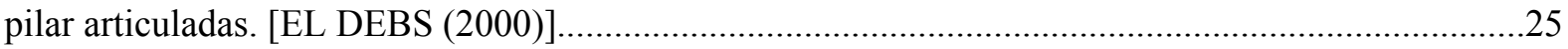

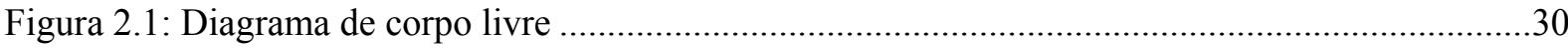

Figura 2.2: Seção transversal deformada após solicitação ………………............................................

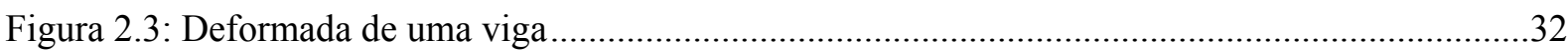

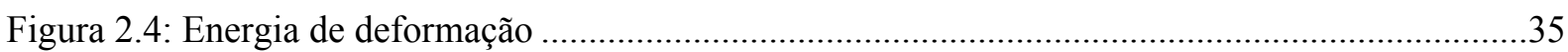

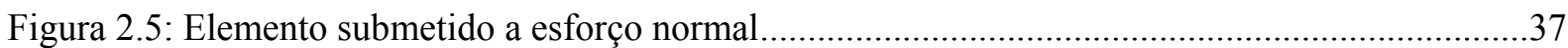

Figura 2.6: Parâmetros nodais (graus de liberdade) de elemento submetido a esforço normal .............40

Figura 2.7: Funções de forma de elemento submetido a esforço normal ................................................40

Figura 2.8: Parâmetros nodais (graus de liberdade) de elemento submetido à flexão ............................41

Figura 2.9: Funções de forma de elemento submetido à flexão ..............................................................41

Figura 2.10: Relações geométricas de um elemento de comprimento dx .............................................44

Figura 2.11 Comportamento não-linear: Matriz de rigidez secante [(CORREA (1991) Adaptado]......46

Figura 2.12: Comportamento não-linear: Matriz de rigidez tangente [(CORREA (1991) Adaptado]...46

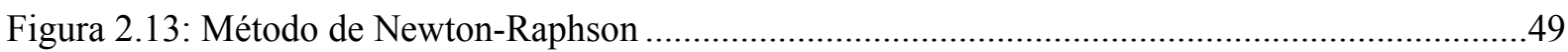

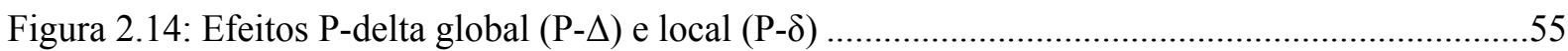

Figura 2.15: Esquema de carregamento e configuração deformada para análise (P- $\Delta) \ldots \ldots \ldots \ldots \ldots \ldots \ldots \ldots . . . . . .55$

Figura 2.16: Estágios da relação momento x curvatura [ fib (1999) Adaptado] ....................................57

Figura 2.17: Relação momento x curvatura [NBR 6118:2003] ……..................................................58

Figura 2.18: Diagrama tensão x deformação [NBR 6118:2003] ...........................................................62

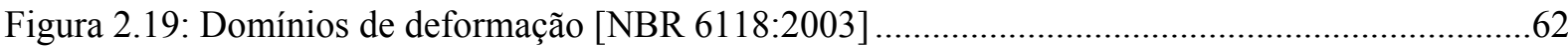

Figura 2.20: Distribuição de deformações em uma seção de concreto amado.......................................63

Figura 2.21: Deformações, tensões e resultantes de tensão em uma seção de concreto armado............69

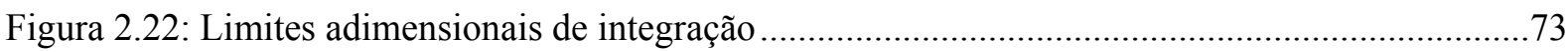

Figura 2.23: Exemplo de representação gráfica do processo iterativo de obtenção da linha neutra

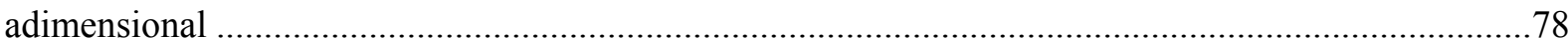

Figura 2.24: Seção transversal e arranjo de armadura de uma seção de pilar ........................................78

Figura 2.25: Diagrama M x N x 1/r modificado sob ação do esforço normal........................................79

Figura 2.26: Diagrama tensão x deformação do concreto modificado sob ação da fluência ...................80

Figura 2.27: Diagrama M x N x 1/r modificado sob ação da fluência ...................................................83

Figura 2.28: Diagrama tensão-deformação para aços de armaduras ativas [NBR 6118:2003]..............84 
Figura 2.29: Seção transversal e arranjo de armadura ativa em duas camadas ..................................... 85

Figura 2.30: Diagrama M x N x 1/r modificado sob ação de armadura ativa ........................................ 86

Figura 2.31: Diagrama momento versus rotação [EL DEBS (2000) Modificado] ................................ 95

Figura 2.32: Ligações viga-pilar articuladas [EL DEBS (2000)] ........................................................ 96

Figura 2.33: Ligações viga-viga sobre pilar com estabelecimento de continuidade para momento fletor

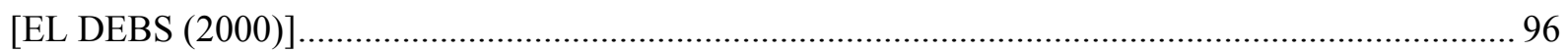

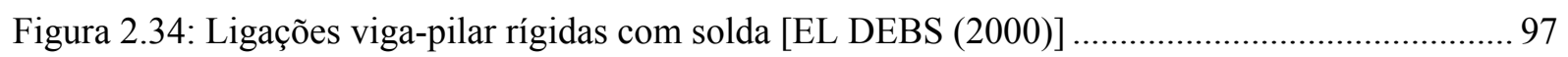

Figura 2.35: Ligações viga-pilar rígidas com emenda da armadura e concreto moldado no local [EL

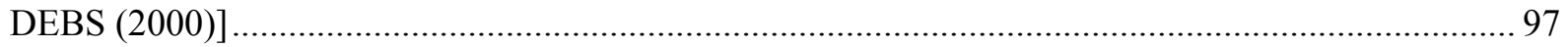

Figura 2.36: Ligações viga-pilar rígidas com cabos de protensão [EL DEBS (2000)] ......................... 98

Figura 2.37: Ligação viga-pilar semi-rígida com chumbador [BALDISSERA (2006)] ....................... 99

Figura 2.38: Ligação viga-pilar semi-rígida com chumbador inclinado [BALDISSERA (2006)]........ 99

Figura 2.39: Energia de deformação de uma mola a deslocamento e rotação ........................................ 101

Figura 2.40: Diagrama momento x rotação de ligação com comportamento bi-linear assimétrico. [EL

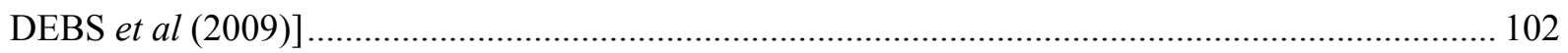

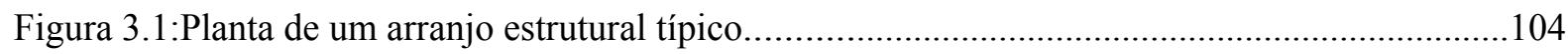

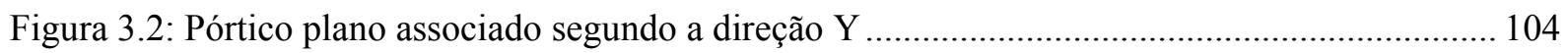

Figura 3.3: Ligação viga-pilar semi-rígida com chumbadores ........................................................... 105

Figura 3.4: Ligação pilar-fundação rígida com colarinho sobre o bloco …………............................... 105

Figura 3.5: Seção transversal genérica de uma viga em concreto pré-moldado composta................... 107

Figura 3.6: Esquema de modelagem estrutural e soma de efeitos para fases construtivas no

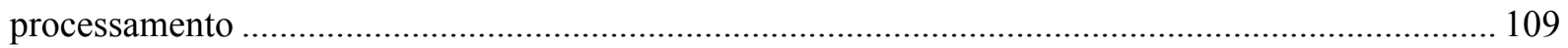

Figura 3.7: Diagrama momento x rotação de ligação com comportamento bi-linear assimétrico. [EL

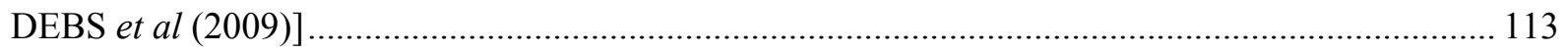

Figura 3.8: Mecanismo resistente ao momento fletor negativo [EL DEBS et al (2009)] .................... 114

Figura 3.9: Posição deformada da extremidade da viga e suas componentes deformáveis ao momento

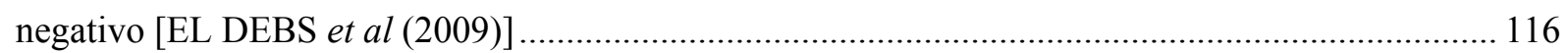

Figura 3.10: Mecanismo resistente ao momento fletor positivo [EL DEBS et al (2009)] .................. 119

Figura 3.11: Posição deformada da extremidade da viga e suas componentes deformáveis ao momento

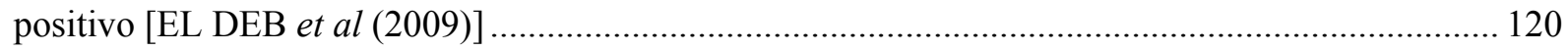

Figura 3.12: Momento x rotação da ligação segundo resultados teóricos e experimentais [EL DEB et al

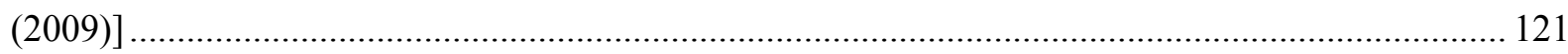

Figura 4.1: Esquema de modelagem da ligação na estrutura em concreto pré-moldado......................125

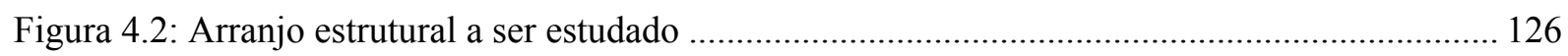

Figura 4.3: Seção transversal e disposição de armadura do pilar em concreto pré-moldado (P50x50) 
Figura 4.4: Seção transversal e disposição de armadura passiva da viga em concreto pré-moldado em seção composta destinada a estrutura com modulação de $7,5 \mathrm{~m}$. 128

Figura 4.5: Diagrama $\mathrm{M}$ x N x 1/r segundo a $1^{\mathrm{a}}$ combinação de ações para o pilar central 130

Figura 4.6: Diagrama $\mathrm{M} \times \mathrm{N}$ x 1/r segundo a $1^{\mathrm{a}}$ combinação de ações para o pilar lateral 130

Figura 4.7: Diagrama $M \times N$ x 1/r segundo a 2a combinação de ações para o pilar central 130

Figura 4.8: Diagrama $\mathrm{M} \times \mathrm{N}$ x 1/r segundo a $2^{\mathrm{a}}$ combinação de ações para o pilar lateral 131

Figura 4.9: Diagrama $\mathrm{M} \times \mathrm{N}$ x 1/r segundo a $3^{\mathrm{a}}$ combinação de ações para o pilar central 131

Figura 4.10: Diagrama $M \times N$ x 1/r segundo a $3^{\mathrm{a}}$ combinação de ações para o pilar lateral. 131

Figura 4.11: Diagrama M x N x 1/r segundo a combinação de ação (ELS) para o pilar central. 132

Figura 4.12: Diagrama M x N x 1/r segundo a combinação de ação (ELS) para o pilar lateral. 132

Figura 4.13: Diagrama dos coeficientes redutores de rigidez versus força normal adimensional para pilares (P50x50) em estruturas com modulação de 7,5m e carga acidental de $3 \mathrm{kN} / \mathrm{m}^{2}$. 133

Figura 4.14: Função redução de rigidez segundo aproximação polinomial e em potência 134

Figura 4.15: Função redução de rigidez segundo aproximação linear 135

Figura 4.16: Função redução de rigidez segundo aproximação linear em dois subdomínios 136

Figura 4.17: Função redução de rigidez segundo aproximação linear em três subdomínios 136

Figura 4.18: Seção composta em concreto pré-moldado simplificada. 138

Figura 4.19: Diagrama $M \times N \times 1 / \mathrm{r}$ da viga em concreto pré-moldado com armadura passiva para estrutura com modulação de 7,5m

Figura 4.20: Seção transversal e disposição de armadura passiva e ativa da viga em concreto prémoldado em seção composta destinada a estrutura com modulação de $7,5 \mathrm{~m}$. 142

Figura 4.21: Distribuição da armadura ativa com aderência ao longo do eixo da viga para estrutura com modulação de $7,5 \mathrm{~m}$. 143

Figura 4.22: Diagrama M x N x 1/r sob efeito da protensão com 6 cabos. .145

Figura 4.23: Diagrama M x N x 1/r sob efeito da protensão com 9 cabos 145

Figura 4.24: Diagrama M x N x 1/r adaptado sob efeito da protensão com 9 e 6 cabos....... 145

Figura 4.25: Diagrama de momento x rotação da ligação viga-pilar junto ao pilar central 149

Figura 4.26: Diagrama de momento fletor obtido segundo a $1^{\text {a }}$ combinação de ações no tempo inicial

Figura 4.27: Diagrama de momento fletor obtido segundo a $1^{\text {a }}$ combinação de ações no tempo infinito

Figura 4.28: Diagrama de momento para $1^{\mathrm{a}}$ combinação de ações utilizando armadura ativa nas vigas sem considerar a fluência 154

Figura 4.29: Diagrama de momento fletor obtido segundo a $2^{\mathrm{a}}$ combinação de ações 156

Figura 4.30: Diagrama de momento fletor obtido segundo a $3^{\text {a }}$ combinação de ações 157

Figura 4.31: Diagrama de momento fletor obtido segundo a combinação de ações do ELS 159 
Figura 4.32: Diagrama de momento fletor obtido segundo a $1^{\mathrm{a}}$ combinação de ações com ligação viga-

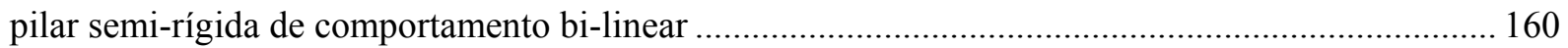

Figura 4.33: Seção de viga alterada pela adoção de abas ..................................................................... 161

Figura 4.34: Seção de viga composta por duas fases de concreto moldado in loco (CML) ................ 162

Figura 4.35: Interação solo-estrutura discretizada por molas ............................................................. 164

Figura 4.36: Modelos estruturais de comportamento equivalente...................................................... 164

Figura 4.37: Rigidez da ligação pilar-fundação para estacas com $\mathrm{f}_{\mathrm{ck}}=20 \mathrm{MPa}$................................. 166

Figura 4.38: Rigidez da ligação pilar-fundação para estacas com $\mathrm{f}_{\mathrm{ck}}=40 \mathrm{MPa}$................................ 166

Figura 4.39: Diagrama de momento fletor obtido considerando a ligação semi-rígida pilar-fundação

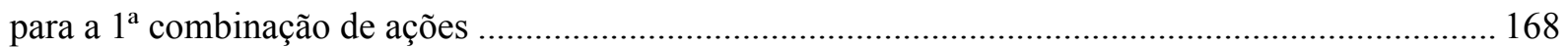

Figura 4.40: Evolução dos deslocamentos segundo o processo (P- $\Delta)$............................................. 170

Figura 4.41: Seção transversal e disposição de armadura do pilar em concreto pré-moldado (P40x40)

Figura 4.42: Diagrama dos coeficientes redutores de rigidez versus força normal adimensional para pilares (P50x50) em estruturas com modulação de 7,5m com carga acidental de $3 \mathrm{kN} / \mathrm{m}^{2}$ e $5 \mathrm{kN} / \mathrm{m}^{2}$

Figura 4.43: Funções aproximadoras dos coeficientes redutores de rigidez versus força normal adimensional para pilares (P50x50)

Figura 4.44: Análise comparativa para momento fletor positivo na ligação segundo a $1^{\mathrm{a}}$ combinação de ações nas estruturas com modulação de $7,5 \mathrm{~m}$ 176

Figura 4.45: Análise comparativa para momento fletor negativo na ligação junto ao pilar central segundo a $1^{\mathrm{a}}$ combinação de ações nas estruturas com modulação de $7,5 \mathrm{~m}$ 176

Figura 4.46: Análise comparativa para momento fletor negativo na ligação junto ao pilar lateral segundo a $1^{\text {a }}$ combinação de ações nas estruturas com modulação de $7,5 \mathrm{~m}$ 176 Figura 4.47: Análise comparativa para momento fletor positivo na ligação segundo a $2^{\mathrm{a}}$ combinação de ações nas estruturas com modulação de 7,5m

Figura 4.48: Parâmetro de estabilidade $\gamma_{\mathrm{z}}$ considerando comportamento linear assimétrico da ligação nas estruturas com modulação de $7,5 \mathrm{~m}$

Figura 4.49: Parâmetro de estabilidade $\gamma_{\mathrm{z}}$ considerando o modelo elasto-plástico assimétrico da ligação na estrutura com modulação de $7,5 \mathrm{~m}$

Figura 4.50: Seção transversal e disposição de armadura do pilar em concreto pré-moldado (P60x60)

Figura 4.51: Diagrama dos coeficientes redutores de rigidez versus força normal adimensional para pilares (P40x40) em estruturas com modulação de $(7,5 \mathrm{~m} ; 10 \mathrm{~m})$ e carga acidental de $\left(3 \mathrm{kN} / \mathrm{m}^{2} ; 5 \mathrm{kN} / \mathrm{m}^{2}\right)$ 
Figura 4.52: Funções aproximadoras dos coeficientes redutores de rigidez versus força normal adimensional para pilares (P40x40)

Figura 4.53: Seção transversal e disposição de armadura passiva e ativa da viga em concreto prémoldado em seção composta destinada a estrutura com modulação de $10 \mathrm{~m}$.

Figura 4.54: Distribuição da armadura ativa com aderência ao longo do eixo da viga para estrutura com modulação de $10 \mathrm{~m}$ 183

Figura 4.55: Diagrama M x N x 1/r sob efeito da protensão com 14 cabos 184

Figura 4.56: Diagrama M x N x 1/r sob efeito da protensão com 10 cabos 184

Figura 4.57: Diagrama M x N x 1/r adaptado sob efeito da protensão com 14 e 10 cabos 185 Figura 4.58: Análise comparativa para momento fletor positivo na ligação segundo a $1^{\mathrm{a}}$ combinação de ações nas estruturas com modulação de $10 \mathrm{~m}$

Figura 4.59: Análise comparativa para momento fletor negativo na ligação junto ao pilar central segundo a $1^{\mathrm{a}}$ combinação de ações nas estruturas com modulação de $10 \mathrm{~m}$. 188 Figura 4.60: Análise comparativa para momento fletor negativo na ligação junto ao pilar lateral segundo a $1^{\mathrm{a}}$ combinação de ações nas estruturas com modulação de $10 \mathrm{~m}$. 188 Figura 4.61: Análise comparativa para momento fletor positivo na ligação segundo a $2^{\mathrm{a}}$ combinação nas estruturas com modulação de $10 \mathrm{~m}$. 188 Figura 4.62: Parâmetro de estabilidade $\gamma_{\mathrm{z}}$ considerando comportamento linear assimétrico da ligação nas estruturas com modulação de $10 \mathrm{~m}$.....

Figura 4.63: Parâmetro de estabilidade $\gamma_{\mathrm{z}}$ considerando o modelo elasto-plástico assimétrico da ligação na estrutura com modulação de $10 \mathrm{~m}$.

Figura A.1: Geometria, condição de vinculação e carregamento da estrutura.....................................203

Figura A.2: Modelo de ligação semi-rígida assimétrica.....................................................................204

Figura B.1: Geometria, condição de vinculação e carregamento da estrutura.......................................207

Figura B.2: Variação do momento fletor da ligação no ponto A..........................................................208

Figura B.3: Variação do deslocamento na direção $\mathrm{x}$ do nó de aplicação da carga P*.........................209

Figura C.1: Esquema de modelagem das fases de execução da estrutura em concreto pré-moldado.212 



\section{LISTA DE TABELAS}

Tabela 2.1: Relações fundamentais

Tabela 2.2: Exemplo para dados de entrada na obtenção do diagrama $\mathrm{M}$ x N x 1/r....

Tabela 2.3: Exemplo do processo iterativo para obtenção do momento resistente de uma seção para curvatura pré-definida

Tabela 2.4: Quadro comparativo de formulação para obtenção do coeficiente redutor de rigidez segundo diferentes normas e influência de variáveis

Tabela 2.5: Comparação de resultados com chumbadores inclinados e retilíneos [EL DEBS \& BALDISSERA (2008)]

Tabela 3.1: Situações de cálculo de uma viga em seção composta....................................................106

Tabela 3.2: Ações permanentes diretas consideradas separadamente (NBR 8681:2003)

Tabela 4.1: Variáveis analisadas.

Tabela 4.2: Discretização e esforços obtidos segundo tipo de elemento finito 124

Tabela 4.3: Dados do exemplo numérico da estrutura típica 126

Tabela 4.4: Ação do vento na estrutura com modulação de 7,5m 127

Tabela 4.5: Carga normal atuante nos pilares (P50x50) para a estrutura com modulação de 7,5m e carga acidental de $3 \mathrm{kN} / \mathrm{m}^{2}$

Tabela 4.6: Força normal adimensional atuante nos pilares (P50x50) para a estrutura com modulação de $7,5 \mathrm{~m}$ e carga acidental de $3 \mathrm{kN} / \mathrm{m}^{2}$

Tabela 4.7: Coeficientes redutores de rigidez dos pilares (P50x50) para a estrutura com modulação de $7,5 \mathrm{~m}$ e carga acidental de $3 \mathrm{kN} / \mathrm{m}^{2}$

Tabela 4.8: Coeficientes redutores de rigidez para pilar segundo as diversas prescrições normativas 137 Tabela 4.9: Coeficientes redutores de rigidez para a viga com armadura passiva sob efeito da fluência na estrutura com modulação de $7,5 \mathrm{~m}$

Tabela 4.10: Dados para definição da rigidez equivalente da viga com armadura passiva para estrutura com modulação de $7,5 \mathrm{~m}$.

Tabela 4.11: Coeficientes redutores de rigidez para a viga com armadura passiva sob efeito da fluência na estrutura com modulação de 7,5m segundo a expressão da NBR 6118:2003 adaptada 140

Tabela 4.12: Estados limites de serviço segundo combinações de ações.

Tabela 4.13: Condições de verificação para o ELU na situação em vazio da viga para estrutura com modulação de $7,5 \mathrm{~m}$.

Tabela 4.14: Tensões atuantes na viga em concreto pré-moldado segundo as situações de cálculo para a estrutura com modulação de $7,5 \mathrm{~m}$.

Tabela 4.15: Coeficientes redutores de rigidez para a viga com armadura passiva e armadura ativa sob efeito da fluência na estrutura com modulação de 7,5m 
Tabela 4.16: Dados para definição da rigidez equivalente para seção da viga em concreto protendido na estrutura com modulação de $7,5 \mathrm{~m}$.

Tabela 4.17: Dados de cálculo para caracterização da ligação ao momento negativo junto ao pilar central na estrutura com modulação de $7,5 \mathrm{~m}$.....

Tabela 4.18: Dados de cálculo para caracterização da ligação ao momento positivo junto ao pilar central na estrutura com modulação de $7,5 \mathrm{~m}$.....

Tabela 4.19: Rigidez e momentos resistentes nas ligações destinadas a estrutura com modulação de $7,5 \mathrm{~m}$.

Tabela 4.20: Distribuição de momento fletor e $\gamma_{z}$ segundo a $1^{a}$ combinação de ações com e sem o efeito da fluência nas vigas.

Tabela 4.21: Distribuição de momento fletor e $\gamma_{z}$ segundo a $1^{\mathrm{a}}$ combinação de ações considerando a modelagem das vigas segundo a rigidez secante

Tabela 4.22: Distribuição de momento fletor e $\gamma_{z}$ segundo a $1^{\mathrm{a}}$ combinação de ações considerando a modelagem das vigas e pilares segundo a rigidez secante

Tabela 4.23: Distribuição de momento fletor e $\gamma_{z}$ segundo a $1^{\mathrm{a}}$ combinação de ações utilizando armadura ativa nas vigas sem considerar a fluência

Tabela 4.24: Distribuição de momento fletor e $\gamma_{z}$ segundo a $1^{\text {a }}$ combinação de ações utilizando armadura ativa nas vigas considerando a rigidez secante ao momento positivo sem considerar a fluência 155

Tabela 4.25: Parâmetros de análise segundo combinação de ações 157

Tabela 4.26: Força normal no $1^{\circ}$ pavimento segundo combinação de ações.

Tabela 4.27: Parâmetros críticos segundo combinação de ações 158

Tabela 4.28: Distribuição de momento fletor e deslocamento segundo a combinação de ações em serviço considerando o efeito da fluência na análise das vigas

Tabela 4.29: Distribuição de momento fletor e $\gamma_{z}$ segundo a $1^{\mathrm{a}}$ combinação de ações considerando o comportamento bi-linear assimétrico da ligação viga-pilar.

Tabela 4.30: Situações de cálculo de uma viga em seção composta com duas fases de CML.....

Tabela 4.31: Parâmetros de análise segundo combinação de ações para seção composta alternativa 163

Tabela 4.32: Dados da fundação adotada para estrutura com modulação de 7,5m ...

Tabela 4.33: Distribuição de momento fletor e $\gamma_{z}$ para $1^{\mathrm{a}}$ combinação de ações considerando a ligação semi-rígida pilar-fundação.

Tabela 4.34: Processo (P- $\Delta$ )

Tabela 4.35: Análise de convergência do processo (P- $\Delta$ ) . 170

Tabela 4.36: Análise da não-linearidade geométrica segundo diferentes métodos para $1^{\mathrm{a}}$ combinação de ações ...... 170 
Tabela 4.37: Força normal adimensional atuante nos pilares (P40x40) para a estrutura com modulação de $7,5 \mathrm{~m}$ e carga acidental de $3 \mathrm{kN} / \mathrm{m}^{2}$

Tabela 4.38: Coeficientes redutores de rigidez dos pilares (P40x40) para a estrutura com modulação de $7,5 \mathrm{~m}$ e carga acidental de $3 \mathrm{kN} / \mathrm{m}^{2}$.

Tabela 4.39: Parâmetros de análise segundo combinação de ações para modelo com 5 e 4 pavimentos, modulação de $7,5 \mathrm{~m}$ e carga acidental de $3 \mathrm{kN} / \mathrm{m}^{2}$.

Tabela 4.40: Força normal adimensional atuante nos pilares (P50x50) para a estrutura com modulação de $7,5 \mathrm{~m}$ e carga acidental de $5 \mathrm{kN} / \mathrm{m}^{2}$

Tabela 4.41: Coeficientes redutores de rigidez dos pilares (P50x50) para a estrutura com modulação de $7,5 \mathrm{~m}$ e carga acidental de $5 \mathrm{kN} / \mathrm{m}^{2}$ .173

Tabela 4.42: Funções de redução de rigidez segundo subdomínios para pilar (P50x50). 175

Tabela 4.43: Força normal adimensional atuante nos pilares (P40x40) para a estrutura com modulação de $7,5 \mathrm{~m}$ e carga acidental de $5 \mathrm{kN} / \mathrm{m}^{2}$

Tabela 4.44: Coeficientes redutores de rigidez dos pilares (P40x40) para a estrutura com modulação de $7,5 \mathrm{~m}$ e carga acidental de $5 \mathrm{kN} / \mathrm{m}^{2}$.

Tabela 4.45: Parâmetros de análise segundo combinação de ações para modelo com 6,5 e 4 pavimentos, modulação de $7,5 \mathrm{~m}$ e carga acidental de $5 \mathrm{kN} / \mathrm{m}^{2}$. 175

Tabela 4.46: Relação entre a rigidez da viga e dos pilares para estrutura com modulação de 7,5m....178 Tabela 4.47: Ação do vento na estrutura com modulação de 10,0 m

Tabela 4.48: Força normal adimensional atuante nos pilares (P60x60) para a estrutura com modulação de $10 \mathrm{~m}$ e carga acidental de $3 \mathrm{kN} / \mathrm{m}^{2}$ e $5 \mathrm{kN} / \mathrm{m}^{2}$ 180

Tabela 4.49: Coeficientes redutores de rigidez dos pilares (P60x60) para a estrutura com modulação de $10 \mathrm{~m}$ e carga acidental de $3 \mathrm{kN} / \mathrm{m}^{2}$ e $5 \mathrm{kN} / \mathrm{m}^{2}$

Tabela 4.50: Força normal adimensional atuante nos pilares (P40x40) para a estrutura com modulação de $10 \mathrm{~m}$ e carga acidental de $3 \mathrm{kN} / \mathrm{m}^{2}$ e $5 \mathrm{kN} / \mathrm{m}^{2}$

Tabela 4.51: Coeficientes redutores de rigidez dos pilares (P40x40) para a estrutura com modulação de $10 \mathrm{~m}$ e carga acidental de $3 \mathrm{kN} / \mathrm{m}^{2}$ e $5 \mathrm{kN} / \mathrm{m}^{2}$.

Tabela 4.52: Funções de redução de rigidez segundo subdomínios para pilar (P40x40)......

Tabela 4.53: Condições de verificação para o ELU na situação em vazio da viga para estrutura com modulação de $10 \mathrm{~m}$

Tabela 4.54: Tensões atuantes na viga em concreto pré-moldado segundo as situações de cálculo para a estrutura com modulação de $10 \mathrm{~m}$.

Tabela 4.55: Coeficientes redutores de rigidez para a viga com armadura passiva e armadura ativa sob efeito da fluência na estrutura com modulação de $10 \mathrm{~m}$.

Tabela 4.56: Dados de cálculo para caracterização da ligação ao momento negativo junto ao pilar central na estrutura com modulação de $10 \mathrm{~m}$ 
Tabela 4.57: Dados de cálculo para caracterização da ligação ao momento positivo junto ao pilar central na estrutura com modulação de $10 \mathrm{~m}$ 186

Tabela 4.58: Rigidez e momentos resistentes nas ligações destinadas a estrutura com modulação de $10 \mathrm{~m}$

Tabela 4.59: Parâmetros de análise segundo combinação de ações na estrutura com módulo de $10 \mathrm{~m}$ e carga acidental de $3 \mathrm{kN} / \mathrm{m}^{2}$

Tabela 4.60: Parâmetros de análise segundo combinação de ações na estrutura com módulo de $10 \mathrm{~m}$ e carga acidental de $5 \mathrm{kN} / \mathrm{m}^{2}$

Tabela 4.61: Relação entre a rigidez da viga e dos pilares para estrutura com modulação de $10 \mathrm{~m} . . . .189$

Tabela 5.1: Distribuição dos coeficientes redutores de rigidez dos pilares .192

Tabela A.1: Distribuição de momento fletor na ligação segundo a rigidez dos elementos adjacentes. .204

Tabela B.1: Distribuição de momento fletor nas ligações segundo carregamento atuante. .208

Tabela B.2: Deslocamento na direção $\mathrm{x}$ do nó de aplicação da carga $\mathrm{P}^{*}$ 209 


\section{SUMÁRIO}

1. INTRODUÇÃO

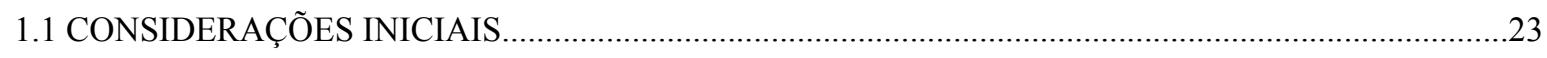

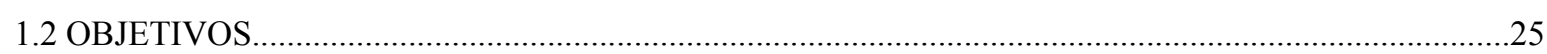

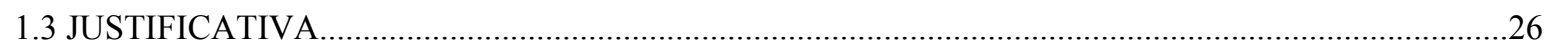

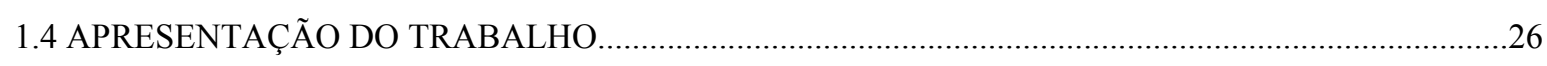

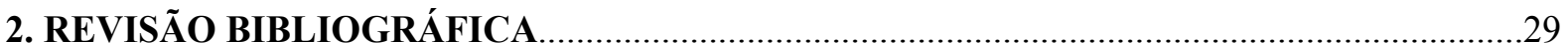

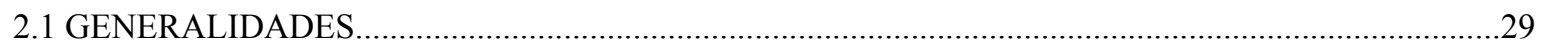

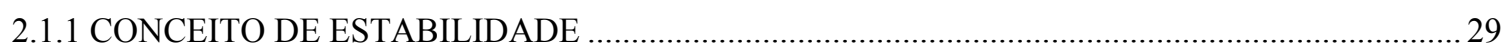

2.1.2 RELAÇÕES FUNDAMENTAIS DE ELEMENTOS SOB FLEXÃO …………………………........ 30

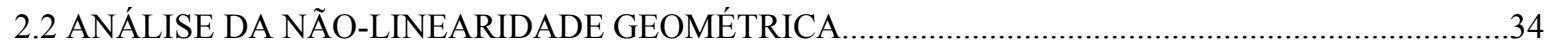

2.2.1 ANÁLISE DA NÃO-LINEARIDADE GEOMÉTRICA SEGUNDO O MÉTODO DOS

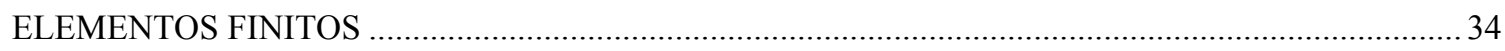

2.2.2 MÉTODO APROXIMADO PARA CONSIDERAÇÃO DA NÃO-LINEARIDADE GEOMÉTRICA

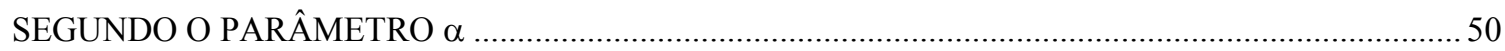

2.2.3 MÉTODO APROXIMADO PARA CONSIDERAÇÃO DA NÃO-LINEARIDADE GEOMÉTRICA

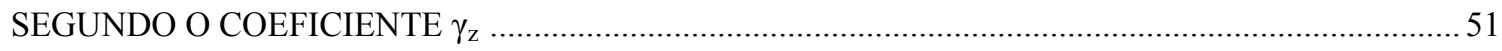

2.2.4 MÉTODO APROXIMADO PARA CONSIDERAÇÃO DA NÃO-LINEARIDADE GEOMÉTRICA

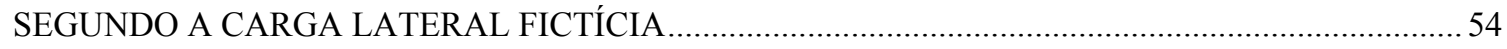

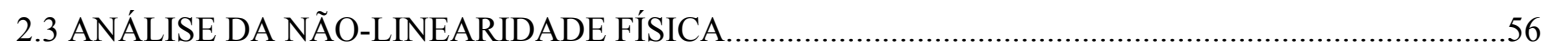

2.3.1 ANÁLISE DA NÃO-LINEARIDADE FÍSICA SEGUNDO DIAGRAMA M X N X 1/r..................56

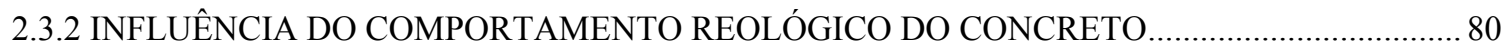

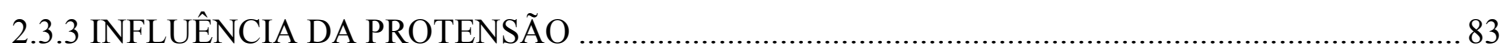

2.3.4 ANÁLISE DA NÃO-LINEARIDADE FÍSICA SEGUNDO MÉTODOS APROXIMADOS .............87

2.4 LIGAÇÕES DE ESTRUTURAS DE CONCRETO PRÉ-MOLDADO......................................................93

2.4.1 PROCEDIMENTOS DE PROJETO PARA LIGAÇÕES...................................................................... 93

2.4.2 LIGAÇÕES CONCEBIDAS COM COMPORTAMENTO SEMI-RÍGIDO …………………..........98

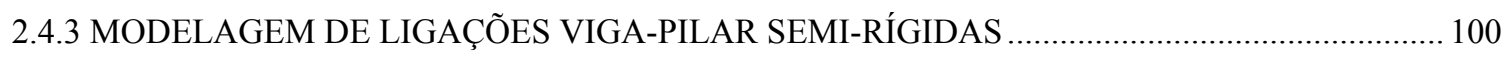

3. TIPO ESTRUTURAL ESTUDADO E PROCEDIMENTOS DE PROJETO...........................103

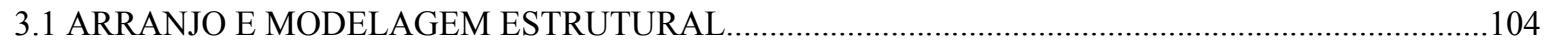

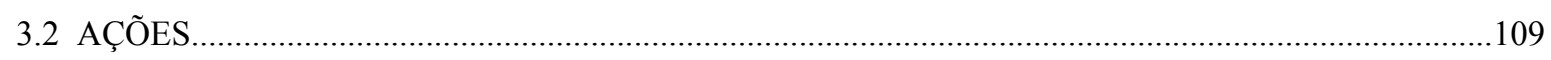

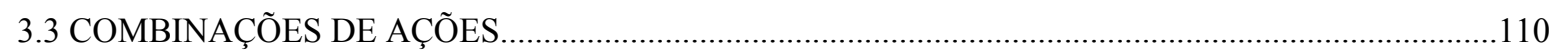

3.4 CARACTERIZAÇÃO DA LIGAÇÃO EMPREGADA........................................................................113

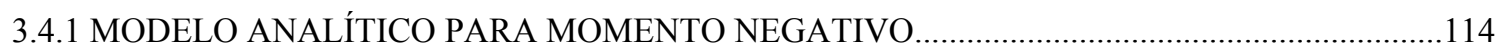

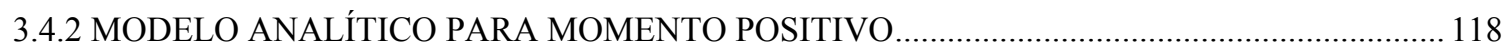




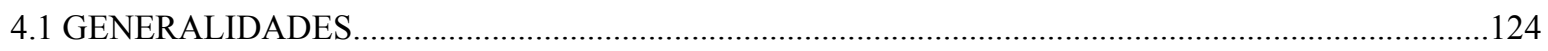

4.2 EXEMPLO NUMÉRICO DE UMA ESTRUTURA TÍPICA....................................................................126

4.2.1 CARACTERIZAÇÃO DA NÃO-LINEARIDADE FÍSICA (RIGIDEZ) DOS ELEMENTOS ........128

4.2.2 AVALIAÇÃO DE FUNÇÕES E COEFICIENTES REDUTORES DE RIGIDEZ ..............................132

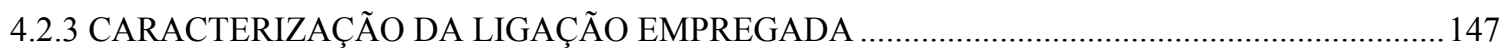

4.3 ESTUDO DA VARIAÇÃO DE PARÂMETROS DA ESTRUTURA TÍPICA............................................150

4.3.1 INFLUÊNCIA DO EFEITO REOLÓGICO DO CONCRETO ............................................................ 150

4.3.2 INFLUÊNCIA DA CONSIDERAÇÃO DA RIGIDEZ SECANTE NA MODELAGEM DE VIGAS E

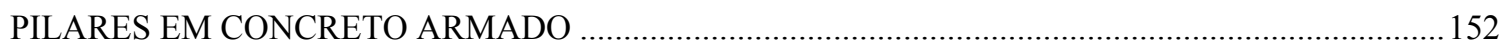

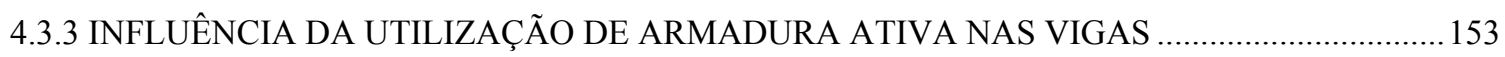

4.3.4 INFLUÊNCIA DA CONSIDERAÇÃO DA RIGIDEZ SECANTE NA MODELAGEM DE VIGAS

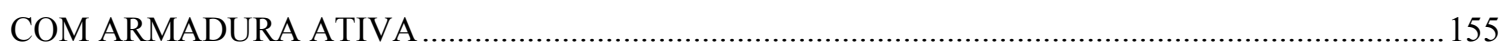

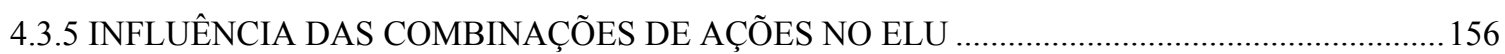

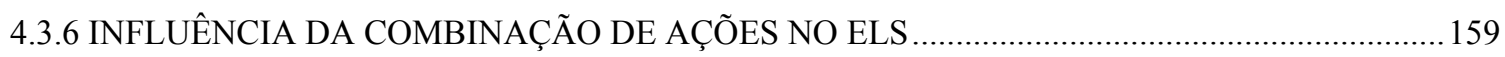

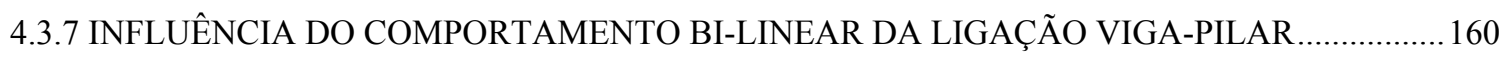

4.3.8 INFLUÊNCIA DA UTILIZAÇÃO DE SEÇÃO COMPOSTA ALTERNATIVA (CONCRETAGEM

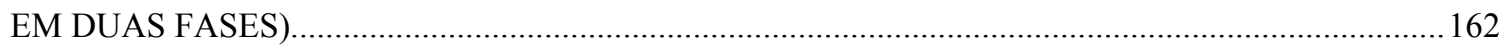

4.3.9 INFLUÊNCIA DA PRESENÇA DA LIGAÇÃO SEMI-RÍGIDA PILAR-FUNDAÇÃO...................163

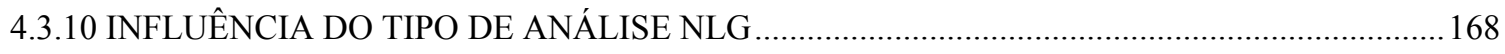

4.4 ANÁLISE DA VARIAÇÃO DE PARÂMETROS GEOMÉTRICOS E DE CARREGAMENTO DA

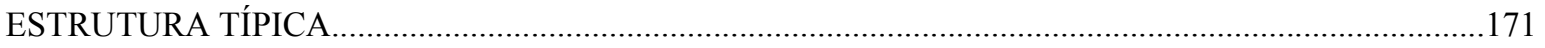

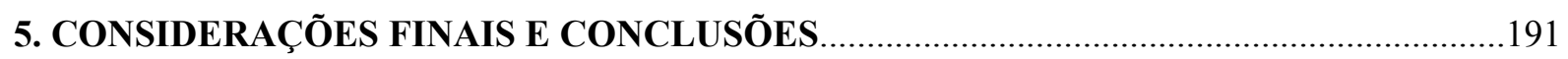

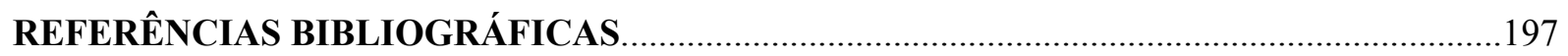

APÊNDICE A - INFLUÊNCIA DA RIGIDEZ DOS ELEMENTOS ADJACENTES NO

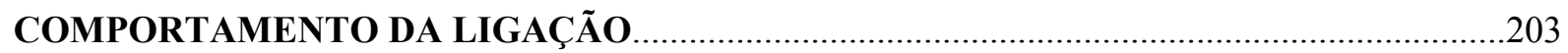

APÊNDICE B - NÃO-LINEARIDADE FÍSICA PRESENTE EM LIGAÇÕES SEMI-RÍGIDAS

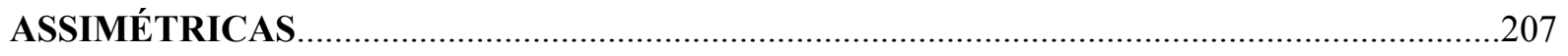

APÊNDICE C - ESTRATÉGIAS DE MODELAGEM NUMÉRICA DAS ESTRUTURAS EM

CONCRETO PRÉ-MOLDADO DE MÚLTIPLOS PAVIMENTOS.........................................211 


\section{INTRODUÇÃO}

\subsection{CONSIDERAÇÕES INICIAIS}

A utilização do sistema construtivo em concreto pré-moldado em edificações de múltiplos pavimentos acompanha o desenvolvimento da construção civil em torno da industrialização, racionalização, controle de qualidade e sustentabilidade. Tendo em vista a viabilização e difusão deste sistema construtivo, o presente trabalho aborda alguns dos principais parâmetros de projeto que envolve a análise da estabilidade global em edificações de múltiplos pavimentos em concreto pré-moldado.

O sistema construtivo em concreto pré-moldado teve sua utilização restringida a edificações de pequeno porte devido ao sistema estrutural ser basicamente isostático. A principal característica de uma estrutura isostática, composta por ligações articuladas é a sua maior deslocabilidade, que pode ocasionar problemas de estabilidade.

A Figura 1.1 ilustra o sistema estrutural formado por pilares engastados na fundação com ligações viga-pilar articuladas e o respectivo comportamento em relação às ações que provocam tombamento.
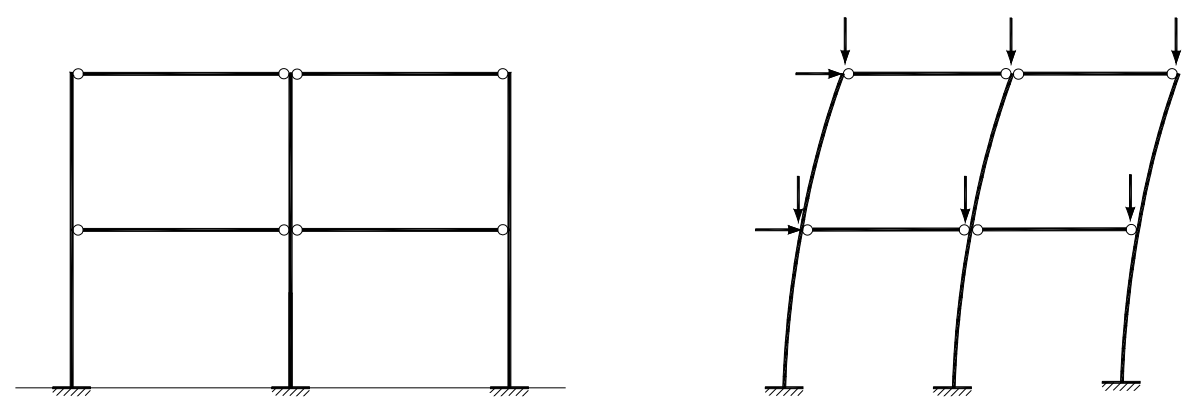

Figura 1.1: Sistema estrutural formado por ligações viga-pilar articuladas. [EL DEBS (2000)] 
A estabilidade global de estruturas em concreto pré-moldado sofre grande influência de suas ligações, uma vez que a absorção de esforços pela ligação limita a deslocabilidade da estrutura. A ação do vento é uma das ações mais preponderantes no dimensionamento de uma estrutura em concreto pré-moldado de múltiplos pavimentos, em uma estrutura isostática a deslocabilidade é maior que em estruturas hiperestáticas e, portanto tem efeito de primeira ordem significativo, conseqüentemente influenciando no efeito de segunda ordem.

Dá-se o nome de efeito de primeira ordem à análise da estrutura na sua configuração geométrica inicial, ou seja, não deformada. Os efeitos de segunda ordem são aqueles que se somam aos obtidos numa análise de primeira ordem, quando a análise do equilíbrio passa a ser efetuada considerando a configuração deformada da estrutura.

A estabilidade global de estruturas de concreto pré-moldado de múltiplos pavimentos pode ser assegurada de diversas formas segundo o sistema estrutural adotado. No sistema estrutural constituído por pórticos, a estabilidade global é garantida pelo enrijecimento das ligações viga-pilar e geralmente com pilares engastados na fundação. Na Figura 1.2 são ilustrados o sistema estrutural formado por pilares engastados na fundação com ligações vigapilar rígidas ou semi-rígidas e o respectivo comportamento em relação às ações que provocam tombamento.
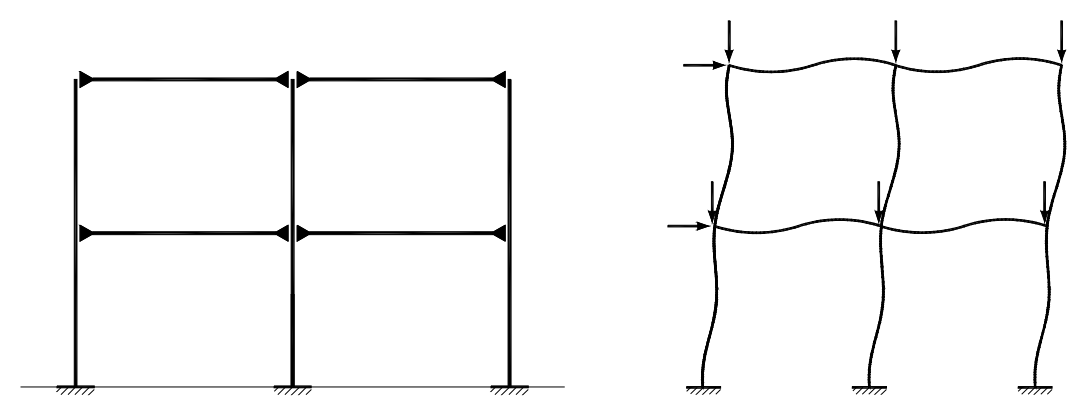

Figura 1.2: Sistema estrutural formado por ligações viga-pilar rígidas ou semi-rígidas. [EL DEBS (2000)]

No sistema estrutural formado por sistemas de contraventamento, paredes ou painéis estruturais podem servir de elementos de contraventamento. Além disto, outra alternativa de contraventamento é a utilização de núcleo de rigidez. A Figura 1.3 ilustra o sistema estrutural formado por sistemas de contraventamento com ligações viga-pilar articuladas e pilares engastados na fundação. O comportamento em relação às ações que provocam tombamento também é ilustrado. 

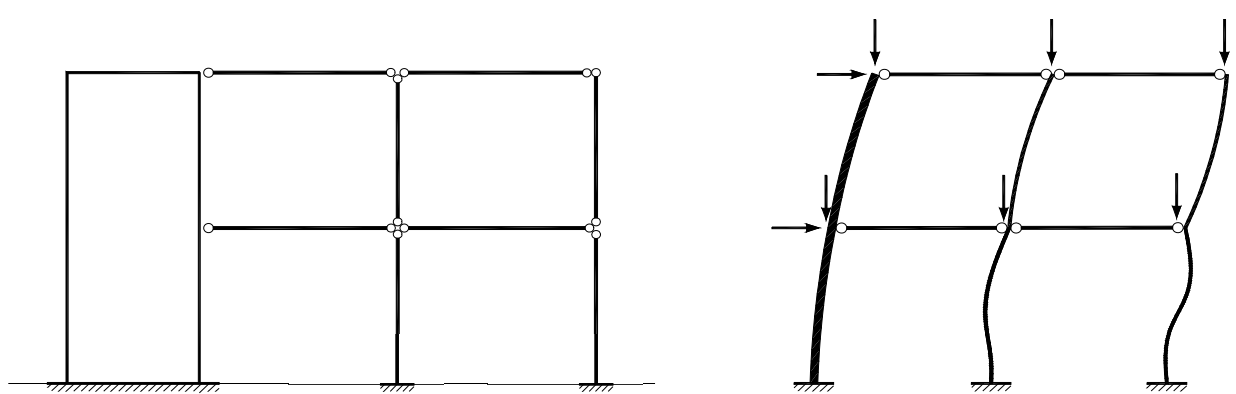

Figura 1.3: Sistema estrutural formado por parede ou núcleo de contraventamento com ligações viga-pilar articuladas. [EL DEBS (2000)]

O sistema estrutural considerado no presente trabalho é aquele constituído por pórticos com ligação viga-pilar semi-rígida e pilares engastados na fundação, conforme ilustra a Figura 1.2 .

A tipologia adotada para a ligação semi-rígida nas simulações realizadas é formada por chumbadores retos e capa de concreto moldada in loco com armadura passante através dos pilares centrais. Nos pilares de extremidade a armadura de continuidade é ancorada em luvas metálicas. Nas direções em que não for constituído pórtico pela combinação pilar-viga a estabilidade deverá ser assegurada pela rigidez dos pilares. Os esforços horizontais provenientes da ação do vento são transferidos para os demais componentes pela laje comportando-se como diafragma.

\subsection{OBJETIVOS}

O objetivo principal do trabalho em questão é analisar a influência dos principais parâmetros de projeto na estabilidade global de estruturas de concreto pré-moldado de múltiplos pavimentos considerando a não-linearidade física, não-linearidade geométrica e ligações semi-rígidas.

Como objetivos específicos tem-se:

- Avaliar para uma situação típica a consideração simplificada da não-linearidade geométrica em estruturas de concreto pré-moldado por intermédio do coeficiente $\gamma_{\mathrm{z}} ;$

$>$ Avaliar as expressões aproximadas prescritas em normas referentes à consideração simplificada da não-linearidade física de elementos em concreto prémoldado; 
$>$ Avaliar a redução da rigidez dos elementos estruturais de concreto pré-moldado em função do comportamento das ligações.

\subsection{JUSTIFICATIVA}

O estudo dos limites de parâmetros e formas simplificadas na análise de edifícios de concreto pré-moldado de múltiplos pavimentos contribui para a difusão do sistema construtivo, tornando acessíveis parâmetros de projeto para a concepção do sistema aos projetistas de estruturas.

Além disto, o escasso volume de estudos no meio técnico e acadêmico do comportamento estrutural de edifícios de concreto pré-moldado de múltiplos pavimentos, principalmente no que se refere à rigidez dos elementos estruturais justificam o presente trabalho.

A atribuição de valores mais precisos de rigidez e resistência para elementos e ligações nas estruturas de múltiplos pavimentos em concreto pré-moldado pode induzir a uma configuração de esforços e deslocamentos na estrutura mais próxima do seu real comportamento.

\subsection{APRESENTAÇÃO DO TRABALHO}

O presente trabalho está estruturado em quatro capítulos, referências bibliográficas, três apêndices além desta introdução.

O Capítulo 2 é reservado para a revisão bibliográfica, onde inicialmente são apresentadas generalidades envolvendo o conceito de estabilidade e relações fundamentais de elementos sob flexão. A análise da não-linearidade geométrica foi abordada por diferentes formas aproximadas: método dos elementos finitos, parâmetro $\alpha$, coeficiente $\gamma_{z}$ e método da carga lateral fictícia $(\mathrm{P}-\Delta)$.

A não-linearidade física foi estudada de duas formas: aproximada e não-aproximada. $\mathrm{Na}$ forma não-aproximada utiliza-se o diagrama $\mathrm{M}$ x N x 1/r, envolvendo a sua construção e os efeitos da força normal, fluência e protensão. Na forma aproximada são apresentadas diversas expressões normativas.

As ligações das estruturas de concreto pré-moldado foram abordadas segundo os procedimentos de projeto, o comportamento semi-rígido e a modelagem das mesmas. 
O Capítulo 3 descreve o tipo estrutural estudado e os procedimentos de projeto envolvidos. Foram descritos a forma de modelagem, o arranjo da estrutura, as ações e combinações de ações envolvidas nas análises. A ligação viga-pilar empregada foi caracterizada com o auxílio de formulação analítica para definição da resistência e da rigidez ao momento negativo e positivo.

Consta no Capítulo 4 a análise numérica do trabalho, onde foi feito um estudo de caso completo de uma estrutura típica de múltiplos pavimentos em concreto pré-moldado envolvendo não-linearidade física, geométrica e ligações semi-rígidas. São analisadas variações de geometria e carregamento da estrutura típica.

O Capítulo 5 traz as conclusões, as considerações finais e as sugestões para trabalhos futuros.

Por fim, o apêndice A aborda a influência da rigidez dos elementos adjacentes no comportamento da ligação. $\mathrm{O}$ apêndice $\mathrm{B}$ aborda a não-linearidade física presente em ligações semi-rígidas assimétricas e o apêndice $\mathrm{C}$ aborda estratégias de modelagem numérica das estruturas em concreto pré-moldado de múltiplos pavimentos. 



\section{REVISÃO BIBLIOGRÁFICA}

\section{1 GENERALIDADES}

\subsubsection{CONCEITO DE ESTABILIDADE}

Segundo REIS \& CAMOTIN (2001), na análise e dimensionamento de estruturas a noção de "estabilidade" aparece sempre associada ao conceito de equilíbrio, na medida em que é utilizada para classificar "configurações de equilíbrio". Assim, admite-se que uma estrutura, submetida a um sistema de forças exteriores, exibe uma configuração de equilíbrio caracterizada pelos valores de deslocamentos dos seus pontos. A estabilidade dessa configuração pode ser avaliada através do comportamento da estrutura, após sofrer uma perturbação causada por uma pequena ação exterior arbitrária. A configuração de equilíbrio é dita "estável" ou "instável" consoante ao regresso ou não da estrutura, quando cessa a perturbação.

Conforme o item 15.2 da NBR 6118:2003, em estruturas de concreto armado o estado limite último de instabilidade é atingido sempre que, ao crescer a intensidade do carregamento e, portanto das deformações, há elementos submetidos à flexo-compressão em que o aumento da capacidade resistente passa a ser inferior ao aumento da solicitação.

Existem nas estruturas três formas básicas de instabilidade:

Instabilidade por bifurcação do equilíbrio ou por flambagem. Este tipo de instabilidade está associado a uma situação teórica, ideal, onde não há imperfeições geométricas iniciais. $\mathrm{O}$ elemento quando submetido a um carregamento axial crescente de compressão no centro geométrico da seção sofre 
uma mudança brusca na configuração de equilíbrio indeformada e estável para uma nova configuração de equilíbrio deformada e estável;

$>$ Instabilidade por ponto limite com reversão ou por "snap-through". Este tipo de instabilidade está associado geralmente às estruturas abatidas, onde a estrutura analisada se encontra no ponto limite e uma vez submetida a um aumento de carga muda dinamicamente sua configuração de equilíbrio para uma forma afastada e estável de equilíbrio;

$>$ Instabilidade por ponto limite sem reversão. Este tipo de instabilidade é característico das estruturas de concreto armado, onde sempre há imperfeições geométricas iniciais e o material tem comportamento elasto-plástico.

Nas estruturas de concreto armado a instabilidade ocorre devido à interação entre fenômenos de instabilidade, correspondentes a não-linearidade geométrica, e a plasticidade, correspondente a não-linearidade física.

\subsubsection{RELAÇÕES FUNDAMENTAIS DE ELEMENTOS SOB FLEXÃO}

Antes de qualquer abordagem referente ao objeto de estudo do trabalho, são definidas algumas relações fundamentais estabelecidas segundo a condição de equilíbrio de um elemento infinitesimal, conforme ilustra a Figura 2.1:

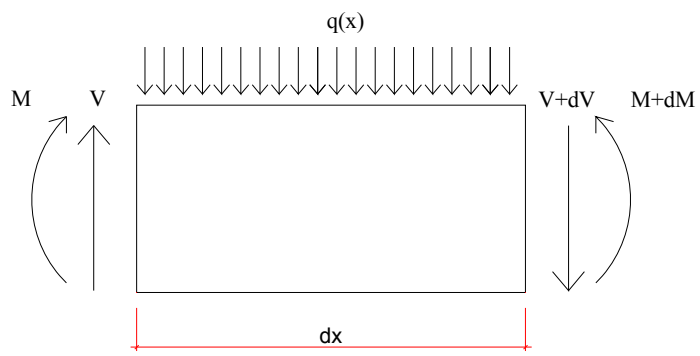

Figura 2.1: Diagrama de corpo livre

A partir da condição de equilíbrio na direção vertical tem-se:

$$
V-(V+d V)-q(x) d x=0
$$

Reordenando a expressão (2.1), obtém-se:

$$
\frac{d V}{d x}=-q(x)
$$


A partir da condição de equilíbrio em relação ao momento fletor tem-se:

$$
M+d M-(V+d V) d x-M-\frac{q d x^{2}}{2}=0
$$

Reordenando a expressão (2.3) e desprezando os termos de segunda ordem, obtém-se:

$$
\frac{d M}{d x}=V
$$

Derivando a expressão (2.4) e igualando-se a (2.2) tem-se:

$$
\frac{d M^{2}}{d^{2} x}=-q(x)
$$

A expressão (2.5) relaciona a segunda derivada do momento fletor com a taxa de carregamento do elemento infinitesimal.

A partir da condição de compatibilidade de deformações, considerando válida a hipótese cinemática de Euler-Bernoulli de que a seção transversal do elemento inicialmente plana e ortogonal ao eixo permanece plana e indeformada no seu plano e ortogonal ao eixo deslocado e com o auxílio da Figura 2.2, obtém-se a equação expressa em (2.6).

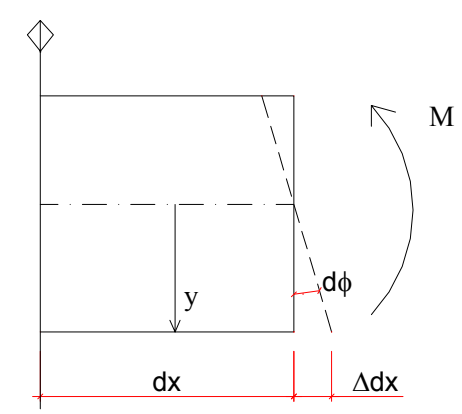

Figura 2.2: Seção transversal deformada após solicitação

Segundo o ilustrado na Figura 2.2, tem-se:

$$
\Delta d x=y d \phi
$$

Dividindo todos os membros da equação (2.6) por $\mathrm{dx}$ :

$$
\frac{\Delta d x}{d x}=\frac{y d \phi}{d x}
$$

Onde:

$$
\frac{\Delta d x}{d x}=\varepsilon
$$




$$
\begin{aligned}
& \frac{d \phi}{d x}=v^{\prime \prime}(x) \\
& v(x) \text { representa a função que descreve o deslocamento transversal do }
\end{aligned}
$$
elemento, linha elástica.

Portanto:

$$
\varepsilon=y v^{\prime \prime}(x)
$$

Estabelecendo a condição constitutiva, tem-se:

$$
\sigma=E \varepsilon
$$

Substituindo-se (2.10) em (2.11), tem-se:

$$
\sigma=E y v^{\prime \prime}(x)
$$

O momento fletor pode ser obtido segundo a soma do produto das tensões normais na seção pela distância ao centro de gravidade da mesma, portanto:

$$
M=\int_{s} \sigma \cdot y d s
$$

Substituindo (2.12) em (2.13), tem-se:

$$
M=\int_{s} E y v^{\prime \prime}(x) \cdot y d s
$$

Para eixos escolhidos que forem principais de inércia, tem-se:

$$
\int_{s} y^{2} d s=I
$$

Portanto:

$$
M=-E I v^{\prime \prime}(x)
$$

A segunda derivada da equação da linha elástica relaciona-se com a curvatura, o que pode ser verificado com o auxílio da Figura 2.3.

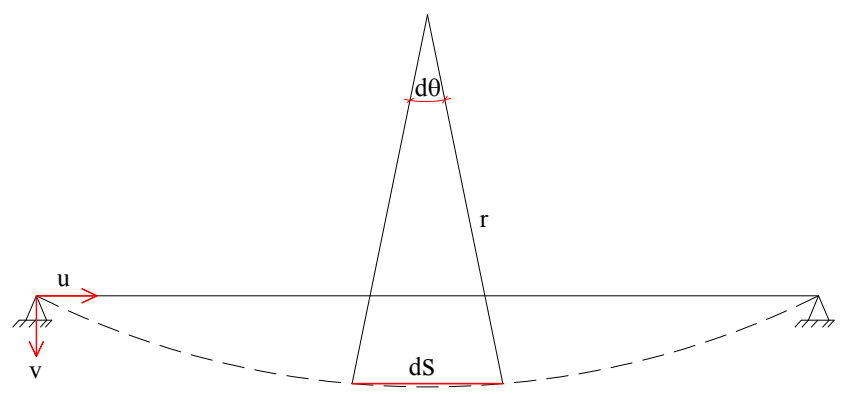

Figura 2.3: Deformada de uma viga 
Da Figura 2.3 tem-se:

$$
d s=r . d \theta
$$

Reordenando a equação (2.17):

$$
\frac{1}{r}=\frac{d \theta}{d s}
$$

Multiplicando por $d u$ o denominador e o numerador tem-se:

$$
\begin{aligned}
& \frac{1}{r}=\frac{d \theta}{d u} \frac{d u}{d s} \\
& \operatorname{tg} \theta=\frac{d v}{d u}
\end{aligned}
$$

Isolando $\theta$ tem-se:

$$
\theta=\operatorname{arctg}\left(\frac{d v}{d u}\right)
$$

Derivando a equação (2.21) em relação a $u$ :

$$
\frac{d \theta}{d u}=\frac{1}{1+\left(\frac{d v}{d u}\right)^{2}} \cdot \frac{d^{2} v}{d u^{2}}
$$

Sabendo que $d s^{2}=d u^{2}+d v^{2}$ e dividindo esta expressão por $d u^{2}$ tem-se:

$$
\frac{d s}{d u}=\left[1+\left(\frac{d v}{d u}\right)^{2}\right]^{1 / 2}
$$

Substituindo as equações (2.22) e (2.23) em (2.19) tem-se:

$$
\frac{1}{r}=\frac{\frac{d^{2} v}{d u^{2}}}{\left[1+\left(\frac{d v}{d u}\right)^{2}\right]^{\frac{3}{2}}}=-\frac{M}{E I}
$$

Como o termo $\left(\frac{d v}{d u}\right)^{2}$ é muito pequeno, despreza-se sua contribuição. A equação da linha elástica de um elemento fletido fica reduzida a seguinte expressão:

$$
\frac{1}{r}=-\frac{M}{E I}
$$

O sinal negativo refere-se à curvatura da parábola em relação ao eixo de referência. A partir das relações deduzidas anteriormente é possível estabelecer as seguintes relações em função da equação da linha elástica, conforme ilustra a Tabela 2.1. 
Tabela 2.1: Relações fundamentais

\begin{tabular}{|c|c|}
\hline Deslocamento & $v$ \\
\hline Rotação & $v^{\prime}$ \\
\hline Momento & $M=-E I v^{\prime \prime}$ \\
\hline Força Cortante & $V=-E I v^{I I I}$ \\
\hline Carregamento & $q=-E I v^{I V}$ \\
\hline
\end{tabular}

\subsection{ANÁLISE DA NÃO-LINEARIDADE GEOMÉTRICA}

\subsubsection{ANÁLISE DA NÃO-LINEARIDADE GEOMÉTRICA SEGUNDO O MÉTODO DOS ELEMENTOS FINITOS}

A não-linearidade geométrica da estrutura ocorre, porque a relação entre esforços e deslocamentos não é linear. Ela ganha maior importância quando os deslocamentos excessivos podem comprometer a estabilidade da estrutura. Neste item, a não-linearidade geométrica é abordada de forma simplificada, considerando-se a hipótese dos pequenos deslocamentos. Sendo assim, são introduzidas simplificações no tratamento matemático do problema.

O conhecimento do comportamento de uma estrutura consiste em definir deslocamento, deformação e tensão em um ponto qualquer da estrutura. A obtenção destas variáveis é feita a partir das equações de equilíbrio, de compatibilidade e constitutiva.

A solução matemática exata via métodos analíticos se restringe a um número limitado de problemas. Os métodos numéricos apresentam alternativas suficientemente precisas na resolução de inúmeros problemas de engenharia.

Dentre os métodos aproximados, destacam-se os métodos variacionais e os dos resíduos ponderados.

Segundo ASSAN (2003) o método dos elementos finitos originou-se do método de Rayleigh-Ritz e do método de Garlekin onde o primeiro pertence ao grupo dos métodos variacionais e o segundo pertence ao grupo dos métodos dos resíduos ponderados.

O método de Rayleigh-Ritz consiste em substituir uma função suposta exata que rege um determinado problema por uma função aproximada, formada por uma combinação linear de funções. A função aproximada adotada deve ter o comportamento mais próximo possível da solução exata, esta condição é atendida minimizando o funcional. 
No método da energia a obtenção da forma aproximada é gerada por minimização da energia potencial total do sistema. O funcional da energia potencial total é expresso da seguinte forma:

$$
\Pi=U+\Omega
$$

Onde:

$\Pi$ representa a energia potencial total;

$U$ representa a energia potencial dos esforços internos associada ao trabalho realizado pelos esforços internos sobre os respectivos deslocamentos. Esta parcela também é conhecida como energia de deformação, pois se refere à energia que um dado corpo absorve ao deformar-se sob ação de um carregamento;

$\Omega$ representa a energia potencial das cargas externas associada ao trabalho realizado pelo produto das cargas externas pelos respectivos deslocamentos.

De uma forma geral a energia de deformação interna é assim expressa:

$$
U=\frac{1}{2} \int_{V}(\sigma . \varepsilon+\tau . \gamma) d v
$$

Desprezando a deformação provocada por tensão de cisalhamento a expressão (2.27) fica reduzida a expressão (2.28).

$$
U=\int_{V} \frac{1}{2} \sigma \cdot \varepsilon d v
$$

A energia de deformação pode ser obtida com o auxílio da Figura 2.4, onde a área definida pelo produto entre a tensão e a deformação representa a energia de deformação interna.

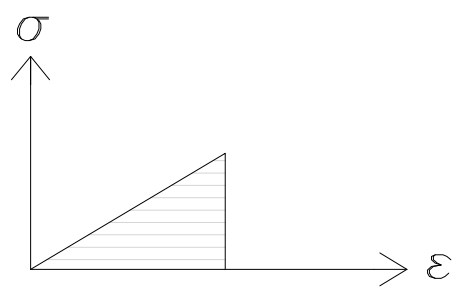

Figura 2.4: Energia de deformação 
Para barras submetidas a esforço normal têm-se as seguintes relações envolvendo a equação que rege o deslocamento longitudinal da barra:

$$
\begin{aligned}
& \frac{\partial u}{\partial x}=u^{\prime}=\varepsilon \\
& \frac{\partial^{2} u}{\partial x^{2}}=u^{\prime \prime}=-\frac{p}{s}
\end{aligned}
$$

A tensão na barra é representada pela expressão (2.31).

$$
\sigma=E . u^{\prime}
$$

Onde:

$$
\begin{aligned}
& u \text { representa o deslocamento longitudinal; } \\
& p \text { representa uma força axial; } \\
& \text { s representa a área da seção transversal. }
\end{aligned}
$$

Substituindo a equação (2.29) na equação (2.31) e posteriormente na equação (2.28), tem-se a energia de deformação interna para barra submetida a esforço normal:

$$
U_{N}=\int_{V} \frac{1}{2} E \varepsilon \cdot \varepsilon \cdot d v=\int_{0}^{L} \frac{1}{2} E S\left(u^{\prime}\right)^{2} d x
$$

Para barras submetidas a esforço de flexão, substituindo (2.10) e (2.12) em (2.28) obtém-se a expressão da energia de deformação interna para barra submetida à flexão:

$$
U_{F}=\int_{0}^{L} \frac{1}{2} E\left(v^{\prime \prime} y\right)\left(v^{\prime \prime} y\right) d x=\int_{0}^{L}\left(\int_{S} \frac{1}{2} E\left(v^{\prime \prime}\right)^{2} y^{2} d s\right) d x=\int_{0}^{L} \frac{1}{2} E I\left(v^{\prime \prime}\right)^{2} d x
$$

Até então, apenas a energia potencial interna foi definida. Agora é abordada a obtenção da energia potencial das cargas externas, mais especificamente da carga concentrada $\mathrm{P}$ ilustrada na Figura 2.5, a energia potencial associada ao trabalho realizado pela carga $\mathrm{P}$ pode ser dividida em duas parcelas. Na primeira o trabalho realizado pela força $\mathrm{P}$ ocorre sobre 
o encurtamento da barra na ausência de flexão $\mathrm{u}(\mathrm{L})$. Na segunda parcela o trabalho realizado pela força $\mathrm{P}$ ocorre sobre o encurtamento da barra devido à flexão $(\Delta)$.

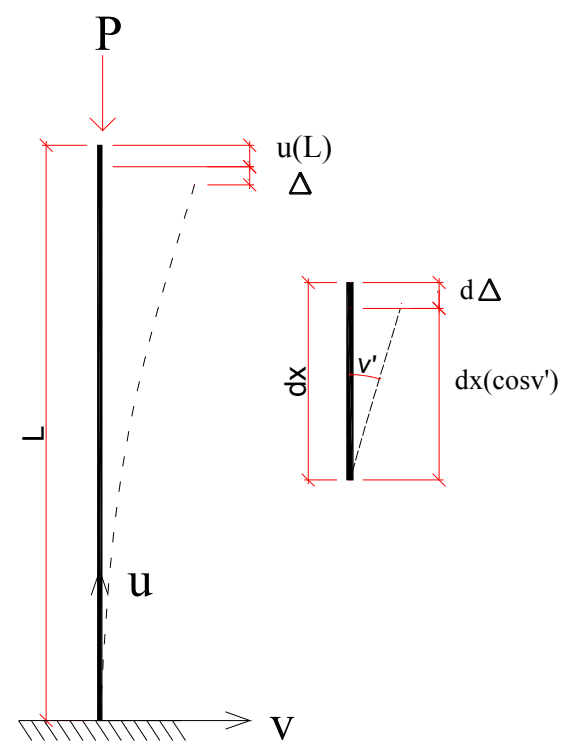

Figura 2.5: Elemento submetido a esforço normal

Considerando a hipótese de pequenos giros e deslocamentos, da Figura 2.5, tem-se:

$$
d \Delta=d x\left(1-\cos v^{\prime}\right)
$$

O termo cosseno pode ser escrito na forma de série:

$$
\cos v^{\prime}=1-\frac{\left(v^{\prime}\right)^{2}}{2 !}+\frac{\left(v^{\prime}\right)^{4}}{4 !}-\frac{\left(v^{\prime}\right)^{6}}{6 !}+\ldots
$$

Desprezando os termos de ordem superior na expressão (2.35) obtém-se a expressão (2.36).

$$
d \Delta=d x\left(1-\left(1-\frac{\left(v^{\prime}\right)^{2}}{2 !}\right)\right) \Rightarrow \therefore d \Delta=d x \frac{\left(v^{\prime}\right)^{2}}{2}
$$

Integrando a expressão (2.36), tem-se.

$$
\Delta=\int_{0}^{L} \frac{1}{2}\left(v^{\prime}\right)^{2} d x
$$


Somando a parcela da energia de deformação interna referente à barra submetida a esforço normal e a barra submetida a esforço de flexão tem-se:

$$
U=\int_{0}^{L} \frac{1}{2} E S\left(u^{\prime}\right)^{2} d x+\int_{0}^{L} \frac{1}{2} E I\left(v^{\prime \prime}\right)^{2} d x
$$

A somatória da energia potencial das cargas externas é definida pela contribuição da força concentrada $\mathrm{P}$ associada ao deslocamento $\Delta \mathrm{e}$ ao deslocamento $\mathrm{u}(\mathrm{L})$, sendo assim expresso:

$$
\Omega=-P \int_{0}^{L} \frac{1}{2}\left(v^{\prime}\right)^{2} d x+P u(L)
$$

O sinal positivo de $\mathrm{Pu}(\mathrm{L})$ está associado ao fato do deslocamento provocado pela força $P$ de compressão ser negativo segundo o sistema de referência.

Segundo o método da energia, a variação da energia potencial total é nula, ou seja, um acréscimo de energia potencial interna é consumido pela energia potencial externa. Em outras palavras, uma viga em balanço submetida a um carregamento distribuído quando submetida a um novo acréscimo de carregamento tem sua energia potencial associada ao carregamento aumentada. No entanto, a energia de deformação foi diminuída, pois a viga após se deformar perdeu capacidade de se deformar ainda mais.

O funcional do problema ilustrado pela Figura 2.5 é obtido pela soma das expressões (2.38) e (2.39):

$$
\Pi[u(x), v(x)]=\int_{0}^{L} \frac{1}{2} E S\left(u^{\prime}\right)^{2} d x+\int_{0}^{L} \frac{1}{2} E I\left(v^{\prime \prime}\right)^{2} d x-P \int_{0}^{L} \frac{1}{2}\left(v^{\prime}\right)^{2} d x+P u(L)
$$

Segundo ASSAN (2003) o método dos elementos finitos (MEF) consiste em discretizar o domínio de integração, contínuo, em um número finito de pequenas regiões denominadas elementos finitos.

Conforme explicado, nos métodos aproximados, tais como o de Rayleigh-Ritz ou de Garlekin, adota-se uma função aproximada para descrever o comportamento de um problema, 
para ser mais preciso do campo de deslocamentos. No entanto, nem sempre é fácil adotar funções que representem bem o campo de deslocamentos do problema.

Uma estratégia, no caso da função adotada ser um polinômio, é aumentar o grau do polinômio com intuito de descrever melhor o campo de deslocamentos. Embora esta alternativa possa ser empregada, as diferentes e inúmeras condições de vinculação e de solicitação dificultam sua utilização.

No MEF a idéia básica é dividir o domínio do problema estudado em vários subdomínios e adotar uma função aproximada de simples abordagem matemática, tal como um polinômio para todos os subdomínios. Esta estratégia requer a resolução de sistemas de equações de ordem elevada e só foi viável com o desenvolvimento dos computadores.

Segundo a teoria de segunda ordem a abordagem do problema via MEF é feita de forma separada para a barra submetida a esforço normal e para a barra submetida a esforço de flexão.

A função aproximadora $v(x)$ de um elemento finito é constituída de uma combinação linear de funções no seguinte formato:

$$
v(x)=\sum_{m=1}^{n} \delta_{m} \phi_{m}
$$

Onde:

$$
\begin{aligned}
& \delta_{m} \text { representam os parâmetros nodais; } \\
& \phi_{m} \text { representam as funções de forma. }
\end{aligned}
$$

A função aproximadora adotada para descrever problemas envolvendo barras deve satisfazer algumas condições de existência, sendo basicamente duas condições:

$>$ A função aproximada adotada deve ser contínua no domínio do elemento finito, esta condição é satisfeita caso a função aproximadora adotada seja um polinômio. Nos funcionais existem integrais, para que estas integrais sejam definidas é necessário que a função $v$ e as derivadas de $v$ até a ordem (n-1) sejam contínuas, onde n é o maior grau de derivação encontrado no funcional;

$>$ Os deslocamentos de corpo rígido devem estar incluídos nas funções aproximadoras. 
$\mathrm{Na}$ barra submetida a esforço normal o parâmetro nodal correspondente é o deslocamento longitudinal. A função aproximadora do elemento de barra submetida a esforço normal pode ser um polinômio do primeiro grau.

$$
u(x)=A x+B
$$

Considerando a combinação linear expressa em (2.41), a Figura 2.6 e a Figura 2.7 ilustram os parâmetros nodais e as funções de forma referentes à barra submetida a esforço normal.

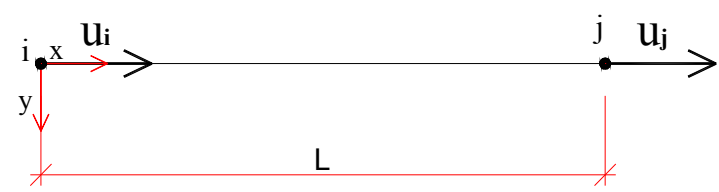

Figura 2.6: Parâmetros nodais (graus de liberdade) de elemento submetido a esforço normal

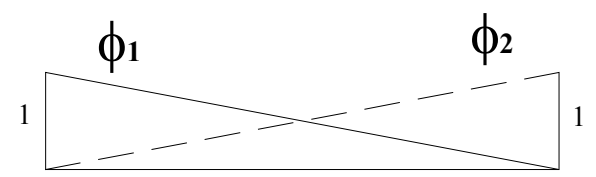

Figura 2.7: Funções de forma de elemento submetido a esforço normal

A função de forma é determinada impondo-se as condições de contorno na função aproximadora (2.42), tem-se.

$$
\begin{aligned}
& u(0)=u_{i} \\
& u(L)=u_{j}
\end{aligned}
$$

Substituindo-se as condições de contorno (2.43) e (2.44) em (2.42) obtém-se os coeficientes A e B e a expressão (2.42) pode ser escrita da seguinte forma:

$$
u(x)=u_{i}\left(1-\frac{x}{L}\right)+u_{j}\left(\frac{x}{L}\right)
$$

Segundo a notação expressa em (2.41) a função aproximadora da barra submetida a esforço normal assume o seguinte formato: 


$$
u(x)=u_{i} \phi_{1}+u_{j} \phi_{2}
$$

Uma vez obtida a função aproximadora em relação aos parâmetros nodais e as funções de forma, substituindo-se a função encontrada no funcional expresso em (2.40), realizando as operações matemáticas do funcional e minimizando o funcional em relação aos parâmetros nodais associados ao deslocamento axial, obtém-se o sistema sem as condições de contorno impostas apresentado em (2.47).

$$
\left[\begin{array}{cc}
\frac{E S}{L} & -\frac{E S}{L} \\
-\frac{E S}{L} & \frac{E S}{L}
\end{array}\right]\left\{\begin{array}{l}
u_{i} \\
u_{j}
\end{array}\right\}=\left\{\begin{array}{c}
0 \\
-P
\end{array}\right\}
$$

Na barra submetida à flexão os parâmetros nodais correspondem ao deslocamento transversal e a rotação. A função aproximadora do elemento de barra submetida à flexão pode ser um polinômio do terceiro grau.

$$
v(x)=A x^{3}+B x^{2}+C x+D
$$

Considerando a combinação linear expressa em (2.41), a Figura 2.8 e a Figura 2.9 ilustram os parâmetros nodais e as funções de forma referentes à barra submetida à flexão.

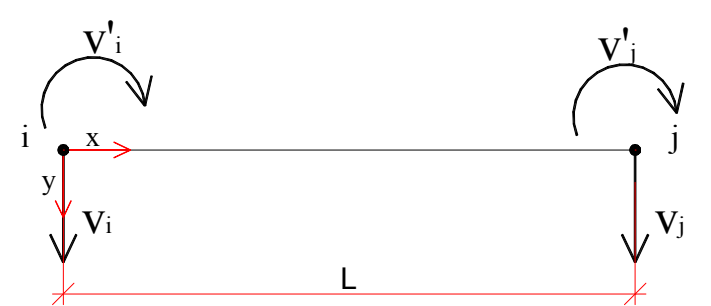

Figura 2.8: Parâmetros nodais (graus de liberdade) de elemento submetido à flexão

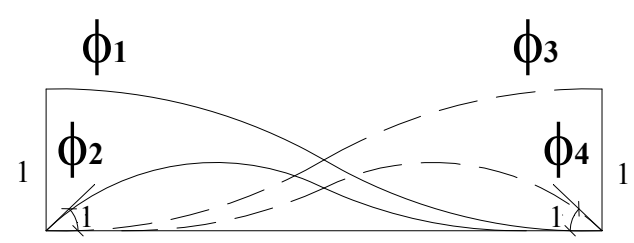

Figura 2.9: Funções de forma de elemento submetido à flexão 
As funções de forma para o elemento submetido à flexão são determinadas impondose as condições de contorno na função aproximadora (2.48), tem-se.

$$
\begin{gathered}
v(0)=v_{i} \\
v^{\prime}(0)=v_{i}^{\prime} \\
v(L)=v_{j} \\
v^{\prime}(L)=v_{j}^{\prime}
\end{gathered}
$$

Substituindo-se as condições de contorno (2.49), (2.50), (2.51) e (2.52) em (2.48) obtém-se os coeficientes A, B, C e D. A expressão (2.48) pode ser escrita da seguinte forma:

$$
v(x)=v_{i}\left[\frac{2 x^{3}}{L^{3}}-\frac{3 x^{2}}{L^{2}}+1\right]+v_{i}^{\prime}\left[\frac{x^{3}}{L^{2}}-\frac{2 x^{2}}{L}+x\right]+v_{j}\left[-\frac{2 x^{3}}{L^{3}}+\frac{3 x^{2}}{L^{2}}\right]+v_{j}^{\prime}\left[\frac{x^{3}}{L^{2}}-\frac{x^{2}}{L}\right]
$$

Segundo a notação expressa em (2.41) a função aproximadora da barra submetida à flexão assume o seguinte formato.

$$
v(x)=v_{i} \phi_{1}(x)+v_{i}^{\prime} \phi_{2}(x)+v_{j} \phi_{3}(x)+v_{j}^{\prime} \phi_{4}(x)
$$

Uma vez obtida a função aproximadora em relação aos parâmetros nodais e as funções de forma, substitui-se a função encontrada no funcional expresso em (2.40). Realizando as operações matemáticas do funcional e minimizando o funcional em relação aos parâmetros nodais associados à rotação e ao deslocamento transversal, obtém-se o sistema sem as condições de contorno impostas do problema ilustrado na Figura 2.5.

$$
\left[\begin{array}{cccc}
\frac{12 E I}{L^{3}} & \frac{6 E I}{L^{2}} & \frac{-12 E I}{L^{3}} & \frac{6 E I}{L^{2}} \\
\frac{6 E I}{L^{2}} & \frac{4 E I}{L} & \frac{-6 E I}{L^{2}} & \frac{2 E I}{L} \\
\frac{-12 E I}{L^{3}} & \frac{-6 E I}{L^{2}} & \frac{12 E I}{L^{3}} & \frac{-6 E I}{L^{2}} \\
\frac{6 E I}{L^{2}} & \frac{2 E I}{L} & \frac{-6 E I}{L^{2}} & \frac{4 E I}{L}
\end{array}\right]-P\left[\begin{array}{cccc}
\frac{6}{5 L} & \frac{1}{10} & \frac{-6}{5 L} & \frac{1}{10} \\
\frac{1}{10} & \frac{2 L}{15} & \frac{-1}{10} & \frac{-L}{30} \\
\frac{-6}{5 L} & \frac{-1}{10} & \frac{6}{5 L} & \frac{-1}{10} \\
\frac{1}{10} & \frac{-L}{30} & \frac{-1}{10} & \frac{2 L}{15}
\end{array}\right]\left\{\begin{array}{l}
v_{i} \\
v_{i}^{\prime} \\
v_{j} \\
v_{j}^{\prime}
\end{array}\right\}=\left\{\begin{array}{l}
0 \\
0 \\
0 \\
0
\end{array}\right\}
$$


O sistema descrito em (2.55) pode ser assim expresso:

$$
\begin{aligned}
& {\left[K_{L}+K_{G}\right]\{U\}=\{F\}} \\
& {\left[K_{r}\right]\{U\}=\{F\}}
\end{aligned}
$$

Onde:

$\left[K_{L}\right]$ representa a matriz de rigidez linear convencional local;

$\left[K_{G}\right]$ representa a matriz de rigidez geométrica local;

$\left[K_{T}\right]$ representa a matriz de rigidez tangente;

$\{F\}$ representa o vetor de forças nodais local;

$\{U\}$ representa o vetor de deslocamentos nodais.

Nota-se que a matriz de rigidez geométrica tem a função de penalizar a matriz de rigidez elástica linear quando o valor associado à matriz de rigidez geométrica for de compressão, caso este objeto de estudo. No caso de tração o valor associado à matriz de rigidez geométrica incrementará a matriz de rigidez elástica, este caso refere-se ao estudo de cabos.

A formulação via MEF para consideração da não-linearidade geométrica apresenta muitas variações na literatura. A forma apresentada e deduzida até então pode ser considerada aproximada, leva em conta a teoria de segunda ordem, sendo válida a hipótese dos pequenos deslocamentos. Neste formato aproximado ocorre a "linearização" do problema.

Existem basicamente duas formas de se representar a matriz de rigidez do elemento, na primeira é somada matrizes de rigidez complementares a matriz de rigidez linear convencional.

$\mathrm{Na}$ segunda forma os elementos da matriz de rigidez linear convencional são multiplicados por funções de estabilidade, como pode ser visto em REIS \& CAMOTIN (2001) e em CHAN \& GU (2000) onde são apresentadas algumas funções de estabilidade.

Conforme já comentado, a estratégia de aumentar a discretização da estrutura em elementos finitos visa melhorar a convergência da solução aproximada para a solução exata.

No caso de um elemento submetido à compressão, conforme ilustrado na Figura 2.5, a utilização de um único elemento finito, cuja função aproximada é um polinômio do terceiro 
grau, não representa bem o formato da equação da linha elástica do problema. As funções que melhor representariam este problema correspondem a um polinômio de ordem superior ou funções que combinem seno e cosseno. As funções de estabilidade são usualmente compostas por funções do tipo seno e cosseno. Este problema é contornado com o aumento da discretização da estrutura em estudo.

Segundo REIS \& CAMOTIN (2001), para barras de seção e compressão constantes, a discretização em no mínimo três elementos finitos representa uma boa aproximação, tomando-se um polinômio do terceiro grau como função aproximadora.

A forma de matriz de rigidez apresentada em (2.56) tem sua utilização restringida para casos de estruturas com pequenas rotações $\left(\theta^{2}<<1\right)$ conforme apresenta COOK et al (1989). Neste formato de matriz assumi-se que a força normal é constante ao longo do elemento.

Neste caso, considera-se que a deformação longitudinal é da mesma ordem de grandeza que a metade do quadrado da rotação. Esta afirmação pode ser confirmada com o auxílio da Figura 2.10 e das expressões (2.58) a (2.60).

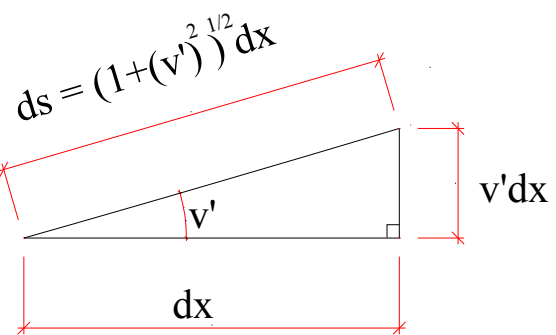

Figura 2.10: Relações geométricas de um elemento de comprimento dx

Da Figura 2.10 obtém-se a expressão (2.58).

$$
d s^{2}=d x^{2}+\left(v^{\prime} d x\right)^{2}
$$

A expressão (2.58) pode ser reescrita em (2.59).

$$
d s=\left(1+\left(v^{\prime}\right)^{2}\right)^{1 / 2} d x \approx\left(1+\frac{\left(v^{\prime}\right)^{2}}{2}\right) d x
$$

Sendo assim, tem-se:

$$
\varepsilon=\frac{d s-d x}{d x} \approx \frac{\left(v^{\prime}\right)^{2}}{2}
$$


Considerando que a máxima deformação no concreto é de $2 \%$ obtém-se a partir da expressão (2.60) uma rotação correspondente a 3,63․

CORREA (1991) apresenta extensa revisão bibliográfica sobre a NLG, o tema é tratado de forma elucidativa, onde são definidas as matrizes que contemplam a NLG em sua totalidade. Dentre os trabalhos citados na revisão bibliográfica, destaca-se o de WEN \& RAHIMZADEH (1983) pela abordagem matricial apresentada.

A obtenção da forma não-aproximada da NLG reside basicamente nos termos da medida de deformação adotada. Problemas sem restrição de deslocamento e deformação fazem uso da medida de deformação de Green, conforme expresso em (2.61).

$$
\varepsilon=\underbrace{u^{\prime}-y v^{\prime \prime}}_{\text {Linear }}+\underbrace{\frac{1}{2}\left(v^{\prime}\right)^{2}+\frac{1}{2}\left(u^{\prime}-y v^{\prime \prime}\right)^{2}}_{\text {Não-linear }}
$$

Substituindo a expressão (2.61) em (2.28) e realizando as operações matemáticas, obtém-se a energia de deformação que contempla a NLG de forma não-aproximada.

Em CORREA (1991) a energia de deformação é obtida omitindo-se o último termo da expressão (2.61), esta omissão pode ser feita considerando-se que este termo torna-se desprezível na presença dos outros.

As matrizes de rigidez contemplando a NLG são definidas de acordo com a forma de construção da curva força $\mathrm{x}$ deslocamento. A curva força $\mathrm{x}$ deslocamento pode ser construída basicamente de duas formas, segundo aproximação secante ou tangente.

Em problemas com comportamento não-linear, a matriz de rigidez é definida em função dos deslocamentos, portanto a cada incremento de deslocamento a matriz de rigidez deve ser atualizada. Quando a matriz de rigidez relaciona as forças aplicadas no fim do processo aos correspondentes deslocamentos, a mesma é denominada matriz de rigidez secante. A obtenção da matriz de rigidez secante ocorre pela primeira derivação da energia de deformação em relação aos parâmetros nodais de deslocamento. A Figura 2.11 ilustra esta situação. 


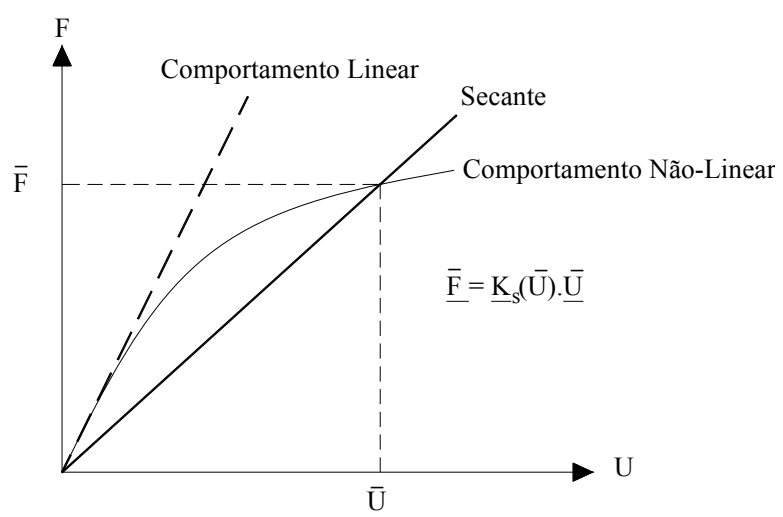

Figura 2.11 Comportamento não-linear: Matriz de rigidez secante [(CORREA (1991) Adaptado]

Quando a matriz de rigidez relaciona incrementos de carga com incrementos de deslocamento, a mesma é denominada matriz de rigidez tangente. A obtenção da matriz de rigidez tangente ocorre pela segunda derivação da energia de deformação em relação aos parâmetros nodais de deslocamento. A Figura 2.12 ilustra esta situação.

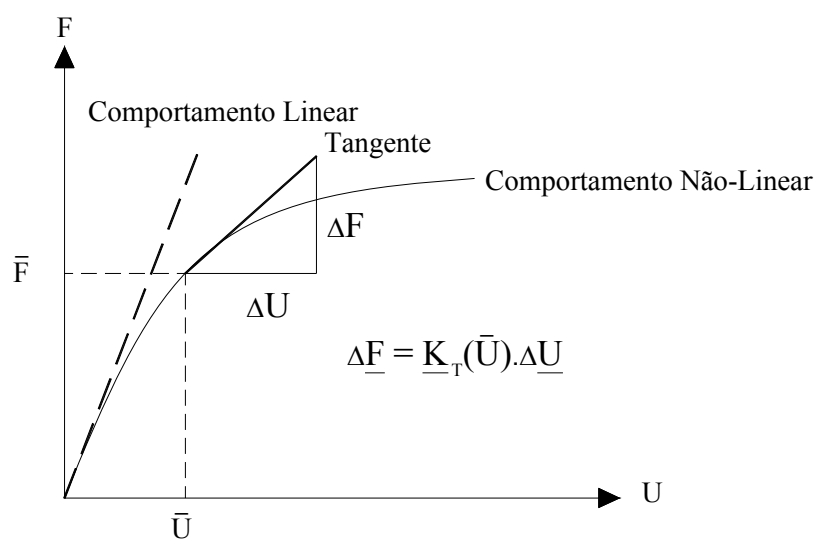

Figura 2.12: Comportamento não-linear: Matriz de rigidez tangente [(CORREA (1991) Adaptado]

CHAJES \& CHURCHILL (1987) apresentam três formas de construção da curva força $\mathrm{x}$ deslocamento não-lineares via MEF. O primeiro denominado método linear incremental, o segundo denominado método não-linear incremental e o terceiro denominado método direto. A estes três métodos estão relacionadas formas diferentes de composição da matriz de rigidez.

No método linear incremental a curva força $\mathrm{x}$ deslocamento é construída a partir de pequenos incrementos de carga. No início de cada incremento é calculada uma matriz de rigidez tangente para previsão do deslocamento provocado pelo incremento de carga. Os deslocamentos são utilizados para calcular a mudança nos esforços internos, mudanças no estado de deformação e tensão durante os passos de carga são negligenciados. 
No método não-linear incremental a curva força x deslocamento também é construída a partir de pequenos incrementos de carga, da mesma forma que os deslocamentos são calculados para cada incremento de carga. A diferença deste método para o linear incremental reside na forma como o deslocamento é calculado para cada incremento de carga. No método linear incremental a matriz de rigidez é calculada a partir do estado de tensão e deformação no início de cada incremento de carga. Já no método não-linear incremental, matrizes complementares são adicionadas as já apresentadas para contemplar os deslocamentos ocorridos durante o incremento de carga. Estes deslocamentos não são conhecidos no início do processo, requerendo desta forma uma solução iterativa. A matriz de rigidez assume o seguinte formato:

$$
\left[K_{\text {inc }}\right]=\left[K_{L}\right]+\left[K_{G}\right]+\frac{E S}{2}\left[K_{1}\right]+\frac{E S}{3}\left[K_{2}\right]
$$

Onde:

$\mathrm{K}_{\mathrm{L}}$ e $\mathrm{K}_{\mathrm{G}}$ têm o mesmo significado apresentado em (2.55), sendo que estas matrizes são independentes dos deslocamentos ocorridos.

$\mathrm{K}_{1}$ e $\mathrm{K}_{2}$ representam respectivamente a matriz associada aos termos lineares e aos termos quadráticos dos deslocamentos incrementais. Estas matrizes contemplam a mudança nos esforços axiais e nos deslocamentos ocorridos durante o incremento de carga.

O método direto é caracterizado pela adoção de uma matriz de rigidez denominada secante, nesta formulação o deslocamento total é associado ao carregamento total. A matriz de rigidez secante fica assim expressa:

$$
\left[K_{\mathrm{sec}}\right]=\left[K_{L}\right]+\frac{E S}{2}\left[K_{1}\right]+\frac{E S}{3}\left[K_{2}\right]
$$

CHAJES \& CHURCHILL (1987) apresentam de forma explícita todos os termos das matrizes abordadas.

De uma forma geral, a matriz de rigidez é composta pela matriz de rigidez linear convencional somada a matrizes de rigidez complementares, que tem a função de assumir os efeitos da não-linearidade geométrica. A quantidade de matrizes complementares e os termos 
que compõe estas matrizes variam basicamente com o grau de simplificação empregado na análise da não-linearidade geométrica. O formato geral pode ser expresso da seguinte forma:

$$
K_{T}=K_{L}+K_{i-2}+K_{i-1}+K_{i}+\ldots+K_{n}
$$

$\mathrm{Na}$ literatura podem ser encontrados outros formatos e formas de abordagem da matriz de rigidez contemplando-se grandes deslocamentos, conforme pode ser observado em YANG \& LEU (1994), CHANG (2004) e GU \& CHAN (2005).

Estruturas associadas à engenharia civil admitem pequenas deformações, uma vez que os principais materiais empregados, como o concreto, admitem pequenas deformações. Sendo assim, o desempenho obtido com composições matriciais simplificadas pode ser satisfatório.

Algumas aplicações importantes, como a obtenção da carga crítica de flambagem e os modos de instabilidade podem ser obtidos com a formulação simplificada de composição da matriz de rigidez expressa em (2.56).

Após apresentadas algumas das possíveis variações de abordagem da matriz de rigidez para análise da não-linearidade geométrica, é analisado o processo de cálculo para utilização das matrizes de rigidez. De uma forma geral, estes processos envolvem métodos incrementais e iterativos. Para cada situação de carregamento existe a necessidade de consideração da posição deslocada da estrutura e da atualização da matriz de rigidez, que é função dos deslocamentos.

A técnica incremental visa descrever o comportamento da estrutura por meio da soma de cálculos "linearizados", através da matriz de rigidez para cada incremento de carga. Sendo assim, é interessante dividir o carregamento total em passos de carga para que seja descrito o comportamento da curva força $\mathrm{x}$ deslocamento da estrutura, esta técnica permite verificar a cada incremento de carga a convergência do problema.

No presente trabalho, por simplificação no processamento, todo o carregamento foi dividido em passos de carga. Uma outra alternativa seria incrementar apenas o carregamento horizontal, mantendo-se no modelo todo o carregamento vertical.

Dentre as técnicas incrementais e iterativas existentes, o método de Newton-Raphson é o mais conhecido. Existem diversas variações na utilização do método de Newton-Raphson, basicamente as variações ocorrem no número de vezes em que a matriz de rigidez é atualizada. 
No método original, a matriz de rigidez é atualizada a cada iteração, a matriz de rigidez é definida com base no incremento de deslocamentos e forças residuais. $\mathrm{O}$ deslocamento total obtido no final de cada iteração é atualizado pelo incremento de deslocamentos obtidos na iteração. A Figura 2.13 ilustra o processo descrito para o método de Newton-Raphson. A expressão (2.65) descreve o processo de obtenção do deslocamento final.

$$
\left[K_{i}^{T}\right]\left\{\Delta U_{i}\right\}=\left\{F^{a}\right\}-\left\{F_{i}^{n r}\right\}
$$

Em que:

$$
\begin{aligned}
& \left\{\Delta U_{i}\right\}=\left\{U_{i+1}\right\}-\left\{U_{i}\right\} \\
& \{R\}=\left\{F^{a}\right\}-\left\{F_{i}^{n r}\right\}
\end{aligned}
$$

Onde:

$\left\{U_{i}\right\}$ vetor de deslocamento nodal da iteração i

$\left\{U_{i+1}\right\}$ vetor de deslocamento nodal da iteração $i+1$

$\left[K_{i}^{T}\right]$ representa a matriz de rigidez tangente correspondente à iteração i

$\left\{F_{i}^{n r}\right\}$ representa o vetor de cargas nodais associado ao deslocamento $\mathrm{U}_{\mathrm{i}}$

$\left\{F^{a}\right\}$ representa o vetor de cargas nodais

$\{R\}$ representa a força residual a ser anulada a menos de uma tolerância

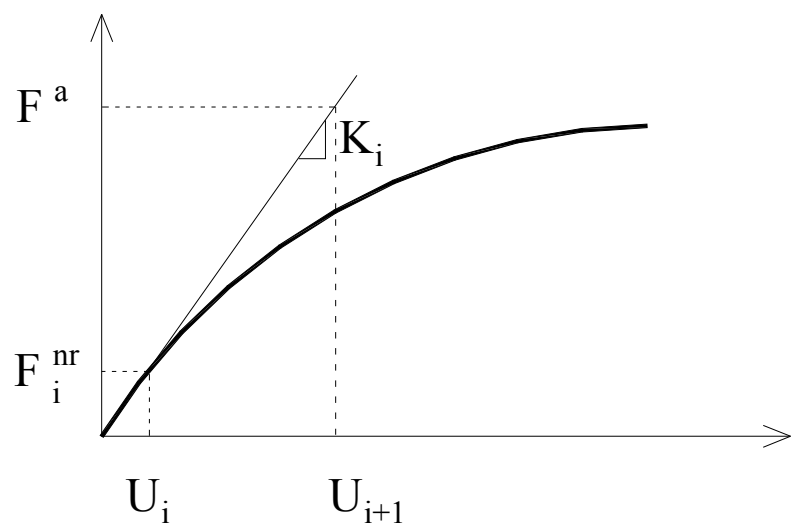

Figura 2.13: Método de Newton-Raphson 


\subsubsection{MÉTODO APROXIMADO PARA CONSIDERAÇÃO DA NÃO-LINEARIDADE GEOMÉTRICA SEGUNDO O PARÂMETRO $\alpha$}

Para avaliar a dispensa da consideração dos esforços globais de segunda ordem a NBR 6118:2003 faz menção ao parâmetro $\alpha$. O parâmetro $\alpha$ foi instituído no trabalho de BECK \& KONIG (1966).

A NBR 6118:2003 assim expressa o parâmetro $\alpha$ :

$$
\begin{array}{ll}
\alpha=H_{t o t} \sqrt{\frac{N_{k}}{E_{c s} I_{c}}} & \\
\alpha_{1}=0,2+0,1 n & n \leq 3 \\
\alpha_{1}=0,6 & n \geq 4
\end{array}
$$

Onde:

n é o número de níveis de barras horizontais acima da fundação ou de um nível pouco deslocável do subsolo;

$H_{\text {tot }}$ é a altura total da estrutura, medida a partir do topo da fundação ou de um nível pouco deslocável do subsolo;

$\mathrm{N}_{\mathrm{k}}$ é a somatória de todas as cargas verticais atuantes na estrutura (a partir do nível considerado para o cálculo de $H_{t o t}$ ), com seu valor característico;

$E_{c s} I_{c}$ representa a somatória dos valores de rigidez de todos os pilares na direção considerada. No caso de estruturas de pórticos, de treliças ou mistas, ou com pilares de rigidez variável ao longo da altura, pode ser considerado o valor da expressão $E_{c s} I_{c}$ de um pilar equivalente de seção constante.

Ainda segundo a NBR 6118:2003 o valor limite de $\alpha_{1}=0,6$ prescrito para $n \geq 4$ é, em geral, aplicável às estruturas usuais de edifícios. Pode ser adotado para associações de pilares parede e para pórticos associados a pilares-parede. Pode ser aumentado para $\alpha_{1}=0,7$ no caso de contraventamento constituído exclusivamente por pilares-parede e deve ser reduzido para $\alpha_{1}=0,5$ quando só houver pórticos.

Para que seja obtida a rigidez de um pilar equivalente de seção constante é necessário obter o deslocamento no topo da estrutura. A partir do deslocamento obtido na análise da estrutura e com o auxílio da expressão que define o deslocamento no topo de um pilar 
carregado por uma ação horizontal unitária uniformemente distribuída, conforme expresso em (2.69), encontra-se a rigidez equivalente do pilar $(\mathrm{EI})_{\mathrm{eq}}$ :

$$
(E I)_{e q}=\frac{q\left(H_{t o t}\right)^{4}}{8 . \delta^{T}}
$$

Onde:

q representa uma ação horizontal unitária uniformemente distribuída;

$\delta^{\mathrm{T}}$ representa o deslocamento no topo da estrutura.

Os valores limites indicados de $\alpha$ correspondem a no máximo um acréscimo de $10 \%$ no efeito de primeira ordem.

\subsubsection{MÉTODO APROXIMADO PARA CONSIDERAÇÃO DA NÃO-LINEARIDADE GEOMÉTRICA SEGUNDO O COEFICIENTE $\gamma_{\mathrm{z}}$}

O coeficiente $\gamma_{z}$ teve origem nos estudos de FRANCO \& VASCONCELOS (1991), com o objetivo de propor um método simples de se estabelecer a mobilidade da estrutura e uma forma de se estimar, com uma certa precisão, os esforços de segunda ordem. Este coeficiente é utilizado como um fator majorador das ações que causam os efeitos de primeira ordem com intuito de se obter os esforços finais na estrutura, os quais já incluem os esforços de segunda ordem. Desta forma dispensa-se a análise de segunda ordem.

Em uma análise de primeira ordem, a ação do vento na estrutura gera um momento de tombamento denominado $M_{1}$. O deslocamento provocado por esta ação horizontal gera momentos complementares na estrutura, denominados $\Delta M$, devido ao deslocamento das cargas verticais presentes na estrutura, conseqüentemente a estrutura é submetida a um novo estado de carregamento que gera novos deslocamentos das cargas verticais. Este processo é iterativo e sua análise visa estudar a configuração estável de equilíbrio da estrutura.

Sendo assim o momento total assumi a seguinte forma:

$$
M_{T}=M_{1}+\Delta M_{2}+\Delta M_{3}+\ldots+\Delta M_{n}
$$

No caso da estrutura estudada ser estável, o processo iterativo irá convergir para a configuração de equilíbrio final da estrutura. A progressão dos deslocamentos da estrutura 
segue uma progressão geométrica decrescente de razão $r \leq 1$. A razão geométrica encontrada é valida para estruturas cuja relação constitutiva do material é linear.

Onde:

$$
r=\frac{\Delta M_{2}}{M_{1}}=\frac{\Delta M_{3}}{\Delta M_{2}}=\frac{\Delta M_{3}}{\Delta M_{2}}=\ldots=\frac{\Delta M_{n}}{\Delta M_{n-1}}
$$

Da expressão (2.71) tem-se:

$$
\Delta M_{n}=r . \Delta M_{n-1}
$$

A expressão (2.70) pode ser reescrita da seguinte forma:

$$
M_{T}=\left(1+\frac{\Delta M_{2}}{M_{1}}+\frac{\Delta M_{3}}{\Delta M_{2}} \frac{\Delta M_{2}}{M_{1}}+\ldots+\frac{\Delta M_{n}}{M_{1}}\right) M_{1}
$$

Substituindo as relações apresentadas em (2.71) em (2.73) tem-se:

$$
M_{T}=\left(1+r+r^{2}+r^{3}+\ldots+r^{n-1}\right) M_{1}
$$

Estudando o problema no limite para n tendendo ao infinito, tem-se a expressão:

$$
\lim _{n \rightarrow \infty}\left(1+r+r^{2}+r^{3}+\ldots+r^{n-1}\right) M_{1}=\frac{1}{1-r} M_{1}
$$

Sendo assim de (2.75) e (2.71) e considerando $r=\frac{\Delta M_{2}}{M_{1}}$ obtido em análise de primeira ordem tem-se:

$$
M_{T}=\frac{1}{1-\frac{\Delta M_{2}}{M_{1}}} M_{1}
$$

O coeficiente $\gamma_{z}$ corresponde à parcela que multiplica na expressão (2.76) o termo $M_{1}$. Segundo a NBR 6118:2003 o coeficiente $\gamma_{z}$ mede a importância do efeito de segunda ordem 
global e é aplicado em estruturas com no mínimo quatro pavimentos. A definição deste coeficiente é feita a partir de uma análise linear de primeira ordem, onde o coeficiente é dado pela seguinte expressão:

$$
\gamma_{z}=\frac{1}{1-\frac{\Delta M_{t o t, d}}{M_{1, t o t, d}}}
$$

Onde:

$M_{1, t o t, d}$ é o momento de tombamento, ou seja, a soma dos momentos de todas as forças horizontais da combinação considerada, com seus valores de cálculo, em relação à base da estrutura;

$\Delta \mathrm{M}_{\mathrm{tot}, \mathrm{d}}$ é a soma dos produtos de todas as forças verticais atuantes na estrutura, na combinação considerada, com seus valores de cálculo, pelos deslocamentos horizontais de seus respectivos pontos de aplicação, obtidos da análise de $1^{\mathrm{a}}$ ordem.

A ação final considerando o efeito de primeira e de segunda ordem para valores de $\gamma_{z}>1,1$ é obtida pela seguinte expressão:

$$
F_{\text {FINAL }}=0,95 \times \gamma_{Z} \times F_{1^{\mathrm{a}} \text { ordem }}
$$

Para valores menores de $\gamma_{z} \leq 1,1$ a NBR 6118:2003 permite a dispensa da consideração dos efeitos globais de $2^{\mathrm{a}}$ ordem.

No estudo feito por CARMO (1995) conclui-se que o valor médio do majorador dos esforços, conforme cálculo feito por processos tradicionais como o processo $\mathrm{P}-\Delta$ e o processo rigoroso, pode sofrer variações para faixas da altura da estrutura, diminuindo na maioria das vezes, à medida que se aproxima do topo.

Segundo o item 15.5.3 e 15.7.2 da NBR 6118:2003 o processo descrito acima só é válido para $\gamma_{\mathrm{z}} \leq 1,3$ e em estruturas reticuladas de, no mínimo, quatro pavimentos.

No trabalho apresentado por CARMO (1995), foram estudados os efeitos de segunda ordem em trinta edifícios de concreto moldado in loco com mais de quatro pavimentos, a análise permitiu correlacionar o parâmetro $\alpha$ e o coeficiente $\gamma_{\mathrm{z}}$, obtendo-se a expressão:

$$
\gamma_{z}=0,9+0,52 \alpha-0,62 \alpha^{2}+0,46 \alpha^{3}
$$


Nota-se que segundo a expressão (2.79) para o valor de $\alpha=0,6$ obtém-se um $\gamma_{\mathrm{z}}=1,088$, valor muito próximo de 1,1 que é o valor correspondente para estruturas classificadas como de nós fixos. Onde, portanto, é dispensada a consideração dos efeitos de segunda ordem em uma análise global.

PINTO (1997) apresentou estudo envolvendo a aplicabilidade do coeficiente $\gamma_{z}$ e suas limitações em diversas estruturas de concreto moldado in loco. Foram comparados os esforços obtidos pelo coeficiente $\gamma_{z}$ e os encontrados com a teoria da não-linearidade geométrica. A não-linearidade física foi considerada de forma simplificada, fazendo uso das expressões que a NBR 6118:1978 prescreve para redução da rigidez de elementos estruturais.

$\mathrm{Na}$ revisão bibliográfica até então apresentada a NLG foi abordada de forma aproximada e não-aproximada. Na forma não-aproximada a abordagem requer análises matemáticas mais sofisticadas, que exigem o uso intensivo do computador. A importância da análise aproximada da NLG, como na definição do coeficiente $\gamma_{z}$, reside na avaliação da mobilidade da estrutura. O coeficiente $\gamma_{\mathrm{z}}$ pode ser considerado um importante indicador da mobilidade da estrutura na fase de concepção, permitindo a alteração de arranjos e seções ainda na fase de estudo da estrutura.

\subsubsection{MÉTODO APROXIMADO PARA CONSIDERAÇÃO DA NÃO-LINEARIDADE GEOMÉTRICA SEGUNDO A CARGA LATERAL FICTÍCIA}

O método da carga lateral fictícia é baseado no conceito de acrescentar cargas laterais fictícias à estrutura com intuito de obter o resultado equivalente ao efeito de segunda ordem.

O processo de estudo da configuração de equilíbrio via método da carga lateral fíctícia requer uma análise iterativa, pois não é conhecida a geometria deformada do elemento no momento da formulação das equações de equilíbrio.

$\mathrm{O}$ método da carga lateral fictícia também é conhecido como $(\mathrm{P}-\Delta)$, onde $\mathrm{P}$ representa a carga vertical e $\Delta$ representa o deslocamento horizontal.

Em análises preliminares, de pré-dimensionamento o efeito de segunda ordem pode ser estudado de maneira simplificada. Na literatura encontram-se alguns métodos para análise do (P- $\Delta)$, dentre os quais, o método da carga lateral fictícia e o método da carga de gravidade iterativa. A Figura 2.14 ilustra dois tipos de efeito P-delta, um global (P- $\Delta$ ) relacionado à estabilidade da estrutura e outro local $(\mathrm{P}-\delta)$ relacionado à estabilidade dos elementos da estrutura. 


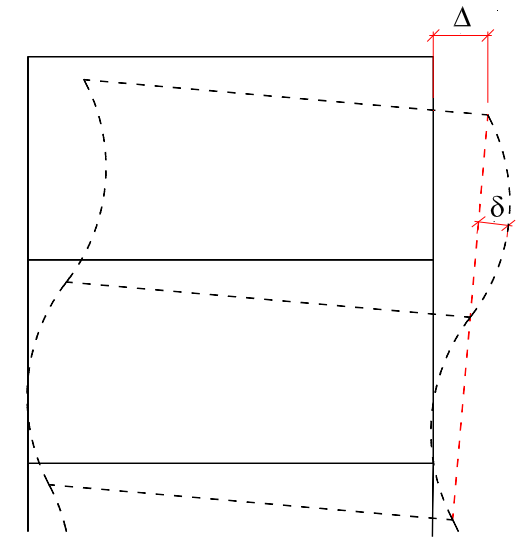

Figura 2.14: Efeitos P-delta global (P- $\Delta)$ e local $(\mathrm{P}-\delta)$

A fim de elucidar o método de análise ( $\mathrm{P}-\Delta)$ é exposto o método da carga lateral fictícia. O método da carga lateral fictícia consiste primeiramente em avaliar os deslocamentos entre pavimentos provocados pelas ações horizontais em uma análise de $1^{\mathrm{a}}$ ordem, estes deslocamentos geram momentos provocados pela excentricidade da carga vertical de cada pavimento. Estes momentos podem ser substituídos por binários de cargas laterais fictícias. A Figura 2.15 e a expressão (2.80) ilustram a forma de se determinar a carga lateral fictícia.

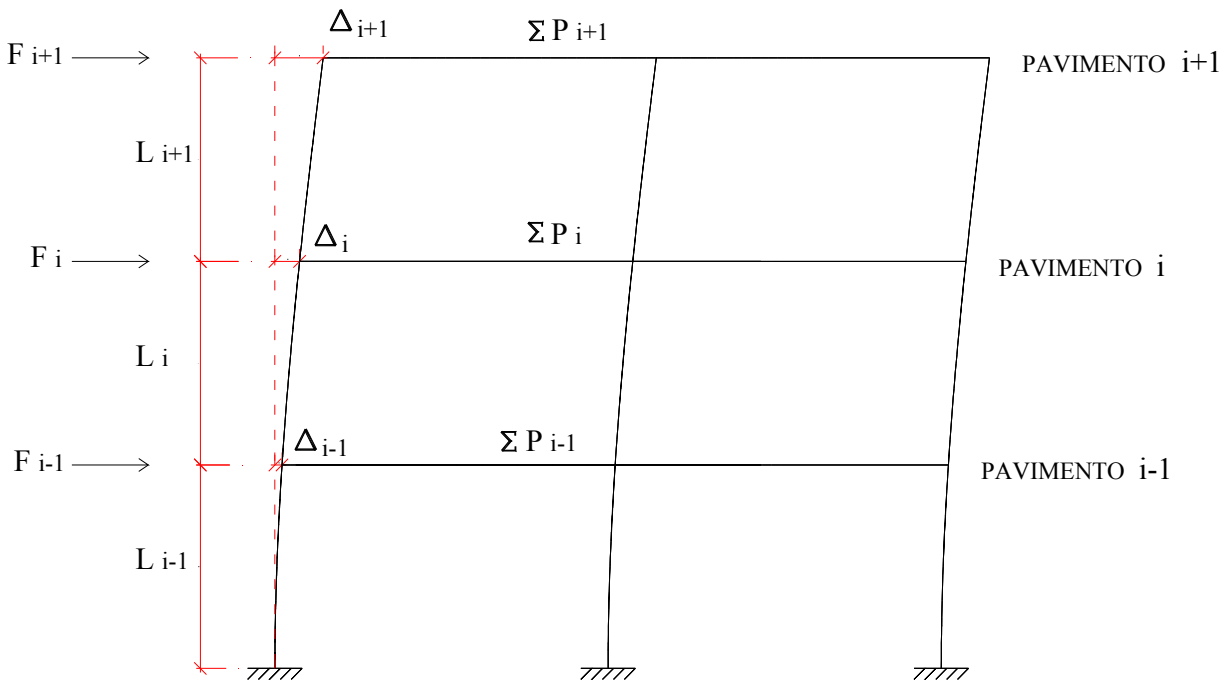

Figura 2.15: Esquema de carregamento e configuração deformada para análise (P- $\Delta$ )

$$
F_{i}=\frac{\left(\sum P_{i}\right) \Delta_{i}}{L_{i}}-\frac{\left(\sum P_{i+1}\right) \Delta_{i+1}}{L_{i+1}}
$$


Onde:

$F_{i}$ representa a carga lateral fictícia associada ao pavimento i

$\sum P_{i}$ representa a somatória das cargas verticais até o pavimento i

$\Delta$ representa o deslocamento relativo entre os pavimentos i e i-1

$L$ representa a diferença de altura entre os pavimentos i e i-1

Uma vez determinada à carga lateral fíctícia, devido aos esforços de $1^{\mathrm{a}}$ ordem, a estrutura é analisada novamente em uma $1^{\text {a }}$ iteração, sendo que a carga lateral fictícia determinada nas iterações é sempre somada à carga horizontal de $1^{\text {a }}$ ordem. Sendo assim determinam-se os deslocamentos referentes a esta $1^{\text {a }}$ iteração. A carga lateral fíctícia obtida na $1^{\mathrm{a}}$ iteração é somada a carga horizontal de $1^{\mathrm{a}}$ ordem determinando-se os deslocamentos da $2^{\mathrm{a}}$ iteração.

Embora este método seja considerado aproximado, FUSCO (1981) o descreve como um processo de cálculo suficientemente rigoroso na análise de pórticos múltiplos com barras perpendiculares entre si.

Segundo MACGREGOR (1997) o critério de parada para o processo iterativo envolvendo o método da carga lateral fictícia refere-se aos deslocamentos. Enquanto os deslocamentos forem incrementados em mais de 5\% em relação à iteração anterior a análise deve continuar até ser verificada a convergência. A interpretação física da convergência é a configuração final de deformação da estrutura, ou seja, a estrutura está em equilíbrio.

\subsection{ANÁLISE DA NÃO-LINEARIDADE FÍSICA}

\subsubsection{ANÁLISE DA NÃO-LINEARIDADE FÍSICA SEGUNDO DIAGRAMA M $\mathrm{x}$ N $1 / \mathbf{r}$}

A consideração da não-linearidade física pode ser feita segundo o diagrama momento $(\mathrm{M}) \times$ normal $(\mathrm{N}) \times$ curvatura $(1 / \mathrm{r})$ ou segundo tratamento matricial que leva em conta as relações constitutivas dos materiais.

Nos últimos anos, muitos avanços ocorreram no campo da análise da não-linearidade física, seja pelo desenvolvimento de modelos mais representativos das relações constitutivas 
entre os materiais ou pelo estudo via mecânica do dano e da fratura. No presente trabalho é analisada a NLF segundo os diagramas $\mathrm{M}$ x N x 1/r, devido a sua maior simplicidade e aplicabilidade em projetos estruturais.

A não-linearidade física refere-se ao fato do material empregado na estrutura não ter um comportamento que obedece à lei de Hooke, ou seja, quando a deformação é proporcional a tensão.

Dependendo da intensidade do carregamento a que a estrutura está submetida, pode ser atingido o momento de fissuração. A fissuração provoca uma redução na área íntegra de concreto, diminuindo assim o momento de inércia da seção (I). A deformação diferida ao longo do tempo devido à fluência e o escoamento das armaduras também se referem a nãolinearidade física. A Figura 2.16 ilustra os diversos estágios da relação momento x curvatura.

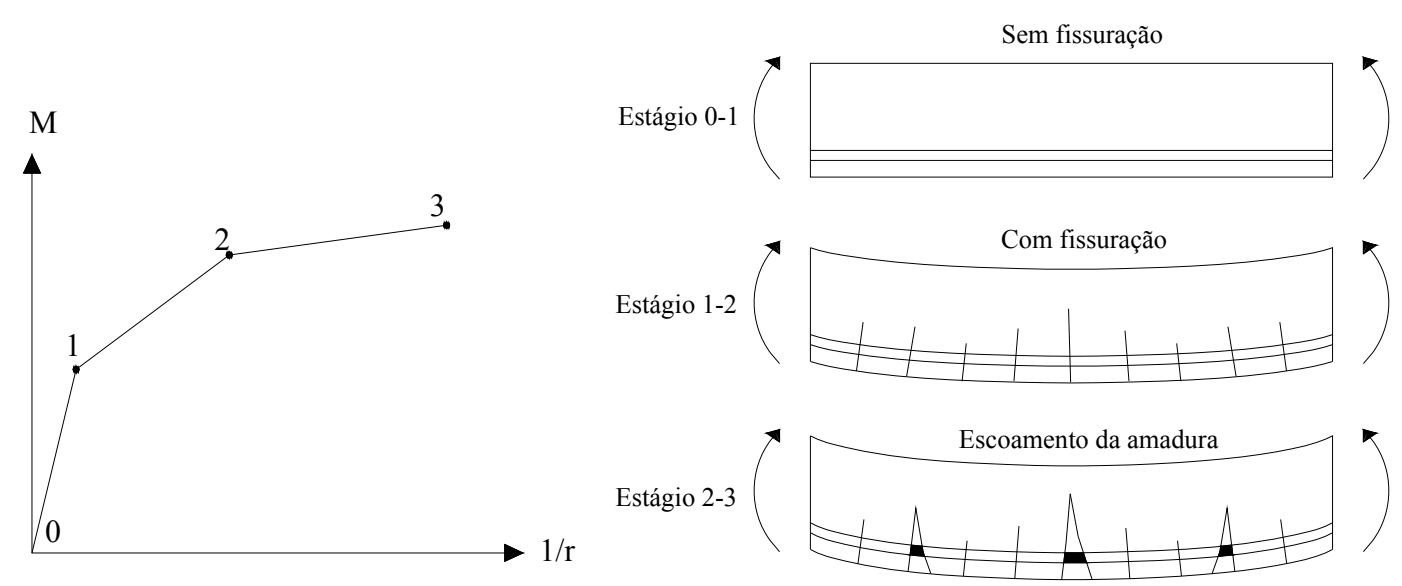

Figura 2.16: Estágios da relação momento x curvatura [ fib (1999) Adaptado]

A relação momento x curvatura pode ser dividida em três estágios, de acordo com o acréscimo de carregamento:

Estágio 0-1: Neste estágio o nível de tensões que o concreto armado está submetido não é suficiente para ultrapassar o limite de resistência à tração do concreto. A distribuição de tensões é linear ao longo da seção transversal. Não existem fissuras visíveis;

Estágio 1-2: Este estágio tem início no ponto caracterizado pelo momento de fissuração do concreto, a partir do qual é considerado que apenas o aço é responsável por absorver as tensões de tração. O ponto que define o final deste estágio é caracterizado pelo momento de escoamento da armadura tracionada 
ou pela plastificação do concreto comprimido. A distribuição de tensões é admitida linear ao longo da seção transversal neste estágio, sendo possível a visualização de fissuras;

Estágio 2-3: Este estágio tem início no ponto caracterizado pelo momento de escoamento da armadura tracionada ou pela plastificação do concreto comprimido, a partir do qual o acréscimo de momento fletor é pequeno quando comparado com os estágios anteriores. Neste estágio grandes deformações ocorrem, conseqüentemente é grande a magnitude das aberturas das fissuras. Finalmente o estágio tem como limite o momento último ou de ruptura.

A Figura 2.17 ilustra o diagrama $\mathrm{M}$ x N x 1/r prescrito na NBR 6118:2003 para cálculo no estado limite último e para cálculo da rigidez.

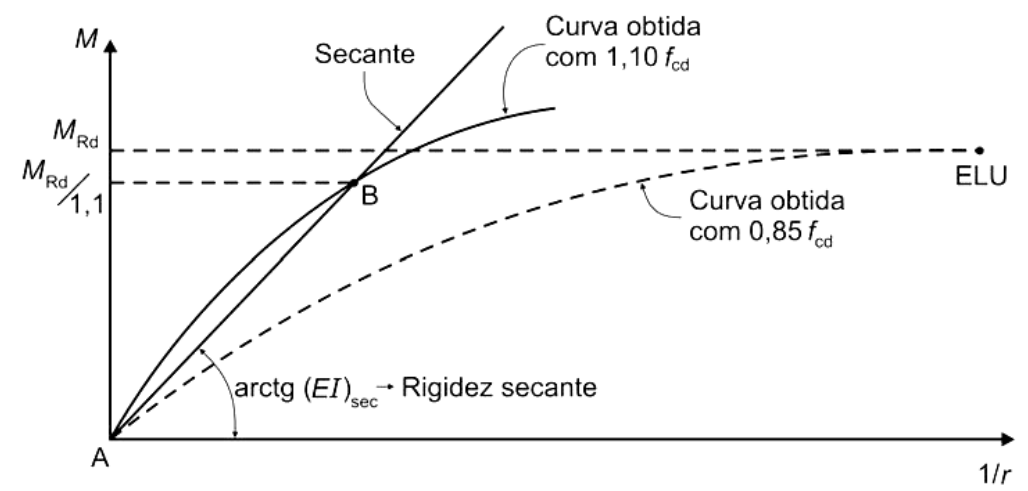

Figura 2.17: Relação momento x curvatura [NBR 6118:2003]

A NBR 6118:2003 prescreve que para efeito de cálculo no ELU a tensão de compressão de projeto no concreto deve ser multiplicada por 0,85 .

Segundo CARVALHO \& FIGUEIREDO (2004) o valor de 0,85 $f_{c d}$ é atribuído à duração do carregamento no ensaio do corpo-de-prova, uma vez que o concreto apresenta resultados de resistência à compressão maior para ensaios de curta duração. Nas estruturas usuais o carregamento permanece atuando na estrutura durante toda sua vida útil, sob cargas permanentes a resistência à compressão do concreto diminui com o tempo, dá-se o nome de efeito Rüsch a este comportamento.

Segundo FRANÇA (1991), o cálculo da rigidez obtido a partir das relações constitutivas baseadas em valores de cálculo da resistência pode conduzir a uma super 
avaliação dos efeitos da não-linearidade. Para efeito de consideração da rigidez a tensão de compressão de projeto no concreto deve ser multiplicada por 1,10. A origem deste coeficiente pondera o fato de que nem todas as seções do elemento estrutural sejam constituídas de material com valores correspondentes a quantis estatísticos inferiores, isto é, nem todas as seções são igualmente ruins ao longo do elemento e afetadas pelas condições que compõe o coeficiente $\gamma_{m}$, coeficiente de ponderação das resistências.

O coeficiente $\gamma_{m}$ é obtido pelo produto de três coeficientes, $\gamma_{m 1}, \gamma_{m 2}$ e $\gamma_{m 3}$.

Onde:

$\gamma_{m 1}$ leva em conta a variabilidade da resistência efetiva, transformando a resistência característica num valor extremo de menor probabilidade de ocorrência;

$\gamma_{m_{2}}$ considera as diferenças entre a resistência efetiva do material da estrutura e a resistência medida convencionalmente em corpos-de-prova padronizados; $\gamma_{m 3}$ considera as incertezas existentes na determinação das solicitações resistentes, seja em decorrência dos métodos construtivos seja em virtude do método de cálculo empregado.

A formulação proposta para consideração da rigidez de elementos estruturais em concreto armado da NBR 6118:2003 teve origem nos estudos de FRANÇA (1991), onde o valor de $1,1 \mathrm{f}_{\mathrm{cd}}$ foi definido. Conforme a NBR 6118:2003, a rigidez dos elementos devem ser calculadas com o valor de tensão no concreto de $1,1 \mathrm{f}_{\mathrm{cd}}$, já incluído o efeito Rüsch.

Em relação à segurança nas ações, para análises de $2^{\mathrm{a}}$ ordem com o auxílio do diagrama M x N x 1/r, a NBR 6118:2003 sugere a utilização da formulação de segurança em que as cargas são majoradas de $\gamma_{f} / \gamma_{f 3}$. Posteriormente a obtenção dos efeitos de $2^{\mathrm{a}}$ ordem as cargas são majoradas de $\gamma_{f 3}$, com $\gamma_{f 3}=1$, 1 . Segundo a NBR 8681:2003 o coeficiente $\gamma_{f 3}$ considera os possíveis erros de avaliação dos efeitos das ações, seja por problemas construtivos, seja por deficiência do método de cálculo empregado.

O cálculo da rigidez secante conforme apresenta a NBR 6118:2003 é obtido da seguinte forma: 
Primeiramente é calculado o momento resistente da seção transversal do elemento $\left(\mathrm{M}_{\mathrm{rd}}\right)$, com o valor de $0,85 \mathrm{f}_{\mathrm{cd}}$ de tensão no concreto e carga atuante majorada de $\gamma_{f}\left(\mathrm{~N}_{\mathrm{d}}\right)$.

Posteriormente é construído o diagrama $\mathrm{M}$ x N x $1 / \mathrm{r}$ com o valor de $1,1 \mathrm{f}_{\mathrm{cd}}$ de tensão no concreto e carga atuante majorada de $\gamma_{f} / \gamma_{f 3}\left(\mathrm{~N}_{\mathrm{d}} / \gamma_{f 3}\right)$.

A rigidez secante é definida pela relação entre o momento resistente $\left(\mathrm{M}_{\mathrm{rd}}\right) / \gamma_{f 3}$ e a correspondente curvatura obtida no diagrama $\mathrm{M}$ x N x 1/r construído com o valor de $1,1 \mathrm{f}_{\mathrm{cd}} \mathrm{de}$ tensão no concreto e carga atuante majorada de $\gamma_{f} / \gamma_{f 3}\left(\mathrm{~N}_{\mathrm{d}} / \gamma_{f 3}\right)$.

Segundo a NBR 9062:2006 para os elementos em concreto pré-fabricado pode-se adotar o coeficiente de ponderação da resistência do material para o concreto, $\gamma_{\mathrm{c}}=1,3$ e para $\mathrm{o}$ aço, $\gamma_{\mathrm{s}}=1$,1. Para elementos em concreto pré-moldado devem ser adotados os valores de $\gamma_{\mathrm{c}}$ $=1,4$ e $\gamma_{\mathrm{s}}=1,15$. Em estruturas em concreto pré-fabricado, o fato da armadura, bem como as formas dos elementos serem executados em uma indústria permite maior precisão no posicionamento das armaduras do elemento, desta forma o coeficiente de ponderação da resistência do material pode ser reduzido.

A obtenção da rigidez em elementos submetidos à força normal pode ser obtida de maneira mais precisa de acordo com os diagramas momento x normal x curvatura. Com o auxílio destes diagramas de interação é possível analisar a validade de expressões aproximadas para a estimativa de rigidez.

Dentre os estudos realizados sobre a utilização dos diagramas $\mathrm{M}$ x N x 1/r no estudo de pilares, podemos citar os trabalhos de PAULA (1988), AMARAL (2000) e CAMADURO (1997).

No trabalho de PAULA (1988) foi apresentado o equacionamento do mecanismo resistente de uma seção de pilar submetido à flexão composta, bem como a rotina para a obtenção do diagrama M x N x 1/r. Foram apresentados algoritmos para o estudo de pilares segundo o método geral e o método do pilar padrão com o auxílio dos diagramas $\mathrm{M} \mathrm{x} \mathrm{N} \mathrm{x} \mathrm{1/r.}$

Dando continuidade ao trabalho desenvolvido por PAULA (1988), AMARAL (2000) incorporou aos algoritmos de obtenção do diagrama $\mathrm{M}$ x N x 1/r o efeito da fluência, para tanto foi utilizado o conceito da teoria linear da fluência. Com intuito de dimensionar pilares, foram desenvolvidos ábacos relacionando índice de esbeltez, curvatura, esforços solicitantes e armadura.

Enquanto os dois trabalhos citados abordavam flexão composta, o trabalho de CAMADURO (1997) tinha como escopo a flexão oblíqua. Foi desenvolvido um programa que permitia além da verificação de pilares segundo a flexão oblíqua a utilização de pilares com qualquer seção transversal. 
A utilização dos diagramas $\mathrm{M}$ x N x 1/r no estudo da rigidez de elementos de concreto foi abordada no trabalho de FRANÇA (1991). Neste trabalho foi apresentada a proposta de troca das relações momento $\mathrm{x}$ normal $\mathrm{x}$ curvatura pelas relações momento $\mathrm{x}$ normal $\mathrm{x}$ rigidez secante.

Dando continuidade ao trabalho de FRANÇA (1991), OLIVEIRA (2004) apresenta ábacos momento x normal x rigidez secante de diversas seções transversais, entre as quais podem ser citadas a seção retangular, circular e circular vazada. Neste trabalho foram apresentados exemplos demonstrando a aplicabilidade de utilização dos ábacos na consideração da não-linearidade física de problemas envolvendo pilares.

MOTA (2006) apresentou o benefício no ganho de rigidez de pilares com a utilização de armadura ativa.

A obtenção do diagrama que relaciona momento fletor (M), força normal (N) e curvatura (1/r) é de fundamental importância para o estudo da rigidez, do estado limite último e do estado limite de serviço de elementos em concreto pré-moldado, conseqüentemente, importante para o estudo da estabilidade global de estruturas em concreto pré-moldado. Estes diagramas representam o comportamento não-linear dos elementos de concreto armado.

A importância do conhecimento da construção do diagrama $\mathrm{M} \times \mathrm{N} \times 1 / \mathrm{r}$ está relacionada à liberdade de se analisar elementos com qualquer tipo de cobrimento, esforço normal, momento fletor, $\mathrm{f}_{\mathrm{ck}}$, taxa de armadura e seção transversal.

As hipóteses adotadas na construção do diagrama $\mathrm{M}$ x $\mathrm{N}$ x 1/r são:

$>$ Seção plana permanece plana para consideração do estado limite último no cálculo das deformações, tal hipótese é válida em virtude de dois fatores. $\mathrm{O}$ primeiro refere-se ao fato dos materiais constituintes do concreto armado admitirem pequenas deformações, e o segundo fator está relacionado ao fato da relação entre o comprimento e a altura da seção dos elementos analisados serem relativamente grandes. Portanto é admitida uma distribuição linear de deformação na seção;

$>$ Existe perfeita solidarização entre os materiais aço e concreto, portanto a deformação do concreto é compatibilizada com a deformação no aço.

Em relação à colaboração do concreto íntegro existente entre as fissuras na capacidade resistente do concreto à tração, conhecida como "tension stiffening", o manual da fib (1999) 
prevê este efeito na relação $\mathrm{M}$ x 1/r. O modelo adotado no presente trabalho não considera este efeito.

As formulações aqui empregadas são válidas até comprovação experimental para concretos com $\mathrm{f}_{\text {ck }}$ de até $50 \mathrm{MPa}$, classe de resistência máxima na qual a NBR 6118:2003 é aplicável.

$\mathrm{O}$ diagrama tensão $\mathrm{x}$ deformação para o concreto tem o formato ilustrado na Figura 2.18 .

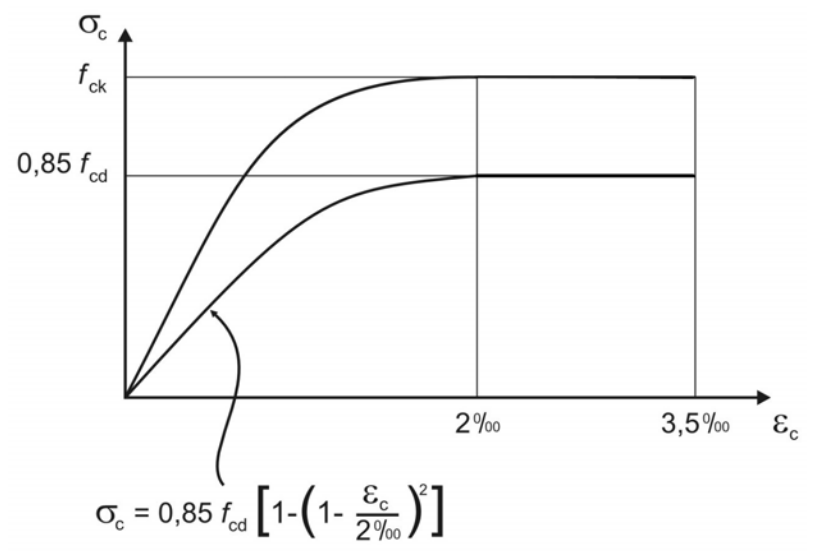

Figura 2.18: Diagrama tensão x deformação [NBR 6118:2003]

Os domínios de deformação podem ser caracterizados por dois modos de ruptura:

Ruptura convencional por deformação plastifica excessiva, no qual pertence o domínio 1,2 e a reta $a$;

$>$ Ruptura convencional por encurtamento limite do concreto, no qual pertence o domínio $3,4,4 a, 5$ e a reta $b$.

A Figura 2.19 ilustra os domínios de deformação prescritos na NBR 6118:2003.

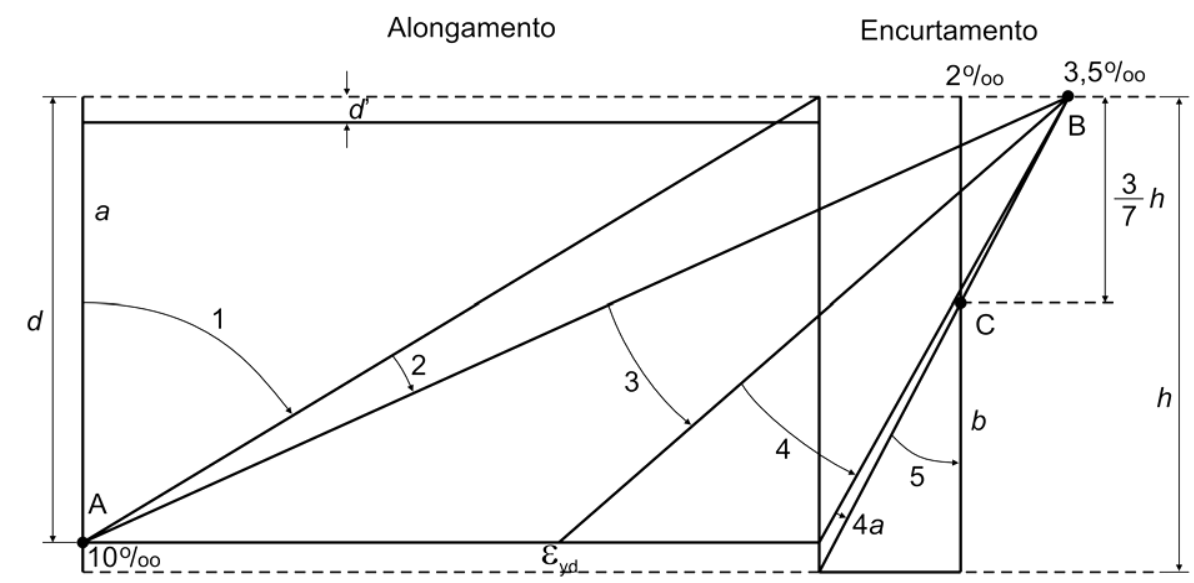

Figura 2.19: Domínios de deformação [NBR 6118:2003] 
A formulação apresentada no presente trabalho para o equacionamento e obtenção do diagrama M x N x 1/r teve como principal referência o trabalho de PAULA (1988).

Segundo os domínios de deformação definidos pela NBR 6118:2003, ilustrados na Figura 2.19, a máxima curvatura admitida segundo as máximas deformações é:

$$
\frac{1}{r}=\frac{3,5 \%+10 \% 0}{d}
$$

$\mathrm{Na}$ determinação do diagrama $\mathrm{M} \times \mathrm{N}$ x $1 / \mathrm{r}$ a linha neutra é representada pelo coeficiente adimensional $\beta_{\mathrm{x}}$, definido pela expressão (2.82).

$$
\beta_{x}=\frac{x}{h}
$$

A Figura 2.20 ilustra a distribuição de deformações em uma seção de concreto armado.

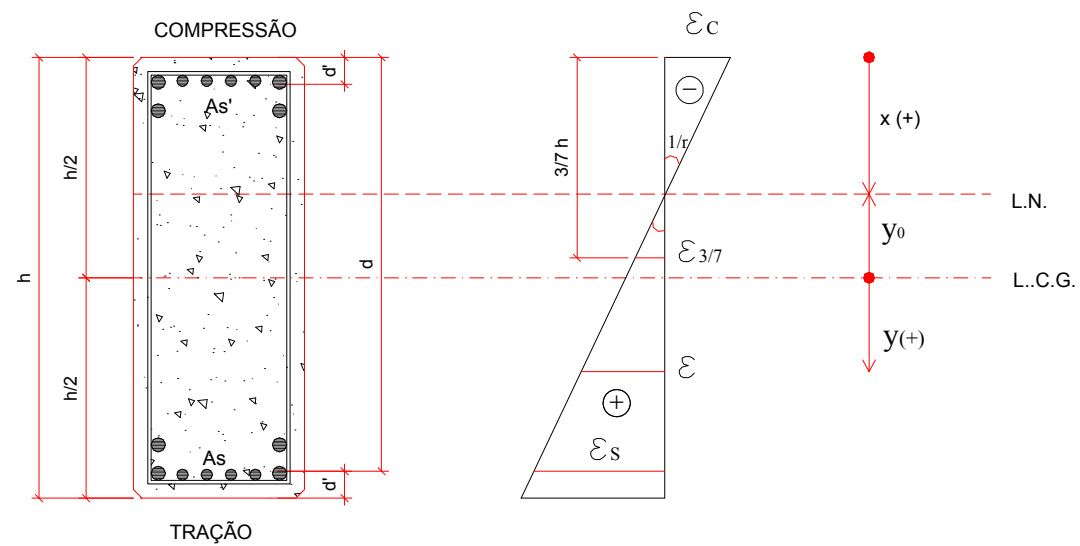

Figura 2.20: Distribuição de deformações em uma seção de concreto amado

Analisando a Figura 2.20 têm-se as seguintes relações:

$$
\frac{-\varepsilon_{c}}{x}=\frac{\varepsilon}{\left(y-y_{0}\right)}=\frac{\varepsilon_{s}}{h-d^{\prime}-x}=\frac{\varepsilon_{3 / 7}}{(3 / 7) h-x}
$$


Onde:

$\varepsilon_{c}$ representa a deformação específica na borda de concreto de maior deformação de encurtamento;

$\varepsilon_{s}$ representa a deformação específica na armadura tracionada;

$\varepsilon_{3 / 7 h}$ representa a deformação específica na fibra de concreto, distante (3/7).h, da borda mais comprimida da seção;

$\varepsilon$ representa a deformação em uma fibra genérica, distante de y do centro geométrico da seção;

$d^{\prime}$ representa o centro geométrico das armaduras longitudinais.

A igualdade (2.83) permite que seja definida a deformação em uma fibra genérica em função do concreto na borda de maior encurtamento, a (3/7).h da borda de maior encurtamento e do aço. As expressões estão descritas, respectivamente, abaixo:

$$
\begin{aligned}
& \varepsilon=\frac{-\varepsilon_{c}\left(y-y_{0}\right)}{x} \\
& \varepsilon=\frac{\varepsilon_{3 / 7}\left(y-y_{0}\right)}{(3 / 7) h-x} \\
& \varepsilon=\frac{\varepsilon_{s}\left(y-y_{0}\right)}{h-d^{\prime}-x}
\end{aligned}
$$

A partir da Figura 2.20 é possível escrever $\varepsilon_{c}, \varepsilon_{3 / 7 h}$ e $\varepsilon_{s}$ em função da $1 /$ r, conforme apresentado nas relações abaixo:

$$
\begin{aligned}
& \varepsilon_{c}=-\frac{1}{r} x \\
& \varepsilon_{3 / 7}=\frac{1}{r}\left(\frac{3}{7} h-x\right) \\
& \varepsilon_{s}=\frac{1}{r}\left(h-d^{\prime}-x\right)
\end{aligned}
$$


Substituindo as expressões (2.87), (2.88) e (2.89) em (2.84), (2.85) e (2.86) respectivamente, é possível representar a deformação $\varepsilon$ em uma fibra genérica qualquer em função da curvatura $(1 / \mathrm{r})$.

$$
\varepsilon=\frac{1}{r}\left(y-y_{0}\right)
$$

Onde:

$$
y_{0}=x-\frac{h}{2}
$$

Definindo-se:

$$
\beta_{y}=\frac{y}{h}
$$

Substituindo (2.91), (2.92) e (2.82) em (2.90) tem-se:

$$
\varepsilon=\frac{h}{r}\left(\beta_{y}+\frac{1}{2}-\beta_{x}\right)
$$

Considerando que:

$$
\beta_{0}=\beta_{y}+\frac{1}{2}
$$

Substituindo (2.94) em (2.93) tem-se:

$$
\varepsilon=\frac{h}{r}\left(\beta_{0}-\beta_{x}\right)
$$


A equação (2.95) expressa a deformação em uma fibra qualquer em função da linha neutra e da curvatura.

Uma vez definida a expressão (2.95), agora é estudado a relação entre a profundidade da linha neutra e a curvatura.

Existem três regiões de trabalho, que uma seção de concreto pode estar submetida.

$\mathrm{Na}$ região I, a seção trabalha nos domínios de deformação 1 e 2, ou seja, o estado limite último é caracterizado pela deformação última do aço e representa o limite inferior da linha neutra. Nesta região a seção pode estar completamente tracionada, portanto $\beta_{x} \leq 0$.

A equação (2.92) fica expressa:

$$
\beta_{y}=\frac{\frac{h}{2}-d^{\prime}}{h}=\frac{1}{2}-\delta^{\prime}
$$

Onde:

$$
\delta^{\prime}=\frac{d^{\prime}}{h}
$$

Substituindo (2.96) em (2.94) tem-se:

$$
\beta_{0}=1-\delta^{\prime}
$$

O estado limite último de tração no aço deve ser respeitado segundo a seguinte expressão:

$$
\varepsilon=\frac{h}{r}\left(\beta_{0}-\beta_{x}\right) \leq 10 \%
$$

O estado limite último do aço, aqui definido pela deformação de $10 \%$, refere-se à máxima deformação na qual a abertura de fissura é admissível na seção resistente de concreto armado. 
Substituindo (2.98) em (2.99) tem-se:

$$
\beta_{x} \geq-\frac{10 \% 0}{h / r}+1-\delta^{\prime}
$$

A região II é delimitada pelos domínios de deformação 3, 4 e 4a e o estado limite último é caracterizado pelo encurtamento máximo da fibra de concreto comprimida. Nesta região a seção está parcialmente comprimida, correspondendo ao intervalo $0<\beta_{x}<1$. Nesta região a equação (2.92) fica assim expressa para a fibra na qual ocorre o máximo encurtamento:

$$
\beta_{y}=-\frac{1}{2}
$$

Substituindo (2.101) em (2.94) tem-se:

$$
\beta_{0}=0
$$

O estado limite último de deformação de compressão na fibra de concreto da borda mais comprimida deve ser respeitado segundo a seguinte expressão:

$$
\varepsilon=\frac{h}{r}\left(\beta_{0}-\beta_{x}\right) \geq-3,5 \%
$$

Substituindo (2.102) em (2.103) tem-se:

$$
\beta_{x} \leq \frac{3,5 \% 0}{h / r}
$$

A região III é delimitada pela expressão $\beta_{x} \geq 1$, nesta região a seção trabalha no domínio de deformação 5 e o estado limite último é caracterizado pelo encurtamento máximo da fibra de concreto comprimida, distante $(3 / 7)$.h, onde $\varepsilon_{3 / 7}=-2 \%$. Nesta região a seção está 
totalmente comprimida, onde a equação (2.92) é expressa desta forma para a fibra distante (3/7)h:

$$
\beta_{y}=\frac{-\frac{h}{2}-\left(-\frac{3 h}{7}\right)}{h}=-\frac{1}{14}
$$

Substituindo (2.105) em (2.94) tem-se:

$$
\beta_{0}=3 / 7
$$

O estado limite último de deformação de compressão na fibra de concreto da borda mais comprimida, distante $3 / 7 \mathrm{~h}$, deve ser respeitado segundo a seguinte expressão:

$$
\varepsilon=\frac{h}{r}\left(\beta_{0}-\beta_{x}\right) \geq-2 \%
$$

Substituindo (2.106) em (2.107) tem-se:

$$
\beta_{x} \leq \frac{2 \% 0}{h / r}+\frac{3}{7}
$$

As equações de equilíbrio de uma seção transversal submetida à flexão composta reta são definidas a partir das equações constitutivas que relacionam tensão e deformação.

A Figura 2.21 ilustra as deformações, tensões e componentes resistentes resultantes na seção transversal de concreto armado. 


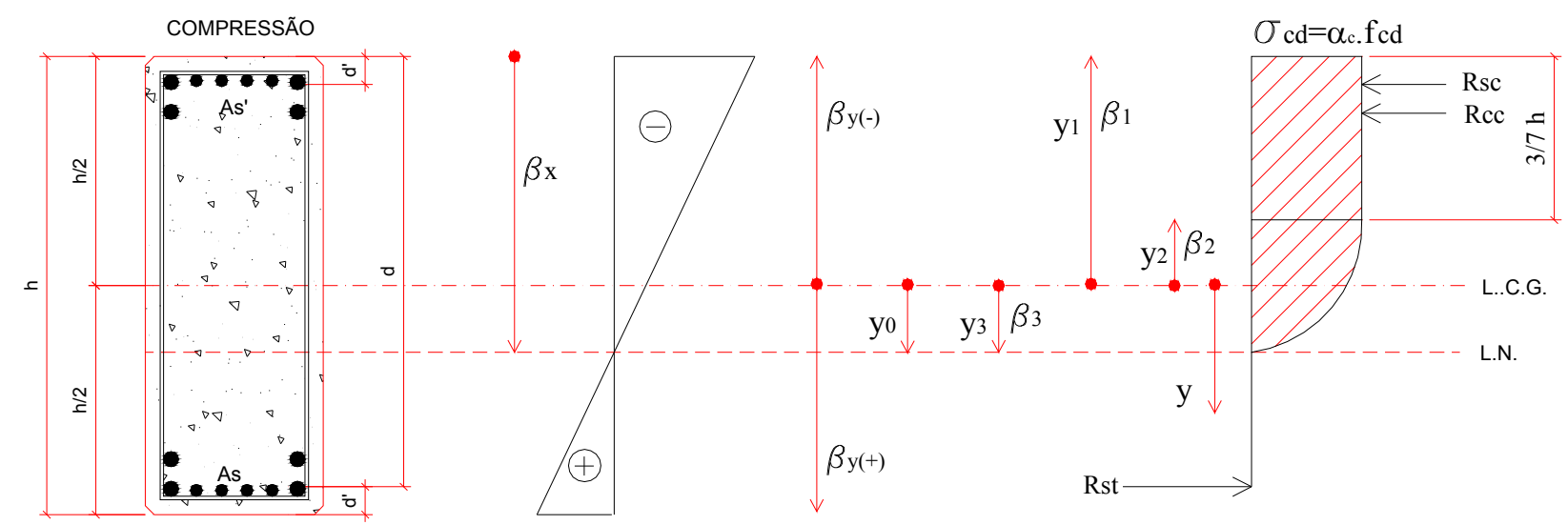

Figura 2.21: Deformações, tensões e resultantes de tensão em uma seção de concreto armado

Segundo o equilíbrio das forças normais internas na seção obtêm-se as expressões referentes à força normal resistente e ao momento fletor resistente:

$$
\begin{aligned}
& N_{R d}=\int_{-h / 2}^{y_{0}} b_{w} \sigma_{c d} d y+\sum_{i=1}^{n} A_{s i} \sigma_{s i} \\
& M_{R d}=\int_{-h / 2}^{y_{0}} y b_{w} \sigma_{c d} d y+\sum_{i=1}^{n} y_{i} A_{s i} \sigma_{s i}
\end{aligned}
$$

Onde:

$b_{w}$ largura da seção transversal;

$\sigma_{c d}$ tensão de cálculo do concreto;

$A_{s i}$ área de aço da armadura na camada $\mathrm{i}$;

$\sigma_{s i}$ tensão no aço da armadura pertencente à camada $\mathrm{i}$;

y posição de fibra genérica;

$y_{i}$ posição da camada i de armadura.

Com o auxílio da Figura 2.21, dividindo-se o domínio de integração do componente resistente do concreto ao esforço normal e momento fletor em dois trechos, um associado ao trecho retangular do diagrama tensão x deformação do concreto e outro referente ao trecho parabólico obtém-se as seguintes expressões:

$$
N_{R d}=\int_{y_{1}}^{y_{2}} \alpha_{c} f_{c d} b_{w} d y-\alpha_{c} f_{c d} b_{w} \int_{y_{2}}^{y_{3}}\left[\frac{\varepsilon_{c}}{1 \%}+\left(\frac{\varepsilon_{c}}{2 \% 0}\right)^{2}\right] d y+\sum_{i=1}^{n} A_{s i} \sigma_{s i}
$$




$$
M_{R d}=\int_{y_{1}}^{y_{2}} \alpha_{c} f_{c d} b_{w} y d y-\alpha_{c} f_{c d} b_{w} \int_{y_{2}}^{y_{3}}\left[\frac{\varepsilon_{c}}{1 \% 00}+\left(\frac{\varepsilon_{c}}{2 \% 00}\right)^{2}\right] y d y+\sum_{i=1}^{n} y_{i} A_{s i} \sigma_{s i}
$$

O coeficiente $\alpha_{c}$ expresso em (2.111) e (2.112) assume o valor de 0,85 quando é analisado o estado limite último e 1,1 quando o objetivo é a obtenção da rigidez.

Da mesma forma abordada em VENTURINI \& RODRIGUES (1987), foi tratada de forma adimensional a formulação para o esforço normal e momento fletor resistente, este formato permite uma maior generalidade para a formulação.

A força normal resistente adimensional e o momento fletor resistente adimensional são definidos pelas seguintes expressões respectivamente:

$$
\begin{aligned}
& v_{R d}=\frac{N_{R d}}{A_{c} \cdot f_{c d}} \\
& \mu_{R d}=\frac{M_{R d}}{A_{c} \cdot h \cdot f_{c d}}
\end{aligned}
$$

Com o auxílio da expressão (2.92) são convertidos os limites do domínio de integração das funções expressas em (2.111). Substituindo a expressão (2.111) na expressão (2.113) obtém-se o esforço normal resistente adimensional. Sendo assim, tem-se:

$$
v_{R d}=\alpha_{c} \int_{\beta_{1}}^{\beta_{2}} d \beta_{y}-\alpha_{c} \int_{\beta_{2}}^{\beta_{3}}\left[\frac{\varepsilon_{c}}{1 \% 00}+\left(\frac{\varepsilon_{c}}{2 \% 0}\right)^{2}\right] d \beta_{y}+\frac{\sum_{i=1}^{n} A_{s i} \sigma_{s i}}{A_{c} f_{c d}}
$$

Onde:

$$
\beta_{i}=\frac{y_{i}}{h}, \text { com i variando de } 1 \text { a } 3
$$

Substituindo a expressão (2.93), que relaciona deformação com a posição adimensional da linha neutra e a curvatura em (2.115) tem-se:

$$
v_{R d}=\alpha_{c} \int_{\beta_{1}}^{\beta_{2}} d \beta_{y}-1000 \alpha_{c} \int_{\beta_{2}}^{\beta_{3}}\left[\frac{h}{r}\left(\beta_{y}+\frac{1}{2}-\beta_{x}\right)+250\left[\frac{h}{r}\left(\beta_{y}+\frac{1}{2}-\beta_{x}\right)\right]^{2}\right] d \beta_{y}+\frac{\sum_{i=1}^{n} A_{s i} \sigma_{s i}}{A_{c} f_{c d}}
$$


Desenvolvendo a expressão (2.116) obtém-se a expressão (2.117).

$$
\begin{aligned}
v_{R d}= & \alpha_{c}\left(\beta_{2}-\beta_{1}\right)-1000 \alpha_{c} \frac{h}{r}\left\{\frac{\beta_{3}{ }^{2}-\beta_{2}{ }^{2}}{2}+k_{1}\left(\beta_{3}-\beta_{2}\right)+250 \frac{h}{r}\left[\frac{\beta_{3}{ }^{3}-\beta_{2}{ }^{3}}{3}+k_{1}\left(\beta_{3}{ }^{2}-\beta_{2}{ }^{2}\right)+k_{1}{ }^{2}\left(\beta_{3}-\beta_{2}\right)\right]\right\}+ \\
& \frac{\sum_{i=1}^{n} A_{s i} \sigma_{s i}}{A_{c} f_{c d}}
\end{aligned}
$$

Onde:

$$
k_{1}=\frac{1}{2}-\beta_{x}
$$

A partir dos coeficientes adimensionais:

$$
\begin{aligned}
& k_{2}=\beta_{3}^{2}-\beta_{2}^{2} \\
& k_{3}=\beta_{3}-\beta_{2} \\
& k_{4}=\beta_{3}^{3}-\beta_{2}^{3}
\end{aligned}
$$

Tem-se:

$$
v_{R d}=\alpha_{c}\left(\beta_{2}-\beta_{1}\right)-1000 \alpha_{c} \frac{h}{r}\left\{\frac{k_{2}}{2}+k_{1} k_{3}+250 \frac{h}{r}\left[\frac{k_{4}}{3}+k_{1} k_{2}+k_{1}{ }^{2} k_{3}\right]\right\}+\frac{\sum_{i=1}^{n} A_{s i} \sigma_{s i}}{A_{c} f_{c d}}
$$

A tensão na armadura passiva em aço CA-50 se relaciona com a deformação, indicada na expressão (2.89), da seguinte forma:

$$
\begin{aligned}
& \sigma_{s}=\varepsilon_{s} E_{s} \Rightarrow \quad \varepsilon_{s}<\varepsilon_{y d} \\
& \sigma_{s}=f_{y d} \Rightarrow \quad \varepsilon_{s} \geq \varepsilon_{y d}
\end{aligned}
$$

Onde:

$$
\begin{aligned}
& E_{S}=210 \mathrm{GPa} \text { (módulo de elasticidade do aço) } \\
& \varepsilon_{y d}=\frac{f_{y d}}{E_{s}}(\text { deformação específica de cálculo do aço })
\end{aligned}
$$




$$
f_{y d}=\frac{f_{y k}}{\gamma_{s}} \text { (tensão de escoamento de cálculo do aço) }
$$

A partir da posição da linha neutra e da curvatura é possível determinar o esforço normal resistente adimensional de uma seção de concreto armado segundo a expressão (2.122).

Com o auxílio da expressão (2.92) são convertidos os limites do domínio de integração da função expressa em (2.112). Substituindo a expressão (2.112) na expressão (2.114) obtémse o momento fletor resistente adimensional assim expresso:

$$
\mu_{R d}=\alpha_{c} \int_{\beta_{1}}^{\beta_{2}} \beta_{y} d \beta_{y}-\alpha_{c} \int_{\beta_{2}}^{\beta_{3}}\left[\frac{\varepsilon_{c}}{1 \% 00}+\left(\frac{\varepsilon_{c}}{2 \% 00}\right)^{2}\right] \beta_{y} d \beta_{y}+\frac{\sum_{i=1}^{n} y_{s i} A_{s i} \sigma_{s i}}{A_{c} h f_{c d}}
$$

Substituindo (2.93) em (2.123) e desenvolvendo a expressão, tem-se:

$$
\mu_{R d}=\frac{\alpha_{c}}{2} \cdot k_{6}-1000 \cdot \alpha_{c} \frac{h}{r}\left\{\frac{k_{4}}{3}+\frac{k_{1} \cdot k_{2}}{2}+250 \cdot \frac{h}{r}\left[\frac{k_{5}}{4}+2 \cdot k_{1} \cdot \frac{k_{4}}{3}+k_{1}^{2} \cdot \frac{k_{2}}{2}\right]\right\}+\frac{\sum_{i=1}^{n} y_{s i} A_{s i} \sigma_{s i}}{A_{c} h f_{c d}}
$$

Onde:

$$
\begin{aligned}
& k_{5}=\beta_{3}^{4}-\beta_{2}^{4} \\
& k_{6}=\beta_{2}^{2}-\beta_{1}^{2}
\end{aligned}
$$

A partir da posição da linha neutra e da curvatura é possível determinar o momento fletor resistente adimensional de uma seção de concreto armado segundo a expressão (2.124).

Quando o intervalo de posição da linha neutra for $0<\beta_{x}<1$ a capacidade resistente a esforço normal e momento fletor tem a contribuição do aço e do concreto presente na seção.

Conforme a distribuição de tensões no concreto considera-se o diagrama de tensões segundo a combinação de uma parábola e um retângulo. Segundo a NBR 6118:2003 este diagrama pode ser substituído por um diagrama retangular de altura igual a 0,8 vezes a altura da linha neutra. 
Em relação aos limites adimensionais presentes nas equações (2.122) e (2.124) tem-se que para o limite associado ao início do trecho retangular do diagrama de tensão de compressão no concreto o seguinte:

$$
\beta_{1}=-1 / 2
$$

Além disto, conforme ilustra a Figura 2.22, o máximo trecho reto do diagrama de tensão de compressão no concreto corresponde a 3/7 da altura da seção:

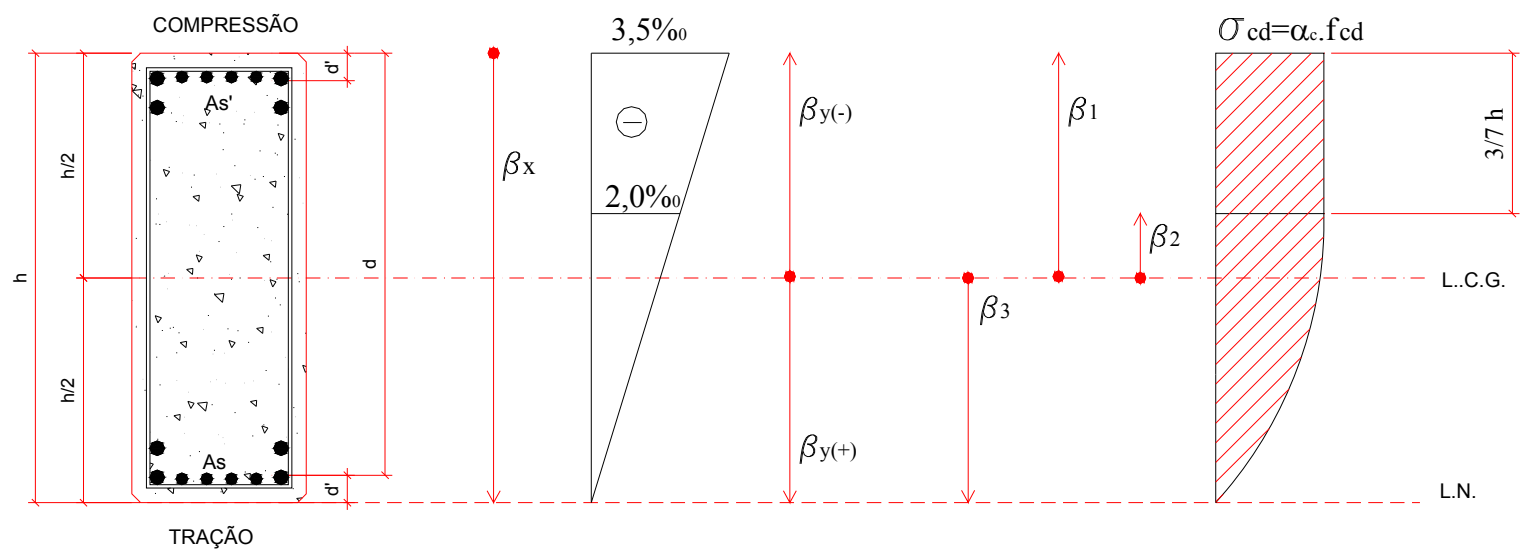

Figura 2.22: Limites adimensionais de integração

O limite adimensional de integração $\beta_{2}$ se comporta de acordo com a seguinte equação:

$$
\beta_{2}=\beta_{1}+\frac{3}{7}
$$

Tendo como variação a inequação expressa em (2.129).

$$
-\frac{1}{2} \leq \beta_{2} \leq-\frac{1}{14}
$$

A expressão que define $\beta_{2}$ pode ser obtida segundo a expressão (2.93). A deformação foi substituída pelo valor de $-2 \%$ e tomou-se $\beta_{y}=\beta_{2}$. Sendo assim, tem-se: 


$$
\beta_{2}=-\frac{0,002}{h / r}+\beta_{X}-1 / 2
$$

O limite adimensional de integração, associado ao final do trecho parabólico do diagrama de tensão de compressão no concreto, tem como condição de contorno deformação nula, definida pela linha neutra. Este limite é regido pela seguinte expressão, obtida impondose deformação nula e tomando-se $\beta_{y}=\beta_{3}$ na expressão (2.93):

$$
\beta_{3}=\beta_{X}-1 / 2
$$

Tendo como variação a inequação expressa em (2.132):

$$
-\frac{1}{2} \leq \beta_{3} \leq \frac{1}{2}
$$

Quando $\beta_{x} \leq 0$ a seção está submetida à tração em sua totalidade, não havendo contribuição do concreto na capacidade resistente ao esforço normal e momento fletor, esta situação é representada pelo mínimo valor de todos os limites de integração presentes nas expressões (2.116) e (2.123). O esforço normal e o momento fletor resistentes adimensionais assumem o seguinte formato respectivamente:

$$
\begin{aligned}
& v_{R d}=\frac{\sum_{i=1}^{n} A_{s i} \sigma_{s i}}{A_{c} f_{c d}} \\
& \mu_{R d}=\frac{\sum_{i=1}^{n} y_{s i} A_{s i} \sigma_{s i}}{A_{c} h f_{c d}}
\end{aligned}
$$

O esforço normal e o momento fletor resistente para $\beta_{x} \geq 1$, domínio de deformação 5 , estão associados ao fato de toda seção estar comprimida, para intervalos de $\beta_{x}>>1$ a aproximação prescrita pela NBR 6118:2003 para substituição do diagrama retângulo-parábola por diagrama retangular de altura igual a 0,8 vezes a altura da linha neutra não é razoável. Neste caso o diagrama de tensão no concreto corresponde a um retângulo de altura unitária. 
FUSCO (1981) apresenta relações entre $\beta_{x}$ e a altura do diagrama de tensão equivalente retangular.

A determinação do diagrama $\mathrm{M} \times \mathrm{N}$ x $1 / \mathrm{r}$ é feita descobrindo-se a força normal resistente $\left(v_{R d}\right)$ capaz de equilibrar uma força normal solicitante pré-fixada $\left(v_{\text {fixo }}\right)$. Este procedimento é incremental e iterativo, uma vez que esta força normal solicitante pré-fixada está associada a uma curvatura e posição de linha neutra. Após a definição da posição da linha neutra é calculado o momento fletor adimensional resistente.

A determinação do diagrama $\mathrm{M} \times \mathrm{N} \mathrm{x} \mathrm{h/r}$ é destinada a uma dada seção, não sendo incluída na análise a esbeltez do elemento.

Os passos para obtenção do diagrama $\mathrm{M} \times \mathrm{N} \times \mathrm{h} / \mathrm{r}$ estão apresentados a seguir, segundo modelo adaptado de PAULA (1988).

1. Para a iteração "i" com incremento adimensional de curvatura $\Delta_{\mathrm{i}}$, defini-se a curvatura adimensional $(\mathrm{h} / \mathrm{r})_{\mathrm{i}}$ da seção transversal, de acordo com a expressão:

$$
(h / r)_{i}=(h / r)_{i-1}+\Delta_{i}
$$

2. Definem-se os valores extremos do intervalo, para variação da profundidade da linha neutra.

2.1. Limite inferior de $\beta_{x}$ :

Considera-se para o limite inferior de $\beta_{x}$, ou seja, $\beta_{x} \leq 0$, a expressão:

$$
\beta_{x} \geq-\frac{10 \% 0}{h / r}+1-\delta^{\prime}
$$

2.2. Limite superior de $\beta_{x}$ :

Considera-se para o limite superior de $\beta_{x}$, no caso, $0<\beta_{x}<1$, a expressão:

$$
\beta_{x} \leq \frac{3,5 \% 0}{h / r}
$$

Considera-se no caso em que $\beta_{x} \geq 1$, a expressão:

$$
\beta_{x} \leq \frac{2 \% 0}{h / r}+\frac{3}{7}
$$

3. Calculam-se as forças normais adimensionais resistentes, $v_{R d 1}$ e $v_{R d 2}$, correspondentes aos limites, inferior e superior de $\beta_{x}$, respectivamente, com o auxílio da expressão (2.122): 
4. Verifica-se a força normal solicitante pré-fixada em relação à força normal resistente definida no passo 3 .

4.1. Se $v_{f x x o}<v_{R d 1}$ ou $v_{f x o}>v_{R d 2}$, o equilíbrio é impossível, uma vez que os limites de resistência são ultrapassados. Nesse caso interrompe-se o procedimento.

4.2. Se $v_{f i x o}$ for igual ou aproximadamente igual, com uma certa tolerância, a $v_{R d 1}$ ou $v_{R d 2}$, passa-se ao passo 9. Caso contrário, vá para o passo 5.

5. Calcula-se um novo valor para $\beta_{x}$, interpolando-se linearmente os valores $\beta_{x}$ inferior $\left(\beta_{x i}\right)$ e superior $\left(\beta_{x s}\right)$, segundo a seguinte expressão:

$$
\beta_{x}=\frac{\left(v_{f i x o}-v_{R d 1}\right)\left(\beta_{x s}-\beta_{x i}\right)}{v_{R d 2}-v_{R d 1}}+\beta_{x i}
$$

6. Com o valor de $\beta_{x}$, calculado no passo 5 e usando-se a expressão (2.122), obtém-se um novo valor para a força normal resistente, adimensional, $v_{R d}$.

7. Verificar o equilíbrio:

7.1. Se $v_{R d}=v_{f x o}$, a menos de uma tolerância pré-fixada, vá para o passo 9.

7.2. Se o número de iterações extrapolar um valor fixado, deve-se interromper o procedimento.

8. Substituindo-se convenientemente $v_{R d 1}$ pelo valor de $v_{R d}$, calculado em 6 , e $\left(\beta_{x i}\right)$ pelo valor de $\beta_{x}$, calculado em 5 , de forma que a força normal pré-fixada se encontre dentro do novo intervalo, retorna-se ao passo 5.

9. Calcula-se o momento fletor adimensional resistente, empregando-se a expressão (2.124).

10. Retorna-se ao passo 1 para novo valor de $\mathrm{h} / \mathrm{r}$.

O algoritmo descrito foi implementado com o auxílio de uma planilha eletrônica, com 4 iterações em média obteve-se o valor da linha neutra correspondente a força normal adimensional solicitante pré-fixada.

Com intuito de ilustrar o processo iterativo, a Tabela 2.2 apresenta os dados de entrada de uma análise e a Tabela 2.3 apresenta a seqüência de cálculo para obtenção da linha neutra a partir de uma curvatura e força normal adimensional pré-fixada, a tensão no concreto foi considerada igual a $1,1 \mathrm{f}_{\mathrm{cd}}$. Segundo convenção adotada, deformação negativa, corresponde à 
força positiva (compressão). Na planilha eletrônica em Excel desenvolvida, é possível compor a seção com até 10 níveis de armadura, este recurso foi implementado tendo em vista as variações nos arranjos de armadura. Além disto, não é possível considerar como concentrada a armadura presente nas seções que tenham relação entre o centro de gravidade da armadura e a seção maior que 0,1 . Os diagramas $\mathrm{M} \times \mathrm{N}$ x $1 / \mathrm{r}$ foram construídos com incrementos de curvatura $(\mathrm{h} / \mathrm{r}=0,0005)$.

Tabela 2.2: Exemplo para dados de entrada na obtenção do diagrama $\mathrm{M} \mathrm{x} \mathrm{N} \mathrm{x} \mathrm{1/r}$

\begin{tabular}{|c|c|c|c|c|c|c|c|c|c|}
\hline \multicolumn{10}{|c|}{ Dados de entrada } \\
\hline $\mathrm{B}_{\mathrm{w}}(\mathrm{m})$ & $\mathrm{H}(\mathrm{m})$ & $\mathrm{A}_{\mathrm{sc}}\left(\mathrm{cm}^{2}\right)$ & $\mathrm{A}_{\mathrm{st}}\left(\mathrm{cm}^{2}\right)$ & $\mathrm{d}^{\prime}(\mathrm{m})$ & $\mathrm{d}^{\prime} / \mathrm{h}$ & $\mathrm{f}_{\mathrm{ck}}(\mathrm{MPa})$ & $\mathrm{N}_{\mathrm{d}}(\mathrm{kN})$ & $\mathrm{V}_{\text {fixo }}$ & $\omega$ \\
\hline 0,50 & 0,50 & 30,00 & 30,00 & 0,05 & 0,10 & 35 & 3123,40 & 0,50 & 0,42 \\
\hline
\end{tabular}

$\mathrm{A}_{\mathrm{sc}}$ : Área de armadura comprimida; $\mathrm{A}_{\mathrm{st}}$ : Área de armadura tracionada; $\omega$ : taxa mecânica de armadura

Tabela 2.3: Exemplo do processo iterativo para obtenção do momento resistente de uma seção para curvatura pré-definida

\begin{tabular}{|c|c|c|c|c|c|c|c|c|c|c|c|c|c|c|}
\hline$\gamma$ & \multirow{3}{*}{\multicolumn{2}{|c|}{$\frac{\text { Curvatura }}{\mathrm{h} / \mathrm{r}}$}} & \multirow{2}{*}{\multicolumn{5}{|c|}{ Valores Extremos de $\beta_{x}$}} & & & & & & & \\
\hline & & & & & & & & & & & & & & \\
\hline Iteração & & & $\beta_{x, \text { inf }}$ & $\beta_{\mathrm{x}, \text { sup }}$ & $\beta_{\mathrm{x}, \text { sup }}$ & \multicolumn{2}{|c|}{$\beta_{\mathrm{x}}$} & & & & & & & \\
\hline 1 & \multicolumn{2}{|c|}{0,00550} & $-0,918$ & 0,636 & 0,790 & \multicolumn{2}{|c|}{0,636} & & & & & & & \\
\hline 2 & \multicolumn{2}{|c|}{0,00550} & 0,440 & 0,636 & 0,790 & \multicolumn{2}{|c|}{0,636} & & & & & & & \\
\hline 3 & \multicolumn{2}{|c|}{0,00550} & 0,550 & 0,636 & 0,790 & \multicolumn{2}{|c|}{0,636} & & & & & & & \\
\hline \multirow[t]{2}{*}{4} & \multicolumn{2}{|c|}{0,00550} & 0,560 & 0,636 & 0,790 & 0,6 & & & & & & & & \\
\hline & \multicolumn{14}{|c|}{ (Deformações/Tensões/Limites adimensionais) $\beta_{x i}$} \\
\hline Iteração & $\varepsilon_{\mathrm{cc}}$ & $\varepsilon_{\mathrm{st}}$ & $\sigma_{\mathrm{st}}$ & $\varepsilon_{\mathrm{sc}}$ & $\sigma_{\mathrm{sc}}$ & $\beta_{1}$ & $\beta_{2}$ & $\beta_{3}$ & $\mathrm{k}_{1}$ & $\mathrm{k}_{2}$ & $\mathrm{k}_{3}$ & $\mathrm{k}_{4}$ & $\mathrm{k}_{5}$ & $\mathrm{k}_{6}$ \\
\hline 1 & 0,0051 & 0,0100 & $-43,50$ & 0,0056 & $-43,50$ & $-0,50$ & $-0,50$ & $-0,50$ & 1,42 & 0,00 & 0,00 & 0,00 & 0,00 & 0,00 \\
\hline 2 & $-0,0024$ & 0,0025 & $-43,50$ & $-0,0019$ & 39,69 & $-0,50$ & $-0,42$ & $-0,06$ & 0,06 & $-0,17$ & 0,36 & 0,07 & $-0,03$ & $-0,07$ \\
\hline 3 & $-0,0030$ & 0,0019 & $-40,31$ & $-0,0025$ & 43,50 & $-0,50$ & $-0,31$ & 0,05 & $-0,05$ & $-0,10$ & 0,36 & 0,03 & $-0,01$ & $-0,15$ \\
\hline \multirow[t]{2}{*}{4} & $-0,0031$ & 0,0018 & $-39,51$ & $-0,0025$ & 43,50 & $-0,50$ & $-0,31$ & 0,06 & $-0,06$ & $-0,09$ & 0,36 & 0,03 & $-0,01$ & $-0,16$ \\
\hline & \multicolumn{14}{|c|}{ (Deformações/Tensões/Limites adimensionais) $\beta_{\mathrm{xs}}$} \\
\hline Iteração & $\varepsilon_{\mathrm{cc}}$ & $\varepsilon_{\mathrm{st}}$ & $\sigma_{\mathrm{st}}$ & $\varepsilon_{\mathrm{sc}}$ & $\sigma_{\mathrm{sc}}$ & $\beta_{1}$ & $\beta_{2}$ & $\beta_{3}$ & $\mathrm{k}_{1}$ & $\mathrm{k}_{2}$ & $\mathrm{k}_{3}$ & $\mathrm{k}_{4}$ & $\mathrm{k}_{5}$ & $\mathrm{k}_{6}$ \\
\hline 1 & $-0,0035$ & 0,0015 & $-30,45$ & $-0,0030$ & 43,50 & $-0,50$ & $-0,23$ & 0,14 & $-0,14$ & $-0,03$ & 0,36 & 0,01 & 0,00 & $-0,20$ \\
\hline 2 & $-0,0035$ & 0,0015 & $-30,45$ & $-0,0030$ & 43,50 & $-0,50$ & $-0,23$ & 0,14 & $-0,14$ & $-0,03$ & 0,36 & 0,01 & 0,00 & $-0,20$ \\
\hline 3 & $-0,0035$ & 0,0015 & $-30,45$ & $-0,0030$ & 43,50 & $-0,50$ & $-0,23$ & 0,14 & $-0,14$ & $-0,03$ & 0,36 & 0,01 & 0,00 & $-0,20$ \\
\hline 4 & $-0,0035$ & 0,0015 & $-30,45$ & $-0,0030$ & 43,50 & $-0,50$ & $-0,23$ & 0,14 & $-0,14$ & $-0,03$ & 0,36 & 0,01 & 0,00 & $-0,20$ \\
\hline & \multicolumn{2}{|c|}{ Força adimen. } & & & & & & & & & & & & \\
\hline Iteração & $V_{\mathrm{Rd} 1}$ & $V_{\mathrm{Rd} 2}$ & & & & & & & & & & & & \\
\hline 1 & $-0,418$ & 0,629 & & & & & & & & & & & & \\
\hline 2 & 0,336 & 0,629 & & & & & & & & & & & & \\
\hline 3 & 0,488 & 0,629 & & & & & & & & & & & & \\
\hline 4 & 0,500 & 0,629 & & & & & & & & & & & & \\
\hline
\end{tabular}


O processo iterativo apresentado na Tabela 2.3 é ilustrado graficamente na Figura 2.23 .

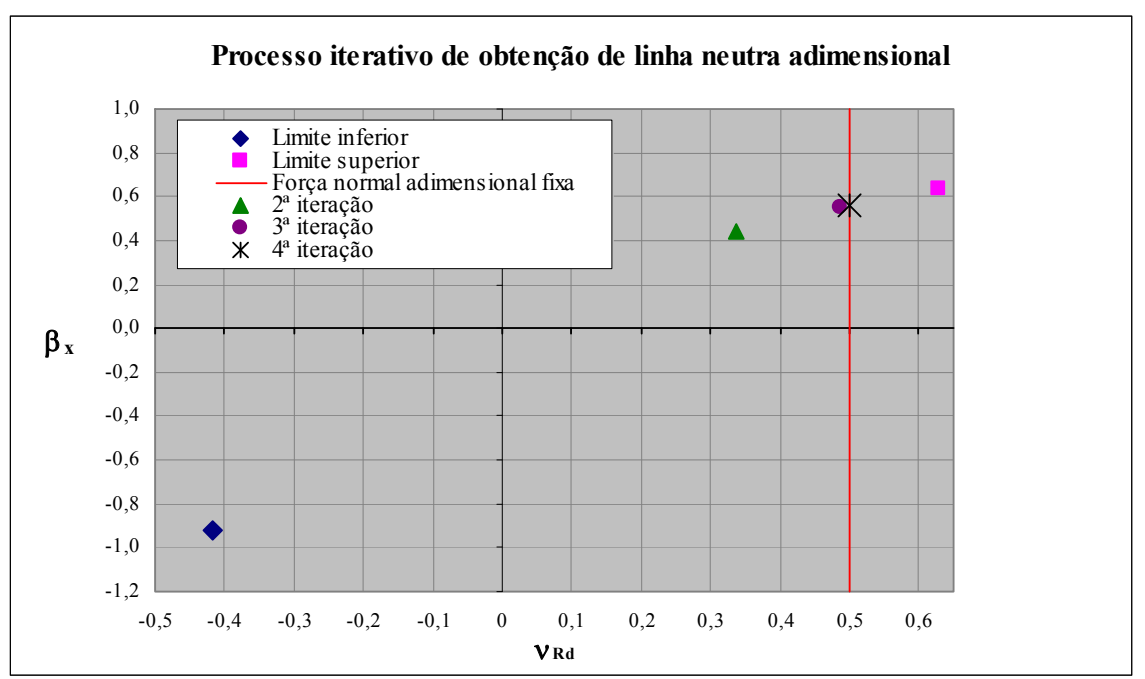

Figura 2.23: Exemplo de representação gráfica do processo iterativo de obtenção da linha neutra adimensional

A partir da obtenção da posição da linha neutra encontra-se o valor de $\mu=0,2906$ ou o $\mathrm{M}_{\mathrm{Rd}}=908,24 \mathrm{kN} . \mathrm{m}$.

Para a seção ilustrada na Figura 2.24 com $\mathrm{f}_{\mathrm{ck}}=35 \mathrm{MPa}$, foi construído o diagrama $\mathrm{M} \mathrm{x}$ $\mathrm{N} \mathrm{x} 1 / \mathrm{r}$ com o valor de $0,85 \mathrm{f}_{\mathrm{cd}}$ de tensão no concreto. A armadura é constituída de aço CA-50. Variando-se apenas os níveis de força normal adimensional, conforme ilustra a Figura 2.25, foi avaliado a variação de comportamento quanto a momento resistente e ductilidade dos elementos.

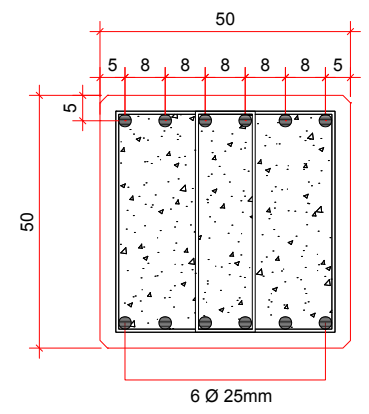

Figura 2.24: Seção transversal e arranjo de armadura de uma seção de pilar 


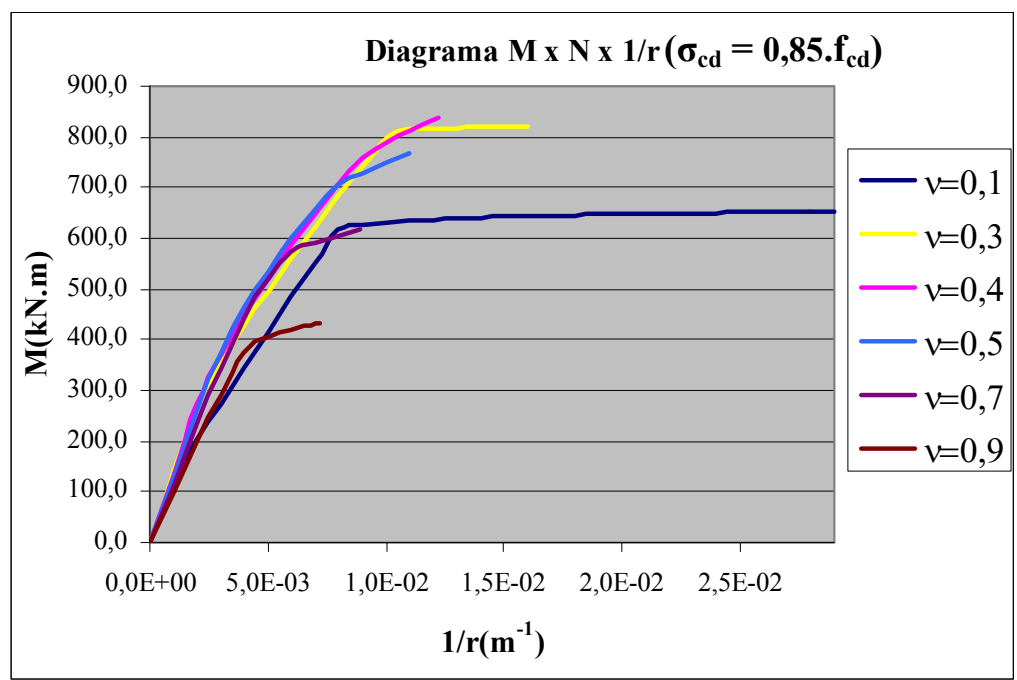

Figura 2.25: Diagrama M x N x 1/r modificado sob ação do esforço normal

Observando o conjunto de diagramas, nota-se que o aumento do nível de esforço normal de compressão diminui a ductilidade dos elementos, portanto a quantidade de energia dissipada durante o fraturamento do elemento diminui com o aumento do nível de compressão.

Além disto, para o problema estudado observa-se que o incremento de força normal provoca um acréscimo do momento fletor resistente até o nível de compressão adimensional de aproximadamente 0,4 . Após este nível existe um decréscimo do momento fletor resistente.

A consideração não simplificada da NLF implica em conhecer o diagrama $\mathrm{M} \mathrm{x} \mathrm{N} \mathrm{x}$ $1 / r$, ou seja, a rigidez, para cada seção em que houver mudança de esforço solicitante, seção transversal, armadura, cobrimento e $\mathrm{f}_{\mathrm{ck}}$. Isto significa que quanto maior for a discretização da estrutura em elementos finitos maior é a representatividade da solução.

A validação da ferramenta desenvolvida foi feita segundo as referências encontradas na bibliografia. Em relação à presença de força normal, relações $\mu \times v \times d / r$ podem ser encontradas para diferentes relações de d'/h e tipos de aço em FUSCO (1981).

Quanto à influência do efeito reológico do concreto no diagrama $\mathrm{M} \times \mathrm{N}$ x $1 / \mathrm{r}$, OLIVEIRA (2004) apresenta ábacos modificados pelo efeito do coeficiente linear de fluência.

Os resultados obtidos de momento fletor resistente e rigidez secante foram comparados com os valores encontrados nos ábacos desenvolvidos por OLIVEIRA (2004). A diferença entre os valores encontrados segundo a ferramenta de cálculo desenvolvida pelo autor e os encontrados por OLIVEIRA (2004) é da ordem de $1 \%$.

Os valores apresentados nos ábacos por FUSCO (1981) também foram comparados com os obtidos pela ferramenta desenvolvida, atendendo satisfatoriamente os resultados. 


\subsubsection{INFLUÊNCIA DO COMPORTAMENTO REOLÓGICO DO CONCRETO}

A não-linearidade do diagrama $\mathrm{M}$ x N x 1/r sofre influência da deformação diferida ao longo do tempo, conhecida como fluência. A fluência, por definição, é a deformação diferida ao longo do tempo causada por tensões constantes. A fluência é considerada segundo a teoria linear. A NBR 6118:2003 prescreve que para tensões de compressão menores que 0,5 $f_{c}$ (resistência à compressão do concreto), pode-se admitir uma relação linear entre tensões e deformações.

Segundo FUSCO (1981) como a fluência ocorre sob ação dos esforços permanentes de serviço, as tensões no concreto são suficientemente baixas, sendo válida a teoria linear da fluência, na qual é admitida uma função $\phi$ de fluência independente da tensão aplicada.

A Figura 2.26 ilustra a mudança no comportamento do diagrama tensão x deformação do concreto sob ação da fluência.

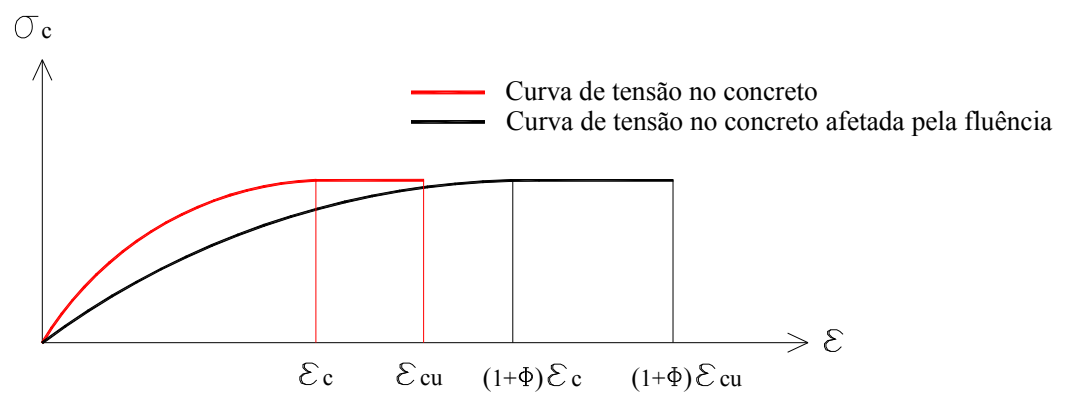

Figura 2.26: Diagrama tensão x deformação do concreto modificado sob ação da fluência

A deformação total do concreto assume a seguinte forma:

$$
\varepsilon_{c, t o t a l}=\varepsilon_{c}+\varepsilon_{c c}=(1+\phi) \varepsilon_{c c}
$$

Onde:

$\varepsilon_{c}$ deformação imediata no concreto;

$\varepsilon_{c c}$ deformação por fluência do concreto.

O coeficiente de fluência pode ser expresso pela soma abaixo:

$$
\phi=\phi_{a}+\phi_{d}+\phi_{f}
$$


Onde:

$\phi_{a}$ é o coeficiente de deformação rápida, é irreversível e ocorre nas primeiras 24h após a aplicação da carga;

$\phi_{d}$ é o coeficiente de deformação lenta reversível;

$\phi_{f}$ é o coeficiente de deformação lenta irreversível.

A curvatura dos elementos é modificada com a alteração do valor da deformação do concreto da seguinte forma:

Quando $\beta_{x} \leq 0$ não há efeito da fluência. Portanto a curvatura total fica assim definida:

$$
\left(\frac{1}{r}\right)_{\text {total }}=\frac{\varepsilon_{\text {inf }}-\varepsilon_{\text {sup }}}{d}
$$

Onde:

$$
\begin{aligned}
& \varepsilon_{\text {sup }} \text { representa a deformação na fibra superior; } \\
& \varepsilon_{\text {inf }} \text { representa a deformação na fibra inferior (C.G. da armadura). }
\end{aligned}
$$

Quando $0<\beta_{x}<1$ há efeito da fluência agindo somente na fibra superior, pois somente há compressão na fibra superior e a expressão da curvatura total fica assim definida:

$$
\left(\frac{1}{r}\right)_{\text {total }}=\frac{\varepsilon_{\text {inf }}-(1+\phi) \varepsilon_{\text {sup }}}{d}
$$

Quando $\beta_{x} \geq 1$ há efeito da fluência agindo na fibra superior e inferior, pois toda seção está comprimida e a expressão da curvatura total assume a seguinte forma:

$$
\left(\frac{1}{r}\right)_{\text {total }}=\frac{(1+\phi) \varepsilon_{\text {inf }}-(1+\phi) \varepsilon_{\text {sup }}}{d}
$$


Devido ao processo construtivo e de ocupação da edificação, parcelas de carga de longa duração são adicionadas em diferentes instantes, como conseqüência disto o valor do coeficiente de fluência deve ser corrigido por coeficientes que levam em conta a parcela das cargas de longa duração.

Rigorosamente deve ser ponderada a história de carregamento da estrutura, ou seja, para cargas de longa duração a análise deveria ser feita segundo diagramas $\mathrm{M}$ x N x 1/r com $\phi \neq 0$, para o acréscimo de cargas de curta duração a análise deveria ser feita com $\phi=0$.

Entende-se por carga de longa duração a carga permanente e parte da carga acidental ponderada segundo combinação de ações.

Uma forma simplificada de se considerar estas variações consiste em considerar todo o carregamento de longa duração e ponderar os fatores de carregamento de longa duração da seguinte forma:

$$
\phi_{\text {efetivo }}=\chi \cdot \xi \cdot \phi
$$

Onde:

$$
\begin{aligned}
& \chi \text { representa a fração da força normal que produz fluência; } \\
& \xi \text { representa a fração do momento fletor de } 1^{\text {a }} \text { ordem que produz fluência; } \\
& \phi \text { coeficiente de fluência para carregamento total. }
\end{aligned}
$$

A Figura 2.27 ilustra a mudança na configuração do diagrama $\mathrm{M} \times \mathrm{N}$ x $1 / \mathrm{r}$ para diversos coeficientes de fluência para a seção ilustrada da Figura $2.24 \mathrm{com} v=0,5$, aço em CA-50, $\mathrm{f}_{\mathrm{ck}}=35 \mathrm{MPa}$ e tensão considerada no concreto de $0,85 \mathrm{f}_{\mathrm{cd}}$. 


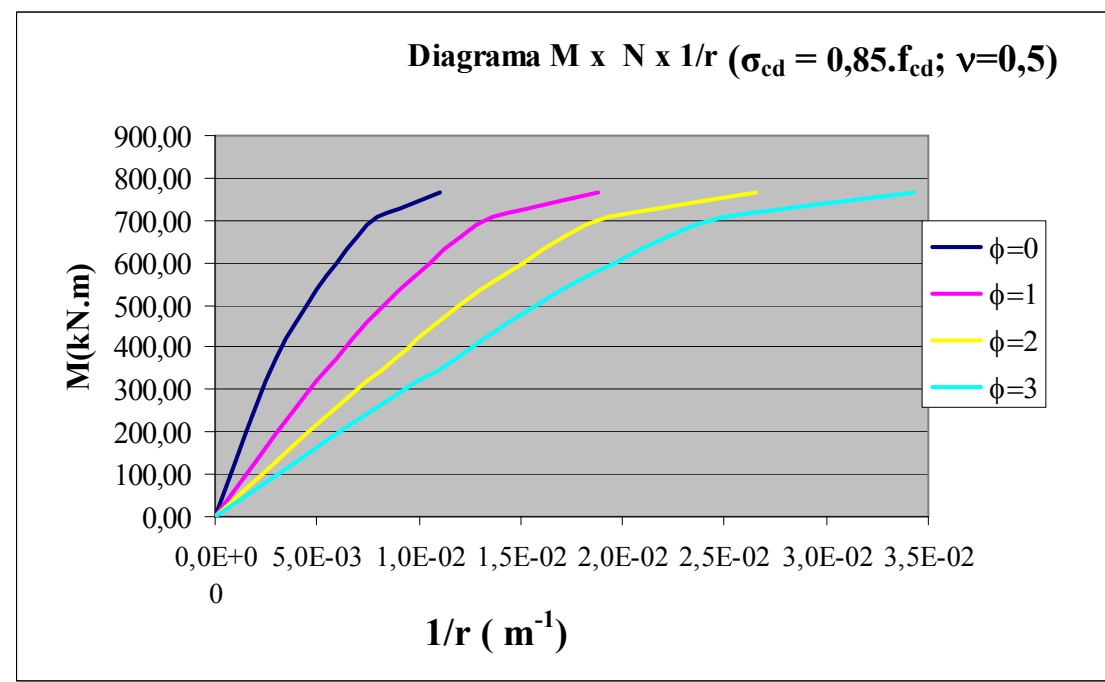

Figura 2.27: Diagrama M x N x 1/r modificado sob ação da fluência

Observando a Figura 2.27 nota-se o aumento da ductilidade com o aumento do efeito da fluência.

As condições de cura, tipo de cimento, umidade, entre outros fatores, influenciam na consideração da fluência. De forma particular as estruturas em concreto pré-moldado de fábrica são mais afetadas pelos efeitos da fluência, seja pelo uso de cimento de alta resistência inicial, que amplifica os efeitos da fluência ou devido à rápida mobilização dos elementos pelo carregamento da estrutura. Uma característica benéfica do concreto pré-moldado de fábrica é a possibilidade de realização de cura do elemento com vapor, atenuando desta forma os malefícios do uso do cimento ARI.

\subsubsection{INFLUÊNCIA DA PROTENSÃO}

O desenvolvimento do concreto protendido contribuiu para a evolução e a difusão do sistema construtivo em concreto pré-moldado, principalmente o concreto protendido com armadura ativa pré-tracionada. No sistema de protensão com armadura ativa pré-tracionada a aderência entre o concreto e a armadura ativa ocorre no momento em que o elemento é concretado. Este sistema de protensão possui algumas particularidades benéficas à préfabricação, dentre as quais se destaca o fato da armadura ativa possuir um traçado retilíneo.

Desta forma, as perdas por atrito cabo-bainha características do sistema de protensão com armadura ativa pós-tracionada ficam eliminadas. Além disto, o traçado retilíneo da armadura ativa beneficia a produção de elementos em série, possibilitando a execução simultânea de diversos elementos em pistas de protensão. Outro benefício do sistema com concreto protendido com armadura ativa pré-tracionada refere-se à possibilidade de se 
reaproveitar os dispositivos de ancoragem da armadura ativa em outras operações de protensão.

Aplicada a protensão, a armadura ativa sofre perdas de protensão, as perdas podem ser divididas em perdas iniciais e diferidas no tempo. Dentre as perdas iniciais, podem ser citadas a perda por deformação da ancoragem e a perda por deformação inicial do concreto.

Em relação às perdas diferidas no tempo, podem ser citadas as perdas devido à retração do concreto, devido à relaxação da armadura e devido à fluência.

De um modo geral, a soma das perdas de protensão iniciais e diferidas no tempo totaliza de $20 \%$ a $25 \%$ da força de protensão.

No ato da protensão, a deformação da armadura ativa corresponde à própria deformação imposta pelo macaco hidráulico. Efetuada a operação de protensão, a armadura ativa é ancorada em dispositivos suscetíveis a acomodações.

É usual que a armadura ativa seja tensionada em apenas um lado da pista de protensão, desta forma o sistema de ancoragem é ativo em uma extremidade da pista e passivo na outra.

No concreto protendido, com armadura ativa pré-tracionada, o elemento estrutural não desempenha o papel de reação da força de protensão. A reação da força de protensão é feita pela cabeceira da pista. A acomodação da ancoragem provoca uma perda de protensão, caracterizada pelo encurtamento do cabo.

$\mathrm{O}$ aço utilizado como armadura ativa tem o diagrama tensão x deformação ilustrado na Figura 2.28.

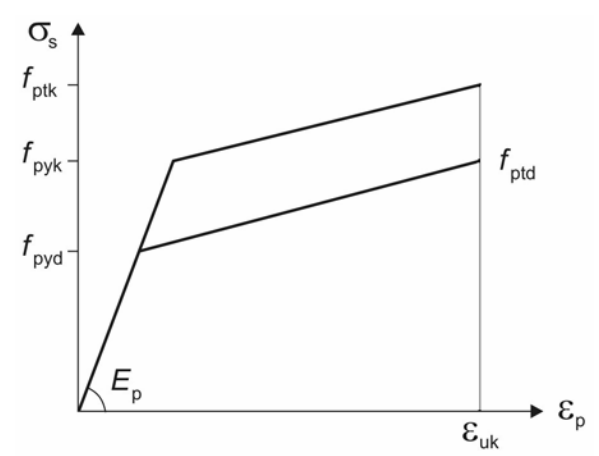

Figura 2.28: Diagrama tensão-deformação para aços de armaduras ativas [NBR 6118:2003]

O módulo de elasticidade do aço constituinte da armadura ativa é de $200 \mathrm{GPa}$, para o aço do tipo CP190 RB.

Onde:

$$
f_{p t k}=1900 \mathrm{MPa} ;
$$




$$
\begin{aligned}
f_{p y k} & =1710 \mathrm{MPa} \\
f_{p y d} & =1487 \mathrm{MPa} \\
\varepsilon_{u k} & =3,5 \%
\end{aligned}
$$

A força aplicada na armadura ativa no ato da protensão está relacionada, segundo a lei constitutiva do material, com a deformação e o módulo de elasticidade. Portanto, a perda de protensão da armadura ativa, ou seja, a diminuição da tensão na armadura ativa corresponde a uma diminuição da deformação presente na armadura.

A deformação total da armadura ativa é obtida somando-se à deformação inicial imposta no ato da protensão a deformação associada à curvatura do elemento estrutural. As perdas de protensão imediatas e diferidas no tempo podem ser consideradas reduzindo a deformação imposta na armadura ativa inicialmente no ato da protensão.

A Figura 2.30 ilustra o diagrama M x N x 1/r modificado pela utilização de diferentes taxas de armadura ativa na seção de concreto ilustrada na Figura 2.29 com $\mathrm{f}_{\mathrm{ck}}=40 \mathrm{MPa}$, tensão considerada no concreto de $0,85 \mathrm{f}_{\mathrm{cd}}$ e deformação na armadura ativa de $7 \%$. A armadura ativa é composta por cordoalhas CP 190 RB 12,7 e a armadura passiva é constituída de aço CA-50.

Não foi computada a armadura de pele presente na seção para efeito de construção do diagrama $\mathrm{M}$ x $\mathrm{N}$ x $1 / \mathrm{r}$.

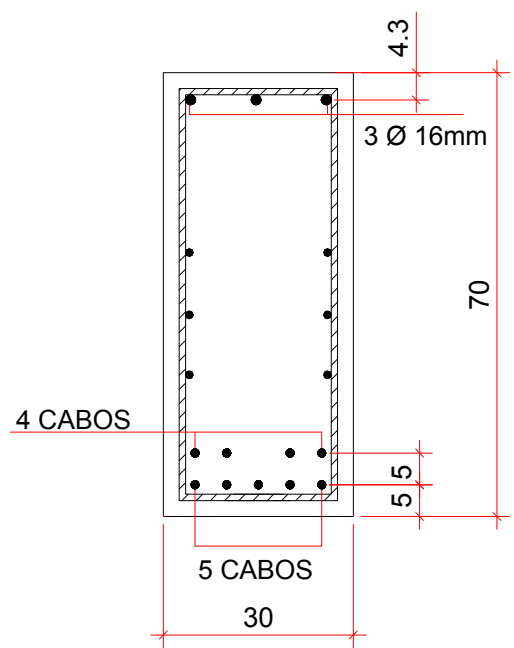

Figura 2.29: Seção transversal e arranjo de armadura ativa em duas camadas 


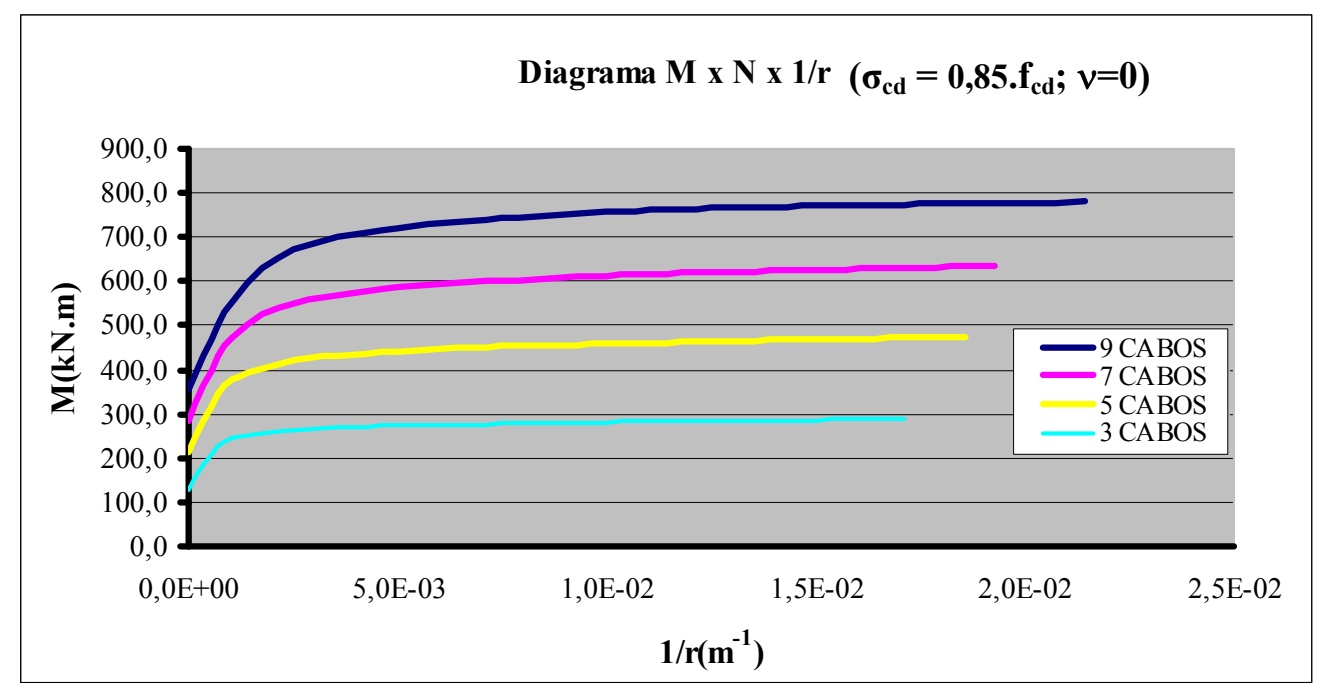

Figura 2.30: Diagrama M x N x 1/r modificado sob ação de armadura ativa

Observando o diagrama $\mathrm{M} \times \mathrm{N}$ x 1/r ilustrado na Figura 2.30, nota-se que para a curvatura inicial o momento atuante na peça é o momento de protensão. Para situação de momento nulo tem-se curvatura negativa, que corresponde à contra-flecha. $\mathrm{O}$ aumento da taxa de armadura ativa aumentou de forma significativa a resistência da seção, ao passo que a ductilidade sofreu um pequeno acréscimo.

LEONHARDT (1983) com o auxílio dos diagramas momento $\mathrm{x}$ curvatura e força $\mathrm{x}$ curvatura aponta as principais diferenças de comportamento resistente entre uma viga em concreto armado e uma viga em concreto protendido para momentos resistentes semelhantes.

$\mathrm{Na}$ viga em concreto protendido, além da curvatura negativa associada ao momento nulo, destaca-se o fato do momento de fissuração encontrar-se em um nível maior devido ao efeito da força normal e ao momento fletor produzido pela protensão. Apesar das diferenças apontadas, para o momento de ruptura, a curvatura observada em uma viga de concreto armado e em uma viga de concreto protendido é aproximadamente a mesma. Portanto, para o momento de ruptura ambas apresentam a mesma flecha.

Quando o projeto da viga em seção composta envolve protensão, a armadura ativa especificada deve atender aos limites de tensão máxima e mínima nas bordas inferiores e superiores da seção para todas as fases de carregamento e configuração de seção da viga.

As variações permitidas para os valores de tensão nas bordas inferiores e superiores da seção são definidas segundo o regime de protensão e estão associadas ao grau de agressividade do ambiente no qual a estrutura esta inserida. $\mathrm{O}$ controle da tensão na armadura é feito levando-se em conta a durabilidade da estrutura, no que se refere ao grau de fissuração e a proteção da armadura. 
A protensão pode ser classificada em três níveis: parcial, limitada e completa. Sendo assim a ordem crescente quanto ao grau de exigência no controle das tensões atuantes.

\subsubsection{ANÁLISE DA NÃO-LINEARIDADE FÍSICA SEGUNDO MÉTODOS APROXIMADOS}

A não-linearidade física está relacionada com a rigidez secante do elemento estrutural, sendo que sua consideração pode ser feita de maneira aproximada por expressões com o seguinte formato:

$$
E I_{\text {sec }}=\alpha E_{c i} I_{c}
$$

A metodologia e formulação para obtenção do coeficiente redutor $\alpha$ são divergentes quando comparadas as normas internacionais. A seguir são apresentadas as formulações encontradas em diferentes normas:

a) NBR 6118:2003

A NBR 6118:2003 permite que a consideração da não-linearidade física seja feita de maneira aproximada para análise da estabilidade global em estruturas reticuladas de no mínimo quatro pavimentos, para isto a rigidez secante $(\mathrm{EI})_{\mathrm{sec}}$, é definida para cada elemento da seguinte forma:

$$
\begin{aligned}
\text { Lajes: } E I_{\mathrm{sec}} & =0,3 E_{c i} I_{c} \\
\text { Vigas: } E I_{\mathrm{sec}} & =0,4 E_{c i} I_{c} \text { para } \mathrm{A}_{\mathrm{s}} \neq \mathrm{A}_{\mathrm{s}} \mathrm{e} \\
E I_{\mathrm{sec}} & =0,5 E_{c i} I_{c} \text { para } \mathrm{A}_{\mathrm{s}}=\mathrm{A}_{\mathrm{s}}
\end{aligned}
$$

Pilares: $E I_{\text {scc }}=0,8 E_{c i} I_{c}$

Onde:

$I_{\mathrm{c}}$ é o momento de inércia da seção bruta de concreto, incluindo, quando for o caso, as mesas colaborantes;

$E_{c i}$ módulo de elasticidade tangente inicial. 
Quando a estrutura de contraventamento for composta exclusivamente por vigas e pilares e $\gamma_{\mathrm{z}}$ for menor que 1,3 , permite-se calcular a rigidez das vigas e pilares por:

$$
E I_{s e c}=0,7 E_{c i} I_{c}
$$

b) NBR 9062:1985

A NBR 9062:1985 no item 5.1.2.4 apresenta a seguinte formulação para obtenção da rigidez secante em pilares de pórticos com armadura simétrica:

$$
\alpha=0,2+15 \rho
$$

Em que:

$$
\rho=\frac{A_{S}}{b d}
$$

Vale ressaltar que a norma vigente NBR 9062:2006 não faz menção ao coeficiente redutor para obtenção da rigidez secante em pilares.

c) ACI $318-08$

O ACI 318-08 (Building Requirements for Structural Concrete and Commentary) apresenta duas expressões, a primeira destinada a situações de elevada carga axial e pequena excentricidade, onde o efeito da esbeltez é preponderante. A segunda expressão é apresentada como uma forma simplificada da primeira.

$$
\begin{aligned}
& E I_{\mathrm{sec}}=\frac{0,2 E_{c} I_{g}+E_{s} I_{s e}}{1+\beta_{d}} \\
& E I_{\mathrm{sec}}=\frac{0,4 E_{c} I_{g}}{1+\beta_{d}}
\end{aligned}
$$


Onde:

$E$ é o módulo de elasticidade do concreto segundo o ACI;

$E_{c}=4700 \sqrt{f^{\prime}}$

$E_{s}$ é o módulo de elasticidade do aço segundo o ACI;

$I_{g}$ é o momento de inércia da seção de concreto em relação ao centro de gravidade da seção sem consideração da armadura;

$I_{s e}$ é o momento de inércia da armadura em relação ao centro de gravidade da seção;

$\beta_{d}$ é o coeficiente referente à fluência do concreto e expressa a relação entre a carga axial permanente e a carga axial total.

Além da formulação apresentada, o ACI 318-08 sugere o coeficiente redutor de 0,7 para pilares e de 0,35 para vigas.

d) PCI (1988)

O Committee on prestressed concrete columns (PCI) apresenta a expressão (2.151) para determinação da rigidez de pilares, nota-se que a expressão é sensível às características geométricas e de vinculação do elemento.

$E I_{\mathrm{sec}}=\frac{E_{c} I_{g} / \lambda_{m}}{1+\beta_{d}}$

Em que:

$$
\begin{aligned}
& \lambda_{m}=\theta \eta \geq 3.0 \\
& \eta=2,5+1,6 \frac{P_{0}}{P} \Rightarrow 6 \leq \eta \leq 70 \\
& \theta=\frac{27}{k L / r}-0,05
\end{aligned}
$$


Onde:

$P$ representa a carga axial na coluna em uma análise de primeira ordem; $P_{0}$ representa a carga máxima centrada admissível na coluna;

$\kappa$ representa o coeficiente de comprimento efetivo da coluna considerando as condições de contorno;

$L$ representa o comprimento da coluna;

$r$ representa o raio de giração da seção.

e) FIB (2002)

A FIB (Federation Internacional du Beton) apresenta, no Bulletin 16: Design examples for FIP recommendations 'practical design of structural concrete', a seguinte expressão para avaliação da rigidez:

$$
E I_{\text {sec }}=\alpha_{\varphi} \alpha_{e} E_{c} I+E_{s} I_{s}
$$

Em que:

$$
\begin{aligned}
& \alpha_{\varphi}=1-0,8 \varphi(1-\lambda / 200) \omega^{0,25} \\
& \alpha_{e}=0,08 v_{0}\left(0,85 f_{c d}\right)^{0,6} e^{(\lambda / 100-2 \omega)} \\
& v_{0}=\frac{N_{d}}{A_{c} 0,85 f_{c d}} \\
& \omega=\frac{A_{s, t o t} f_{y d}}{A_{c} f_{c d}}
\end{aligned}
$$

Onde:

$$
\begin{aligned}
& f_{c d} \text { resistência à compressão de projeto do concreto }(\mathrm{MPa}) \\
& \lambda \text { índice de esbeltez; } \\
& \varphi \text { coeficiente de fluência. }
\end{aligned}
$$

Em relação a elementos submetidos à flexão, além das formulações apresentadas, a NBR 6118:2003 apresenta uma expressão para o cálculo da rigidez equivalente de vigas para 
avaliação de flechas imediatas, a expressão foi adaptada da formulação desenvolvida por BRANSON (1968). Nesta formulação todo o elemento é analisado considerando-se uma única inércia, que leva em conta os trechos fissurados e não fissurados.

Segundo CARVALHO \& FIGUEIREDO (2004) a formulação proposta baseia-se em um método semi-probabilístico, no qual toma a variação da tensão ao longo da seção transversal e ao longo do comprimento de uma maneira simplificada, utilizando expressões empíricas que fornecem valores médios da inércia.

A expressão da rigidez equivalente de vigas é assim expressa:

$$
(E I)_{e q}=E_{c s}\left\{\left(\frac{M_{r}}{M_{a}}\right)^{3} \cdot I_{c}+\left[1-\left(\frac{M_{r}}{M_{a}}\right)^{3}\right] \cdot I_{I I}\right\}
$$

Para seções retangulares, segundo CARVALHO (2005) a inércia da seção no estádio II é assim expressa, sendo que as parcelas referentes à armadura negativa compõem a expressão somente quando as mesmas contribuem para o momento resistente:

$$
\mathrm{I}_{\mathrm{x}, \mathrm{II} 0}=\frac{\mathrm{b}_{\mathrm{w}} \cdot \mathrm{x}_{\mathrm{II}}^{3}}{3}+\alpha_{p} \cdot \mathrm{A}_{\mathrm{p}} \cdot\left(\mathrm{x}_{\mathrm{II}}-\mathrm{d}_{\mathrm{p}}\right)^{2}+\alpha_{s} \cdot \mathrm{A}_{\mathrm{s}} \cdot\left(\mathrm{x}_{\mathrm{II}}-\mathrm{d}_{\mathrm{s}}\right)^{2}+\left(\alpha_{s}-1\right) \cdot \mathrm{A}_{\mathrm{s}}^{\prime} \cdot\left(\mathrm{x}_{\mathrm{II}}-\mathrm{d}^{\prime}\right)^{2}
$$

Em que a posição da linha neutra é obtida segundo a equação do equilíbrio de forças atuantes na seção:

$$
\begin{aligned}
& x_{I I}=\frac{-\left(A_{s}^{\prime} \cdot\left(\alpha_{s}-1\right)+A_{p} \cdot \alpha_{p}+A_{s} \cdot \alpha_{s}\right)+}{b_{w}} \\
& \frac{\sqrt{\left(A_{s}^{\prime} \cdot\left(\alpha_{s}-1\right)+A_{p} \cdot \alpha_{p}+A_{s} \cdot \alpha_{s}\right)^{2}-2 \cdot b_{w} \cdot\left(-d^{\prime} \cdot A_{s}^{\prime} \cdot\left(\alpha_{s}-1\right)-d_{p} \cdot A_{p} \cdot \alpha_{p}-d_{s} \cdot A_{s} \cdot \alpha_{s}\right)}}{b_{w}}
\end{aligned}
$$

Em que:

$$
\alpha_{s}=\frac{E_{s}}{E_{c s}}
$$




$$
\alpha_{p}=\frac{E_{p}}{E_{c s}}
$$

Onde:

$I_{c}$ momento de inércia da seção bruta de concreto;

$I_{I I}$ momento de inércia da seção fissurada de concreto no estádio II;

$\mathrm{X}_{\text {II }}$ posição da linha neutra no estádio II;

$M_{a}$ momento fletor na seção crítica considerada;

$M_{r}$ momento de fissuração do elemento;

$E_{c s}$ módulo de elasticidade secante;

$A_{s}$ área da armadura passiva tracionada;

$A_{s}{ }^{\prime}$ área da armadura passiva comprimida;

$A_{p}$ área da armadura ativa;

$d_{s}$ distância do centro de gravidade da armadura passiva tracionada a face superior da viga;

$d_{p}$ distância do centro de gravidade da armadura ativa a face superior da viga;

$d^{\prime}$ distância do centro de gravidade da armadura passiva comprimida a face superior da viga;

$\alpha$ assume o valor de 1,2 para seções em forma de " $\mathrm{T}$ " ou duplo " $\mathrm{T}$ " e 1,5 para seções retangulares;

$y_{t}$ distância do centro de gravidade à fibra mais tracionada.

Para as peças em concreto protendido não há expressão prescrita na NBR 6118:2003, mas segundo CARVALHO (2005) o momento de fissuração do elemento pode ser adaptado para:

$$
M_{r}=\frac{\alpha \cdot\left(f_{c t k, \mathrm{inf}}+\frac{N_{p}}{A}\right) \cdot I_{c}}{y_{t}}+M_{p}
$$

Em que:

$\mathrm{N}_{\mathrm{p}}$ força normal de protensão; 
A área de concreto da seção transversal;

$\mathrm{M}_{\mathrm{p}}$ momento de protensão;

$\mathrm{f}_{\text {ctk,inf }}$ resistência à tração direta inferior.

Em relação às formulações apresentadas para consideração simplificada da rigidez pelas diferentes normas, a Tabela 2.4 apresenta um resumo das considerações feitas por cada uma, desta forma explicitando a aplicabilidade e limitações das mesmas.

Tabela 2.4: Quadro comparativo de formulação para obtenção do coeficiente redutor de rigidez segundo diferentes normas e influência de variáveis

\begin{tabular}{|c|c|c|c|c|c|c|}
\cline { 2 - 7 } \multicolumn{1}{c|}{} & VALOR & $\begin{array}{c}\text { FORÇA } \\
\text { NORMAL }\end{array}$ & FLUÊNCIA & ARMADURA & ESBELTEZ & $\begin{array}{c}\text { MOMENTO } \\
\text { FLETOR }\end{array}$ \\
\hline NBR 6118:2003 & FIXO & NÃO & NÃO & NÃO & NÃO & NÃO \\
\hline NBR 9062:1985 & VARIÁVEL & NÃO & NÃO & SIM & NÃO & NÃO \\
\hline NBR 9062:2006 & --- & --- & --- & --- & --- & --- \\
\hline ACI 318-08 & VARIÁVEL & NÃO & SIM & SIM & NÃO & NÃO \\
\hline PCI (1988) & VARIÁVEL & SIM & SIM & NÃO & SIM & NÃO \\
\hline FIB (2002) & VARIÁVEL & SIM & SIM & SIM & SIM & NÃO \\
\hline NBR 6118:2003* & VARIÁVEL & NÃO & NÃO & SIM & --- & SIM \\
\hline
\end{tabular}

*Segundo rigidez equivalente de vigas

\subsection{LIGAÇÕES DE ESTRUTURAS DE CONCRETO PRÉ-MOLDADO}

\subsubsection{PROCEDIMENTOS DE PROJETO PARA LIGAÇÕES}

O projeto de estruturas de múltiplos pavimentos em concreto pré-moldado deve contemplar as características do sistema construtivo em concreto pré-moldado. Segundo EL DEBS (2000), as razões pelas quais o projeto de estruturas de concreto pré-moldado diferencia-se das estruturas de concreto moldado in loco referem-se às necessidades de se considerar situações de cálculo além da situação final da estrutura e de se considerar as particularidades das ligações entre os elementos de concreto pré-moldado que configuram a estrutura.

O projeto de ligações destinadas a estruturas em concreto pré-moldado deve abranger situações de montagem, transporte, fabricação e manutenção. Nas situações de montagem e transporte, questões relacionadas ao peso próprio dos dispositivos da ligação, tempo de fixação da ligação e equipamentos utilizados devem ser contemplados no projeto. 
A fabricação dos dispositivos da ligação deve levar em conta a facilidade de execução, a disponibilidade de matéria-prima e da mão-de-obra necessária.

Quando necessária a manutenção da ligação, deve ser previsto em projeto o acesso a mesma. Os projetos das ligações devem ter como premissa a durabilidade e o adequado comportamento em serviço, quando possível as ligações devem apresentar comportamento dúctil.

Em EL DEBS (2000) maiores informações podem ser obtidas sobre o projeto de estruturas em concreto pré-moldado e ligações. Os temas são abordados de forma abrangente, envolvendo as diversas aplicações deste sistema construtivo.

Em ELLIOTT (1996) é dado ênfase ao estudo de estruturas em concreto pré-moldado de múltiplos pavimentos com sistema estrutural reticulado. Dentre os temas abordados podem ser citados os que envolvem sistemas de pavimento em concreto pré-moldado, elementos compostos, ligações e estabilidade global. Os temas são apresentados com diversos exemplos numéricos.

No PCI (2004) e no PCI (2008) informações complementares podem ser encontradas do projeto de ligações destinadas a estruturas em concreto pré-moldado. No primeiro trabalho o tema é explorado de forma genérica, uma vez que esta publicação engloba todo o projeto de uma estrutura em concreto pré-moldado. O segundo trabalho aborda exclusivamente o projeto de ligações destinadas a estruturas em concreto pré-moldado, inúmeras tipologias de ligações são ilustradas e suas aplicações apresentadas com exemplos numéricos.

Em fib (2008) as ligações são abordadas basicamente quanto às considerações gerais de projeto e aos mecanismos básicos de transferência de força.

Segundo o MC-CEB/90 (1993) os princípios gerais para o projeto de ligações são:

As ligações devem assegurar a rigidez e a estabilidade global da estrutura;

D Devem ser levadas em conta as tolerâncias de fabricação e montagem;

$>$ A análise das ligações se estende às extremidades dos elementos que nelas concorrem;

$>$ Devem ser previstas acomodações da ligação, até a mesma atingir sua capacidade.

Como já mencionado anteriormente as ligações influenciam de maneira significativa no comportamento da estrutura. A principal característica que diferencia uma ligação articulada de uma semi-rígida ou rígida é a capacidade de absorver momento fletor. As ligações viga-pilar semi-rígidas e rígidas têm capacidade de absorver momento fletor, conseqüentemente estruturas dimensionadas com estas ligações deformam e deslocam menos, 
contribuindo para atender as exigências do estado limite de serviço, além de garantir a estabilidade global da estrutura.

De uma forma geral, as ligações com capacidade de transmitir momento fletor exigem maiores trabalhos de execução.

A Figura 2.31 ilustra o diagrama momento versus rotação para uma ligação rígida, semi-rígida e articulada.
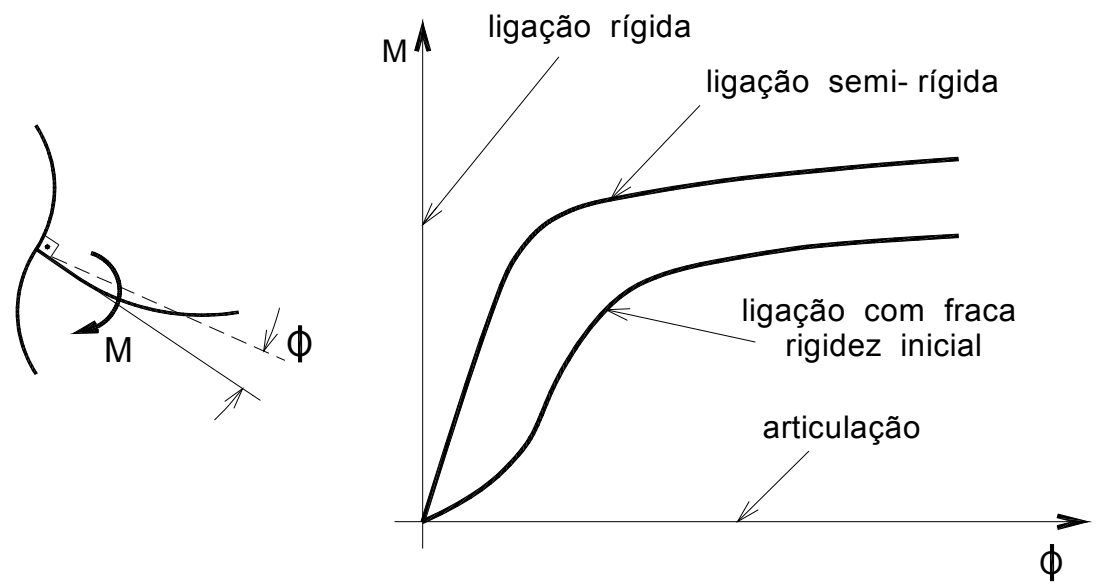

Figura 2.31: Diagrama momento versus rotação [EL DEBS (2000) Modificado]

Para a correta previsão do comportamento da ligação e de sua contribuição na estabilidade da estrutura é necessário caracterizar a ligação quanto à rigidez ou a deformabilidade. Segundo EL DEBS (2000), a deformabilidade de uma ligação é definida como a relação do deslocamento relativo entre os elementos que compõem a ligação com o esforço solicitante na direção desse deslocamento. A rigidez corresponde ao inverso da defomabilidade.

$\mathrm{Na}$ análise da contribuição do efeito da ligação na estabilidade global da edificação é necessário conhecer a rigidez da ligação ao momento positivo e negativo. O método dos componentes tem sido a forma mais utilizada de definir a capacidade resistente das ligações, este método consiste em analisar a contribuição de cada elemento da ligação no mecanismo resistente.

A importância na definição de tolerâncias de fabricação e montagem está relacionada com a construtibilidade, a previsão de variação de esforços na ligação e nos elementos, a aceitação visual do produto e a aceitabilidade condicionada a valores prescritos em normas.

A análise das ligações deve se estender às extremidades dos elementos que nela concorrem, pois o caminho das forças nas regiões próximas a ligação exigem verificações e 
dimensionamentos específicos. Estas regiões são conhecidas pela descontinuidade da estrutura.

As acomodações das ligações muitas vezes retardam a mobilização dos mecanismos resistentes das mesmas. Em ligações com pinos ou parafusos mal ajustados, podem ocorrer deformações antes do acionamento dos mecanismos resistentes da ligação. Em ligações com elastômeros ou argamassas isto também pode ocorrer.

Existem várias tipologias de ligações viga-pilar empregadas em estruturas de concreto pré-moldado. O comportamento das ligações viga-pilar pode variar entre situações de baixa e de alta absorção de momento fletor, neste contexto, a tipologia da ligação assume grande importância. Na Figura 2.32 podem ser observadas tipologias de ligações viga-pilar articuladas. No trabalho de FERREIRA (1999), é apresentado um estudo teórico-experimental de ligação viga-pilar com seção não composta em que o apoio era constituído de almofada de elastômero e a ligação viga-consolo era constituída de chumbadores.

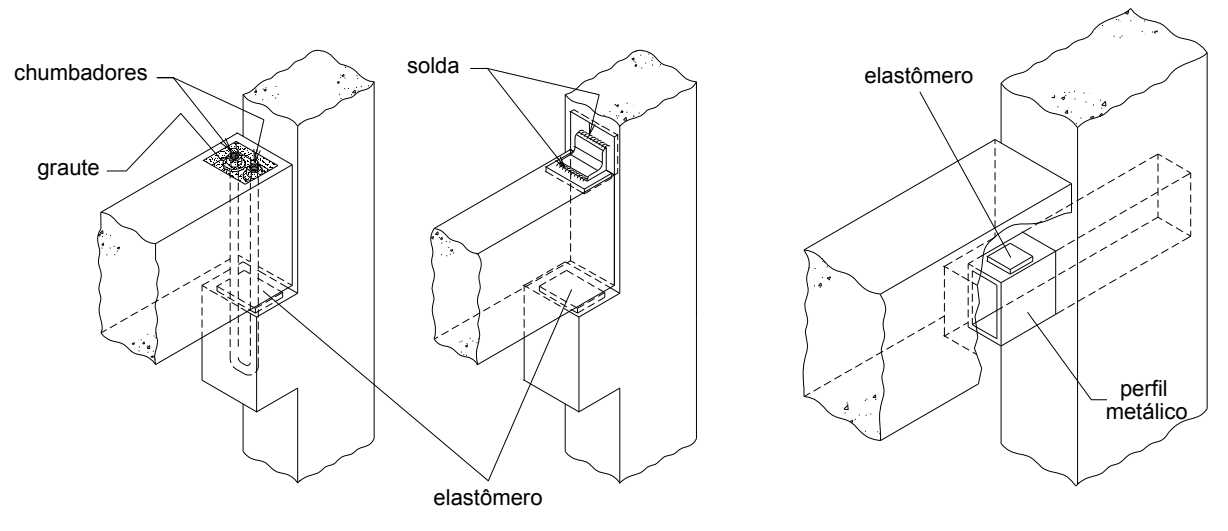

Figura 2.32: Ligações viga-pilar articuladas [EL DEBS (2000)]

Na Figura 2.33 estão ilustradas tipologias de ligações viga-pilar com comportamento semi-rígido.

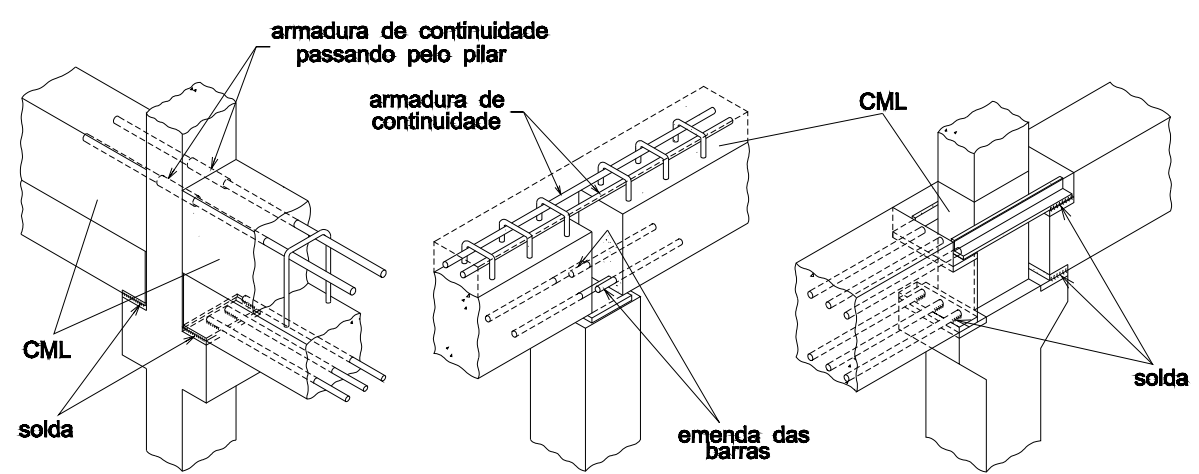

Figura 2.33: Ligações viga-viga sobre pilar com estabelecimento de continuidade para momento fletor [EL DEBS (2000)] 
Na Figura 2.34, na Figura 2.35 e na Figura 2.36 estão ilustradas tipologias de ligações com comportamento rígido ao momento fletor. FERREIRA (1999) apresentou um estudo teórico-experimental para ligação viga-pilar em seção não composta com chapas soldadas na armadura positiva e negativa da viga. $\mathrm{O}$ resultado experimental apresentou uma rigidez à flexão da ordem de $83 \%$ da rigidez da ligação monolítica.
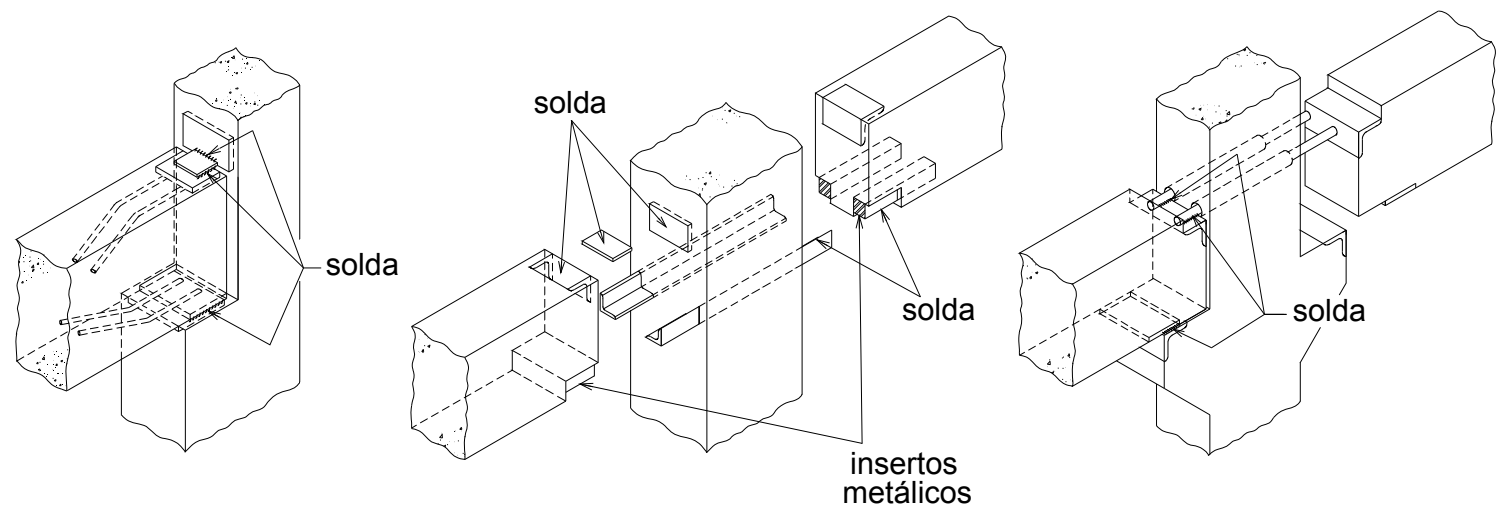

Figura 2.34: Ligações viga-pilar rígidas com solda [EL DEBS (2000)]
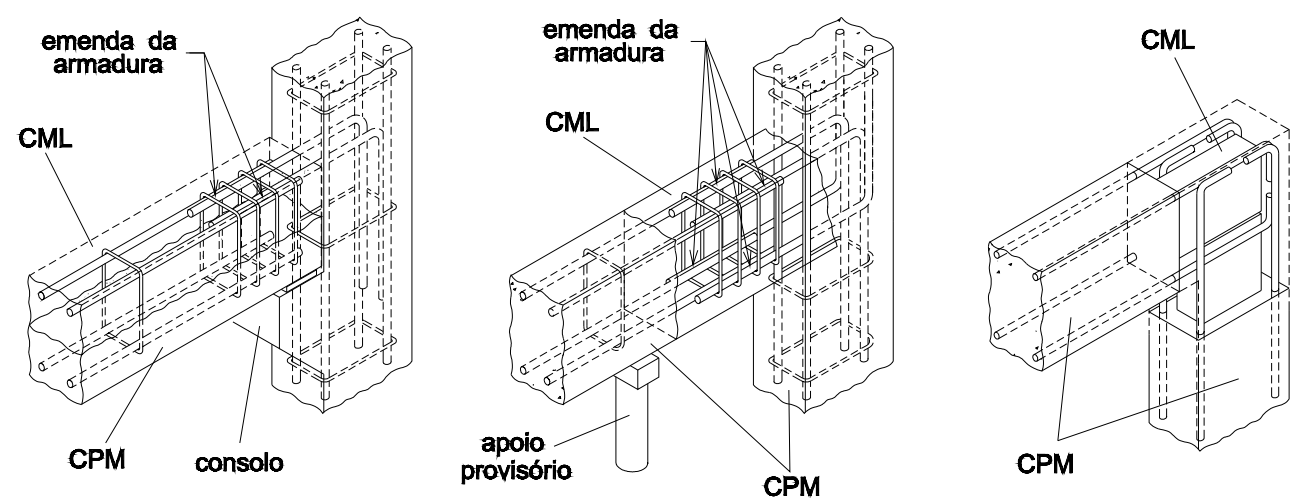

Figura 2.35: Ligações viga-pilar rígidas com emenda da armadura e concreto moldado no local [EL DEBS (2000)] 


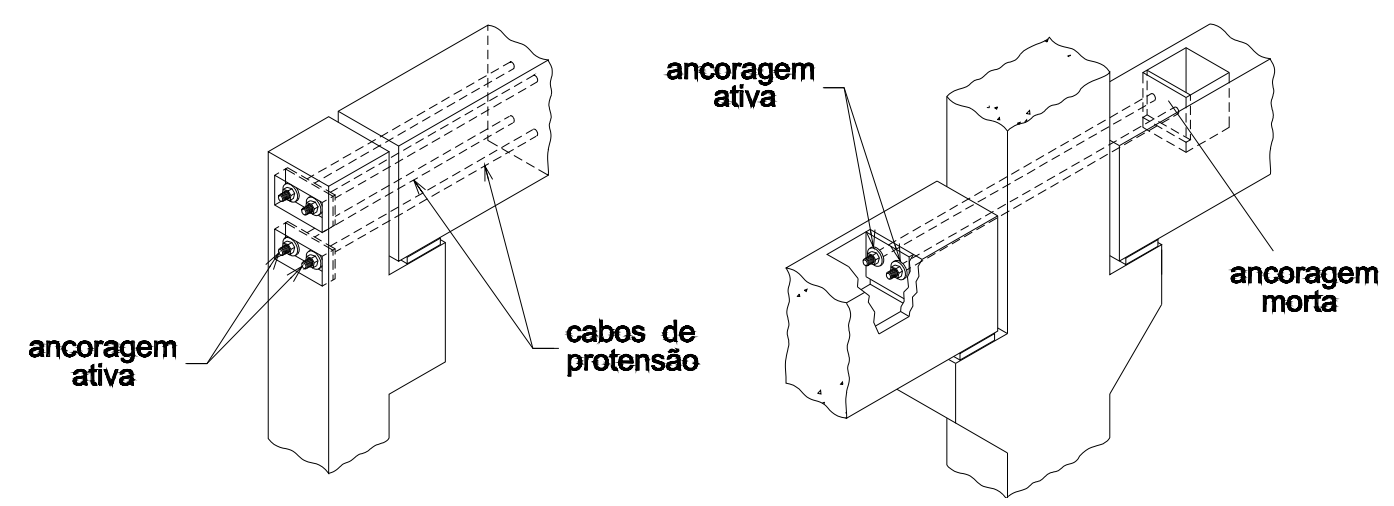

Figura 2.36: Ligações viga-pilar rígidas com cabos de protensão [EL DEBS (2000)]

Como pode ser visto, as tipologias das ligações viga-pilar variam segundo o tipo de interface. $\mathrm{Na}$ interface viga-consolo podem ser citadas as ligações com emprego de chapa soldada, chumbador com ancoragem química e chumbador com ancoragem mecânica.

$\mathrm{Na}$ interface viga-pilar podem ser citadas as ligações com chapas soldadas, com armadura passante nos pilares centrais e barra-luva nos pilares de extremidade. Podem ser observadas tipologias de ligações para seções compostas e não compostas. Além disto, o tipo de apoio pode variar basicamente em aparelho de apoio constituído de almofada em elastômero, chapas de aço ou argamassa. Embora existam tipologias de ligação viga-pilar de comportamento rígido ao momento fletor, no geral as ligações apresentam comportamento intermediário. Vale ressaltar as particularidades de cada ligação, muitas vezes o emprego de ligações soldadas se torna dificultoso pela falta de mão-de-obra qualificada ou pela falta de equipamento em obra.

Além disto, o projeto e execução das ligações soldadas devem prever ductilidade frente à alternância de esforços solicitantes.

\subsubsection{LIGAÇÕES CONCEBIDAS COM COMPORTAMENTO SEMI-RÍGIDO}

As estruturas de múltiplos pavimentos em concreto pré-moldado cujo arranjo estrutural é formado por pórticos, geralmente são concebidas com ligações viga-pilar de comportamento semi-rígido. A especificação de ligações com este comportamento está associada à necessidade de garantir a rigidez e a estabilidade global da estrutura. As ligações de comportamento rígido poderiam cumprir este papel com um desempenho melhor. No entanto, ligações com comportamento rígido geralmente apresentam maiores trabalhos de execução. Além disto, a tipologia de ligação usualmente empregada nas estruturas de concreto 
pré-moldado confere um comportamento semi-rígido. Principalmente devido às características da ligação viga-consolo. A Figura 2.37 ilustra a tipologia da ligação viga-pilar usualmente empregada.

O comportamento das ligações semi-rígidas foi estudado em diversos trabalhos, dentre os quais podem ser citados os trabalhos desenvolvidos na EESC/USP de MIOTTO (2002) e BALDISSERA (2006) e na UFSCar por CATOIA (2007) e KATAOKA (2007).

MIOTTO (2002) avaliou a ligação semi-rígida destinada a edifícios de múltiplos pavimentos em ensaio envolvendo seção composta com ligação viga-pilar com armadura passante nos pilares centrais, conforme ilustra a Figura 2.37. A principal característica desta ligação é a rigidez e a resistência ao momento negativo.

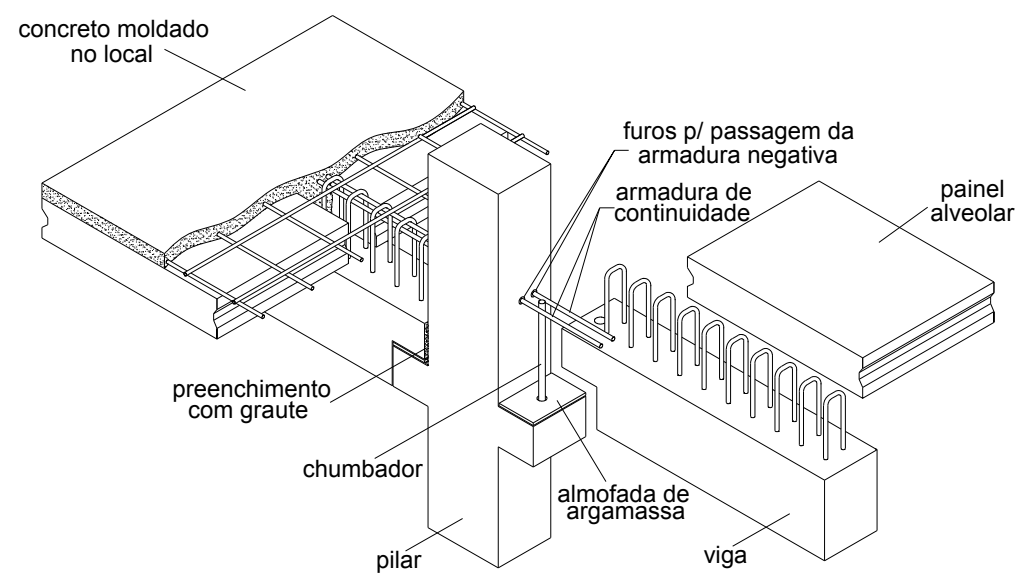

Figura 2.37: Ligação viga-pilar semi-rígida com chumbador [BALDISSERA (2006)]

No que se refere à absorção de momento fletor positivo, o trabalho de BALDISSERA (2006) compara a eficiência de absorção de momento fletor positivo da ligação com chumbador reto e chumbador inclinado, conforme ilustra a Figura 2.38.

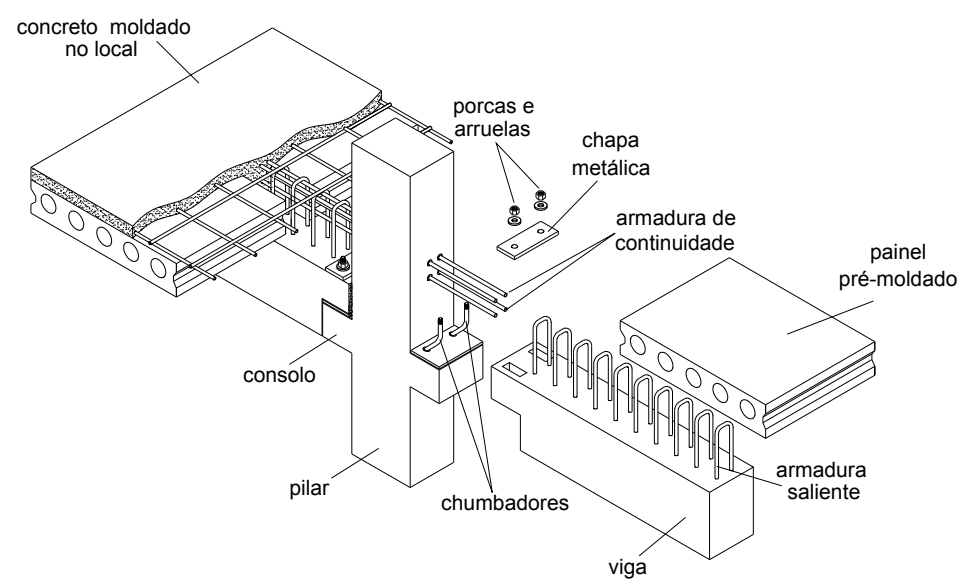

Figura 2.38: Ligação viga-pilar semi-rígida com chumbador inclinado [BALDISSERA (2006)] 
Em EL DEBS \& BALDISSERA (2008) a eficiência da ligação por meio de chumbador reto e inclinado no combate ao momento fletor positivo foi avaliada, como pode ser visto na Tabela 2.5, onde se comparou a rigidez e a resistência à flexão da ligação.

Verificou-se que a ligação com chumbador inclinado apresenta melhor desempenho no combate ao momento fletor positivo, esta característica é importante em edifícios de múltiplos pavimentos, uma vez que os esforços horizontais geram momento positivo na ligação. Em relação à absorção de momento fletor negativo as ligações ensaiadas nos trabalhos citados têm desempenho semelhante.

Tabela 2.5: Comparação de resultados com chumbadores inclinados e retilíneos [EL DEBS \& BALDISSERA (2008)]

\begin{tabular}{|c|c|c|}
\cline { 2 - 3 } \multicolumn{1}{c|}{} & \multicolumn{2}{c|}{ Momento positivo } \\
\cline { 2 - 3 } \multicolumn{1}{c|}{} & Inclinado & Retilíneo \\
\hline Rigidez da ligação K $(\mathrm{MN} . \mathrm{m} / \mathrm{rad})$ & 26,5 & 11,0 \\
\hline Momento fletor último $\mathrm{M}_{\mathrm{y}}(\mathrm{kN} . \mathrm{m})$ & 141,7 & 37,5 \\
\hline
\end{tabular}

No trabalho de CATOIA (2007), foi avaliada a absorção ao momento fletor negativo de uma ligação viga-pilar de extremidade com a armadura negativa sendo ancorada por meio de luvas no pilar, a viga em concreto pré-moldado ensaiada era protendida.

Em KATAOKA (2007) foi investigado a contribuição da armadura de continuidade passante nas laterais do pilar na rigidez e controle de fissuração da ligação viga-pilar. Foram ensaiados dois modelos, no primeiro toda a armadura de continuidade foi especificada de forma passante através do pilar. No segundo modelo, metade da armadura de continuidade foi especificada passante através do pilar e a outra metade foi especificada passante nas laterias do pilar. Os resultados apresentados comprovaram a eficiência da armadura de continuidade passante nas laterais do pilar em comparação com a armadura de continuidade passante através do pilar. Destaca-se que a eficiência da armadura de continuidade passante na lateral do pilar no comportamento da ligação sofre influência do detalhamento da armadura.

\subsubsection{MODELAGEM DE LIGAÇÕES VIGA-PILAR SEMI-RÍGIDAS}

A consideração da ligação em elementos de concreto pré-moldado pode ser feita basicamente de três formas, segundo EL DEBS (2000): 
$>$ Mediante modelagem da região da ligação;

$>$ Mediante a introdução de elementos fíctícios;

$>$ Mediante a incorporação da deformabilidade da ligação nos elementos adjacentes à ligação.

$\mathrm{Na}$ primeira forma, a modelagem é feita de forma bidimensional ou tridimensional com o auxílio de métodos numéricos, como por exemplo, o método dos elementos finitos.

A segunda forma está relacionada com a idealização da ligação segundo a associação de barras reais ou fictícias.

A análise feita na terceira forma consiste em modificar a rigidez dos elementos que concorrem à ligação, isto pode ser feito com o auxílio de matrizes de correção.

No presente trabalho a abordagem é feita pela segunda forma de consideração. A incorporação da ligação no método dos elementos finitos pode ser feita calculando-se a contribuição da ligação, aqui idealizada como uma mola, na energia interna de deformação.

Com o auxílio da Figura 2.39 é possível montar a parcela de energia de deformação interna considerando as parcelas referentes às ligações, conforme expresso em (2.166).

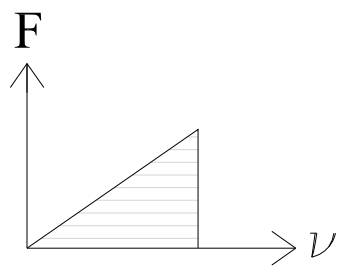

$$
\operatorname{tg}\left(\frac{F}{v}\right)=K_{1}
$$

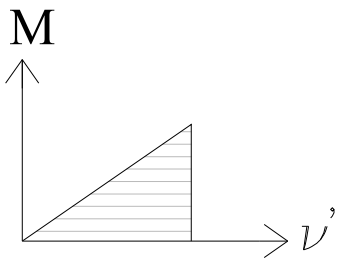

$$
\operatorname{tg}\left(\frac{M}{v^{\prime}}\right)=K_{2}
$$

Figura 2.39: Energia de deformação de uma mola a deslocamento e rotação

$$
U=\frac{1}{2} K_{1}(v)^{2}+\frac{1}{2} K_{2}\left(v^{\prime}\right)^{2}
$$

O comportamento da curva momento x rotação de uma ligação apresenta trajetória não-linear, alguns modelos analíticos tratam a questão tornando-a linear por trechos. Pode ser encontrada na literatura a configuração tri-linear, conforme apresentado em MIOTTO (2002) ou bi-linear, conforme apresentado em EL DEBS et al (2009). Em ambos os trabalhos foi adotado o método dos componentes para caracterizar as ligações. 
Os estágios dos três trechos lineares podem ser interpretados de forma análoga ao comportamento de viga ilustrado na Figura 2.16, ou seja, o primeiro trecho é delimitado pela fissuração, o segundo pela plastificação do concreto ou escoamento da armadura e o terceiro pela ruptura. Na Figura 2.40 está ilustrada a configuração bi-linear apresentada por EL DEBS et al (2009).

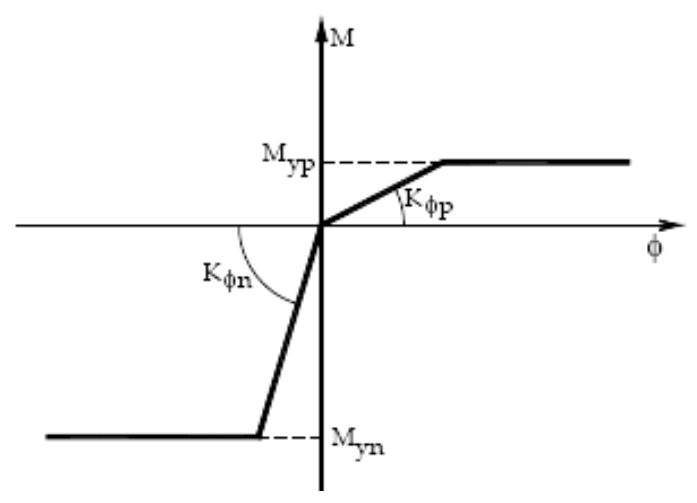

Figura 2.40: Diagrama momento x rotação de ligação com comportamento bi-linear assimétrico. [EL DEBS et al (2009)] 


\section{TIPO ESTRUTURAL ESTUDADO E PROCEDIMENTOS DE PROJETO}

O sistema estrutural responsável pela estabilidade global da estrutura de múltiplos pavimentos em concreto pré-moldado no presente trabalho é formado por pórticos com ligações viga-pilar semi-rígidas e pilares engastados na fundação. Os mecanismos resistentes da ligação são basicamente mobilizados por chumbadores retos e capa de concreto moldada in loco com armadura passante através dos pilares centrais. Nos pilares de extremidade a armadura de continuidade é ancorada em luvas metálicas.

$\mathrm{O}$ arranjo da estrutura é apresentado segundo o sistema construtivo e o processo construtivo em concreto pré-moldado adotado no trabalho. A modelagem estrutural é definida tendo em vista o arranjo da estrutura, as características da estrutura em planta e a estratégia de consideração da não-linearidade física e geométrica do problema.

As ações pertinentes à análise da estabilidade global e as combinações de ações críticas são abordadas tendo em vista as particularidades das estruturas de múltiplos pavimentos em concreto pré-moldado.

É apresentada a formulação analítica para caracterizar a ligação quanto à resistência e rigidez aos momentos fletores positivo e negativo.

Embora seja importante, não é abordada a avaliação de situações transitórias, ou seja, situações de desmoldagem, transporte, armazenamento e montagem. 


\subsection{ARRANJO E MODELAGEM ESTRUTURAL}

A modelagem da estrutura pode ser feita basicamente de três formas, em pórtico plano, em pórtico plano associado ou em pórtico espacial. Na Figura 3.1 está ilustrado um arranjo estrutural em planta e a sua respectiva forma de modelagem na direção y em pórtico plano associado, conforme ilustra a Figura 3.2.

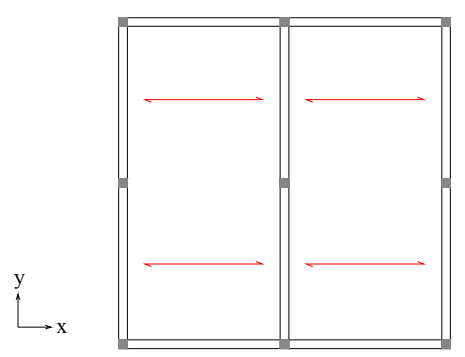

Figura 3.1:Planta de um arranjo estrutural típico

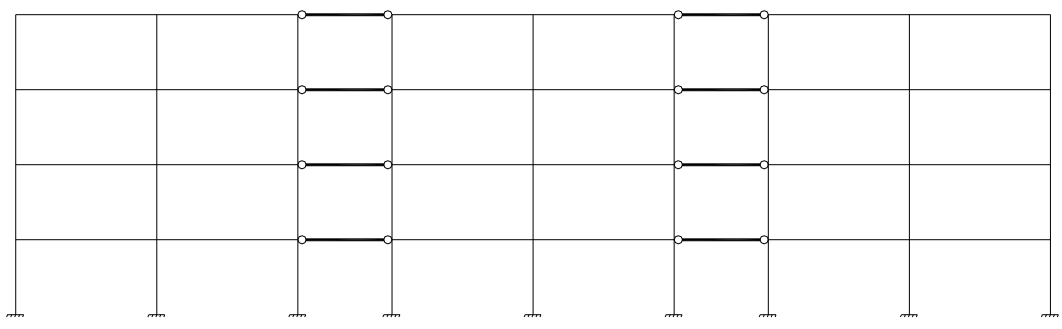

Figura 3.2: Pórtico plano associado segundo a direção Y

Algumas características da estrutura beneficiam a utilização de uma ou outra forma de modelagem. Em estruturas com arranjo simétrico a modelagem em pórtico plano ou associado pode ser bem representativa. Já em estruturas com arranjo assimétrico, a modelagem em pórtico espacial ganha importância. No presente trabalho, em virtude da simetria e do arranjo em planta da estrutura a ser analisada, é adotada a modelagem em pórtico plano.

A Figura 3.3 ilustra a ligação viga-pilar semi-rígida utilizada nos pilares centrais. 


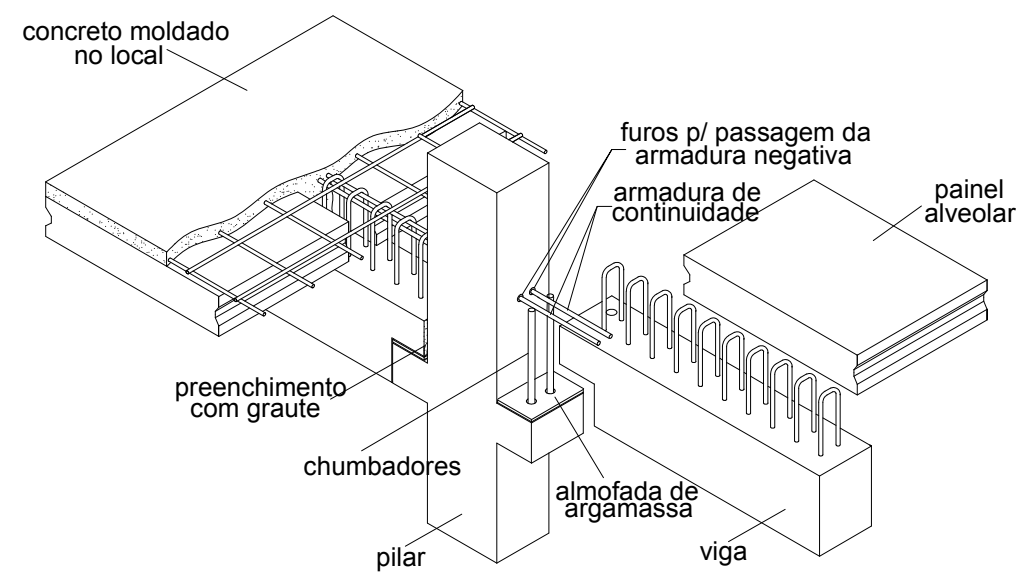

Figura 3.3: Ligação viga-pilar semi-rígida com chumbadores

Nos eixos em que não for constituído pórtico pela combinação pilar-viga a estabilidade deverá ser garantida pela rigidez dos pilares. Os esforços horizontais provenientes da ação do vento são transferidos para os demais componentes pela laje comportando-se como diafragma. No presente trabalho não foram abordados os mecanismos de transferência de forças entre o sistema composto por viga, laje alveolar e capa de concreto moldada in loco.

A ligação pilar-fundação é modelada com comportamento rígido. A Figura 3.4 ilustra uma ligação pilar-fundação típica destinada à estrutura em concreto pré-moldado com colarinho sobre o bloco.

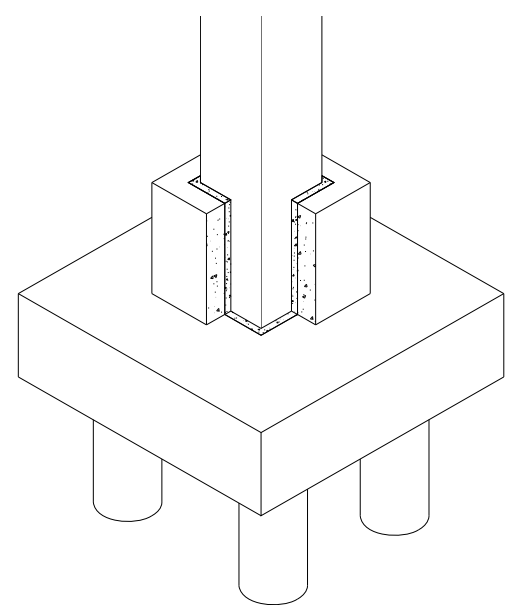

Figura 3.4: Ligação pilar-fundação rígida com colarinho sobre o bloco

Conforme ilustra a Figura 3.3, a seção da viga em concreto pré-moldado é composta pela capa em concreto moldado in loco, geralmente existem três situações de cálculo para a viga em seção composta. 
$\mathrm{Na} 1^{\mathrm{a}}$ situação, onde a seção resistente da viga é representada pela seção em concreto pré-moldado, a única ação sobre a mesma é o peso próprio. Esta situação ganha importância quando a viga é concebida com armadura ativa, deve-se portanto, verificar as tensões atuantes no elemento na situação em vazio.

As situações de cálculo seguem a seqüência de execução e solicitação da viga em seção composta. A $2^{\mathrm{a}}$ situação, caracterizada pela ação do peso próprio da viga, da laje e da capa, possui esquema estrutural isostático para efeito de dimensionamento da viga.

Segundo a seqüência construtiva, a vedação é executada após a capa estrutural da laje atingir a resistência especificada em projeto. Desta forma o esquema estrutural apresentado na $2^{\mathrm{a}}$ situação sofre uma alteração para a ação do peso próprio da capa, de isostático para hiperestático. Com o decorrer do tempo os efeitos reológicos do concreto provocam um aumento da deformação do elemento e, portanto induzem a uma mudança na configuração do diagrama de momento fletor, provocando o aparecimento de momento fletor negativo junto aos apoios causado pelo peso próprio da capa. Neste trabalho não é considerado este efeito, portanto considera-se mantido o esquema estrutural e de carregamento apresentado na Tabela 3.1 para a $2^{\mathrm{a}}$ situação.

Após a capa adquirir resistência, a seção da viga assume uma altura maior e a ligação apresenta comportamento semi-rígido. Sendo assim, a $3^{\text {a }}$ situação de cálculo fica definida, onde a viga é submetida à ação do peso próprio do revestimento do piso e da carga acidental de ocupação. As situações de cálculo da viga estão apresentadas na Tabela 3.1:

Tabela 3.1: Situações de cálculo de uma viga em seção composta

\begin{tabular}{|c|c|c|c|}
\hline SITUAÇÃO & ALTURA DA VIGA & CARREGAMENTO & ESQUEMA \\
\hline $1^{\mathrm{a}}$ & $\mathrm{H}_{\mathrm{v}}$ & $\mathrm{G}_{\mathrm{VIGA}}$ & ISOSTÁTICO \\
\hline $2^{\mathrm{a}}$ & $\mathrm{H}_{\mathrm{v}}$ & $\mathrm{G}_{\mathrm{VIGA}}+\mathrm{G}_{\mathrm{LAJE}}+\mathrm{G}_{\mathrm{CAPA}}$ & ISOSTÁTICO \\
\hline $3^{\mathrm{a}}$ & $\mathrm{H}_{\mathrm{v}}+\Delta \mathrm{H}_{\mathrm{v}}$ & $\mathrm{G}_{\text {REVEST }}+\mathrm{Q}$ & HIPERESTÁTICO \\
\hline
\end{tabular}

$\mathrm{H}_{\mathrm{v}}$ : altura da seção da viga; $\Delta \mathrm{H}_{\mathrm{v}}$ : altura do complemento da seção da viga formada pela soma da altura da laje e da capa moldada in loco; $\mathrm{G}_{\mathrm{VIGA}}$ : peso próprio da viga; $\mathrm{G}_{\mathrm{LAJE}}$ : peso próprio da laje; $\mathrm{G}_{\mathrm{CAPA}}$ : peso próprio da capa; $\mathrm{G}_{\mathrm{REVEST}}$ : peso próprio do revestimento; $\mathrm{Q}$ : carga acidental.

A seção genérica da viga em concreto pré-moldado composta pela capa de concreto moldada in loco pode ser observada na Figura 3.5. 


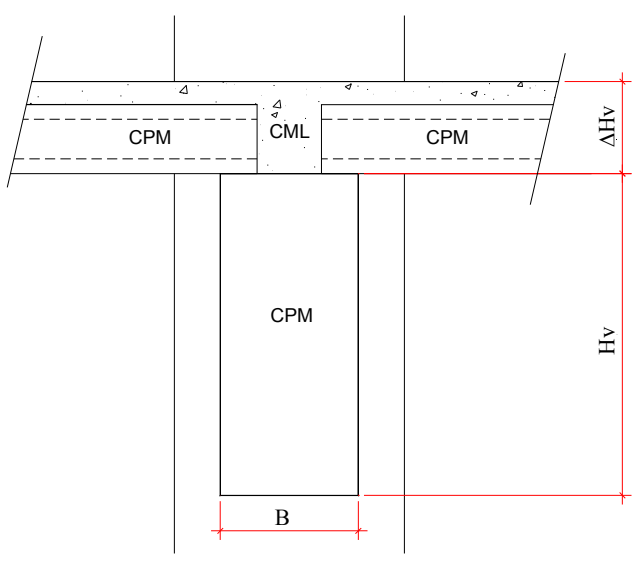

Figura 3.5: Seção transversal genérica de uma viga em concreto pré-moldado composta

As ações atuantes na estrutura são definidas segundo cada combinação de ações, na análise da estabilidade global a ação do vento é tomada como carga acidental em todas as combinações, portanto considera-se que a vedação da estrutura já foi executada.

Uma vez definidas as ações atuantes na estrutura, é feita a caracterização dos elementos de viga e pilar com o auxílio dos diagramas $\mathrm{M}$ x N x 1/r construídos por ferramenta de cálculo desenvolvida pelo autor. Sendo assim, a resistência e a rigidez dos elementos são caracterizadas. Os diagramas $\mathrm{M}$ x N x 1/r descrevem a não-linearidade física dos elementos.

A consideração do efeito reológico do concreto é contemplada na modelagem das vigas por meio de coeficientes lineares de fluência, para efeito de análise da estabilidade global adota-se o coeficiente linear de fluência igual a 2 na construção dos diagramas $\mathrm{M} \mathrm{x} \mathrm{N} \mathrm{x}$ 1/r. A consideração da fluência deve ser avaliada segundo a natureza e a história de carregamento da estrutura. Nas combinações de ações utilizadas na análise da estabilidade global, a ação das cargas de natureza permanente e geralmente parte das cargas de origem acidental atuam na estrutura. Sendo assim, é válida a consideração do efeito reológico do concreto. A ação do vento para efeito de análise da estabilidade global é tomada como ação de curta duração. Este comportamento é ponderado na modelagem dos pilares, onde a fluência não é considerada na construção dos diagramas $\mathrm{M} \times \mathrm{N} \times 1 / \mathrm{r}$. Embora as ações sejam consideradas segundo seus valores de projeto, ou seja, majorados, considera-se a ação da fluência atuando nestes carregamentos por simplificação na análise do problema.

A resistência e a rigidez das ligações viga-pilar são caracterizadas segundo o método dos componentes, definindo-se basicamente o momento de plastificação, a rigidez secante e o momento de ruptura caracterizado pela máxima rotação da ligação. 
A análise da estrutura segue com o auxílio do programa ANSYS, as relações $\mathrm{M} \mathrm{x} \mathrm{N} \mathrm{x}$ 1/r de vigas e pilares e M x rotação das ligações são inseridas como entrada de dados e o processamento da estrutura é realizado.

Todos os valores de momento fletor apresentados para os elementos da estrutura e ligações contemplam a não-linearidade geométrica de forma não-aproximada segundo o programa ANSYS.

Todas as análises numéricas contemplaram a consideração da NLF segundo o diagrama $M \times N \times 1 / r$, inclusive as análises onde foi definido o coeficiente $\gamma_{z}$ e envolveram o processo $\mathrm{P}-\Delta$.

Na Figura 3.6 é ilustrado o esquema de modelagem estrutural e a soma de efeitos das fases construtivas da estrutura no processamento. Primeiramente a estrutura foi modelada considerando a configuração articulada das ligações viga-pilar e a atuação do peso próprio da viga em concreto pré-moldado, da laje em concreto pré-moldado e da capa moldada in loco.

A partir desta situação obteve-se o diagrama de momento fletor da estrutura para esta $1^{a}$ condição. Em uma segunda etapa, a estrutura foi modelada considerando a efetivação das ligações viga-pilar semi-rígidas. Nesta etapa, é considerado o peso próprio da vedação executada após a capa da laje atingir a resistência especificada em projeto. Além disto, é considerado o peso próprio do revestimento executado, da carga acidental de ocupação e da ação do vento. Para efeito de análise não-linear geométrica, o carregamento proveniente da $1^{\text {a }}$ condição é tomado como concentrado nos nós da interface pilar-consolo. Vale ressaltar que os diagramas $\mathrm{M}$ x $\mathrm{N}$ x 1/r utilizados na modelagem da estrutura contemplaram o carregamento da estrutura na combinação de ação utilizada. O esquema de modelagem ilustrado na Figura 3.6 tem por objetivo apresentar uma forma de se obter a soma dos esforços de momento fletor para as situações em que a ligação apresenta comportamento articulado e semi-rígido. 
Estrutura com ligação viga-pilar articulada

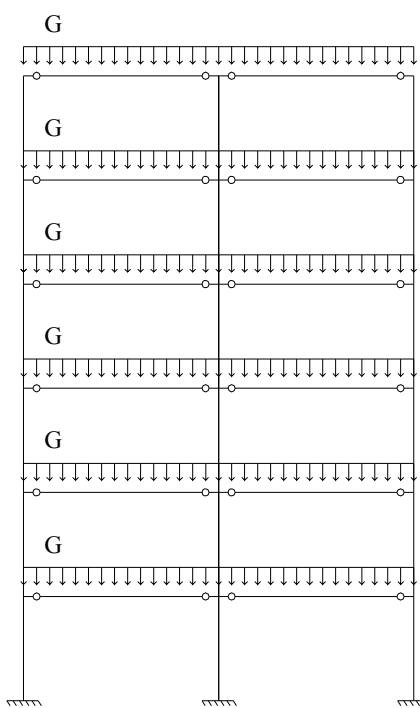

Estrutura com ligação viga-pilar semi-rígida

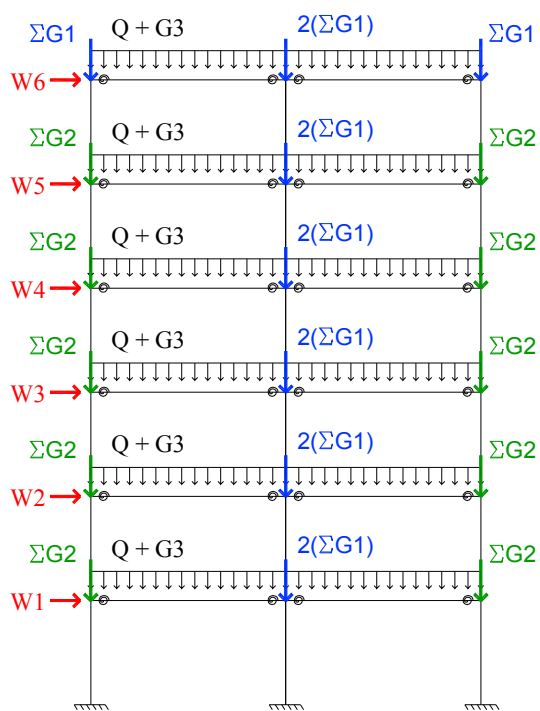

G: Corresponde ao peso próprio da laje, da viga em concreto pré-moldado e da capa moldada in loco por metro linear

Q: Corresponde à carga acidental de ocupação por metro linear

$\Sigma$ G1: Corresponde a somatória no trecho de influência do peso próprio da laje, da viga em concreto pré-moldado e da capa moldada in loco

$\Sigma \mathrm{G} 2$ : Corresponde à somatória no trecho de influência do peso próprio da laje, da viga em concreto prémoldado, da capa moldada in loco e do peso próprio da vedação

G3: Corresponde ao peso próprio do revestimento do piso

$\mathrm{W}$ : Corresponde à ação do vento por pavimento

Figura 3.6: Esquema de modelagem estrutural e soma de efeitos para fases construtivas no processamento

\subsection{AÇÕES}

As ações atuantes na estrutura podem ser divididas basicamente em ações permanentes e ações acidentais. No grupo pertencente às ações permanentes se encontram o peso próprio de vigas pré-moldadas, lajes pré-moldadas, capa moldada in loco e alvenaria de vedação. Já no grupo pertencente às ações acidentais se encontram a carga de ocupação da estrutura e a ação do vento. Nos próximos parágrafos, é dada atenção especial à ação do vento.

A determinação da ação do vento foi feita segundo as prescrições da NBR 6123:1988, para todos os exemplos numéricos considera-se a ação do vento com velocidade básica de $V_{0}=45 \mathrm{~m} / \mathrm{s}$, fator topográfico $S_{1}=1$ e fator estatístico $S_{3}=1$.

O fator $S_{2}$ depende da rugosidade do terreno, das dimensões da edificação em planta e em altura. Em relação às dimensões da edificação, segundo o item 5.3.2 da NBR 6123:1988 
se enquadram na Classe B toda edificação ou parte da edificação para a qual a maior dimensão horizontal ou vertical da superfície frontal esteja entre $20 \mathrm{~m}$ e $50 \mathrm{~m}$.

Os arranjos estruturais a serem estudados se enquadram nesta classe. A rugosidade do terreno foi considerada em todos os arranjos segundo a categoria IV, aplicável a terrenos cobertos por obstáculos numerosos e pouco espaçados, em zona florestal, industrial ou urbanizados.

A altura sobre o nível do terreno da edificação, bem como a classe e categoria da edificação são contempladas na tabela 2 da NBR 6123:1988 para determinação do fator $S_{2}$.

A velocidade característica fica determinada pela seguinte expressão:

$$
V_{k}=V_{0} S_{1} S_{2} S_{3}
$$

Uma vez determinada a velocidade característica determina-se a pressão dinâmica:

$$
q=0,613 \cdot V_{k}^{2}
$$

Desta forma obtém-se a força de arrasto:

$$
F_{a}=C_{a} q A_{e}
$$

Onde:

$C_{a}$ é o coeficiente de arrasto;

$A_{e}$ é a área frontal efetiva.

\subsection{COMBINAÇÕES DE AÇÕES}

Segundo a NBR 6118:2003 a combinação última (ELU) é descrita pela seguinte expressão:

$$
F_{d}=\gamma_{g} F_{g k}+\gamma_{g g} F_{g g k}+\gamma_{q}\left(F_{q 1 k}+\sum \psi_{0 j} F_{q j k}\right)+\gamma_{a q} \psi_{0 s} F_{a q k}
$$


Onde:

$F_{d}$ é o valor de cálculo das ações para combinação última;

$F_{g k}$ representa as ações permanentes diretas;

$F_{g k}$ representa as ações indiretas permanentes como a retração $F_{g g k}$ e variáveis como a temperatura $F_{\varepsilon q k}$;

$F_{q k}$ representa as ações variáveis diretas das quais $F_{q 1 k}$ é escolhida principal;

$\gamma_{g}$ representa o coeficiente de ponderação para as ações permanentes;

$\gamma_{q}$ representa o coeficiente de ponderação para as ações variáveis diretas;

$\gamma_{g g}$ representa o coeficiente de ponderação para as ações indiretas permanentes;

$\gamma_{\varepsilon q}$ representa o coeficiente de ponderação para as ações indiretas variáveis;

$\psi_{0 j}$ representa o fator de redução de combinação para as ações variáveis diretas;

$\psi_{0 \varepsilon}$ representa o fator de redução de combinação para as ações variáveis indiretas.

Nos exemplos numéricos foram consideradas três combinações para o ELU, na primeira combinação a ação do vento é considerada como carga acidental principal e a carga acidental de ocupação como secundária, esta combinação tem importância para a verificação da estabilidade global da estrutura como um todo. A segunda combinação não contempla a contribuição da carga acidental de ocupação, e a sua verificação é de suma importância devido ao momento positivo provocado pela ação do vento nas ligações. Na terceira combinação de ações a carga acidental de ocupação é considerada como principal e a carga acidental proveniente da ação do vento é considerada secundária. Não foram consideradas as ações indiretas permanentes e variáveis.

Segundo a NBR 8681:2003 o coeficiente $\gamma_{g}$, pode assumir diferentes valores segundo o tipo de material considerado e do processo construtivo utilizado. Processos construtivos mais controlados admitem coeficientes de ponderação menores. A Tabela 3.2 apresenta o valor prescrito para o coeficiente $\gamma_{g}$ para situações usuais em edifícios de múltiplos pavimentos em concreto pré-moldado. 
Tabela 3.2: Ações permanentes diretas consideradas separadamente (NBR 8681:2003)

\begin{tabular}{|c|c|}
\hline Tipo de ação & Efeito desfavorável \\
\hline Peso próprio de estruturas pré-moldadas & 1,3 \\
\hline Peso próprio de estruturas moldadas no local & 1,35 \\
\hline Elementos construtivos industrializados & 1,35 \\
\hline Elementos construtivos industrializados com adições in loco & 1,4 \\
\hline
\end{tabular}

A consideração do peso próprio de estruturas pré-moldadas nos exemplos numéricos refere-se aos pilares, vigas e lajes alveolares ponderados pelo coeficiente 1,3. As vedações em alvenaria, revestimentos e o peso próprio da capa que compõe a laje alveolar são ponderados por simplificação por coeficiente igual a 1,4.

Por se tratar de estruturas de múltiplos pavimentos em concreto pré-moldado de no mínimo 4 pavimentos, o efeito do desaprumo não é considerado, a NBR 6118:2003 permite que seja considerado na combinação de ações a situação mais crítica entre a causada pela ação do vento ou pelo efeito do desaprumo.

As cargas acidentais atuantes nos exemplos numéricos terão como referência de atuação locais em que há elevada concentração de pessoas. Após todas as ponderações feitas nos parágrafos anteriores obtêm-se três expressões de combinações de ações para o estado limite último conforme segue:

$$
\begin{aligned}
& F_{d, 1}=\gamma_{g} \cdot G+1,4(W+0,7 \cdot Q) \\
& F_{d, 2}=\gamma_{g} \cdot G+1,4 \cdot W \\
& F_{d, 3}=\gamma_{g} \cdot G+1,4(0,6 \cdot W+Q)
\end{aligned}
$$

Onde:

$G$ representa as ações permanentes diretas;

$Q$ representa a carga acidental de ocupação;

$W$ representa a ação do vento.

Segundo a NBR 9062:2006 a combinação de ações para verificação do estado limite de serviço (ELS) em estruturas de concreto pré-moldado é a freqüente (CF), a expressão para a combinação freqüente está descrita na NBR 6118:2003 como:

$$
F_{d, s e r}=\sum F_{g i k}+\psi_{1} F_{q 1 k}+\sum \psi_{2 j} F_{q j k}
$$


Onde:

$$
\begin{aligned}
& F_{d, \text { ser }} \text { é o valor de cálculo das ações para combinações de serviço; } \\
& \psi_{1} \text { é o fator de redução de combinação freqüente para ELS; } \\
& \psi_{2} \text { é o fator de redução de combinação quase permanente para ELS. }
\end{aligned}
$$

A combinação de ação para ELS foi considerada conforme a expressão (3.9), onde a ação do vento foi tomada como principal:

$$
F_{d, s e r}=G+0,3 \cdot W+0,4 \cdot Q
$$

\subsection{CARACTERIZAÇÃO DA LIGAÇÃO EMPREGADA}

No presente trabalho as ligações são modeladas segundo o comportamento linear e bilinear. No modelo linear defini-se apenas a rigidez secante ao momento positivo e negativo da ligação, não sendo delimitado o momento de plastificação e o trecho correspondente a plastificação. O modelo bi-linear é ilustrado na Figura 3.7.

A formulação analítica adotada é a apresentada no trabalho de EL DEBS et al (2009), esta formulação refere-se a ligações semi-rígidas destinadas a seções compostas, com ligação viga-pilar com armadura passante nos pilares centrais ou barra-luva nos pilares de extremidade. A ligação viga-consolo é formada por chumbadores, o apoio é constituído de almofada de argamassa.

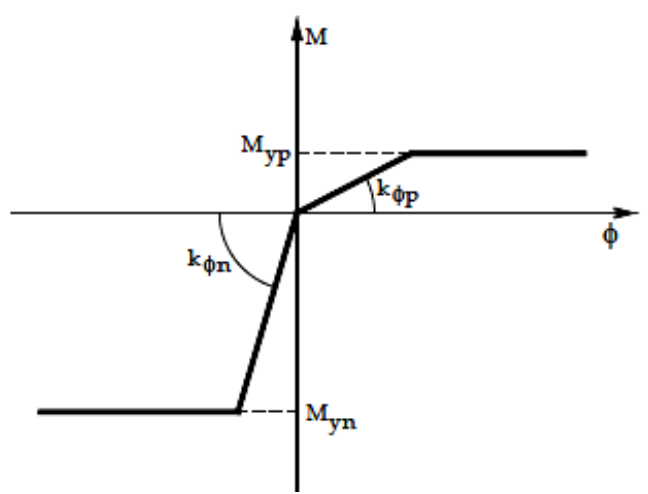

Figura 3.7: Diagrama momento x rotação de ligação com comportamento bi-linear assimétrico. [EL DEBS et al (2009)] 


\subsubsection{MODELO ANALÍTICO PARA MOMENTO NEGATIVO}

A rigidez e o momento de plastificação da ligação podem ser determinados com auxílio da Figura 3.8. Na região entre a viga e o pilar, preenchida por graute e para o aparelho de apoio foi admitida distribuição linear de tensões de compressão. A contribuição do chumbador foi negligenciada.

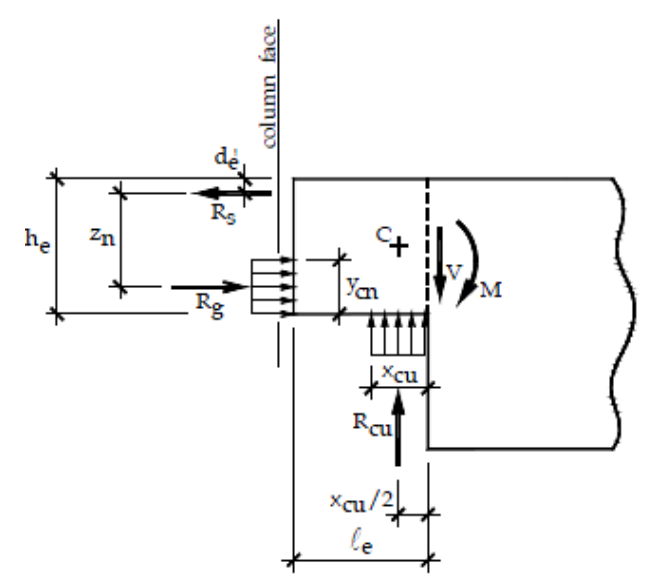

Figura 3.8: Mecanismo resistente ao momento fletor negativo [EL DEBS et al (2009)]

O sistema de forças horizontais e verticais, além do momento foi equacionado em relação ao ponto $\mathrm{C}$, onde a resultante das forças no aparelho de apoio está posicionada.

A seguir apresenta-se o equacionamento para determinação da contribuição de cada componente da ligação, bem como a capacidade resistente da ligação como um todo no combate ao momento fletor negativo.

O equilíbrio do sistema de forças resultantes dos componentes da ligação na direção horizontal esta expresso em (3.10):

$$
R_{s}=R_{g}
$$

Sendo:

$$
\begin{aligned}
& R_{s}=A_{s} f_{y d} \\
& R_{g}=y_{c n} f_{c g d} b_{w}
\end{aligned}
$$

O momento fletor negativo resistente de projeto é expresso em (3.13), segundo a contribuição da resultante da força de tração na armadura de continuidade: 


$$
M_{y n}=A_{s} f_{y d} z_{n}
$$

Em que:

$$
\begin{aligned}
& z_{n}=h_{e}-d_{e}{ }^{\prime}-\frac{y_{c n}}{2} \\
& y_{c n}=\frac{A_{s} f_{y d}}{f_{c g d} b_{w}}
\end{aligned}
$$

Onde:

$R_{s}$ resultante da força de tração na armadura de continuidade;

$R_{g}$ resultante da força de compressão na interface inferior da extremidade da viga junto ao pilar;

$A_{s}$ área de seção transversal da armadura de continuidade;

$f_{y d}$ tensão de escoamento de projeto da armadura de continuidade;

$b_{w}$ largura da extremidade da viga;

$f_{c g d}$ tensão de compressão de projeto do graute;

$y_{c n}$ dimensão da região sob tensão de compressão na interface inferior da extremidade da viga junto ao pilar;

$M_{y n}$ momento fletor negativo resistente de projeto;

$z_{n}$ braço de alavanca;

$h_{e}$ altura da extremidade da viga;

$d_{e}{ }^{\prime}$ distância do centro de gravidade da armadura de continuidade à face superior da viga;

$x_{c u}$ dimensão da região comprimida junto ao aparelho de apoio.

Segundo EL DEBS et al (2009), a dimensão da região comprimida junto ao aparelho de apoio varia com a rigidez do aparelho. Se o aparelho de apoio é muito deformável, a dimensão da região comprimida tende ao final da extremidade da viga. Se a distribuição de tensões adotada for triangular, o valor de $x_{c u}$ é de $2 l_{e} / 3$. 
Em relação à deformação do sistema, a Figura 3.9 ilustra a posição deformada da extremidade da viga. Os componentes deformáveis da ligação são:

A região submetida a tensões de tração junto à face superior da extremidade da viga, caracterizada pela rigidez da armadura $k_{s}$;

A região submetida a tensões de compressão junto a face inferior da extremidade da viga, caracterizada pela rigidez do graute $k_{g}$;

A região submetida a tensões de compressão junto ao aparelho de apoio, caracterizada pela rigidez do aparelho de apoio $k_{c u}$.

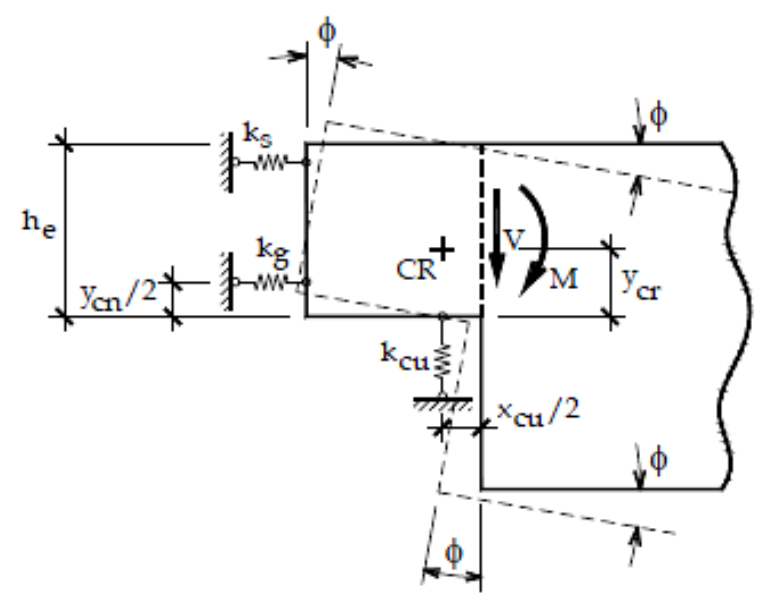

Figura 3.9: Posição deformada da extremidade da viga e suas componentes deformáveis ao momento negativo [EL DEBS et al (2009)]

Considera-se que o giro da extremidade da viga ocorre em relação ao ponto $\mathrm{CR}$, centro de rotação da extremidade da viga. $\mathrm{O}$ ponto $\mathrm{CR}$ coincide com o ponto $\mathrm{C}$.

A distância da face inferior da extremidade da viga ao centro de rotação, $y_{c r}$, é assim expressa, de acordo com o equilíbrio de momentos produzidos pelas forças atuantes nas molas em relação ao ponto $\mathrm{CR}$ :

$$
y_{c r}=\frac{k_{s}\left(h_{e}-d_{e}{ }^{\prime}\right)+k_{g}\left(y_{c n} / 2\right)}{k_{s}+k_{g}}
$$

A rigidez da armadura de continuidade é expressa em (3.17): 


$$
k_{s}=\frac{\sigma_{s} A_{s}}{w_{y}}
$$

Onde:

$w_{y}$ é a abertura da suposta fissura junto à face superior da extremidade da viga.

Este valor pode ser estimado de acordo com a expressão (3.18), onde o primeiro termo é indicado em fib (1999) e o segundo termo é indicado por ENGSTROM (1992b):

$$
w_{y}=2 \cdot\left[\frac{\left(1+\alpha_{w}\right) s_{1}^{\alpha_{w}} \phi}{8\left(1+\alpha_{e} \rho_{s, e f}\right)} \cdot \frac{\sigma_{s}^{2}}{\tau_{\max } E_{s}}\right]^{\frac{1}{1+\alpha_{w}}}+\frac{4 \phi f_{y d}}{E_{s}}
$$

Sendo:

$$
\begin{aligned}
& \alpha_{e}=\frac{E_{s}}{E_{c, t o p}} \\
& \tau_{\text {max }}=2,5 \sqrt{f_{c d, t o p}} \\
& \rho_{s, e f}=\frac{A_{s}}{A_{c, e f}}
\end{aligned}
$$

Onde:

$A_{s}$ área da seção transversal da armadura de continuidade;

$A_{c, e f}$ área de concreto que envolve a armadura de continuidade;

$\sigma_{s}$ tensão na armadura de continuidade;

$\phi$ diâmetro da armadura de continuidade [mm];

$E_{s}$ módulo de elasticidade do aço;

$E_{c, t o p}$ módulo de elasticidade do concreto da capa;

$f_{c d, \text { top }}$ resistência à compressão de projeto do concreto da capa;

$\alpha_{w}=0,4$

$s_{1}=1$. 
A rigidez da armadura é definida pelo ponto de escoamento, portanto a tensão $\sigma_{s}$ corresponde à tensão de escoamento do aço.

A rigidez correspondente à região comprimida junto à face inferior da extremidade da viga é expressa em (3.22):

$$
k_{g}=\frac{y_{c n} b_{w}}{D_{g j}}
$$

Onde:

$D_{g j}$ representa a deformabilidade do graute em termos de tensão.

Os valores de deformabilidade do graute podem ser encontrados em BLJUGER (1988) e BARBOZA (2002).

A rigidez da ligação ao momento fletor negativo em relação ao ponto CR pode ser calculada pela seguinte expressão:

$$
k_{\phi n}=\left[k_{s}\left(h_{e}-y_{c r}-d_{e}^{\prime}\right)^{2}+k_{g}\left(y_{c r}-y_{c n} / 2\right)^{2}\right]
$$

\subsubsection{MODELO ANALÍTICO PARA MOMENTO POSITIVO}

A determinação do momento fletor positivo resistente pode ser determinado com auxílio da Figura 3.10. A distribuição de tensões na interface superior da extremidade da viga junto ao pilar é admitida retangular. A contribuição do aparelho de apoio no combate ao momento solicitante é negligenciada.

O sistema de forças horizontais e verticais, além do momento foi equacionado em relação ao ponto $\mathrm{C}$, correspondente à posição do chumbador. 


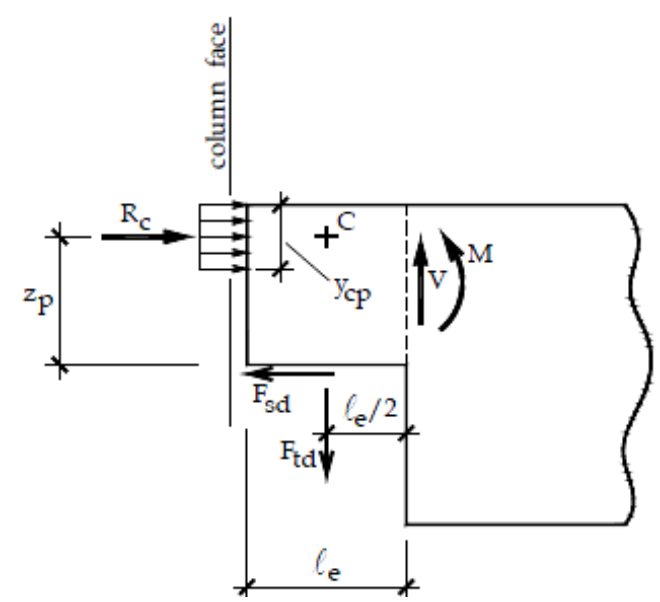

Figura 3.10: Mecanismo resistente ao momento fletor positivo [EL DEBS et al (2009)]

O momento fletor positivo resistente de projeto é determinado pela expressão (3.24):

$$
M_{y p}=F_{s d} z_{p}
$$

Sendo:

$$
\begin{aligned}
& z_{p}=h_{e}-\frac{y_{c p}}{2} \\
& F_{s d}=2 c \phi_{d}^{2} \sqrt{f_{y d} f_{c c d, \max }} \\
& y_{c p}=\frac{F_{s d}}{b_{f} f_{c d, t o p}}
\end{aligned}
$$

Onde:

$y_{c p}$ dimensão da região sob tensão de compressão na interface superior da extremidade da viga junto ao pilar;

$C=1,245$ coeficiente que pode ser encontrado em ENGSTROM (1992a);

$\phi_{d}$ diâmetro do chumbador;

$f_{y d}$ tensão de escoamento do chumbador;

$f_{c c d, \max }$ o maior valor de resistência à compressão de projeto do graute ou concreto em contato com o chumbador;

$b_{f}$ é a largura da mesa colaborante da viga; 
$F_{s d}$ força de projeto responsável pela formação de rótula plástica nos chumbadores;

$F_{t d}$ força de projeto de tração atuante nos chumbadores.

Em relação à deformação do sistema, a Figura 3.11 ilustra a posição deformada da extremidade da viga. Os componentes deformáveis da ligação são:

A região submetida a tensões de compressão junto à face superior da extremidade da viga, caracterizada pela rigidez do concreto à compressão $k_{c}$;

A região submetida a tensões de tração no chumbador, caracterizada pela rigidez a tração do chumbador $k_{t d}$;

A região submetida a tensões de cisalhamento no chumbador, caracterizada pela rigidez ao cisalhamento do chumbador $k_{s d}$.

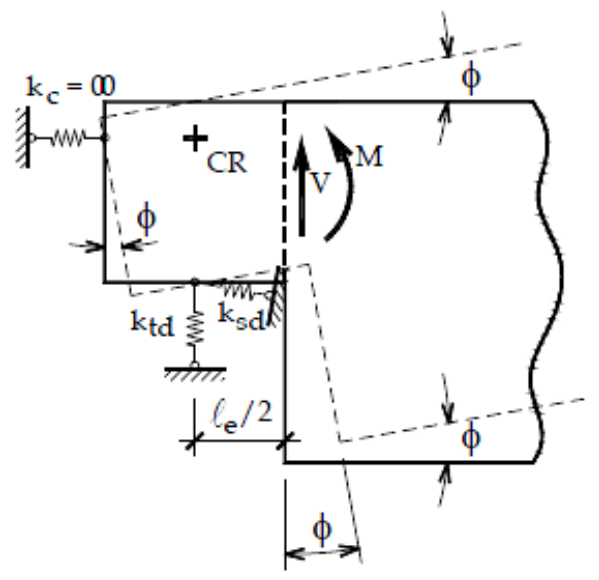

Figura 3.11: Posição deformada da extremidade da viga e suas componentes deformáveis ao momento positivo [EL DEB et al (2009)]

A rigidez $k_{c}$ tende ao infinito, o centro de rotação $(\mathrm{CR})$ alinha-se com a região submetida a tensões de compressão no concreto. Neste caso também o ponto CR coincide com o ponto $\mathrm{C}$ usado para calcular o momento positivo de plastificação.

A rigidez da ligação ao momento fletor positivo em relação ao ponto $\mathrm{CR}$ pode ser calculada pela seguinte expressão: 


$$
k_{\phi p}=k_{s d}\left(h_{e}-\frac{y_{c p}}{2}\right)^{2}
$$

Sendo:

$$
k_{s d}=\frac{F_{s d}}{a_{v y}}
$$

Onde:

$$
a_{v y} \text { é o deslocamento transversal do chumbador quando submetido ao máximo }
$$
esforço.

Maiores informações sobre como proceder o cálculo do deslocamento transversal do chumbador podem ser encontradas em ENGSTROM (1992a). O deslocamento pôde ser obtido do MC-CEB/90 (1993), que indica o valor de $0,10 \phi_{d}$.

Em relação à verificação da formulação apresentada, ensaios feitos por MIOTTO (2002) comprovam a validade das expressões com certa representatividade. A Figura 3.12 ilustra os resultados experimentais versus resultados teóricos obtidos para a relação momento $\mathrm{x}$ rotação em modelos submetidos a momento positivo e negativo.

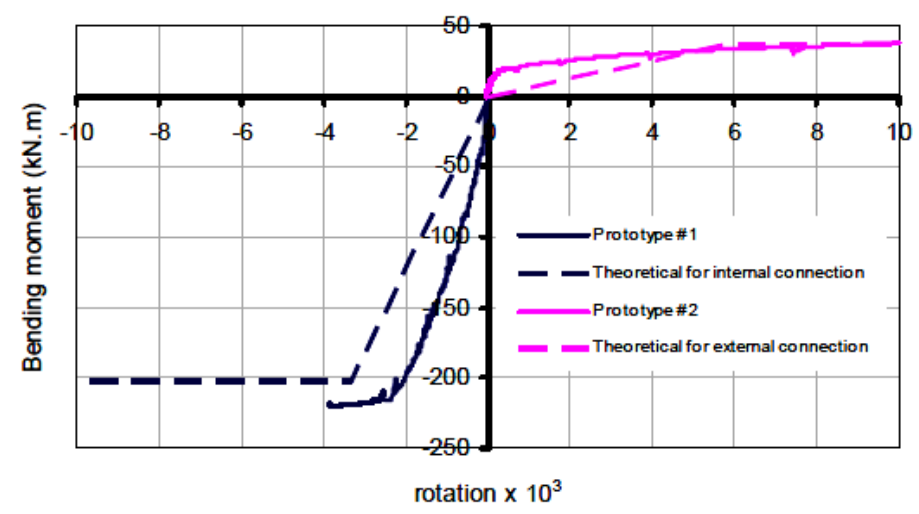

Figura 3.12: Momento x rotação da ligação segundo resultados teóricos e experimentais [EL DEB et al (2009)]

Nota-se que os valores de momento de plastificação teóricos e experimentais se assemelham com boa aproximação. No entanto, a rigidez obtida pela análise teórica é menor 
em relação à análise experimental, tanto para o momento positivo como para o momento negativo.

A imprecisão na avaliação da rigidez para o momento fletor negativo provém da dificuldade de avaliação da abertura de fissuras e da deformabilidade do graute na junta vigapilar. No caso da rigidez ao momento fletor positivo a dificuldade consiste em avaliar o deslocamento do chumbador submetido à carga máxima.

Em relação ao tipo de apoio, quanto maior a deformabilidade do aparelho de apoio maior é a deformabilidade da ligação, portanto não é interessante fazer uso de uma almofada de elastômero. Com o intuito de incrementar a rigidez da ligação a rotação, sugere-se a adoção de almofada de argamassa ou chapa de aço. 


\section{ANÁLISE NUMÉRICA}

Primeiramente é analisada em um estudo de caso completo a estabilidade global de um edifício de 6 pavimentos com modulação de 7,5m, avaliando-se formas de consideração da não-linearidade física e geométrica. A utilização de armadura passiva e ativa nos elementos de viga, a consideração de ligação com comportamento semi-rígido na fundação e o efeito reológico do concreto são apresentados. A distribuição de esforços e a estabilidade global da estrutura é avaliada segundo diferentes combinações de ações, além disto, é considerado o impacto da adoção do modelo elasto-plástico na modelagem das ligações vigapilar semi-rígidas.

Coeficientes e funções redutores de rigidez são apresentados a partir dos diagramas $M$ x N x 1/r obtidos para as seções dos elementos definidas na modelagem da estrutura.

Em uma segunda etapa são avaliadas estruturas com 6,5 e 4 pavimentos com modulações de 7,5m e $10 \mathrm{~m}$. As cargas acidentais avaliadas são de 3 e $5 \mathrm{kN} / \mathrm{m}^{2}$.

$\mathrm{Na}$ Tabela 4.1 são apresentadas as variáveis de geometria e carregamento analisadas na simulação numérica.

Tabela 4.1: Variáveis analisadas

\begin{tabular}{|c|c|c|c|}
\hline $\mathrm{N}^{\mathrm{o}}$ Pavimentos & 4 & 5 & 6 \\
\hline Modulação $(\mathrm{m})$ & 7,5 & 10,0 \\
\hline Carga acidental $\left(\mathrm{kN} / \mathrm{m}^{2}\right)$ & 3 & \multicolumn{2}{|c|}{5} \\
\hline
\end{tabular}

Os coeficientes redutores de rigidez são definidos para cada modelo e os valores encontrados para o momento positivo e para o momento negativo atuante nas ligações são comparados com os valores resistentes. 


\subsection{GENERALIDADES}

A avaliação das formas simplificadas de análise da não-linearidade geométrica foi feita com auxílio do programa ANSYS versão 10.0. Após a definição dos diagramas $\mathrm{M} \mathrm{x} \mathrm{N} \mathrm{x}$ $1 / \mathrm{r}$ dos elementos, descrevendo a não-linearidade física, foram pesquisados elementos finitos na biblioteca do ANSYS que permitissem que a relação constitutiva fosse representada segundo a relação momento $\mathrm{x}$ curvatura. Dois elementos finitos de viga permitem esta consideração, o BEAM188 e o BEAM189. O BEAM188 tem sua deformação regida por uma função linear, já o BEAM189 tem sua deformação regida por uma função quadrática. Foi constatada uma limitação do elemento BEAM188 e BEAM189 para representação da curva momento x curvatura. O recurso do programa ANSYS só permite a representação de diagramas momento $\mathrm{x}$ curvatura de comportamento simétrico, desta forma para a representação de vigas onde geralmente o comportamento é assimétrico foi necessário processar a estrutura para posteriormente definir a rigidez segundo o diagrama de momento fletor.

Avaliando o desempenho dos elementos finitos segundo diferentes discretizações, foram modeladas três estruturas em pórtico plano de 4 pavimentos com as mesmas características geométricas, de rigidez e de carregamento e comparados os valores de momento obtidos com o elemento finito de referência BEAM3 cuja função aproximadora é uma função polinomial de terceiro grau. Para tanto foi utilizada a discretização apresentada na Tabela 4.2 segundo o tipo de elemento finito e elemento estrutural.

Tabela 4.2: Discretização e esforços obtidos segundo tipo de elemento finito

\begin{tabular}{|c|c|c|c|c|}
\cline { 2 - 5 } \multicolumn{1}{c|}{} & \multicolumn{2}{c|}{ DISCRETIZAÇÃO } & \multicolumn{2}{c|}{ ESFORÇOS OBTIDOS (kN.m) } \\
\cline { 2 - 5 } \multicolumn{1}{c|}{} & PILAR & VIGA & PILAR & VIGA \\
\hline BEAM3 & 8 & 16 & 185,27 & 1207,00 \\
\hline BEAM188 & 8 & 16 & 187,30 & 1209,00 \\
\hline BEAM189 & 8 & 48 & 183,86 & 1213,00 \\
\hline
\end{tabular}

A diferença entre os valores obtidos para os esforços apresentada na Tabela 4.2 não excedeu $2 \%$, nota-se que a discretização adotada para o elemento BEAM189 é três vezes maior para as vigas quando comparada a discretização adotada no elemento BEAM188 e BEAM3. Os resultados apresentados permitem avaliar que o elemento finito BEAM188 possa ser utilizado com representatividade, pois mesmo com uma discretização menos refinada que a adotada no elemento BEAM189 os resultados apresentaram correspondência. 
Desta forma a não-linearidade física foi incorporada no modelo pela utilização do elemento finito BEAM188 que permite que a relação constitutiva dos elementos seja expressa pela relação momento x curvatura. A relação momento x curvatura foi gerada pela ferramenta de cálculo desenvolvida no trabalho.

O elemento finito BEAM188 possui 6 graus de liberdade por nó, três graus de liberdade associados à translação e três graus de liberdade associados à rotação. Este elemento finito tem o potencial de contemplar a deformação dos elementos por força cortante.

A NLG foi analisada segundo o método de Newton-Raphson completo, o critério de parada do processo iterativo foi o de controle dos deslocamentos. A tolerância definida foi de $0,5 \%$, ou seja, o processo iterativo era interrompido quando não houvesse acréscimo de mais de $0,5 \%$ de deslocamentos em relação à iteração anterior. A análise não-linear foi feita dividindo-se o carregamento em 10 passos de carga.

A discretização adotada para modelagem da estrutura via método dos elementos finitos para os pilares foi de 8 elementos finitos por trecho de pilar, onde cada trecho corresponde a região entre pavimentos. Nas vigas foram adotados 16 elementos finitos por trecho de viga, onde cada trecho fica definido pela região entre consolos.

Os consolos foram discretizados em um elemento finito considerando uma rigidez com ordem de grandeza superior a rigidez definida para as vigas.

Os elementos de ligação foram modelados com o auxílio do elemento COMBIN39, este elemento permite que a relação momento x rotação seja representada de forma não-linear e assimétrica. O elemento de ligação é introduzido na estrutura por meio da criação de um elemento finito de comprimento nulo, posicionado entre o elemento finito representante do consolo e o elemento finito representante da viga. O esquema de modelagem da ligação semirígida viga-pilar está ilustrado na Figura 4.1, a ligação transmite momento fletor, força cortante e força normal.

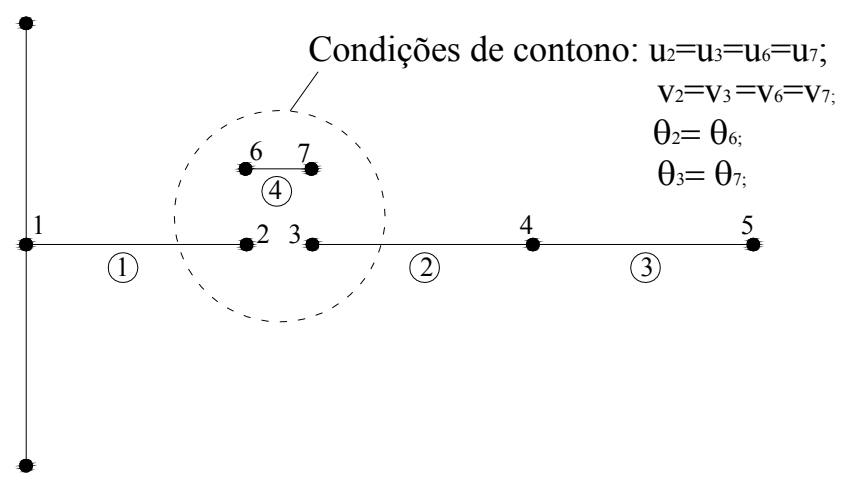

Figura 4.1: Esquema de modelagem da ligação na estrutura em concreto pré-moldado 


\subsection{EXEMPLO NUMÉRICO DE UMA ESTRUTURA TÍPICA}

Tendo em vista atingir os objetivos do trabalho, é analisado um arranjo estrutural usual em edificações de concreto pré-moldado de múltiplos pavimentos, conforme ilustra a Figura 4.2. Na análise numérica, a estrutura é analisada segundo a direção y, com modelagem em pórtico plano. A análise da estrutura na direção x não é contemplada no presente trabalho, embora seja importante na avaliação da estabilidade global do arranjo estrutural estudado.

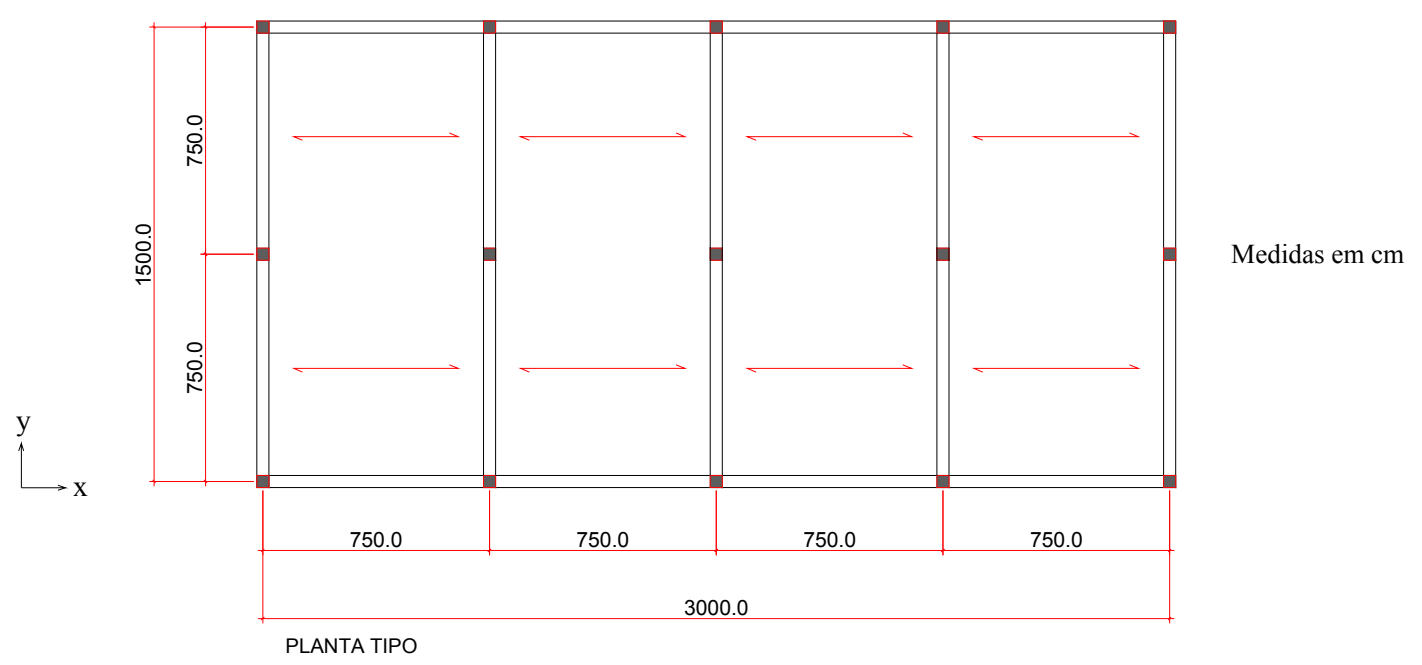

Figura 4.2: Arranjo estrutural a ser estudado

Primeiramente é analisada em um estudo de caso, a estabilidade global de um edifício de 6 pavimentos em concreto pré-moldado. Os dados para análise da estrutura com 6 pavimentos estão descritos na Tabela 4.3.

Tabela 4.3: Dados do exemplo numérico da estrutura típica

\begin{tabular}{|c|c|c|c|c|c|c|}
\hline PAV. & $\mathrm{H}(\mathrm{m})$ & $\mathrm{M}(\mathrm{m})$ & $\mathrm{Q}\left(\mathrm{kN} / \mathrm{m}^{2}\right)$ & $\mathrm{G}_{\text {LAJES }}\left(\mathrm{kN} / \mathrm{m}^{2}\right)$ & $\mathrm{G}_{\text {CAPA }}\left(\mathrm{kN} / \mathrm{m}^{2}\right)$ & $\mathrm{G}_{\text {REVEST. }}\left(\mathrm{kN} / \mathrm{m}^{2}\right)$ \\
\hline 6 & 24 & 7,5 & 3 & 2,2 & 1,5 & 0,5 \\
\hline
\end{tabular}

PAV. : número de pavimentos; H: altura da estrutura, M: módulo da estrutura

Não foi considerada emenda em pilares, uma vez que pilares de até $26 \mathrm{~m}$ de comprimento geralmente não possuem grandes limitações em relação à produção, transporte e montagem. Considera-se para todos os casos estudados um carregamento de $10 \mathrm{kN} / \mathrm{m}$ por pavimento em todo o perímetro da estrutura proveniente do peso próprio da alvenaria.

Para efeito de análise de carregamento considera-se uma espessura média da capa estrutural de $0,06 \mathrm{~m}$, contemplando desta forma a contra-flecha das lajes alveolares. 
A ação do vento para o arranjo selecionado foi definida com o auxílio do item $3.2 \mathrm{e}$ está discriminada em função do número de pavimentos da estrutura e da altura, conforme apresenta a Tabela 4.4, os valores apresentados são característicos.

Tabela 4.4: Ação do vento na estrutura com modulação de 7,5m

\begin{tabular}{|c|c|c|c|c|c|c|c|c|c|c|c|c|}
\hline \multicolumn{13}{|c|}{ Ação do vento- Direção Y } \\
\hline \multicolumn{4}{|c|}{ Modulo 7,5m } & \multicolumn{3}{|c|}{$6 \mathrm{PAV}$} & \multicolumn{3}{|c|}{$5 \mathrm{PAV}$} & \multicolumn{3}{|c|}{4 PAV } \\
\hline $\mathrm{h}(\mathrm{m})$ & $\mathrm{S}_{2}$ & $\mathrm{~V}_{\mathrm{k}}(\mathrm{m} / \mathrm{s})$ & $\mathrm{Q}\left(\mathrm{kN} / \mathrm{m}^{2}\right)$ & $\mathrm{H} / \mathrm{L} 1$ & $\mathrm{C}_{\mathrm{a}}$ & $\mathrm{F}_{\mathrm{a}}(\mathrm{kN})$ & $\mathrm{H} / \mathrm{L} 1$ & $\mathrm{C}_{\mathrm{a}}$ & $\mathrm{F}_{\mathrm{a}}(\mathrm{kN})$ & $\mathrm{H} / \mathrm{L} 1$ & $\overline{\mathrm{C}_{\mathrm{a}}}$ & $\mathrm{F}_{\mathrm{a}}(\mathrm{kN})$ \\
\hline 4 & 0,76 & 34,20 & 0,717 & 0,80 & 1,24 & 26,67 & 0,67 & 1,21 & 26,03 & 0,53 & 1,18 & 25,38 \\
\hline 8 & 0,80 & 36,00 & 0,794 & 0,80 & 1,24 & 29,55 & 0,67 & 1,21 & 28,84 & 0,53 & 1,18 & 28,12 \\
\hline 12 & 0,85 & 38,25 & 0,897 & 0,80 & 1,24 & 33,36 & 0,67 & 1,21 & 32,56 & 0,53 & 1,18 & 31,75 \\
\hline 16 & 0,89 & 40,05 & 0,983 & 0,80 & 1,24 & 36,58 & 0,67 & 1,21 & 35,69 & 0,53 & 1,18 & 17,41 \\
\hline 20 & 0,91 & 40,95 & 1,028 & 0,80 & 1,24 & 38,24 & 0,67 & 1,21 & 18,65 & & & \\
\hline 24 & 0,93 & 41,85 & 1,074 & 0,80 & 1,24 & 19,97 & & & & & & \\
\hline
\end{tabular}

h.: cota do pavimento; H: altura da estrutura; $\mathrm{V}_{\mathrm{k}}$ :Velocidade característica; $\mathrm{S}_{2}$ : Fator que compõe $\mathrm{V}_{\mathrm{k}}$, q: pressão dinâmica; L1: maior dimensão da edificação em planta; $\mathrm{C}_{\mathrm{a}}$ : Coeficiente de arrasto; $\mathrm{F}_{\mathrm{a}}$ : Força de arrasto

A Figura 4.3 ilustra o arranjo de armadura adotado para os pilares da estrutura em aço CA-50, foi adotada a mesma taxa de armadura para todas as seções transversais do pilar, a taxa geométrica de armadura corresponde a 3\%. O concreto utilizado é especificado com $\mathrm{f}_{\mathrm{ck}}=35 \mathrm{MPa}$.

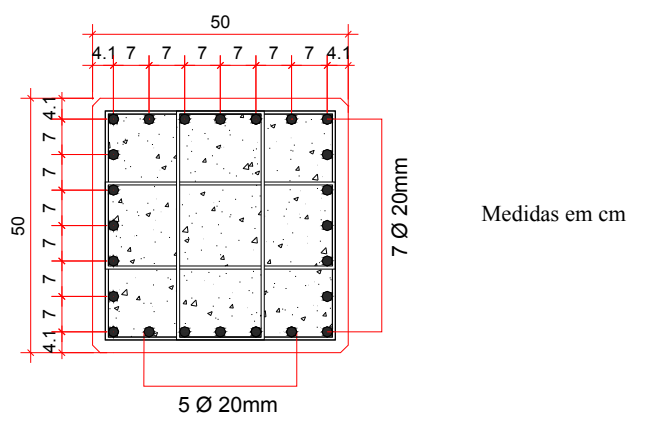

Figura 4.3: Seção transversal e disposição de armadura do pilar em concreto pré-moldado (P50x50)

Na Figura 4.4 está ilustrada a seção da viga em concreto pré-moldado utilizada em todos os pavimentos com $\mathrm{f}_{\mathrm{ck}}=35 \mathrm{MPa}$ em seção composta por capa moldada in loco com $\mathrm{f}_{\mathrm{ck}}=20 \mathrm{MPa}$. A armadura passiva é constituída de aço CA-50. 


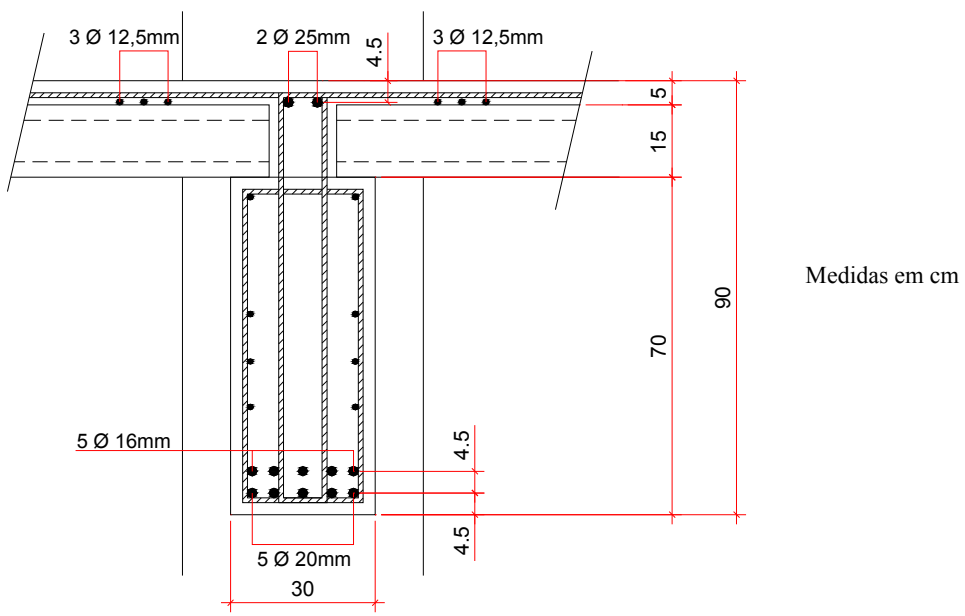

Figura 4.4: Seção transversal e disposição de armadura passiva da viga em concreto pré-moldado em seção composta destinada a estrutura com modulação de $7,5 \mathrm{~m}$

A armadura de pele e a armadura de porta estribo tiveram sua contribuição desprezada para efeito de construção do diagrama $\mathrm{M}$ x N x $1 / \mathrm{r}$.

\subsubsection{CARACTERIZAÇÃO DA NÃO-LINEARIDADE FÍSICA (RIGIDEZ) DOS ELEMENTOS}

São construídos os diagramas M x N x 1/r para as seções dos elementos em estudo e analisados os coeficientes redutores de rigidez da inércia bruta encontrados. São propostas funções de redução de rigidez relacionando coeficiente redutor de rigidez e força normal adimensional. Os coeficientes redutores encontrados com o auxílio das funções de rigidez prescritas em diversas normas são comparados com os valores obtidos segundo o diagrama $\mathrm{M}$ $\mathrm{x} \mathrm{N} \times 1 / \mathrm{r}$.

A não-linearidade física dos elementos é considerada na análise numérica segundo a curva do diagrama $\mathrm{M}$ x N x 1/r obtida com o auxílio da ferramenta de cálculo desenvolvida.

O carregamento normal segundo as combinações de ações para o ELU e ELS está expresso na Tabela 4.5. As combinações de ações utilizadas podem ser encontradas em (3.5), (3.6), (3.7) e (3.9). 
Tabela 4.5: Carga normal atuante nos pilares (P50x50) para a estrutura com modulação de 7,5m e carga acidental de $3 \mathrm{kN} / \mathrm{m}^{2}$

\begin{tabular}{|c|c|c|c|c|c|c|c|c|}
\cline { 2 - 9 } \multicolumn{1}{c|}{} & \multicolumn{2}{c|}{$\mathrm{N}_{\mathrm{d}, 1}(\mathrm{kN})$} & \multicolumn{2}{c|}{$\mathrm{N}_{\mathrm{d}, 2}(\mathrm{kN})$} & \multicolumn{2}{c|}{$\mathrm{N}_{\mathrm{d}, 3}(\mathrm{kN})$} & \multicolumn{2}{c|}{$\mathrm{N}_{\text {ser }}(\mathrm{kN})$} \\
\hline PAVIMENTO & PC & PL & PC & PL & PC & PL & PC & PL \\
\hline 6 & 534,94 & 318,65 & 330,19 & 216,28 & 605,81 & 354,00 & 343,13 & 210,94 \\
\hline 5 & 1069,88 & 742,31 & 660,38 & 537,56 & 1211,62 & 813,09 & 686,25 & 474,38 \\
\hline 4 & 1604,82 & 1165,96 & 990,57 & 858,84 & 1817,44 & 1272,19 & 1029,38 & 737,81 \\
\hline 3 & 2139,75 & 1589,62 & 1320,75 & 1180,12 & 2423,25 & 1731,28 & 1372,50 & 1001,25 \\
\hline 2 & 2674,69 & 2013,28 & 1650,94 & 1501,41 & 3029,06 & 2190,38 & 1715,63 & 1264,69 \\
\hline 1 & 3209,63 & 2436,93 & 1981,13 & 1822,69 & 3634,87 & 2649,47 & 2058,75 & 1528,13 \\
\hline
\end{tabular}

PC (Pilar Central); PL (Pilar Lateral);

$\mathrm{N}_{\mathrm{d}, 1}$ : Carregamento normal segundo a $1^{\mathrm{a}}$ combinação de ações do ELU, onde a carga acidental de vento é tomada como principal;

$\mathrm{N}_{\mathrm{d}, 2}$ : Carregamento normal segundo a $2^{\mathrm{a}}$ combinação de ações do ELU, onde a carga acidental de vento é tomada como a única carga acidental atuante;

$\mathrm{N}_{\mathrm{d}, 3}$ : Carregamento normal segundo a $3^{\mathrm{a}}$ combinação de ações do ELU, onde a carga acidental de ocupação é tomada como principal;

$\mathrm{N}_{\mathrm{d}, \text { ser }}$ : Carregamento normal segundo a combinação de ações do ELS, onde a carga acidental de vento é tomada como principal.

$\mathrm{Na}$ Tabela 4.6, o carregamento normal é apresentado na forma adimensional, esta forma de apresentação facilita a associação entre o incremento de força normal e o aumento de rigidez no elemento.

Tabela 4.6: Força normal adimensional atuante nos pilares (P50x50) para a estrutura com modulação de $7,5 \mathrm{~m}$ e carga acidental de $3 \mathrm{kN} / \mathrm{m}^{2}$

\begin{tabular}{|c|c|c|c|c|c|c|c|c|}
\cline { 2 - 9 } \multicolumn{1}{c|}{} & \multicolumn{2}{c|}{$v_{\mathrm{d}, 1}$} & \multicolumn{2}{c|}{$v_{\mathrm{d}, 2}$} & \multicolumn{2}{c|}{$v_{\mathrm{d}, 3}$} & \multicolumn{2}{c|}{$v_{\text {ser }}$} \\
\hline PAVIMENTO & PC & PL & PC & PL & PC & PL & PC & PL \\
\hline 6 & 0,09 & 0,05 & 0,05 & 0,03 & 0,10 & 0,06 & 0,05 & 0,03 \\
\hline 5 & 0,17 & 0,12 & 0,11 & 0,09 & 0,19 & 0,13 & 0,11 & 0,08 \\
\hline 4 & 0,26 & 0,19 & 0,16 & 0,14 & 0,29 & 0,20 & 0,16 & 0,12 \\
\hline 3 & 0,34 & 0,25 & 0,21 & 0,19 & 0,39 & 0,28 & 0,22 & 0,16 \\
\hline 2 & 0,43 & 0,32 & 0,26 & 0,24 & 0,48 & 0,35 & 0,27 & 0,20 \\
\hline 1 & 0,51 & 0,39 & 0,32 & 0,29 & 0,58 & 0,42 & 0,33 & 0,24 \\
\hline
\end{tabular}

Força normal adimensional: $v_{d, i}=\frac{N_{d, i}}{A_{c} \cdot f_{c d}}$.

Após a definição dos valores de força normal atuantes por combinação de ações considerada e trecho de pilar, são apresentados os diagramas $\mathrm{M}$ x N x 1/r construídos com o valor de tensão no concreto de $1,1 \mathrm{f}_{\mathrm{cd}}$ e cargas atuantes majoradas de $\gamma_{\mathrm{f}}\left(\mathrm{N}_{\mathrm{d}}\right)$ utilizados na modelagem numérica. As Figuras 4.5 a 4.10 ilustram alguns dos diagramas $\mathrm{M}$ x $\mathrm{N}$ x 1/r.

Nas análises numéricas não foi adotada, por simplificação, a formulação em que as cargas atuantes são majoradas de $\gamma_{f} / \gamma_{f 3}\left(\mathrm{~F}_{\mathrm{d}} / \gamma_{f 3}\right)$ e posteriormente a análise dos efeitos de $2^{\mathrm{a}}$ ordem são majoradas com $\gamma_{f 3}=1,1$. 


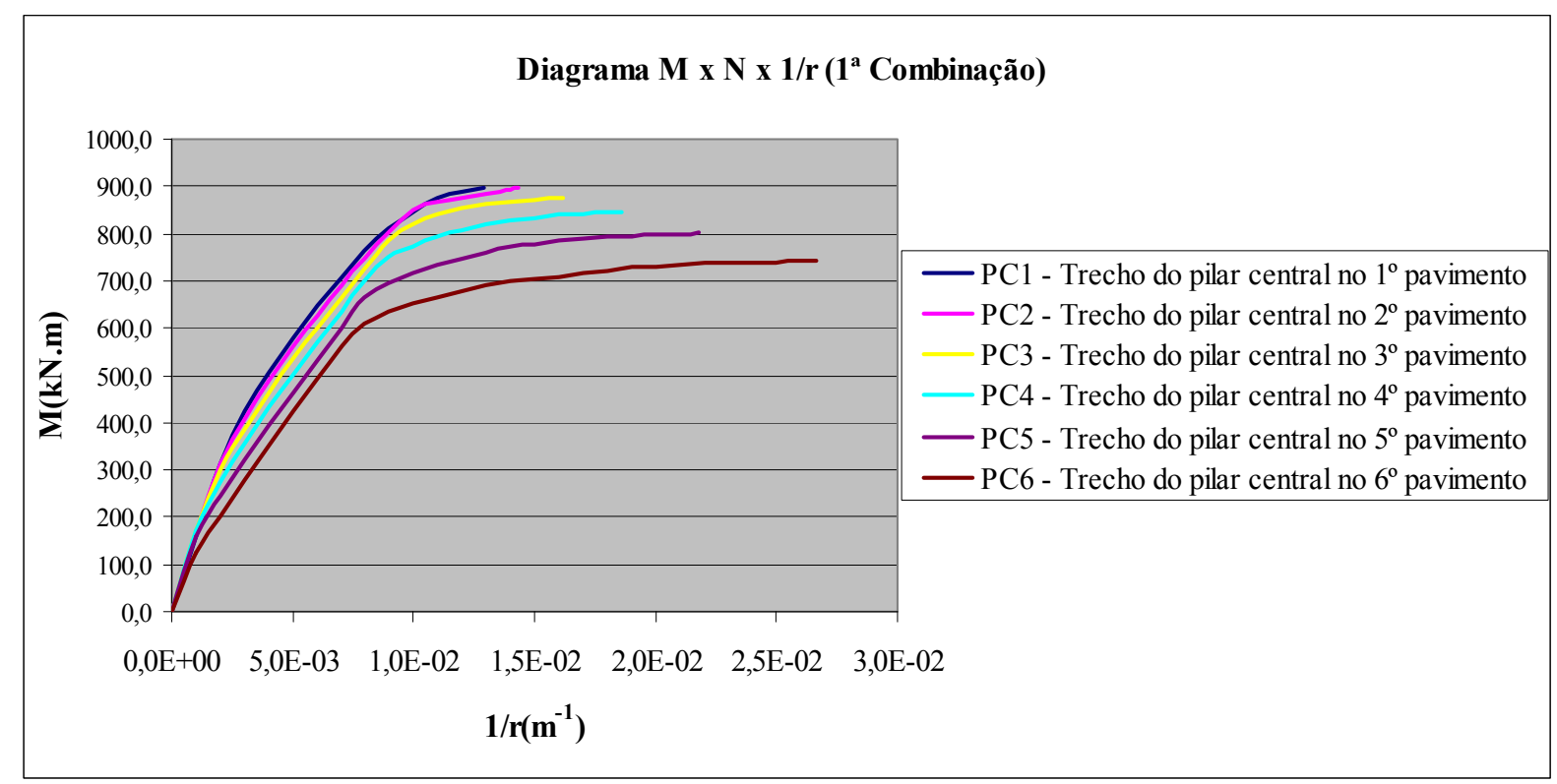

Figura 4.5: Diagrama M x N x 1/r segundo a $1^{\mathrm{a}}$ combinação de ações para o pilar central

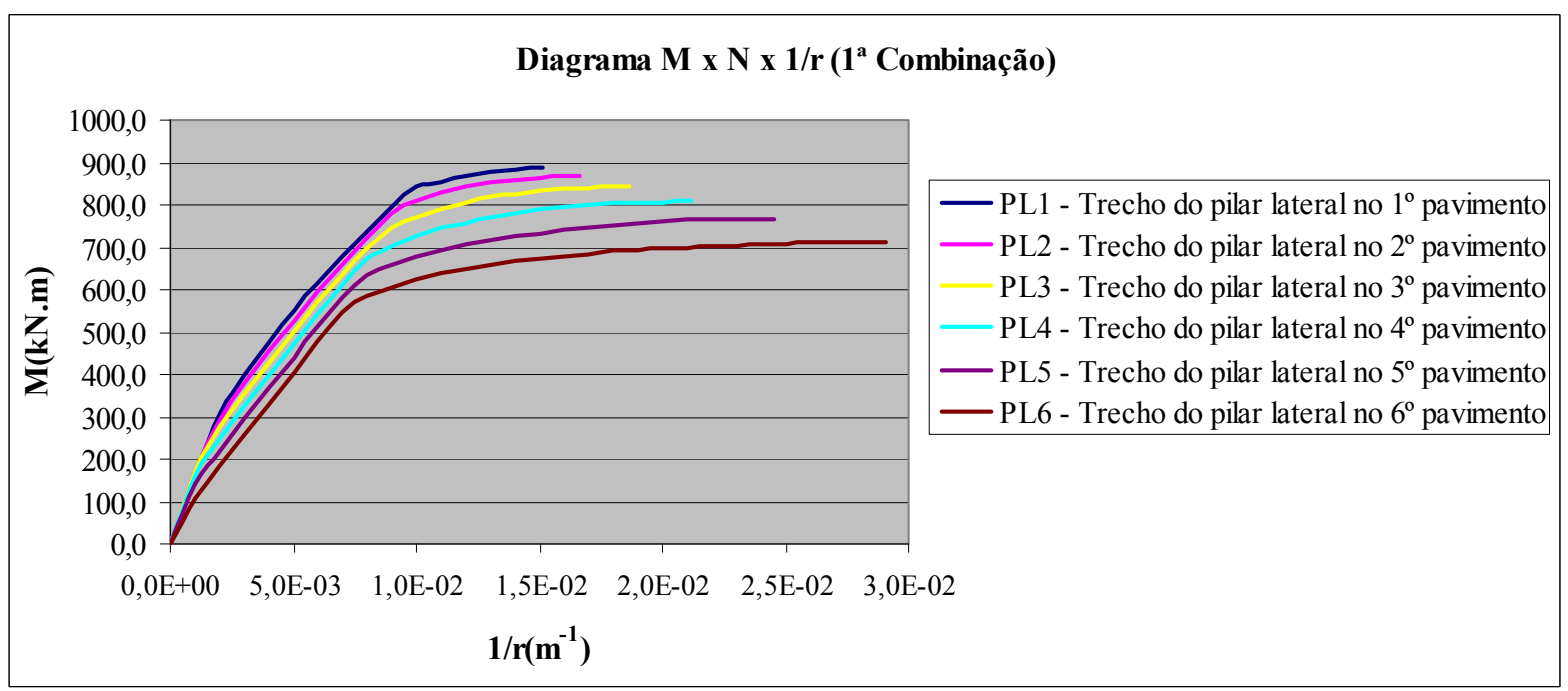

Figura 4.6: Diagrama M x N x 1/r segundo a $1^{\mathrm{a}}$ combinação de ações para o pilar lateral

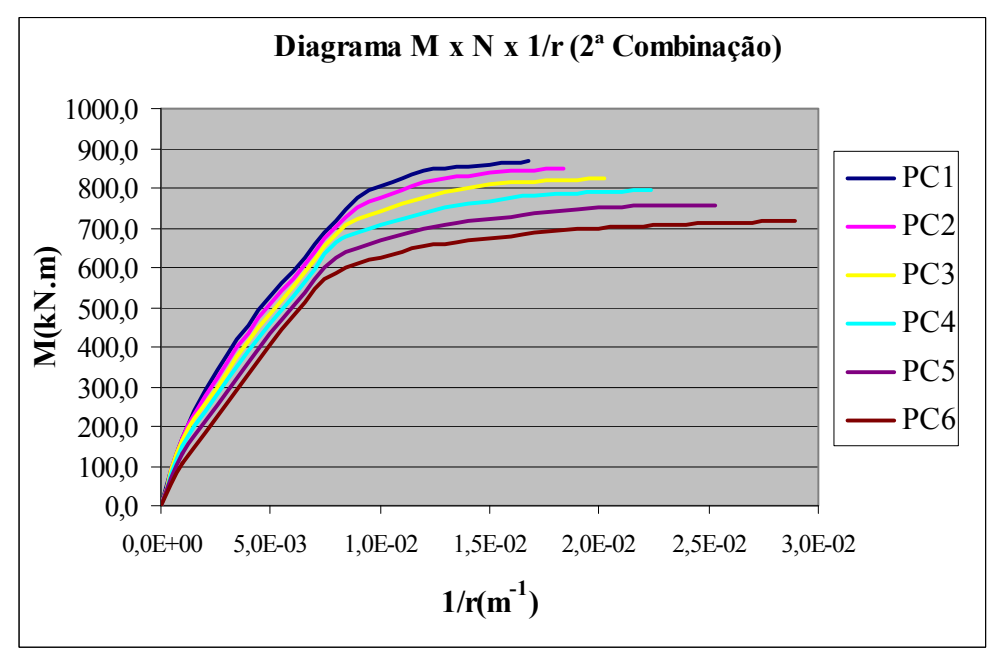

Figura 4.7: Diagrama M x N x 1/r segundo a $2^{\mathrm{a}}$ combinação de ações para o pilar central 


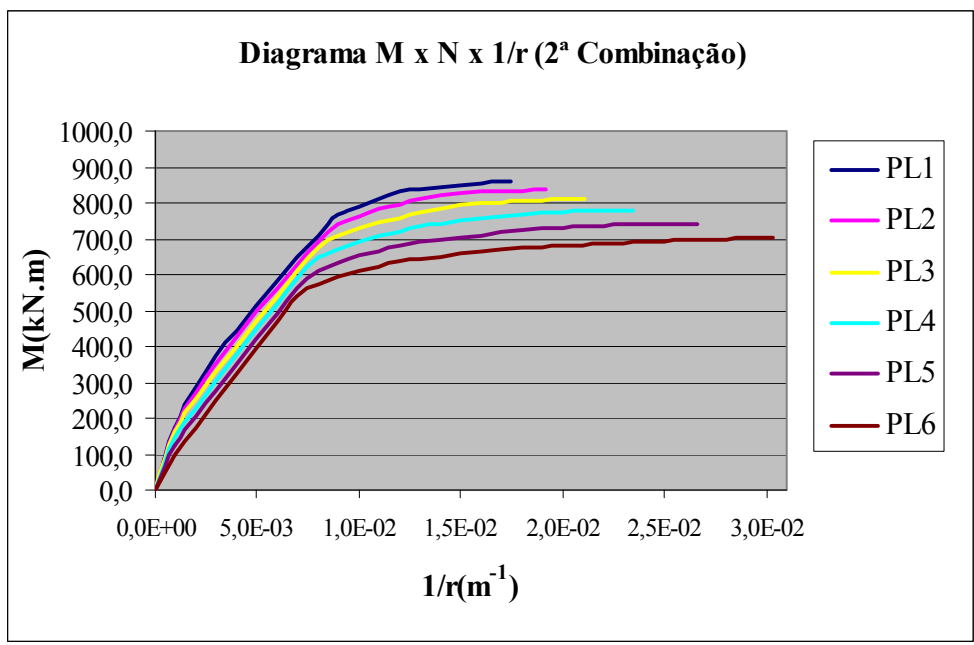

Figura 4.8: Diagrama M x N x 1/r segundo a $2^{\mathrm{a}}$ combinação de ações para o pilar lateral

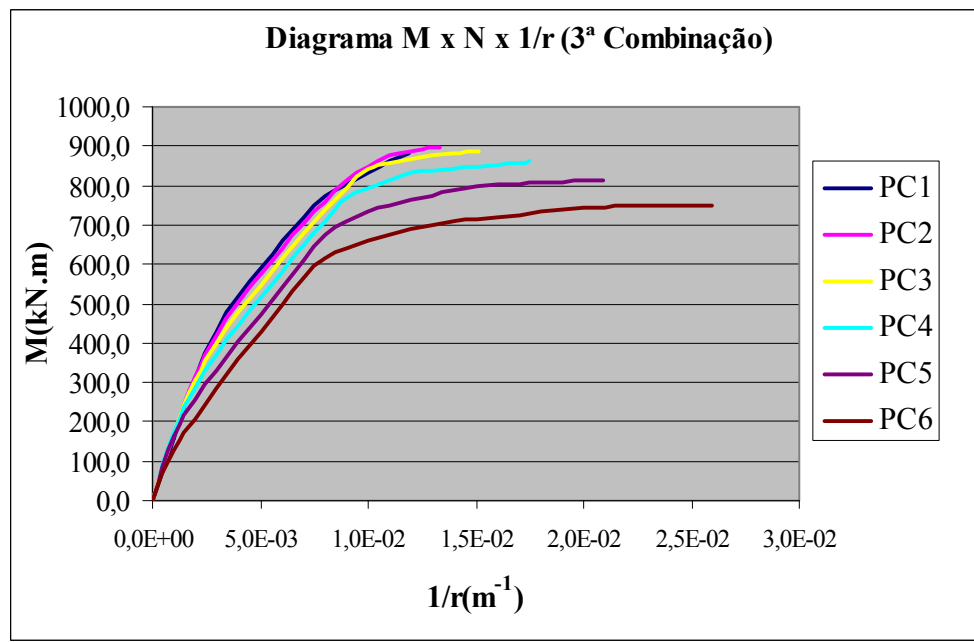

Figura 4.9: Diagrama $M \times N$ x 1/r segundo a $3^{\mathrm{a}}$ combinação de ações para o pilar central

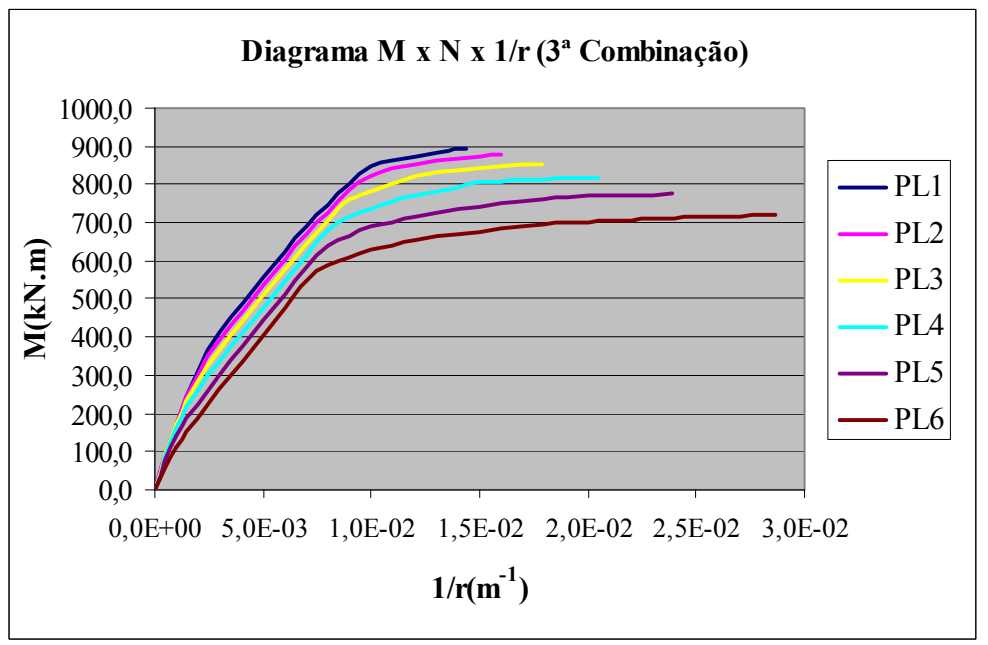

Figura 4.10: Diagrama M x N x 1/r segundo a $3^{\mathrm{a}}$ combinação de ações para o pilar lateral

A metodologia empregada para a construção dos diagramas $\mathrm{M}$ x $\mathrm{N} \times 1 / \mathrm{r}$ nas combinações em ELU para efeito da consideração da rigidez com tensão no concreto de $1,1 f_{\text {cd }}$ 
foi a mesma adotada na análise da rigidez dos elementos no ELS por não existir uma formulação alternativa consagrada. FUSCO (1981) propõe diferentes modelos para consideração da rigidez do concreto a ser considerada, segundo características da estrutura e a natureza da análise.

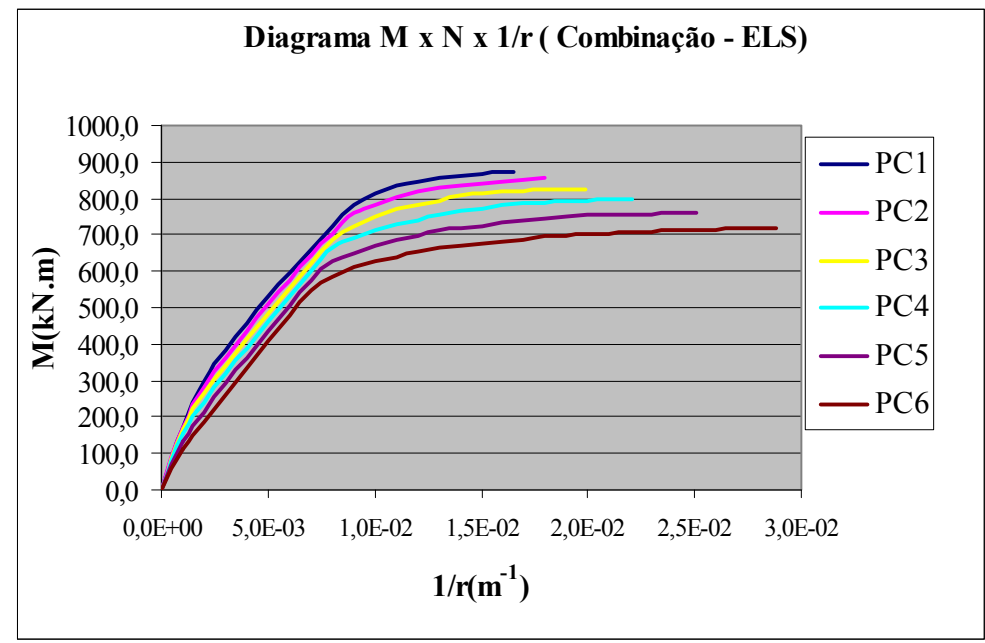

Figura 4.11: Diagrama M x N x 1/r segundo a combinação de ação (ELS) para o pilar central

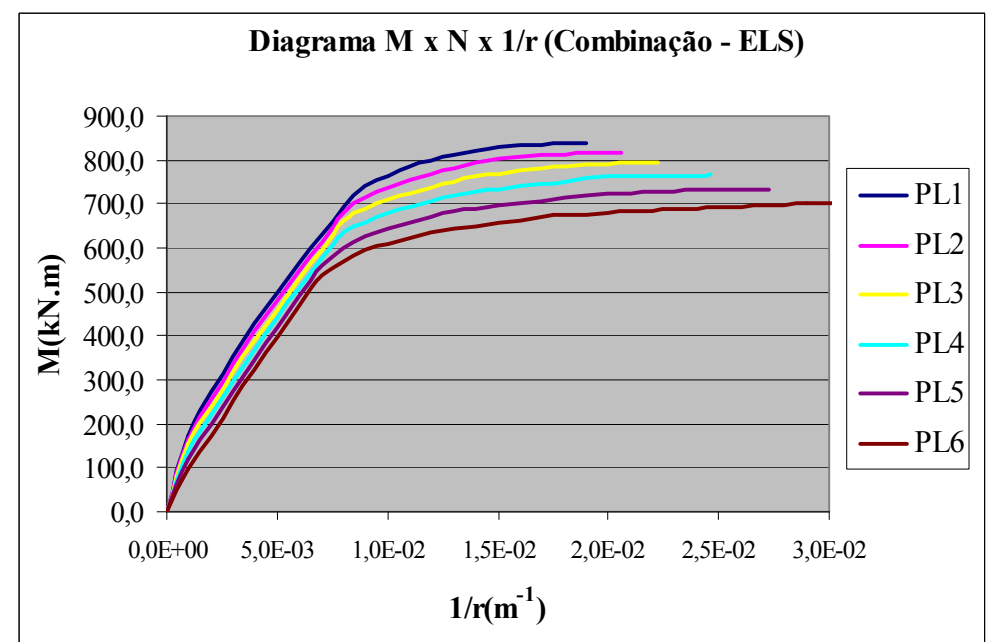

Figura 4.12: Diagrama M x N x 1/r segundo a combinação de ação (ELS) para o pilar lateral

\subsubsection{AVALIAÇÃO DE FUNÇÕES E COEFICIENTES REDUTORES DE RIGIDEZ}

Com intuito de avaliar os coeficientes redutores de rigidez nas seções adotadas, apresentam-se na Tabela 4.7 os coeficientes obtidos segundo o diagrama $\mathrm{M}$ x $\mathrm{N}$ x 1/r construídos com o valor de tensão no concreto de $1,1 \mathrm{f}_{\mathrm{cd}}$ e cargas atuantes majoradas de $\gamma_{f} / \gamma_{f 3}$ $\left(\mathrm{N}_{\mathrm{d}} / \gamma_{f 3}\right)$ para efeito de obtenção dos coeficientes redutores de rigidez correspondentes a rigidez secante. 
Tabela 4.7: Coeficientes redutores de rigidez dos pilares (P50x50) para a estrutura com modulação de $7,5 \mathrm{~m}$ e carga acidental de $3 \mathrm{kN} / \mathrm{m}^{2}$.

\begin{tabular}{|c|c|c|c|c|c|c|c|c|}
\cline { 2 - 9 } \multicolumn{1}{c|}{} & \multicolumn{2}{c|}{$\alpha_{1}$} & \multicolumn{2}{c|}{$\alpha, 2$} & \multicolumn{2}{c|}{$\alpha, 3$} & \multicolumn{2}{c|}{$\alpha_{\text {,ser }}$} \\
\hline PAVIMENTO & PC & PL & PC & PL & PC & PL & PC & PL \\
\hline 6 & 0,366 & 0,343 & 0,345 & 0,333 & 0,375 & 0,347 & 0,345 & 0,334 \\
\hline 5 & 0,430 & 0,397 & 0,384 & 0,366 & 0,446 & 0,404 & 0,388 & 0,359 \\
\hline 4 & 0,493 & 0,441 & 0,422 & 0,409 & 0,501 & 0,453 & 0,426 & 0,397 \\
\hline 3 & 0,514 & 0,492 & 0,459 & 0,443 & 0,527 & 0,498 & 0,467 & 0,423 \\
\hline 2 & 0,539 & 0,509 & 0,495 & 0,483 & 0,566 & 0,516 & 0,497 & 0,451 \\
\hline 1 & 0,583 & 0,528 & 0,507 & 0,501 & 0,625 & 0,538 & 0,510 & 0,490 \\
\hline
\end{tabular}

$\alpha_{, 1}$ : Coeficiente redutor de rigidez dos pilares segundo a $1^{\text {a }}$ combinação de ações do ELU;

$\alpha_{, 2}$ : Coeficiente redutor de rigidez dos pilares segundo a $2^{\mathrm{a}}$ combinação de ações do ELU;

$\alpha_{, 3}$ : Coeficiente redutor de rigidez dos pilares segundo a $3^{\mathrm{a}}$ combinação de ações do ELU;

$\alpha$,ser: Coeficiente redutor de rigidez dos pilares segundo a combinação de ações do ELS.

Analisando os coeficientes redutores de rigidez apresentados na Tabela 4.7 para as combinações de cálculo no ELU, nota-se que para o pilar central o coeficiente redutor da rigidez variou no intervalo de aproximadamente 0,35 a 0,6 e para o pilar lateral o coeficiente variou aproximadamente de 0,35 a 0,5 . Nota-se que o coeficiente redutor de rigidez encontrado na $3^{\mathrm{a}}$ combinação de ações é maior que o coeficiente redutor de rigidez encontrado na $1^{\mathrm{a}}$ combinação de ações e na $2^{\mathrm{a}}$ combinação de ações, isto ocorre devido ao maior efeito da força normal na $3^{\mathrm{a}}$ combinação de ações.

O comportamento do coeficiente redutor de rigidez para as combinações no ELU foi caracterizado em função da força normal adimensional, conforme ilustra a Figura 4.13.

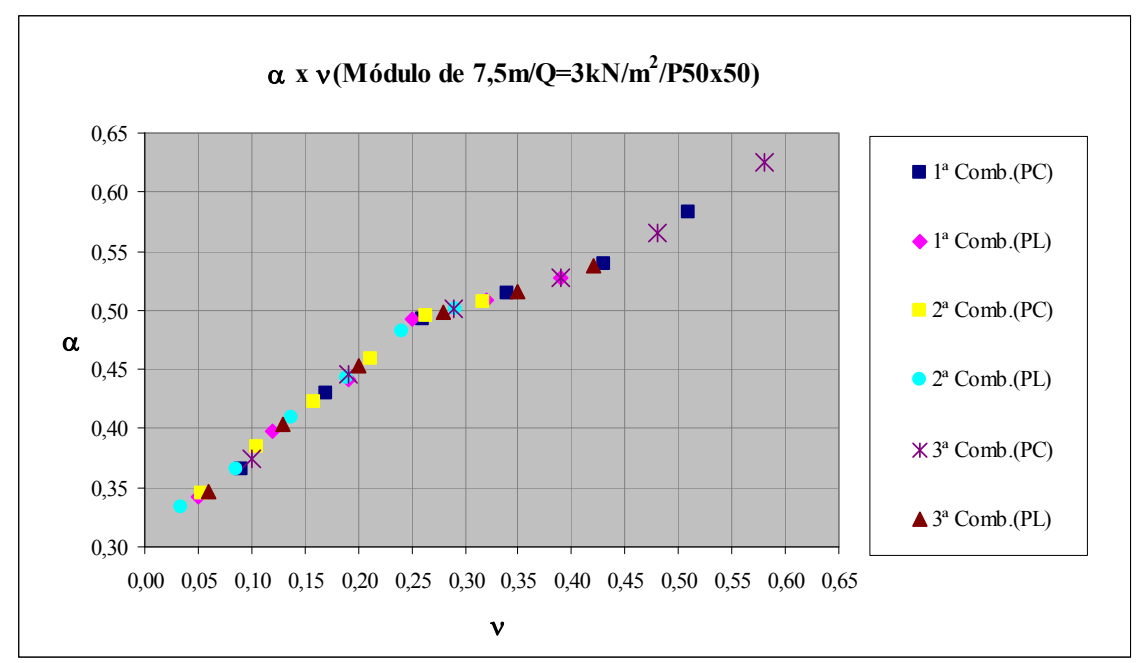

Figura 4.13: Diagrama dos coeficientes redutores de rigidez versus força normal adimensional para pilares (P50x50) em estruturas com modulação de 7,5m e carga acidental de $3 \mathrm{kN} / \mathrm{m}^{2}$.

Com o auxílio dos dados ilustrados na Figura 4.13 é possível obter expressões que descrevam com certa precisão a variação no comportamento do coeficiente redutor de rigidez. 
$\mathrm{Na}$ Figura 4.14 podem ser observadas curvas que descrevem o comportamento aproximado da variação do coeficiente redutor de rigidez segundo a força normal adimensional.

A aproximação obtida com uma função polinomial de terceiro grau ou com uma função potência mostrou-se adequada na descrição da variação do coeficiente redutor, isto pode ser constatado pelos valores de R-quadrado obtidos. Foi construída uma curva de referência formada pelos coeficientes apresentados na Figura 4.13.

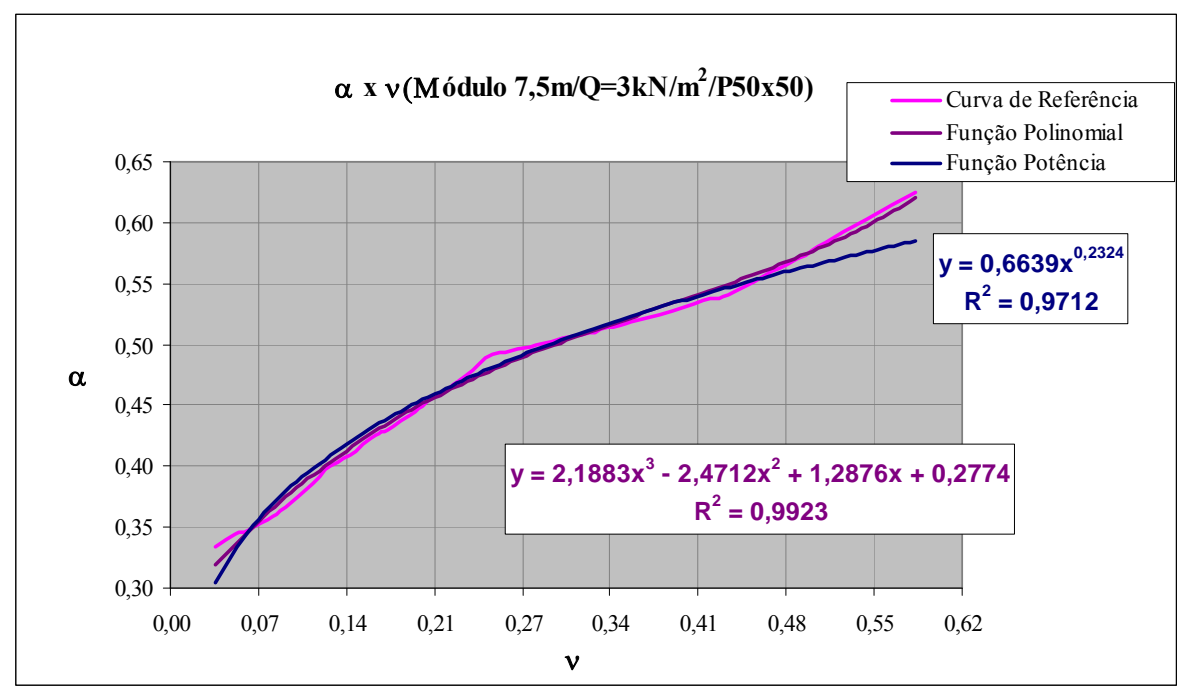

Figura 4.14: Função redução de rigidez segundo aproximação polinomial e em potência

A função polinomial descrita na Figura 4.14 é válida para o domínio de força normal adimensional definido entre 0,03 e 0,58 , podendo ser reescrita no seguinte formato:

$$
\begin{gathered}
\alpha=\overbrace{2,188 \cdot v^{3}-2,471 v^{2}+1,288 v+1,03 .}^{\text {Força normal adimensional }} \cdot \overbrace{\frac{\overbrace{E_{s} I_{s}}^{E I}}{\text { Armadura }}}^{\text {Força normaladimensional }}+\overbrace{\frac{\overbrace{s} I_{s}}{E I}}^{\text {Armadura }}
\end{gathered}
$$

As funções aproximadas que descrevem o comportamento do coeficiente redutor de rigidez podem assumir diferentes formatos conforme é apresentado em (4.1) e (4.2), onde a expressão é basicamente composta por uma parcela que leva em conta a contribuição da força normal na rigidez e outra parcela que leva em conta a contribuição da armadura. A parcela referente à rigidez da armadura corresponde a 0,271 , poderia ser considerada a constante da função. Segundo o diagrama $\mathrm{M}$ x N x 1/r o coeficiente redutor referente à rigidez secante 
associado à força normal adimensional nula é igual a 0,312, a diferença entre os valores encontrados de coeficiente redutor segundo o diagrama $\mathrm{M} \times \mathrm{N}$ x1/r e a parcela associada à armadura na expressão (4.1) corresponde à contribuição do concreto.

O coeficiente multiplicador da parcela referente a armadura na expressão (4.1) e o coeficiente multiplicador da função polinomial em (4.2) referem-se à contribuição do concreto na rigidez.

Outra forma de expressar a variação do coeficiente redutor com o esforço normal é adotar uma função linear conforme ilustra a Figura 4.15.

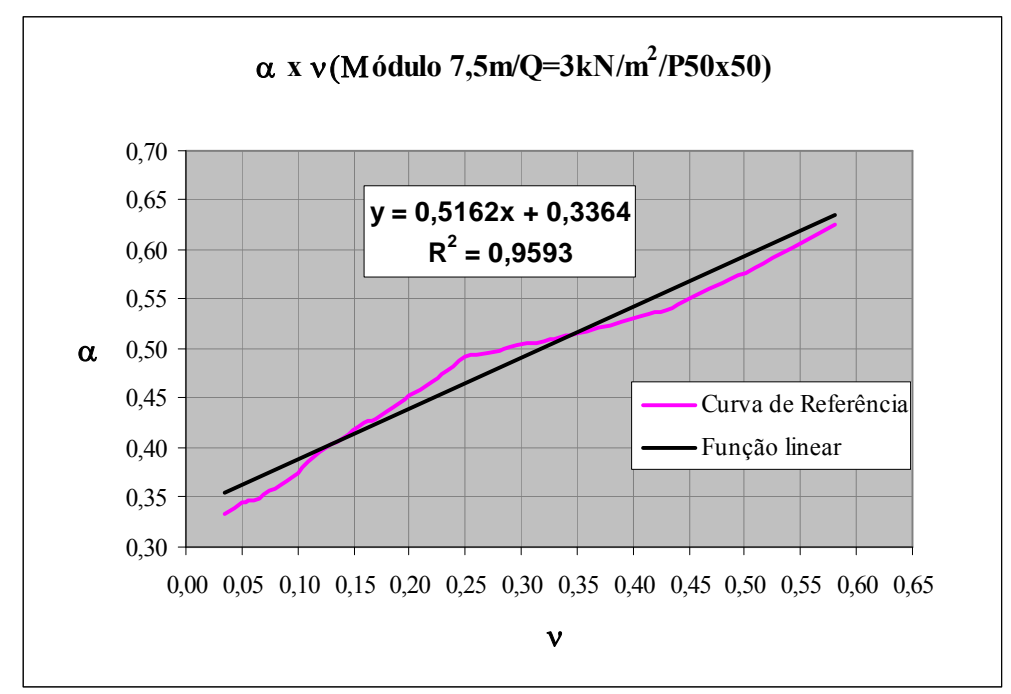

Figura 4.15: Função redução de rigidez segundo aproximação linear

A função polinomial descrita na Figura 4.15 poderia ser reescrita no seguinte formato:

$$
\alpha=0,5 v+1,25 \frac{E_{s} I_{s}}{E I}
$$

Observando a Figura 4.15 nota-se que a função $\alpha$ versus $v$ possui um ponto de inflexão no ponto em que a força normal adimensional assume o valor de aproximadamente 0,35 . Tendo em vista este comportamento, a função de redução de rigidez poderia ser dividida em subdomínios, conforme ilustra a Figura 4.16 e a Figura 4.17. 


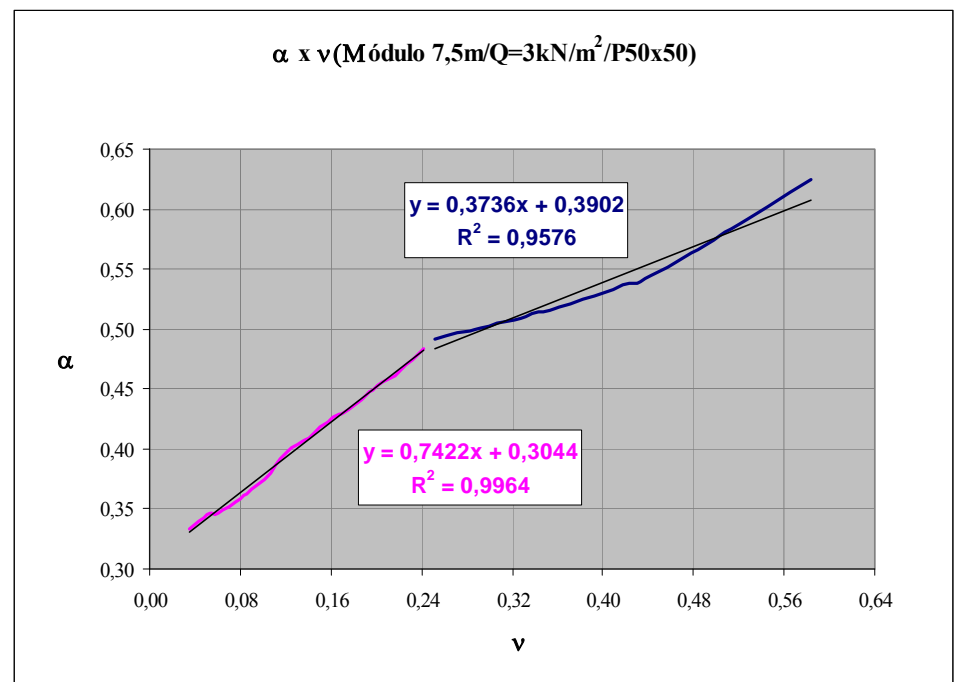

Figura 4.16: Função redução de rigidez segundo aproximação linear em dois subdomínios

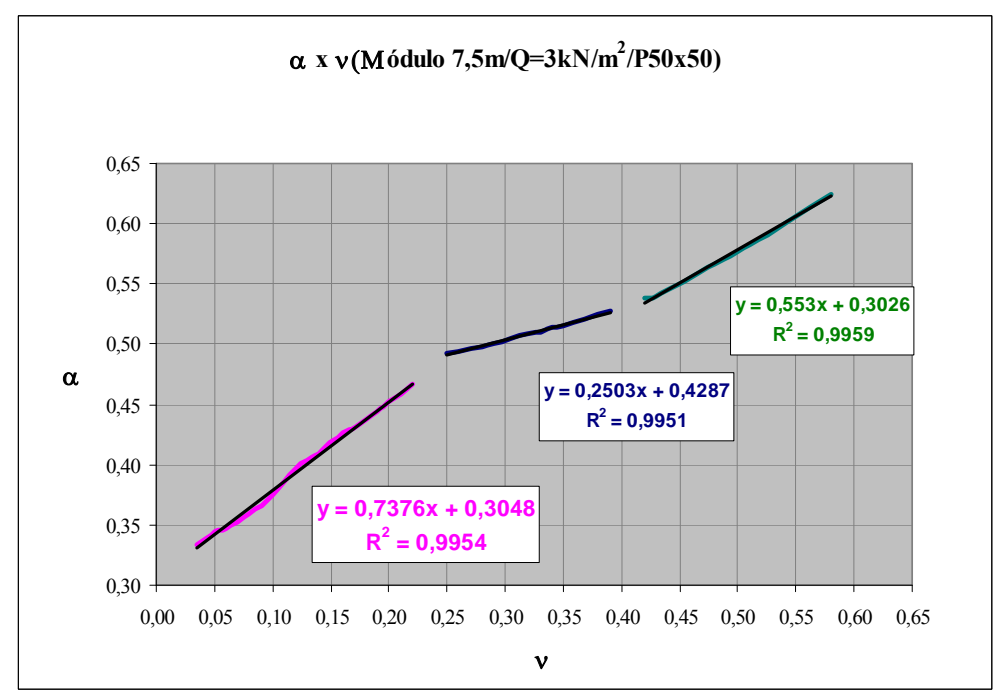

Figura 4.17: Função redução de rigidez segundo aproximação linear em três subdomínios

Os valores encontrados para redução da rigidez segundo o diagrama $\mathrm{M}$ x N x 1/r foram comparados com os valores obtidos pelas funções aproximadas prescritas em normas.

Foram consideradas duas situações limite no que se refere a esforço normal e índice de esbeltez. Em relação ao esforço normal foram consideradas a máxima e a mínima força normal das combinações de ações consideradas. Em relação ao índice de esbeltez, em virtude das ligações viga-pilar das estruturas em concreto pré-moldado de múltiplos pavimentos terem comportamento semi-rígido foram consideradas duas hipóteses. $\mathrm{Na}$ primeira o comprimento efetivo do pilar corresponde à diferença de cota entre pavimentos, na segunda considera-se que o comprimento efetivo corresponde ao máximo índice de esbeltez permitido pela NBR 6118:2003, ou seja, $\lambda=200$. 
A NBR 6118:2003 prescreve que para pilares com força normal adimensional menor que 0,10 é permitida a utilização de pilares $\operatorname{com} \lambda>200$, caso típico de postes e de alguns pilares de galpões industriais. Embora a menor força normal adimensional encontrada seja igual a 0,03 , foi mantida a condição limite de $\lambda=200$, uma vez que os pilares são destinados a estruturas de múltiplos pavimentos. $\mathrm{Na}$ Tabela 4.8 estão apresentados os coeficientes redutores obtidos de acordo com as prescrições normativas investigadas.

Tabela 4.8: Coeficientes redutores de rigidez para pilar segundo as diversas prescrições normativas

\begin{tabular}{|c|c|c|c|c|c|c|c|}
\hline$v$ & $\lambda$ & M x N x 1/r & NBR 6118:2003 & NBR 9062:1985 & ACI 318-08 & PCI & FIB \\
\hline 0,58 & 27,71 & 0,625 & 0,800 & 0,758 & 0,471 & 0,162 & 0,429 \\
\hline 0,58 & 200 & 0,625 & 0,800 & 0,758 & 0,471 & 0,333 & 1,152 \\
\hline 0,03 & 27,71 & 0,333 & 0,500 & 0,758 & 0,471 & 0,015 & 0,280 \\
\hline 0,03 & 200 & 0,333 & 0,500 & 0,758 & 0,471 & 0,168 & 0,317 \\
\hline
\end{tabular}

$v$ : Força normal adimensional; $\lambda$ : Índice de esbeltez.

O coeficiente redutor prescrito pela NBR 6118:2003 para pilares é de 0,8 e para vigas com armadura simétrica é de 0,5 . Segundo o intervalo de variação do coeficiente redutor apresentado na Tabela 4.7, não há correspondência entre os valores encontrados com o coeficiente redutor sugerido para pilares pela NBR 6118:2003. Considerando que o comportamento dos pilares pertencentes ao sexto pavimento é próximo ao de vigas, devido ao baixo nível de esforço normal de compressão, o coeficiente prescrito pela NBR 6118:2003 poderia ser interpretado como 0,5 . No entanto, com uma disposição simétrica de armadura obteve-se o valor de coeficiente redutor segundo o diagrama $\mathrm{M}$ x N x 1/r de aproximadamente 0,35 .

O coeficiente redutor obtido segundo a NBR 9062:1985 não apresentou correspondência com os valores obtidos de coeficiente redutor de rigidez associados aos diagramas M x N x 1/r, mostrando-se inadequado para utilização no exemplo estudado.

O coeficiente redutor encontrado segundo o ACI 318-08 correspondeu aos trechos de pilar intermediários. Vale ressaltar que para efeito de comparação com as outras prescrições normativas, o módulo de elasticidade adotado foi o mesmo obtido segundo a NBR 6118:2003.

As formulações apresentadas pelo PCI e pela FIB contemplam a esbeltez do pilar, no entanto a determinação da esbeltez do pilar torna a análise mais complexa devido à presença da ligação semi-rígida e, conseqüentemente, da deslocabilidade da estrutura. Os valores obtidos para o coeficiente redutor de rigidez segundo o PCI para as duas situações adotadas de esbeltez não apresentaram correspondência com os valores obtidos segundo o diagrama $\mathrm{M} \mathrm{x}$ 
$\mathrm{N} \mathrm{x} \mathrm{1/r.} \mathrm{Os} \mathrm{valores} \mathrm{encontrados} \mathrm{segundo} \mathrm{a} \mathrm{FIB} \mathrm{para} \mathrm{força} \mathrm{normal} \mathrm{adimensional} \mathrm{igual} \mathrm{a} 0,03$ se aproximaram dos valores obtidos com o diagrama $\mathrm{M}$ x $\mathrm{N}$ x $1 / \mathrm{r}$.

A taxa e arranjo de armadura, bem como o nível de esforço normal apresentaram um grau de influência maior na análise. A análise de rigidez secante ocorre na seção do elemento, a esbeltez do elemento está relacionada a uma análise da rigidez do elemento como um todo.

Com o auxílio da Figura 4.4, foi construído o diagrama $\mathrm{M}$ x $\mathrm{N}$ x 1/r para a viga central, a resistência característica à compressão da capa de concreto é de $20 \mathrm{MPa}$ e da viga em concreto pré-moldado de $35 \mathrm{MPa}$. A ferramenta de cálculo desenvolvida é destinada a seções retangulares, desta forma a seção ilustrada na Figura 4.4 foi simplificada conforme ilustra a Figura 4.18.

Na seção simplificada, existe uma compensação da área de concreto desconsiderada presente na capa pela área de concreto ocupada pela laje alveolar.

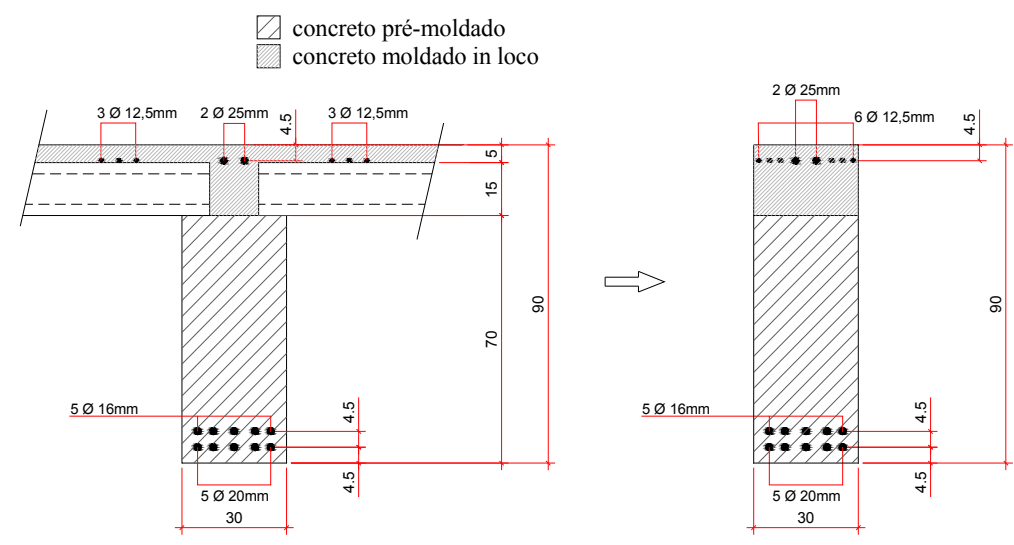

Figura 4.18: Seção composta em concreto pré-moldado simplificada

A Figura 4.19 ilustra o diagrama $\mathrm{M}$ x N x 1/r com efeito da fluência por intermédio do coeficiente linear de fluência igual a 0 e 2 . Em virtude da diferença de resistência do concreto da seção da viga de concreto pré-moldado e da capa moldada in loco, para efeito de construção do diagrama $\mathrm{M} \times \mathrm{N}$ x 1/r o trecho referente ao momento positivo foi construído com $\mathrm{f}_{\mathrm{ck}}=20 \mathrm{MPa}$ e o trecho referente ao momento negativo foi construído com $\mathrm{f}_{\mathrm{ck}}=35 \mathrm{MPa}$. 


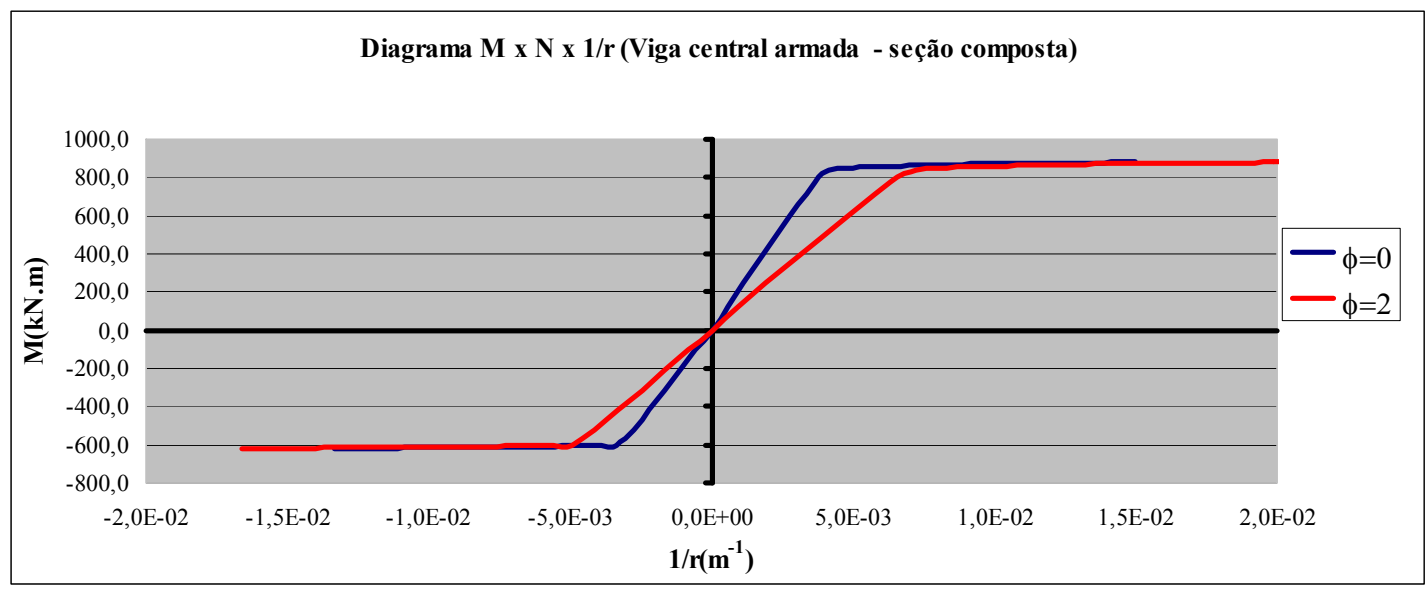

Figura 4.19: Diagrama $\mathrm{M} \times \mathrm{N} \times 1 / \mathrm{r}$ da viga em concreto pré-moldado com armadura passiva para estrutura com modulação de $7,5 \mathrm{~m}$

$\mathrm{Na}$ Tabela 4.9, é possível avaliar o desenvolvimento do coeficiente redutor de rigidez versus o coeficiente de fluência para o momento positivo e para o momento negativo, nota-se a diminuição significativa do coeficiente redutor de rigidez frente à evolução da fluência.

Tabela 4.9: Coeficientes redutores de rigidez para a viga com armadura passiva sob efeito da fluência na estrutura com modulação de $7,5 \mathrm{~m}$

\begin{tabular}{|c|c|c|c|c|}
\hline Fluência $(\varphi)$ & 0 & 1 & 2 & 3 \\
\hline $\mathrm{M}_{\text {pos }}(\alpha)$ & 0,467 & 0,340 & 0,267 & 0,220 \\
\hline $\mathrm{M}_{\text {neg }}(\alpha)$ & 0,310 & 0,249 & 0,209 & 0,180 \\
\hline
\end{tabular}

O coeficiente redutor indicado pela NBR 6118:2003 para vigas com armadura assimétrica é de 0,4 . Valor semelhante ao encontrado para a rigidez secante ao momento positivo com coeficiente linear de fluência igual a 0 .

Segundo a rigidez equivalente prescrita na NBR 6118:2003, baseada na teoria de Branson, obtém-se o valor de 0,475 como coeficiente redutor da rigidez no combate ao momento positivo. $\mathrm{O}$ valor é $1,7 \%$ maior que o obtido segundo o diagrama $\mathrm{M} \times \mathrm{N}$ x $1 / \mathrm{r}$, portanto a adoção da expressão de rigidez equivalente que a NBR 6118:2003 prescreve apresentou resultados satisfatórios, no entanto a expressão não contempla o comportamento reológico do concreto. Sendo assim, propõe-se a utilização de um fator de correção da rigidez equivalente apresentada, conforme é expresso a seguir.

$$
(E I)_{e q}=\frac{E_{c s}\left\{\left(\frac{M_{r}}{M_{a}}\right)^{3} \cdot I_{c}+\left[1-\left(\frac{M_{r}}{M_{a}}\right)^{3}\right] \cdot I_{I I}\right\}}{C}
$$


Em que:

$$
c=1+\phi / 3
$$

Com o auxílio da Figura 4.4 obtêm-se as variáveis apresentadas na Tabela 4.10 necessárias para obtenção da rigidez equivalente.

Tabela 4.10: Dados para definição da rigidez equivalente da viga com armadura passiva para estrutura com modulação de $7,5 \mathrm{~m}$

\begin{tabular}{|c|c|c|c|c|c|}
\hline $\mathrm{E}_{\mathrm{cs}}(\mathrm{GPa})$ & $\mathrm{I}_{\mathrm{c}}\left(\mathrm{m}^{4}\right)$ & $\mathrm{I}_{\mathrm{II}}\left(\mathrm{m}^{4}\right)$ & $\mathrm{M}_{\mathrm{r}}(\mathrm{kN} \cdot \mathrm{m})$ & $\mathrm{M}_{\mathrm{a}}(\mathrm{kN} \cdot \mathrm{m})$ & $\mathrm{EI}_{\mathrm{eq}}\left(\mathrm{kN} \cdot \mathrm{m}^{2}\right)$ \\
\hline 21,29 & 0,0182 & 0,0100 & 94,00 & 362,90 & 216739,76 \\
\hline
\end{tabular}

Para efeito de cálculo do momento atuante positivo foi considerado o valor obtido pela expressão $\mathrm{pl}^{2} / 8$ para todo o carregamento. $\mathrm{O}$ vão considerado para efeito de cálculo do momento atuante foi de $7,0 \mathrm{~m}$.

Adotando-se a expressão apresentada obtém-se os seguintes coeficientes redutores de rigidez:

Tabela 4.11: Coeficientes redutores de rigidez para a viga com armadura passiva sob efeito da fluência na estrutura com modulação de 7,5m segundo a expressão da NBR 6118:2003 adaptada

\begin{tabular}{|c|c|c|c|c|}
\hline FLUÊNCIA $(\varphi)$ & 0 & 1 & 2 & 3 \\
\hline $\mathrm{M}_{\text {pos }}(\alpha)$ & 0,475 & 0,356 & 0,285 & 0,238 \\
\hline
\end{tabular}

A adoção do fator de correção sugerido implicou em um erro de aproximação médio de $6,5 \%$ quando comparados os valores obtidos para os coeficientes redutores de rigidez segundo o diagrama $\mathrm{M} \times \mathrm{N} \times 1 / \mathrm{r}$. Foi constatada uma tendência de aumento do erro de aproximação com o incremento do coeficiente linear de fluência.

Com intuito de avaliar o incremento de rigidez proporcionado pelo uso da armadura ativa na viga, foi avaliada a máxima quantidade de armadura ativa possível de ser empregada. Esta condição foi respeitada segundo os limites de tensão associados às bordas superiores e inferiores da seção.

Foi considerado moderado o nível de agressividade ambiental no qual a estrutura está inserida, correspondendo à classe de agressividade CAAII, conforme a tabela 6.1 da NBR 6118:2003. Para esta classe de agressividade e pelo uso da pré-tração no sistema de protensão, fica definido pela tabela 13.3 da NBR 6118:2003 que o regime de protensão é o limitado. 
Neste regime de protensão devem ser verificadas as seguintes situações, conforme apresenta a Tabela 4.12. Foi adotada a convenção em que tensão negativa corresponde a tração e tensão positiva corresponde a compressão.

Tabela 4.12: Estados limites de serviço segundo combinações de ações

\begin{tabular}{|c|c|c|}
\hline ELS & COMBINAÇÃO DE AÇÕES & TENSÃO \\
\hline ELS-F & FREQUENTE & $-f_{c t, m}<\sigma<0,7 f_{c k}$ \\
\hline ELS-D & QUASE PERMANENTE & $0<\sigma<0,7 f_{c k}$ \\
\hline
\end{tabular}

Tendo em vista aplicar a máxima protensão na viga, e considerando o ciclo de produção de $24 \mathrm{hs}$ para vigas protendidas, foi limitada a tensão de compressão no concreto a 0,7.f $f_{\text {ckj }}$ referente a data de liberação da protensão. Na situação em vazio a viga está submetida apenas ao próprio peso. Sendo assim a armadura ativa deve ser definida respeitando a seguinte inequação na situação em vazio:

$$
\text { 1,2. } f_{c t, m}<\frac{N_{p}}{A} \pm \frac{M_{p}}{I} y \pm \frac{M_{g}}{I} y<0,7 . f_{c k j}
$$

Onde:

$N_{p}$ força de protensão;

$A$ área da seção transversal da viga;

$M_{p}$ momento fletor causado pela força de protensão;

I momento de inércia;

$y$ distância do cg da seção a fíbra considerada;

$f_{c k j}$ resistência à compressão do concreto da data de liberação da protensão.

A seção transversal da viga em concreto pré-moldado em seção composta está ilustrada na Figura 4.20. O concreto pré-moldado da viga apresenta $f_{\text {ck }}=40 \mathrm{MPa}$ e $\mathrm{f}_{\text {ckj }}=28$ $\mathrm{MPa}$, o concreto da capa moldada in loco apresenta $\mathrm{f}_{\mathrm{ck}}=20 \mathrm{MPa}$. A armadura ativa presente na seção é constituída de cordoalhas CP 190 RB 12,7, a armadura passiva é especificada em aço CA-50. 


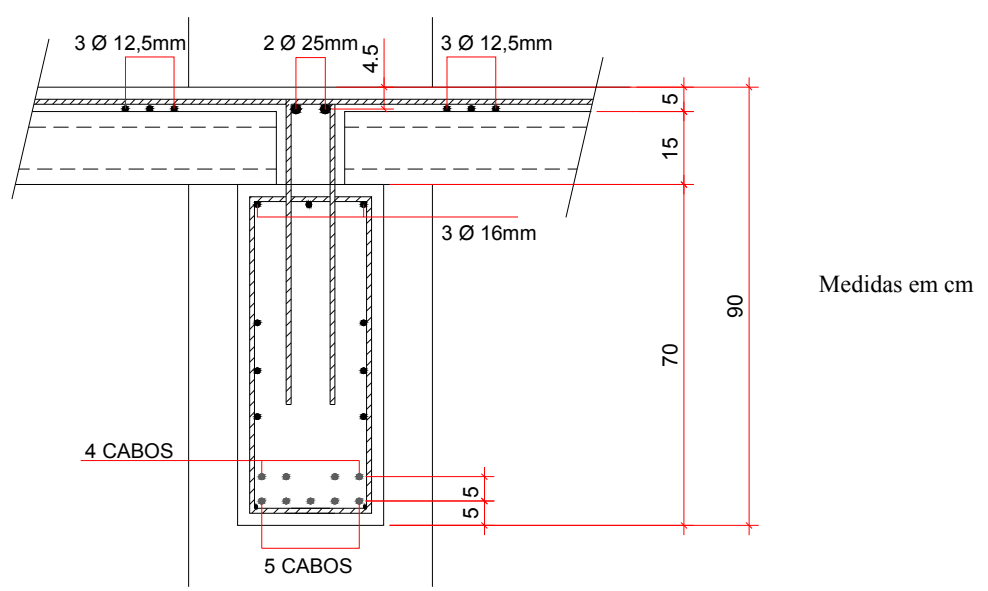

Figura 4.20: Seção transversal e disposição de armadura passiva e ativa da viga em concreto prémoldado em seção composta destinada a estrutura com modulação de $7,5 \mathrm{~m}$

Uma característica do traçado retilíneo da armadura ativa na pré-tração é o formato do diagrama de momento fletor gerado pela armadura ativa, no combate ao momento positivo da viga é interessante que haja uma concentração maior de armadura ativa no meio do vão. Em virtude do traçado retilíneo, este efeito é proporcionado isolando-se a armadura ativa nas regiões de interesse, neste caso junto ao apoio. Geralmente este isolamento é feito com o auxílio de dutos que envolvem as cordoalhas, impedindo a aderência das mesmas ao concreto e conseqüentemente a transferência de esforços. A existência de isolamento no trecho inicial da viga apresenta basicamente três benefícios:

O primeiro refere-se à diminuição da tensão de tração na fibra superior do elemento na situação em vazio, possibilitando uma redução da área armadura negativa necessária para combater as tensões de tração;

$>$ O segundo refere-se à diminuição da tensão de compressão na fibra inferior do elemento na situação em vazio, vale ressaltar que nos trechos iniciais do elemento o peso próprio da peça não contribui para aliviar estas tensões;

$>\mathrm{O}$ terceiro refere-se à diminuição das tensões de fendilhamento em virtude da redução do número de cabos no trecho inicial do elemento. Sendo assim, a armadura de fretagem é menos solicitada.

A Figura 4.21 ilustra o diagrama de distribuição dos cabos com aderência. 


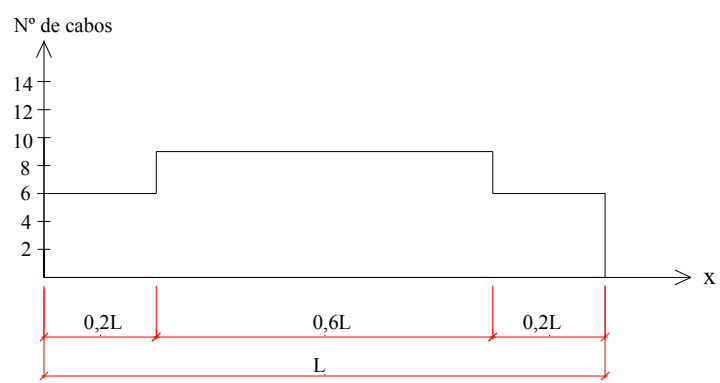

Figura 4.21: Distribuição da armadura ativa com aderência ao longo do eixo da viga para estrutura com modulação de $7,5 \mathrm{~m}$.

$\mathrm{Na}$ Tabela 4.13 estão apresentadas as condições de verificação para o dimensionamento no ELU na situação em vazio para a seção do meio do vão. Foi considerada uma força por cabo no tempo 0 de $141,96 \mathrm{kN}$, o que equivale a uma deformação de $7 \%$ no cabo cuja área é de $101,4 \mathrm{~mm}^{2}$. O momento fletor causado pelo peso próprio da viga foi calculado para um vão de $7 \mathrm{~m}$ de viga.

Tabela 4.13: Condições de verificação para o ELU na situação em vazio da viga para estrutura com modulação de $7,5 \mathrm{~m}$.

\begin{tabular}{|c|c|c|}
\hline Borda & Condição de cálculo & Armadura \\
\hline Inferior & $\frac{N_{p}}{0,21}+\frac{N_{p} \cdot 0,278}{0,008575} 0,35-\frac{32,16}{0,008575} 0,35<196.10^{2}\left(\mathrm{kN} / \mathrm{m}^{2}\right)$ & $\begin{array}{c}9 \text { cabos de } \\
12,7 \mathrm{~mm} \text { CP190 } \\
\text { RB }\end{array}$ \\
\hline Superior & $\frac{N_{p}}{0,21}-\frac{N_{p} \cdot 0,278}{0,008575} 0,35+\frac{32,16}{0,008575} 0,35=-710.10\left(\mathrm{kN} / \mathrm{m}^{2}\right)$ & $\begin{array}{c}3 \text { barras de } \\
16 \mathrm{~mm} \mathrm{CA}-50\end{array}$ \\
\hline
\end{tabular}

$\mathrm{Na}$ situação em vazio a máxima tensão de compressão corresponde a 0,7.f $\mathrm{f}_{\mathrm{ckj}}=19,6$ $\mathrm{MPa}$, a máxima tensão de tração corresponde a 1,2. $\mathrm{f}_{\mathrm{ct}, \mathrm{m}}=-3,32 \mathrm{MPa}$. Não foi adotada a condição de tensão maior ou igual a $1,2 \mathrm{f}_{\mathrm{ct}, \mathrm{m}}$, pelo fato da face superior da viga ser constituída de armadura passiva, entende-se que as tensões de tração devem estar limitadas a abertura de fissuras.

As verificações do elemento no ELS devem ser feitas nas três situações descritas na Tabela 3.1. Sendo que a $1^{\text {a }}$ situação, conhecida como situação em vazio já foi verificada. $\mathrm{Na} 3^{\mathrm{a}}$ situação descrita na Tabela 3.1, para efeito de verificação do ELS-F e ELS-D da viga são consideradas em uma primeira aproximação que as ligações terão comportamento semi-rígido com absorção de $20 \%$ de momento fletor na ligação, a Tabela 4.14 apresenta as tensões atuantes para as situações de cálculo da viga de concreto pré-moldado. As 
verificações para a borda superior e a borda inferior referem-se à seção em concreto prémoldado onde foi efetuada a protensão. Vale ressaltar que na $3^{\mathrm{a}}$ situação a borda inferior da viga em concreto pré-moldado com seção composta coincide com a borda inferior da viga em concreto pré-moldado. A borda superior da viga em concreto pré-moldado com seção composta não coincide com a borda superior da viga em concreto pré-moldado. A tensão atuante nas bordas da viga em concreto pré-moldado para a $3^{\text {a }}$ situação é obtida pela soma da tensão atuante na $2^{\mathrm{a}}$ situação com a tensão proveniente da carga de revestimento e da carga acidental de ocupação atuante na seção composta. Na $2^{\mathrm{a}}$ e $3^{\mathrm{a}}$ situações de cálculo foi considerada uma perda de $20 \%$ na protensão.

Tabela 4.14: Tensões atuantes na viga em concreto pré-moldado segundo as situações de cálculo para a estrutura com modulação de $7,5 \mathrm{~m}$

\begin{tabular}{|c|c|c|c|c|}
\hline \multirow{2}{*}{ Borda } & \multicolumn{4}{|c|}{ Tensão atuante $(\mathrm{MPa})$} \\
\cline { 2 - 5 } & $1^{\text {a }}$ Situação & $2^{\text {a }}$ Situação & \multicolumn{2}{|c|}{$3^{\text {a }}$ Situação } \\
\hline ELS-F/ELS-D & ELS-F/ELS-D & ELS-F & ELS-D \\
\hline Superior & $-7,10$ & 1,52 & $2,68^{(1)} / 1,77^{(2)}$ & $2,38^{(1)} / 1,77^{(2)}$ \\
\hline Inferior & 19,27 & 8,21 & $6,13^{(1)} / 7,76^{(2)}$ & $6,29^{(1)} / 7,65^{(2)}$ \\
\hline
\end{tabular}

(1) Carregamento acidental de ocupação igual a $3 \mathrm{kN} / \mathrm{m}^{2}$;

(2) Carregamento acidental de ocupação igual a $0 \mathrm{kN} / \mathrm{m}^{2}$.

Para a $2^{\mathrm{a}}$ e a $3^{\mathrm{a}}$ situação a máxima tensão corresponde a 0,7. $\mathrm{f}_{\mathrm{ck}}=28 \mathrm{MPa}$, no ELS-F a máxima tensão de tração corresponde a $\mathrm{f}_{\mathrm{ct}, \mathrm{m}}=-3,51 \mathrm{MPa}$ e no ELS-D não é permitida a existência de tensão de tração na borda da seção. As tensões atuantes na borda inferior e superior da seção da viga em concreto pré-moldado atenderam aos limites definidos na Tabela 4.12, com exceção da borda superior da $1^{\mathrm{a}}$ situação já comentada.

A Figura 4.22 e a Figura 4.23 ilustram os diagramas $\mathrm{M}$ x N x 1/r para a seção representada na Figura 4.20 sob efeito da protensão com 6 cabos e 9 cabos respectivamente, a força por cabo considerada corresponde a $113,57 \mathrm{kN}$, o que equivale a uma deformação de $5,6 \%$.

Este valor de deformação na armadura ativa já contempla $20 \%$ de perdas de protensão, para efeito de análise na estabilidade global as perdas de protensão devem ser consideradas no tempo infinito. 


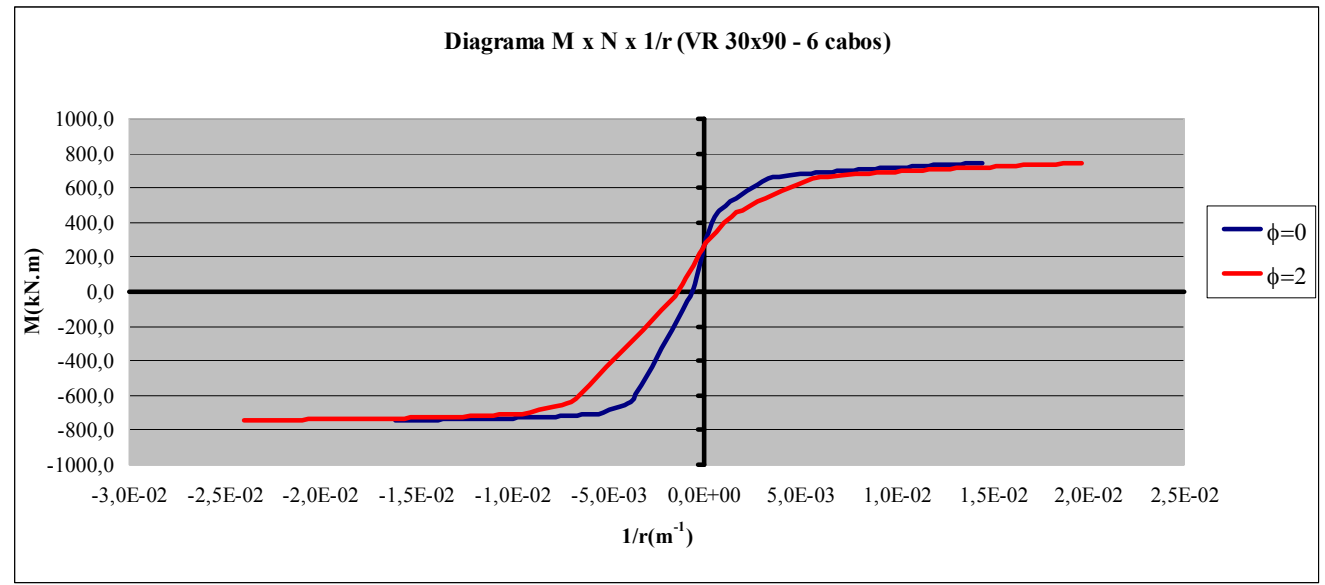

Figura 4.22: Diagrama $\mathrm{M}$ x N x 1/r sob efeito da protensão com 6 cabos.

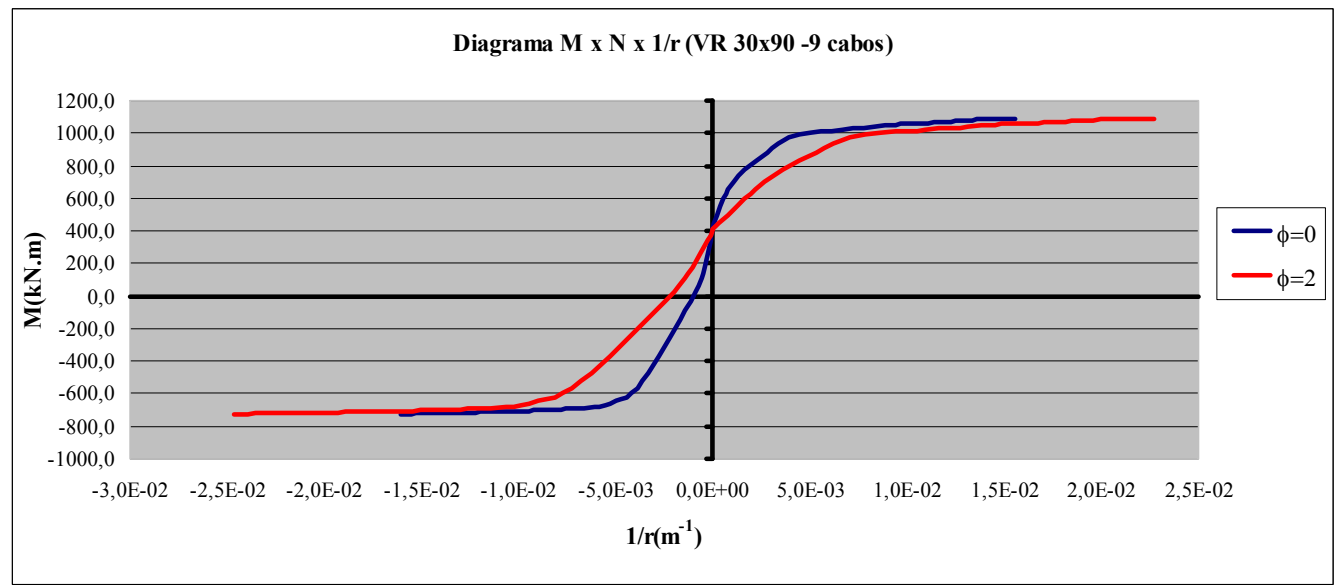

Figura 4.23: Diagrama M x N x 1/r sob efeito da protensão com 9 cabos

Os diagramas $\mathrm{M} \times \mathrm{N}$ x $1 / \mathrm{r}$ ilustrados na Figura 4.22 e na Figura 4.23 sofreram modificações em virtude da condição de contorno encontrada no programa ANSYS onde para curvatura nula tem-se momento nulo. Sendo assim, os diagramas encontrados foram adaptados para os diagramas ilustrados na Figura 4.24. O diagramas adaptados foram referenciados aos diagramas originais com coeficiente linear de fluência igual a 2 .

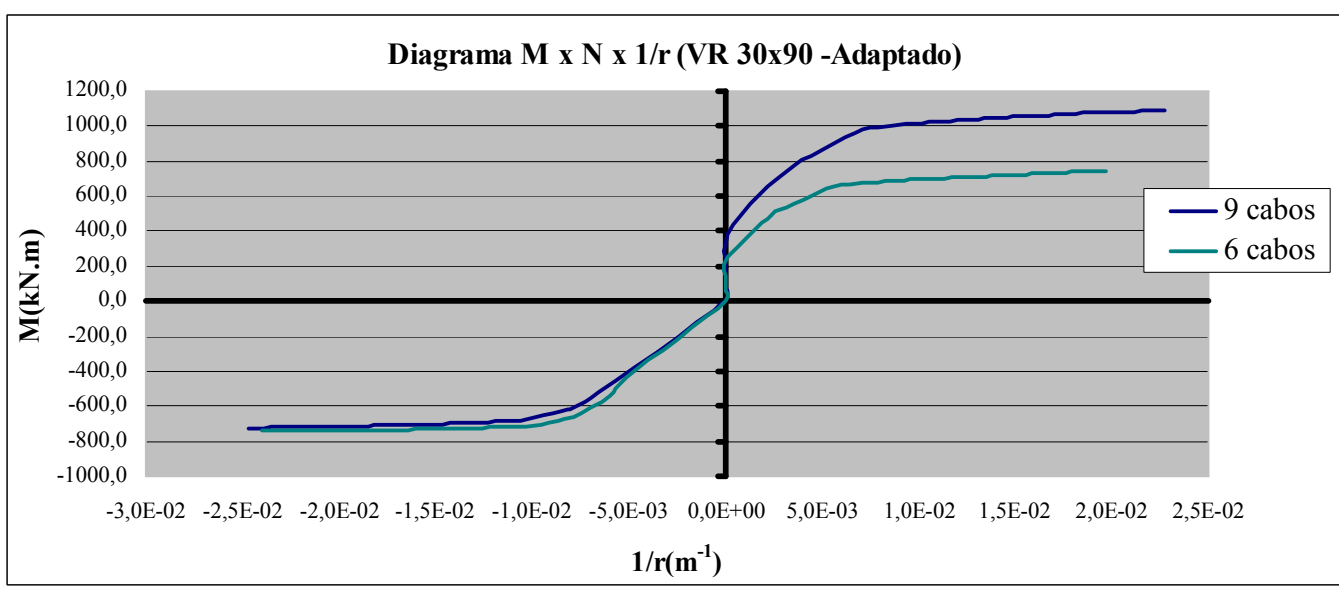

Figura 4.24: Diagrama M x N x 1/r adaptado sob efeito da protensão com 9 e 6 cabos 
A Tabela 4.15 apresenta os coeficientes redutores de rigidez obtidos utilizando armadura ativa na face inferior e armadura passiva na face superior da viga.

Tabela 4.15: Coeficientes redutores de rigidez para a viga com armadura passiva e armadura ativa sob efeito da fluência na estrutura com modulação de $7,5 \mathrm{~m}$

\begin{tabular}{|c|c|c|c|c|c|c|c|c|}
\cline { 2 - 9 } \multicolumn{1}{c|}{} & \multicolumn{4}{c|}{6 cabos } & \multicolumn{4}{c|}{9 cabos } \\
\hline Fluência $(\varphi)$ & 0 & 1 & 2 & 3 & 0 & 1 & 2 & 3 \\
\hline $\mathrm{M}_{\text {pos }}(\alpha)$ & 0,344 & 0,263 & 0,213 & 0,180 & 0,570 & 0,402 & 0,311 & 0,253 \\
\hline $\mathrm{M}_{\text {neg }}(\alpha)$ & 0,242 & 0,174 & 0,136 & 0,112 & 0,211 & 0,150 & 0,116 & 0,095 \\
\hline
\end{tabular}

A utilização da armadura ativa possibilitou um incremento de $22 \%$ na rigidez ao momento positivo para viga com 9 cabos e coeficiente linear de fluência igual a 0 , comparando-se com a viga constituída unicamente de armadura passiva. No entanto, a utilização da armadura ativa causou uma redução de $22 \%$ na rigidez ao momento negativo na viga com 6 cabos.

Com o auxílio das expressões (2.160) a (2.165) obtém-se as variáveis necessárias para obtenção da rigidez equivalente para a viga protendida com 9 cabos.

Tabela 4.16: Dados para definição da rigidez equivalente para seção da viga em concreto protendido na estrutura com modulação de $7,5 \mathrm{~m}$

\begin{tabular}{|c|c|c|c|c|c|}
\hline $\mathrm{E}_{\mathrm{cs}}(\mathrm{GPa})$ & $\mathrm{I}_{\mathrm{c}}\left(\mathrm{m}^{4}\right)$ & $\mathrm{I}_{\mathrm{II}}\left(\mathrm{m}^{4}\right)$ & $\mathrm{M}_{\mathrm{r}}(\mathrm{kN} \cdot \mathrm{m})$ & $\mathrm{M}_{\mathrm{a}}(\mathrm{kN} \cdot \mathrm{m})$ & $\mathrm{EI}_{\mathrm{eq}}\left(\mathrm{kN} \cdot \mathrm{m}^{2}\right)$ \\
\hline 21,29 & 0,0182 & 0,0042 & 710,36 & 362,90 & EI \\
\hline
\end{tabular}

Na Tabela 4.16 pode ser notado que o valor da rigidez equivalente pode ser tomado considerando a inércia bruta da seção, ou seja, o momento atuante é inferior ao momento de fissuração. Na Tabela 4.15, o coeficiente redutor de rigidez obtido segundo a rigidez secante com o auxílio do diagrama $\mathrm{M}$ x N x 1/r apresentou o valor de 0,57 .

Vale ressaltar as diferenças na aplicação de cada método, o momento de referência para cálculo do coeficiente redutor de rigidez segundo a rigidez equivalente é o momento atuante com valor característico. Segundo o método baseado na rigidez secante o momento de referência é o momento resistente associado ao ELU obtido com o valor de $0,85 \mathrm{f}_{\mathrm{cd}}$ dividido por 1,1 que, para este caso, assume o valor de 970,85 kN.m .

Analisando o diagrama M x N x 1/r ilustrado na Figura 4.23 para a seção da viga com 9 cabos, notam-se as diferenças de cada método. 
O momento de protensão para curvatura nula, ou seja, elemento submetido apenas a protensão é de $386,30 \mathrm{kN}$.m. Este valor é inferior ao momento atuante segundo o método da rigidez equivalente.

A inclinação da curva $\mathrm{M}$ x $1 / \mathrm{r}$ é alterada próximo ao valor de 700,00 kN.m de momento, valor associado ao momento de fissuração obtido segundo a expressão (2.165).

\subsubsection{CARACTERIZAÇÃO DA LIGAÇÃO EMPREGADA}

A seguir são apresentados os dados para a caracterização da ligação junto ao pilar central para o momento negativo e positivo, conforme a Tabela 4.17 e Tabela 4.18, respectivamente. No item 3.4 estão apresentadas as formulações analíticas necessárias para a caracterização das ligações.

Tabela 4.17: Dados de cálculo para caracterização da ligação ao momento negativo junto ao pilar central na estrutura com modulação de $7,5 \mathrm{~m}$

\begin{tabular}{|c|c|}
\hline$\varphi_{\text {armadura_médio }}(\mathrm{cm})$ & 1,88 \\
\hline $\mathrm{A}_{\mathrm{s}, \text { neg }}\left(\mathrm{cm}^{2}\right)$ & 17,5 \\
\hline $\mathrm{f}_{\mathrm{yd}, \text { armadura }}(\mathrm{MPa})$ & 435 \\
\hline $\mathrm{d}_{\mathrm{e}}(\mathrm{cm})$ & 4,5 \\
\hline $\mathrm{h}_{\mathrm{e}}(\mathrm{cm})$ & 54 \\
\hline $\mathrm{b}_{\mathrm{w}}(\mathrm{cm})$ & 30 \\
\hline $\mathrm{f}_{\mathrm{cg}}(\mathrm{MPa})$ & 20 \\
\hline $\mathrm{y}_{\mathrm{cn}}(\mathrm{cm})$ & 17,76 \\
\hline $\mathbf{M}_{\mathbf{y n}}(\mathbf{k N} \cdot \mathbf{m})$ & $\mathbf{3 0 9 , 2 1}$ \\
\hline $\mathrm{f}_{\mathrm{c}, \text { top }}(\mathrm{MPa})$ & 20 \\
\hline $\mathrm{E}_{\mathrm{c}, \text { top }}(\mathrm{MPa})$ & 25043,96 \\
\hline $\mathrm{E}_{\mathrm{s}}(\mathrm{MPa})$ & 210000 \\
\hline$\alpha_{\mathrm{e}}$ & 8,39 \\
\hline $\mathrm{A}_{\mathrm{c}, \mathrm{ef}}\left(\mathrm{cm}{ }^{2}\right)$ & 550 \\
\hline$\rho_{\mathrm{s}, \mathrm{ef}}$ & 0,0318 \\
\hline$\tau_{\mathrm{max}}(\mathrm{MPa})$ & 9,45 \\
\hline $\mathrm{w}_{\mathrm{y}(\mathrm{m})}$ & 0,00089 \\
\hline $\mathrm{D}_{\mathrm{gj}}(\mathrm{m} / \mathrm{MPa})$ & $1,00 \mathrm{E}-05$ \\
\hline $\mathrm{y}_{\mathrm{cr}}(\mathrm{cm})$ & 14,49 \\
\hline $\mathrm{k}_{\mathrm{s}}(\mathrm{MN} / \mathrm{m})$ & 853,16 \\
\hline $\mathrm{k}_{\mathrm{g}}(\mathrm{MN} / \mathrm{m})$ & 5328,75 \\
\hline $\mathbf{k}_{\mathbf{\varphi n} \mathbf{n}}(\mathbf{M N} \cdot \mathbf{m} / \mathbf{r a d})$ & $\mathbf{1 2 1 , 3 4}$ \\
\hline
\end{tabular}


Tabela 4.18: Dados de cálculo para caracterização da ligação ao momento positivo junto ao pilar central na estrutura com modulação de $7,5 \mathrm{~m}$

\begin{tabular}{|c|c|}
\hline$\varphi_{\text {chumbador }}(\mathrm{cm})$ & 2 \\
\hline $\mathrm{f}_{\mathrm{cc}, \max }(\mathrm{MPa})$ & 35 \\
\hline $\mathrm{f}_{\mathrm{yd}, \text { chumbador }}(\mathrm{MPa})$ & 209 \\
\hline $\mathrm{c}$ & 1,245 \\
\hline $\mathrm{F}_{\mathrm{sd}}(\mathrm{kN})$ & 72 \\
\hline $\mathrm{y}_{\mathrm{cp}}(\mathrm{cm})$ & 0,458 \\
\hline $\mathrm{h}_{\mathrm{c}}(\mathrm{cm})$ & 54 \\
\hline $\mathbf{M}_{\mathbf{y p}}(\mathbf{k N} . \mathbf{m})$ & $\mathbf{3 8 , 7 1}$ \\
\hline$\alpha_{\mathrm{vy}}(\mathrm{cm})$ & 0,2 \\
\hline $\mathrm{k}_{\mathrm{sd}}(\mathrm{MN} / \mathrm{m})$ & 36 \\
\hline $\mathbf{k}_{\mathbf{\varphi p}}(\mathbf{M N} \cdot \mathbf{m} / \mathbf{r a d})$ & $\mathbf{1 0 , 4 1}$ \\
\hline
\end{tabular}

$\mathrm{Na}$ Tabela 4.19 é possível visualizar um resumo com as características da ligação junto ao pilar central e junto ao pilar lateral em dente gerber utilizadas, a alternativa de viga sem recorte na extremidade também está sendo apresentada.

Tabela 4.19: Rigidez e momentos resistentes nas ligações destinadas a estrutura com modulação de $7,5 \mathrm{~m}$

\begin{tabular}{|c|c|c|c|c|c|c|c|}
\cline { 2 - 8 } \multicolumn{1}{c|}{} & \multicolumn{2}{c|}{$\mathrm{PC}$} & \multicolumn{2}{c|}{$\mathrm{PL}$} & \multicolumn{3}{c|}{$\mathrm{PC} / \mathrm{PL}$} \\
\cline { 2 - 8 } \multicolumn{1}{c|}{} & $\mathrm{M}_{\text {neg( }(1)}$ & $\mathrm{M}_{\text {neg }(2)}$ & $\mathrm{M}_{\text {neg(1) }}$ & $\mathrm{M}_{\text {neg(2) }}$ & $\mathrm{M}_{\mathrm{pos}(3)}$ & $\mathrm{M}_{\mathrm{pos}(4)}$ & $\mathrm{M}_{\text {pos }(5)}$ \\
\hline $\mathrm{K}(\mathrm{MN} . \mathrm{m} / \mathrm{rad})$ & 121,34 & 430,96 & 65,13 & 213,45 & 10,41 & 14,96 & 41,76 \\
\hline $\mathrm{M}_{\mathrm{y}}(\mathrm{kN} . \mathrm{m})$ & 309,21 & 583,26 & 193,25 & 349,85 & 38,71 & 55,74 & 93,14 \\
\hline
\end{tabular}

(1)Viga com extremidade em dente gerber;

(2)Viga com extremidade sem recorte;

(3) Viga com extremidade em dente gerber e chumbador com $\mathrm{f}_{\mathrm{yd}}=209 \mathrm{MPa}$;

(4) Viga com extremidade em dente gerber e chumbador com $\mathrm{f}_{\mathrm{yd}}=435 \mathrm{MPa}$;

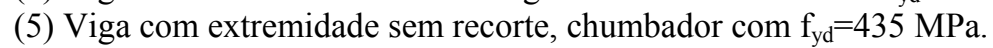

A diferença encontrada tanto para o momento resistente negativo, bem como para rigidez associada ao momento negativo decorre do fato de não haver ancoragem para as barras que passam na capa de concreto nos pilares laterais, no caso em estudo isto provoca uma redução na área de armadura de $17,5 \mathrm{~cm}^{2}$ para $10 \mathrm{~cm}^{2}$.

Para que a durabilidade e o desempenho da ligação fossem preservados, foi definido que o momento atuante sob a combinação de serviço foi limitado a $60 \%$ do momento de plastificação da ligação. A Figura 4.25 ilustra o diagrama momento x rotação da ligação junto ao pilar central para efeito de dimensionamento no ELU e no ELS. 


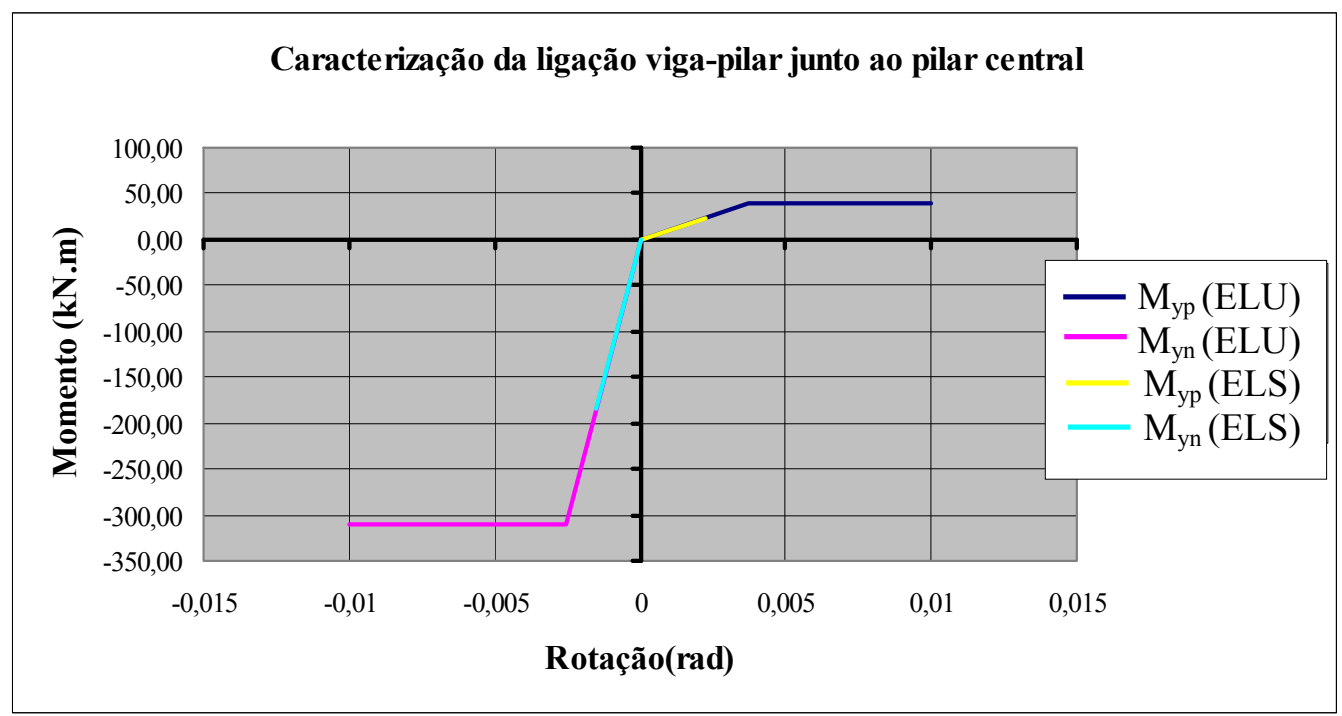

Figura 4.25: Diagrama de momento x rotação da ligação viga-pilar junto ao pilar central 


\subsection{ESTUDO DA VARIAÇÃO DE PARÂMETROS DA ESTRUTURA TÍPICA}

Nos exemplos numéricos do modelo com 6 pavimentos as modelagens numéricas são feitas considerando o modelo linear de comportamento da ligação. Neste modelo é definida apenas a rigidez ao momento positivo e negativo da ligação, não sendo delimitado o momento de plastificação e o trecho correspondente à plastificação. A $1^{\text {a }}$ combinação de ações foi tomada como referência para todas as modelagens, vale ressaltar que os esforços atuantes na estrutura são apresentados contemplando os efeitos não-lineares geométricos.

São avaliadas as seguintes variações na distribuição de esforços e na estabilidade global da estrutura:

> Influência do efeito reológico do concreto;

$>$ Influência da consideração da rigidez secante na modelagem de vigas e pilares em concreto armado;

> Influência da utilização de armadura ativa nas vigas;

$>$ Influência da consideração da rigidez secante na modelagem de vigas em concreto protendido;

$>$ Influência das combinações de ações no ELU;

$>$ Influência da combinação de ações no ELS;

> Influência do comportamento bi-linear da ligação viga-pilar;

$>$ Influência da utilização de seção composta alternativa (concretagem em duas fases);

$>$ Influência da presença da ligação semi-rígida pilar-fundação;

$>$ Influência do tipo de análise NLG.

\subsubsection{INFLUÊNCIA DO EFEITO REOLÓGICO DO CONCRETO}

Para efeito de análise da estabilidade global, foram comparados os efeitos da consideração da fluência nas vigas de concreto armado. A análise corresponde à avaliação no tempo inicial, onde os efeitos reológicos do concreto não são significativos e no tempo infinito onde os efeitos reológicos ganham importância. Os diagramas de momento fletor obtidos para a $1^{\mathrm{a}}$ combinação de ações estão ilustrados na Figura 4.26 e Figura 4.27. A Tabela 4.20 apresenta os principais parâmetros de análise da estrutura, os esforços foram obtidos considerando os efeitos não-lineares geométricos. 
Tabela 4.20: Distribuição de momento fletor e $\gamma_{z}$ segundo a $1^{\mathrm{a}}$ combinação de ações com e sem o efeito da fluência nas vigas

\begin{tabular}{|c|c|c|c|c|c|c|c|c|}
\cline { 2 - 9 } \multicolumn{1}{c|}{} & \multicolumn{7}{c|}{ MOMENTO FLETOR(kN.m) } & \\
\hline Fluência & $\mathrm{M}_{\mathrm{a}}$ & $\mathrm{M}_{\mathrm{b}}$ & $\mathrm{M}_{\mathrm{c}}$ & $\mathrm{M}_{\text {pos }}$ & $\mathrm{M}_{\text {neg,central }}$ & $\mathrm{M}_{\text {neg,lateral }}$ & $\mathrm{M}_{\mathrm{V}}$ & $\gamma_{\mathrm{Z}}$ \\
\hline$\phi=0$ & 280,76 & 360,06 & 353,56 & 48,92 & 337,89 & 252,30 & 356,40 & 1,108 \\
\hline$\phi=2$ & 298,11 & 373,80 & 369,15 & 50,30 & 320,17 & 254,81 & 342,37 & 1,112 \\
\hline
\end{tabular}

$\mathrm{M}_{\mathrm{a}}$ : momento na base do pilar lateral esquerdo do $1^{\circ}$ pavimento; $\mathrm{M}_{\mathrm{b}}$ : momento na base do pilar central do $1^{\circ}$ pavimento; $\mathrm{M}_{\mathrm{c}}$ : momento na base do pilar lateral direito do $1^{\circ}$ pavimento;

$\mathrm{M}_{\text {pos }}$ : maior momento positivo na ligação; $\mathrm{M}_{\text {neg,central }}$ : maior momento negativo na ligação junto ao pilar central; $\mathrm{M}_{\text {neg,lateral }}$ : maior momento negativo na ligação junto ao pilar lateral; $\mathrm{M}_{\mathrm{v}}$ : maior momento positivo na viga.

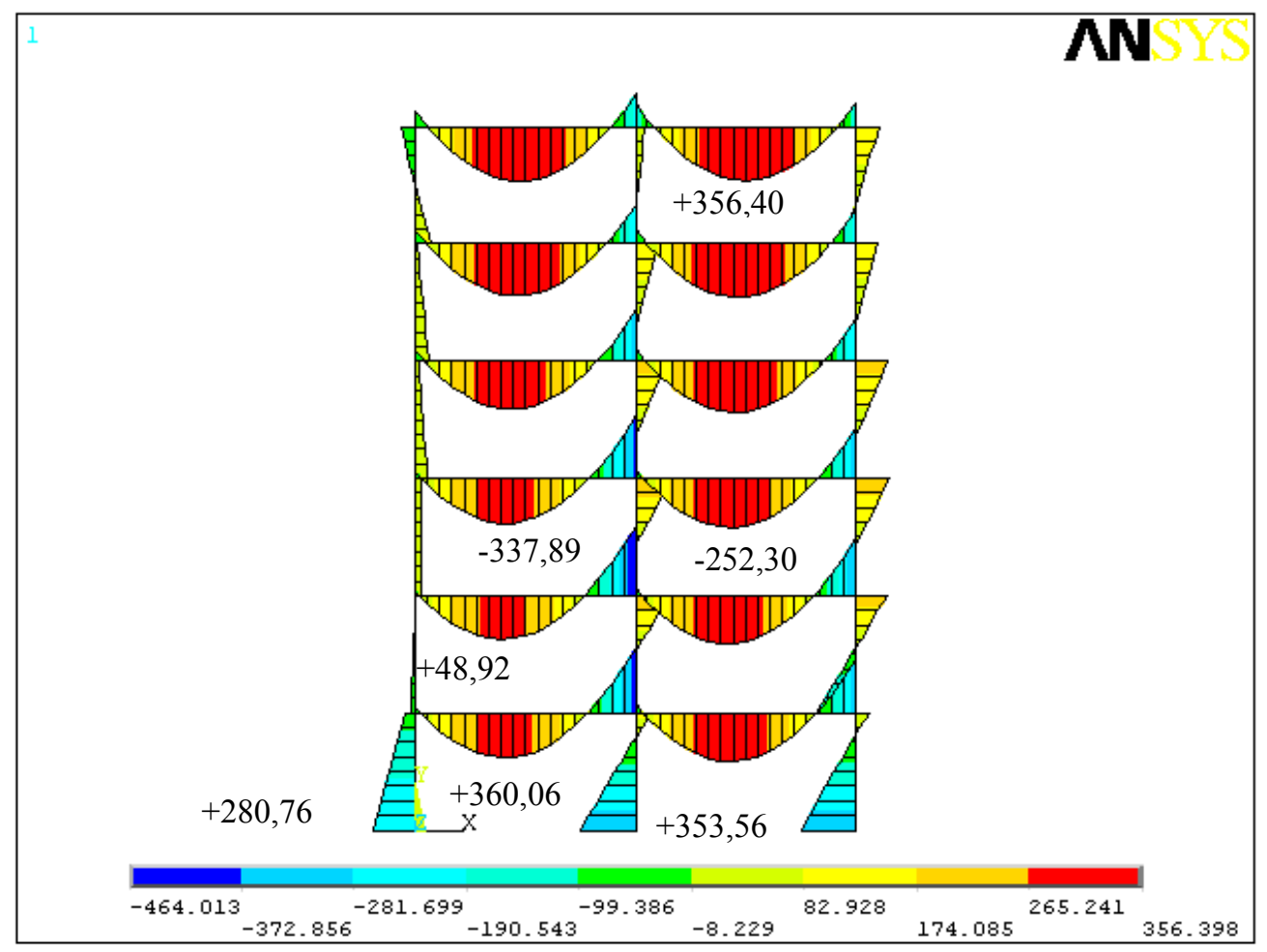

Figura 4.26: Diagrama de momento fletor obtido segundo a $1^{\mathrm{a}}$ combinação de ações no tempo inicial 


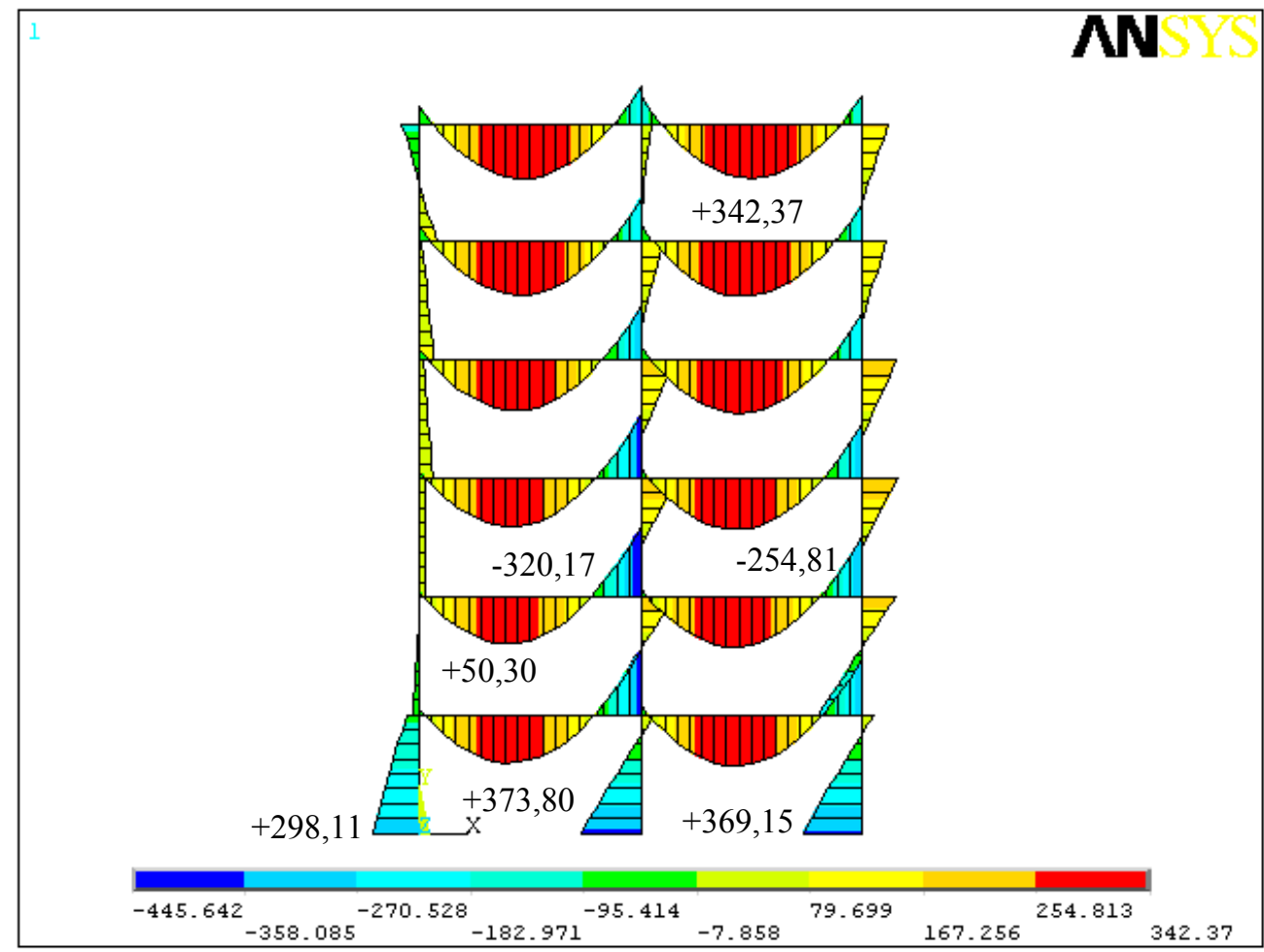

Figura 4.27: Diagrama de momento fletor obtido segundo a $1^{\mathrm{a}}$ combinação de ações no tempo infinito

A partir dos valores apresentados na Tabela 4.20 para o coeficiente $\gamma_{z}$, concluí-se que a omissão do efeito da fluência na rigidez dos elementos torna a estrutura menos deslocável.

Além disto, a consideração da fluência alterou a distribuição de esforços nos elementos. Nos pilares houve um acréscimo médio de 4,5\% nos momentos fletores, já nas vigas houve uma diminuição de, aproximadamente, $4 \%$ nos momentos obtidos. Nas ligações houve uma mudança, em média, de 3\% na distribuição de momento fletor.

\subsubsection{INFLUÊNCIA DA CONSIDERAÇÃO DA RIGIDEZ SECANTE NA MODELAGEM DE VIGAS E PILARES EM CONCRETO ARMADO}

Segundo a NBR 6118:2003 a avaliação da estabilidade global das estruturas pode ser feita de forma mais simplificada, considerando a rigidez secante dos elementos obtida segundo o diagrama $\mathrm{M} \times \mathrm{N}$ x 1/r. Até então, a análise foi feita considerando a curva $\mathrm{M} \times \mathrm{N}$ x $1 /$ r. Foram feitas duas novas análises na estrutura, onde na primeira análise o elemento de viga é modelado considerando a rigidez secante ao momento positivo sob efeito da fluência com $\phi=2$, conforme apresenta a Tabela 4.21. Na segunda análise, os pilares e as vigas foram modelados segundo a rigidez secante, conforme apresenta a Tabela 4.22. Desta forma é 
possível avaliar a mudança na configuração dos esforços e deslocamentos sob estas condições.

Tabela 4.21: Distribuição de momento fletor e $\gamma_{\mathrm{z}}$ segundo a $1^{\mathrm{a}}$ combinação de ações considerando a modelagem das vigas segundo a rigidez secante

\begin{tabular}{|c|c|c|c|c|c|c|c|}
\hline \multicolumn{7}{|c|}{ MOMENTO FLETOR(kN.m) } & \multirow{2}{*}{} \\
\hline $\mathrm{M}_{\mathrm{a}}$ & $\mathrm{M}_{\mathrm{b}}$ & $\mathrm{M}_{\mathrm{c}}$ & $\mathrm{M}_{\mathrm{pos}}$ & $\mathrm{M}_{\text {neg,central }}$ & $\mathrm{M}_{\text {neg,lateral }}$ & $\mathrm{M}_{\mathrm{V}}$ & $\gamma_{\mathrm{Z}}$ \\
\hline 300,46 & 375,73 & 371,18 & 50,41 & 318,62 & 255,05 & 340,87 & 1,113 \\
\hline
\end{tabular}

Tabela 4.22: Distribuição de momento fletor e $\gamma_{z}$ segundo a $1^{\text {a }}$ combinação de ações considerando a modelagem das vigas e pilares segundo a rigidez secante

\begin{tabular}{|c|c|c|c|c|c|c|c|}
\hline \multicolumn{7}{|c|}{ MOMENTO FLETOR(kN.m) } & \multicolumn{1}{c|}{} \\
\hline $\mathrm{M}_{\mathrm{a}}$ & $\mathrm{M}_{\mathrm{b}}$ & $\mathrm{M}_{\mathrm{c}}$ & $\mathrm{M}_{\text {pos }}$ & $\mathrm{M}_{\text {neg,central }}$ & $\mathrm{M}_{\text {neg,lateral }}$ & $\mathrm{M}_{\mathrm{V}}$ & $\gamma_{\mathrm{Z}}$ \\
\hline 247,69 & 366,13 & 332,52 & 66,48 & 354,82 & 284,54 & 343,99 & 1,145 \\
\hline
\end{tabular}

Analisando a Tabela 4.21, nota-se que a modelagem das vigas segundo a rigidez secante provocou mudanças na configuração de esforços da ordem de $0,5 \%$, em relação ao $\gamma_{Z}$ não houve mudanças significativas quando comparado com os valores obtidos com a modelagem segundo o digrama $\mathrm{M}$ x N x1/r, conforme é apresentado na Tabela 4.20.

Os valores de momento obtidos na modelagem da estrutura considerando a rigidez secante de pilares e vigas, conforme apresenta a Tabela 4.22, foram comparados com os valores obtidos na modelagem segundo o diagrama $\mathrm{M}$ x $\mathrm{N}$ x $1 / \mathrm{r}$ e apresentados na Tabela 4.20 .

A mudança na configuração de esforços foi superior, em média, a 10\% para os momentos fletores nos pilares e nas ligações, sendo que para o momento positivo na ligação esta diferença foi da ordem de 30\%. Além disto, foi constatado um aumento nos deslocamentos obtidos, conforme indicado pelo incremento de $3 \%$ do $\gamma_{z}$.

\subsubsection{INFLUÊNCIA DA UTILIZAÇÃO DE ARMADURA ATIVA NAS VIGAS}

Do mesmo modo que o efeito da fluência não deve ser omitido na análise da estabilidade global, a consideração da alteração da rigidez da viga pela adoção de armadura ativa também deve ser contemplada.

$\mathrm{Na}$ Tabela 4.23 pode ser observado que a adoção da armadura ativa alterou a distribuição de esforços na estrutura. Com intuito de avaliar apenas a influência da utilização 
da armadura ativa na distribuição de esforços e na estabilidade global, não foi considerado o efeito da fluência em conjunto.

Tabela 4.23: Distribuição de momento fletor e $\gamma_{z}$ segundo a $1^{\mathrm{a}}$ combinação de ações utilizando armadura ativa nas vigas sem considerar a fluência

\begin{tabular}{|c|c|c|c|c|c|c|c|}
\hline \multicolumn{7}{|c|}{ MOMENTO FLETOR(kN.m) } & \multirow{2}{*}{} \\
\hline $\mathrm{M}_{\mathrm{a}}$ & $\mathrm{M}_{\mathrm{b}}$ & $\mathrm{M}_{\mathrm{c}}$ & $\mathrm{M}_{\text {pos }}$ & $\mathrm{M}_{\text {neg,central }}$ & $\mathrm{M}_{\text {neg, lateral }}$ & $\mathrm{M}_{\mathrm{V}}$ & $\gamma_{\mathrm{Z}}$ \\
\hline 327,98 & 397,86 & 389,80 & 72,34 & 282,19 & 235,49 & 387,93 & 1,131 \\
\hline
\end{tabular}

O comportamento do diagrama de momento fletor na estrutura, alterado pelo uso de armadura ativa nas vigas para a $1^{\mathrm{a}}$ combinação do ELU está ilustrado na Figura 4.28.

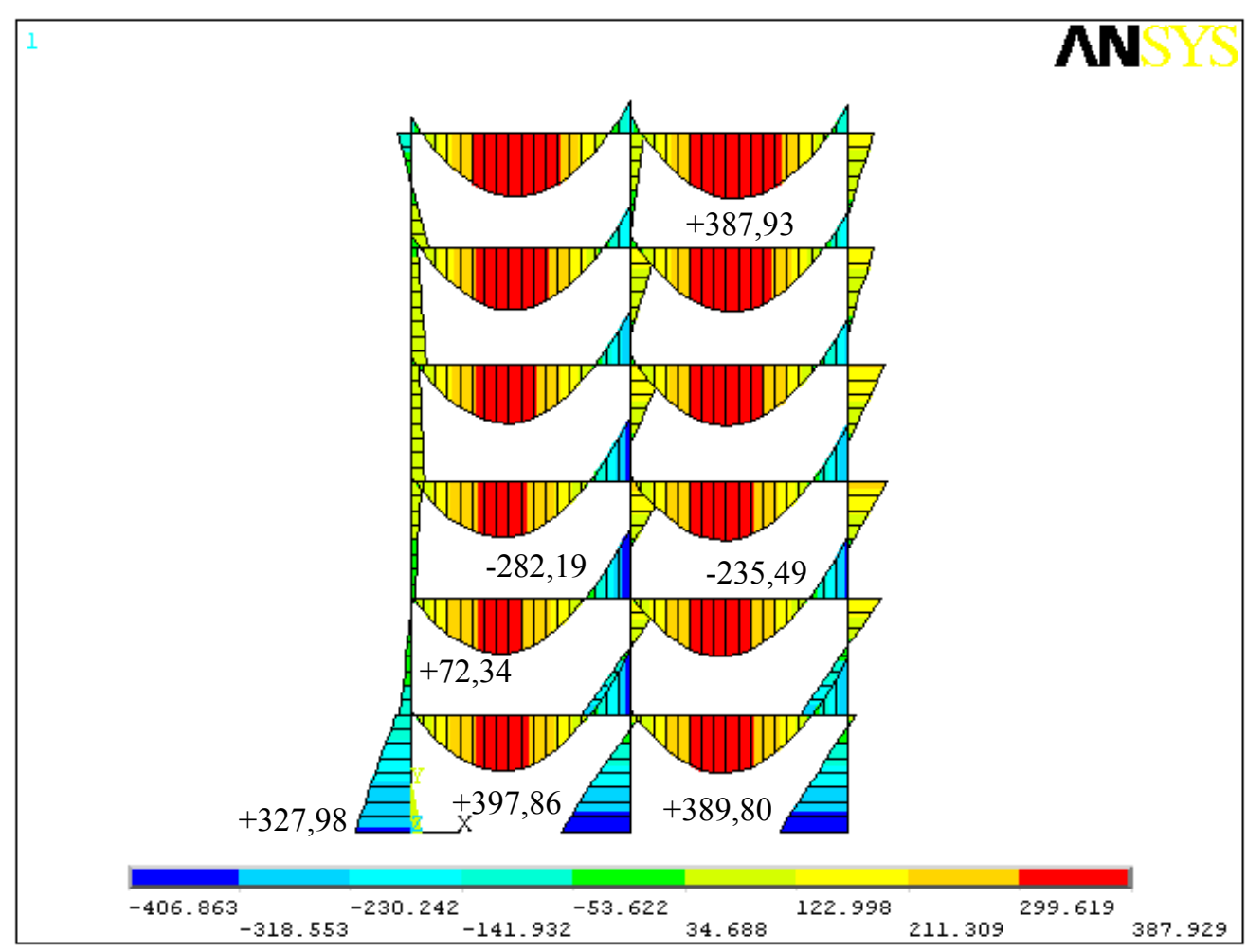

Figura 4.28: Diagrama de momento para $1^{\mathrm{a}}$ combinação de ações utilizando armadura ativa nas vigas sem considerar a fluência

A armadura presente nas vigas ilustradas na Figura 4.4 e na Figura 4.20 não conduzem ao mesmo momento resistente, no entanto, foi comparada a influência da presença da armadura ativa e da armadura passiva nos principais parâmetros de análise da estabilidade global. Comparando-se os resultados apresentados na Tabela 4.20 e na Tabela 4.23 para situação sem consideração da fluência encontra-se um acréscimo de mais de $10 \%$ nos momentos fletores obtidos nos pilares para estrutura com presença de armadura ativa nas 
vigas. Para esta situação houve um acréscimo de $47 \%$ no momento positivo absorvido pela ligação e um decréscimo, em média, de $12 \%$ do momento negativo absorvido pelas ligações.

Em termos de deslocamento, houve um acréscimo de $2 \%$ no valor de $\gamma_{Z}$ na situação em que se emprega armadura ativa nas vigas. Este comportamento pode ser atribuído a maior mobilização da ligação ao momento positivo na situação em que se emprega armadura ativa.

A ligação apresenta comportamento menos rígido ao momento positivo conforme apresentado na Tabela 4.19, portanto a estrutura se torna mais deslocável.

\subsubsection{INFLUÊNCIA DA CONSIDERAÇÃO DA RIGIDEZ SECANTE NA MODELAGEM DE VIGAS COM ARMADURA ATIVA}

Foi avaliada a mudança na configuração de esforços da estrutura quando o elemento de viga é modelado considerando a rigidez secante ao momento positivo, conforme apresenta a Tabela 4.24.

Tabela 4.24: Distribuição de momento fletor e $\gamma_{z}$ segundo a $1^{\mathrm{a}}$ combinação de ações utilizando armadura ativa nas vigas considerando a rigidez secante ao momento positivo sem considerar a fluência

\begin{tabular}{|c|c|c|c|c|c|c|c|}
\hline \multicolumn{7}{|c|}{ MOMENTO FLETOR(kN.m) } & \multirow{2}{*}{$\mathrm{y}_{\mathrm{Z}}$} \\
\hline $\mathrm{M}_{\mathrm{a}}$ & $\mathrm{M}_{\mathrm{b}}$ & $\mathrm{M}_{\mathrm{c}}$ & $\mathrm{M}_{\mathrm{pos}}$ & $\mathrm{M}_{\text {neg,central }}$ & $\mathrm{M}_{\text {neg,lateral }}$ & $\mathrm{M}_{\mathrm{V}}$ & $\gamma_{\mathrm{n}}$ \\
\hline 276,73 & 356,98 & 349,67 & 48,48 & 342,98 & 251,33 & 361,07 & 1,100 \\
\hline
\end{tabular}

Comparando-se os valores de momento fletor da Tabela 4.23 e Tabela 4.24, nota-se que a modelagem das vigas considerando a rigidez secante provocou uma diminuição do momento fletor positivo absorvido pela ligação. Isto ocorreu, pois segundo o diagrama $\mathrm{M} \times \mathrm{N}$ $\mathrm{x} 1 / \mathrm{r}$ a rigidez da viga ao momento fletor para baixos níveis de esforço solicitante é muito superior a obtida segundo a rigidez secante. A maior absorção de momento fletor positivo pela viga provocou uma maior mobilização do momento positivo da ligação, em virtude da menor rigidez ao momento positivo da ligação houve um aumento dos deslocamentos, conforme indicado pelo acréscimo de, aproximadamente, $2,8 \%$ no valor do $\gamma_{\mathrm{z}}$.

Em relação à distribuição de esforços nos outros elementos, houve aumento na absorção de esforços ao momento negativo na ligação quando se faz uso do modelo de rigidez secante. Pode ser constatado que a influência do método de consideração da não-linearidade física em vigas com armadura ativa é maior do que em vigas com armadura passiva. A mudança na configuração de esforços quando se altera o método de análise de diagrama $\mathrm{M} \mathrm{x}$ 
$\mathrm{N} \mathrm{x} \mathrm{1/r} \mathrm{para} \mathrm{rigidez} \mathrm{secante} \mathrm{é} \mathrm{da} \mathrm{ordem} \mathrm{de} 1 \%$ para vigas com armadura passiva e é superior a $10 \%$ para vigas com armadura ativa.

\subsubsection{INFLUÊNCIA DAS COMBINAÇÕES DE AÇÕES NO ELU}

A verificação da estabilidade global de uma estrutura e o dimensionamento dos elementos estruturais e das ligações deve ser analisada segundo uma envoltória de combinações de ações críticas.

A Figura 4.29 e a Figura 4.30 ilustram o comportamento do diagrama de momento fletor para a $2^{\mathrm{a}}$ e $3^{\mathrm{a}}$ combinações de ações para viga em concreto armado com coeficiente linear de fluência igual a 2 . Na $2^{\mathrm{a}}$ combinação de ações a ação do vento é considerada a única ação acidental atuante na estrutura, já na $3^{\text {a }}$ combinação de ações a carga acidental de ocupação é considerada como carga acidental principal.

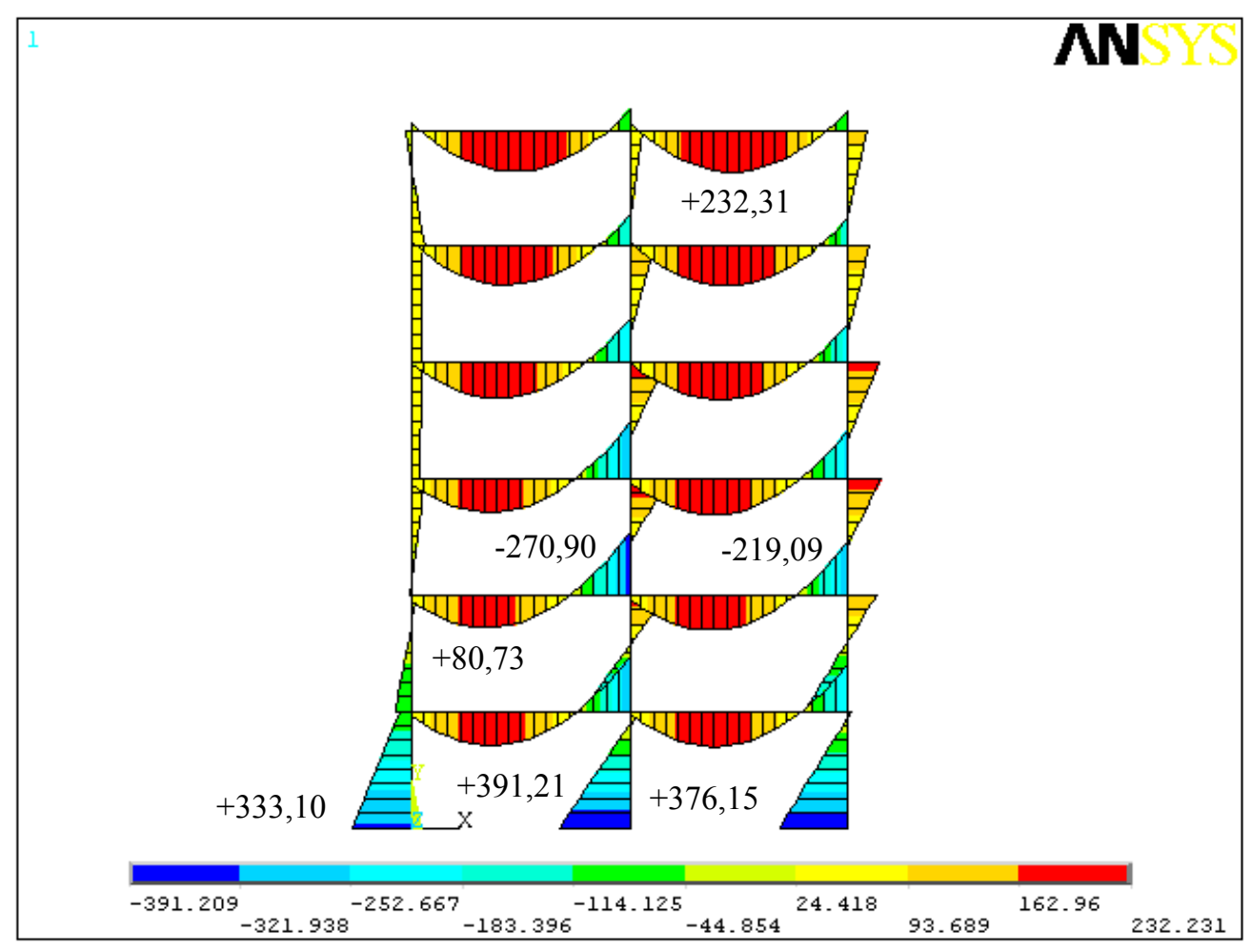

Figura 4.29: Diagrama de momento fletor obtido segundo a $2^{\mathrm{a}}$ combinação de ações 


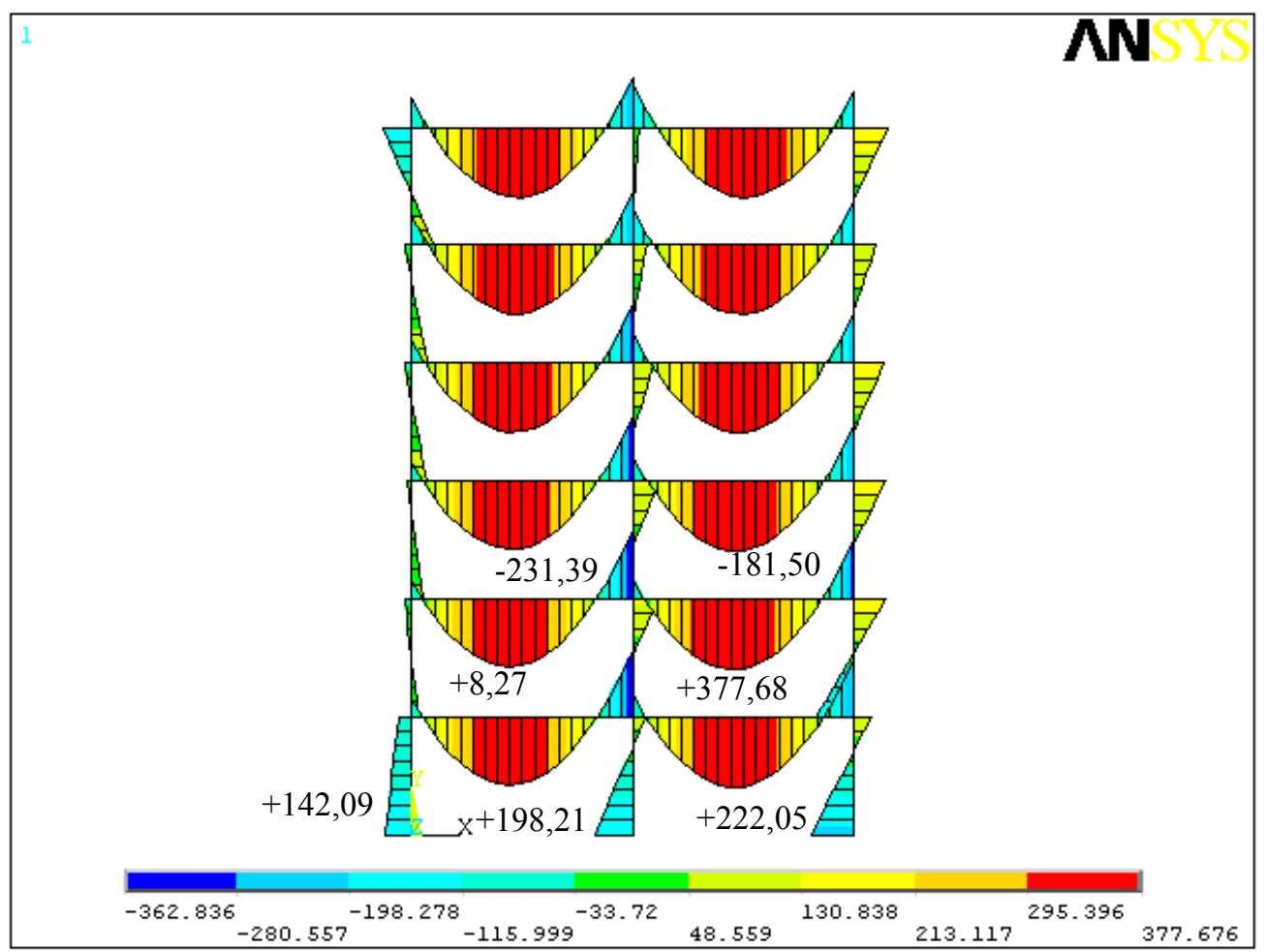

Figura 4.30: Diagrama de momento fletor obtido segundo a $3^{\mathrm{a}}$ combinação de ações

A Tabela 4.25 e a Tabela 4.26 ilustram os principais parâmetros de análise da estrutura segundo a combinação de ações.

Tabela 4.25: Parâmetros de análise segundo combinação de ações

\begin{tabular}{|c|c|c|c|c|c|c|c|c|}
\cline { 2 - 9 } \multicolumn{1}{c|}{} & \multicolumn{7}{c|}{ MOMENTO FLETOR (kN.m) } & \multicolumn{1}{c|}{} \\
\hline Combinação & $\mathrm{M}_{\mathrm{a}}$ & $\mathrm{M}_{\mathrm{b}}$ & $\mathrm{M}_{\mathrm{c}}$ & $\mathrm{M}_{\text {pos }}$ & $\mathrm{M}_{\text {neg,central }}$ & $\mathrm{M}_{\text {neg,lateral }}$ & $\mathrm{M}_{\mathrm{V}}$ & $\gamma_{\mathrm{Z}}$ \\
\hline $1^{\mathrm{a}}$ & 298,11 & 373,80 & 369,15 & 50,30 & 320,17 & 254,81 & 342,37 & 1,112 \\
\hline $2^{\mathrm{a}}$ & 333,10 & 391,21 & 376,15 & 80,73 & 270,90 & 219,09 & 232,31 & 1,099 \\
\hline $3^{\mathrm{a}}$ & 142,09 & 198,21 & 222,05 & 8,27 & 231,39 & 181,50 & 377,68 & 1,098 \\
\hline
\end{tabular}

Tabela 4.26: Força normal no $1^{\circ}$ pavimento segundo combinação de ações

\begin{tabular}{|c|c|c|}
\hline \multicolumn{3}{|c|}{ FORÇA NORMAL $(\mathrm{kN})$} \\
\hline Combinação & $\mathrm{N}_{\mathrm{b}}$ & $\mathrm{N}_{\mathrm{a}} / \mathrm{N}_{\mathrm{c}}$ \\
\hline $1^{\mathrm{a}}$ & 3209,63 & 2436,93 \\
\hline $2^{\mathrm{a}}$ & 1981,13 & 1822,69 \\
\hline $3^{\mathrm{a}}$ & 3634,87 & 2649,47 \\
\hline
\end{tabular}

$\mathrm{N}_{\mathrm{a}}$ : força normal na base do pilar lateral esquerdo do $1^{\circ}$ pavimento;

$\mathrm{N}_{\mathrm{b}}$ : força normal na base do pilar central do $1^{\circ}$ pavimento;

$\mathrm{N}_{\mathrm{c}}$ : força normal na base do pilar lateral direito do $1^{\circ}$ pavimento. 
Observando a Tabela 4.25 é possível mapear os pontos mais críticos segundo as combinações de ações, conforme ilustra os itens destacados na Tabela 4.27.

Tabela 4.27: Parâmetros críticos segundo combinação de ações

\begin{tabular}{|c|c|c|c|c|c|c|c|c|}
\hline Combinação & $\mathrm{M}_{\mathrm{a}}$ & $\mathrm{M}_{\mathrm{b}}$ & $\mathrm{M}_{\mathrm{c}}$ & $\mathrm{M}_{\text {pos }}$ & $\mathrm{M}_{\text {neg,central }}$ & $\mathrm{M}_{\text {neg,lateral }}$ & $\mathrm{M}_{\mathrm{V}}$ & $\gamma_{\mathrm{Z}}$ \\
\hline $1^{\mathrm{a}}$ & & & & & $\mathrm{x}$ & $\mathrm{x}$ & & $\mathrm{x}$ \\
\hline $2^{\mathrm{a}}$ & $\mathrm{x}$ & $\mathrm{x}$ & $\mathrm{x}$ & $\mathrm{x}$ & & & & \\
\hline $3^{\mathrm{a}}$ & & & & & & & $\mathrm{x}$ & \\
\hline
\end{tabular}

No que se refere às ligações, a $1^{\text {a }}$ combinação corresponde à situação mais crítica para o momento negativo, já a $2^{\mathrm{a}}$ combinação corresponde à situação mais crítica para o momento positivo conforme pode ser observado na Tabela 4.27. Os máximos momentos atingidos nas ligações excedem os valores resistentes apresentados na Tabela 4.19. Para efeito de dimensionamento dos pilares a $2^{\mathrm{a}}$ combinação de ações é a mais crítica no que se refere a momento fletor, em se tratando de força normal a $3^{\mathrm{a}}$ combinação de ações é a mais crítica.

Para efeito de análise da estabilidade global a $1^{a}$ combinação de ações se mostrou mais crítica.

$\mathrm{O}$ processo de dimensionamento envolvendo os diagramas $\mathrm{M}$ x $\mathrm{N}$ x $1 / \mathrm{r}$ para uma estrutura com seções e arranjo de armadura conhecidos consiste basicamente em dois passos:

Primeiramente, são obtidos os esforços solicitantes na estrutura considerando a relação constitutiva dos elementos segundo o diagrama $\mathrm{M} \times \mathrm{N}$ x $1 / \mathrm{r}$ com o valor de tensão no concreto de $1,1 \mathrm{f}_{\mathrm{cd}}$.

Posteriormente, verifica-se se o esforço solicitante atende a capacidade resistente da seção segundo o diagrama $\mathrm{M} \times \mathrm{N}$ x $1 / \mathrm{r}$ construído com o valor de tensão no concreto de 0,85 $\mathrm{f}_{\mathrm{cd}}$.

$\mathrm{Na}$ avaliação da rigidez dos elementos estruturais e das ligações a modelagem ideal deve contemplar a interação entre as combinações de ações e o processo construtivo da estrutura. Por exemplo, a segunda combinação de ações provoca um estado de tensão na estrutura que pode levar a plastificação algumas regiões da estrutura. Na terceira combinação de ações outros pontos da estrutura podem sofrer plastificação. Sendo assim, de uma análise estrutural segundo uma determinada combinação de ações para outra análise, deve ser considerado o estado de deformação residual da análise anterior. No presente trabalho não foi considerado este efeito. 


\subsubsection{INFLUÊNCIA DA COMBINAÇÃO DE AÇÕES NO ELS}

A estrutura em questão foi analisada segundo a combinação de serviço com intuito de avaliar se a estrutura respeita os limites de deslocamento prescritos na NBR 9062:2006, no que se refere ao estado limite de serviço. Além disto, são comparados os esforços solicitantes atuantes nas ligações em relação à máxima porcentagem do momento resistente definido segundo o diagrama bi-linear de momento x rotação para a situação em serviço, conforme ilustra a Figura 4.25. Na Tabela 4.28 são apresentados os principais parâmetros de análise.

Tabela 4.28: Distribuição de momento fletor e deslocamento segundo a combinação de ações em serviço considerando o efeito da fluência na análise das vigas

\begin{tabular}{|c|c|c|c|c|c|c|c|c|}
\cline { 2 - 9 } \multicolumn{1}{c|}{} & \multicolumn{7}{c|}{ MOMENTO FLETOR(kN.m) } & \multicolumn{1}{c|}{} \\
\cline { 2 - 9 } \multicolumn{1}{c|}{} & $\mathrm{M}_{\mathrm{a}}$ & $\mathrm{M}_{\mathrm{b}}$ & $\mathrm{M}_{\mathrm{c}}$ & $\mathrm{M}_{\text {pos }}$ & $\mathrm{M}_{\text {neg,central }}$ & $\mathrm{M}_{\text {neg,lateral }}$ & $\mathrm{M}_{\mathrm{V}}$ & $\mathrm{a}(\mathrm{m})$ \\
\hline Máximos valores adotados & & & & 23,226 & 185,53 & 115,95 & & 0,040 \\
\hline $\mathrm{M}_{\mathrm{T}}$ (ANSYS) & 43,63 & 72,63 & 83,42 & 2,88 & 80,44 & 62,70 & 229,86 & 0,013 \\
\hline
\end{tabular}

Os valores obtidos de momento nas ligações e de deslocamento no topo da estrutura são inferiores aos valores admissíveis para o ELS. A Figura 4.31 ilustra o diagrama de momento fletor para combinação em serviço.

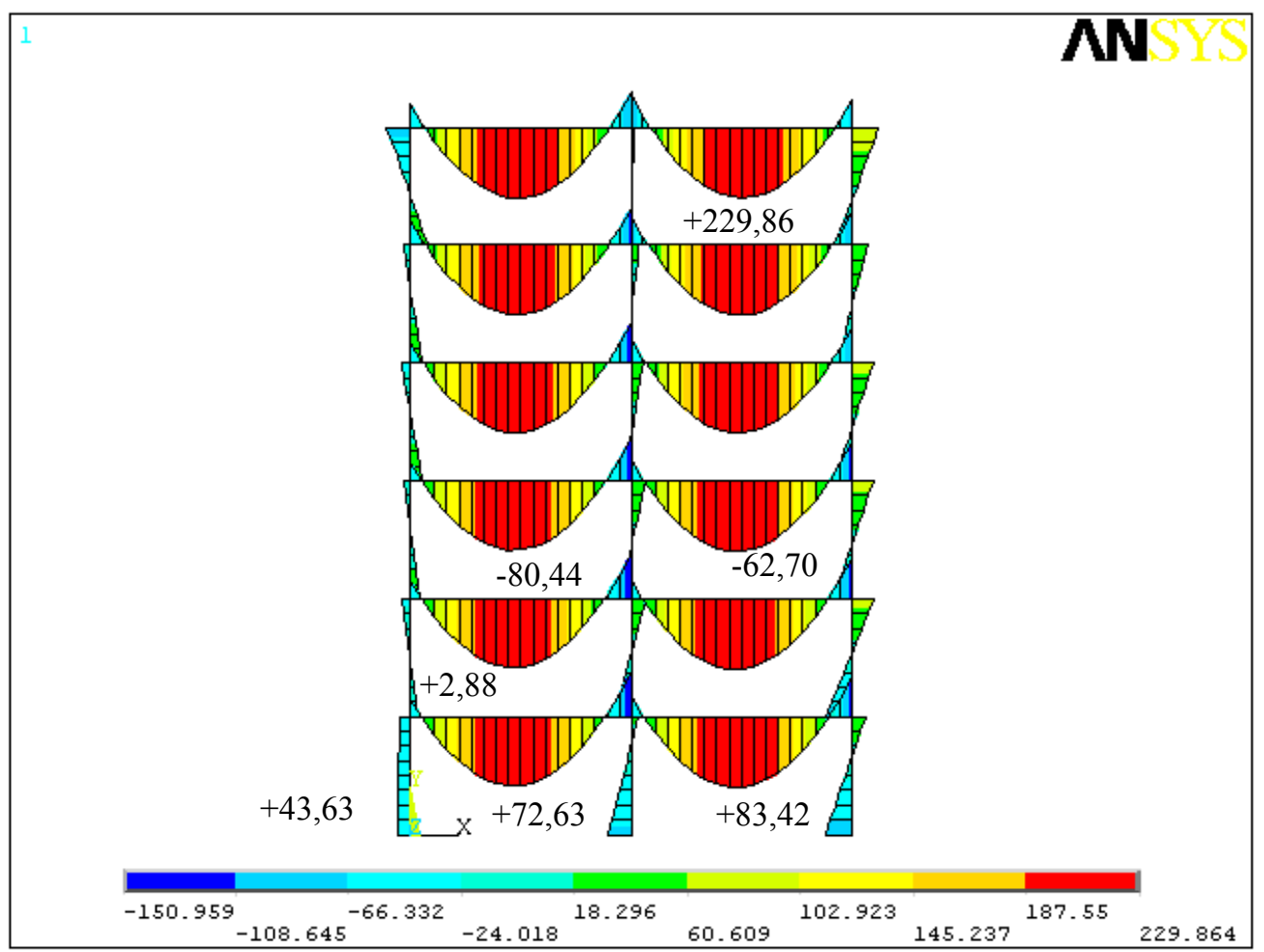

Figura 4.31: Diagrama de momento fletor obtido segundo a combinação de ações do ELS 


\subsubsection{INFLUÊNCIA DO COMPORTAMENTO BI-LINEAR DA LIGAÇÃO VIGA- PILAR}

Foi realizada uma nova simulação numérica considerando o modelo elasto-plástico da ligação viga-pilar. $\mathrm{O}$ trecho correspondente à plastificação da ligação terá como limitante a deformação estipulada do aço em 10\% . Adotando-se esta deformação última, ou seja, plastificando a ligação, obtém-se a máxima rotação admissível da ligação. O nível de fissuração da ligação para efeito de análise da estabilidade global não é verificado, pois se trata de um estado limite último. Este parâmetro deve ser verificado segundo o ELS.

A distribuição de esforços na estrutura, bem como o $\gamma_{Z}$ obtido para a $1^{\text {a }}$ combinação de ações considerando o comportamento bi-linear da ligação estão apresentados na Tabela 4.29.

Tabela 4.29: Distribuição de momento fletor e $\gamma_{z}$ segundo a $1^{\mathrm{a}}$ combinação de ações considerando o comportamento bi-linear assimétrico da ligação viga-pilar

\begin{tabular}{|c|c|c|c|c|c|c|c|c|}
\hline & \multicolumn{7}{|c|}{ MOMENTO FLETOR(kN.m) } & \\
\hline Combinação & $\mathrm{M}_{\mathrm{a}}$ & $\mathrm{M}_{\mathrm{b}}$ & $\mathrm{M}_{\mathrm{c}}$ & $\mathrm{M}_{\mathrm{pos}}$ & $\mathrm{M}_{\text {neg,central }}$ & $\mathrm{M}_{\text {neg,lateral }}$ & $\mathrm{M}_{\mathrm{V}}$ & $\gamma_{z}$ \\
\hline $1^{\mathrm{a}}$ & 332,10 & 420,45 & 396,42 & 38,71 & 309,21 & 193,25 & 342,51 & 1,118 \\
\hline
\end{tabular}

A Figura 4.32 ilustra a distribuição de momento fletor obtida na estrutura com ligação viga-pilar semi-rígida de comportamento bi-linear.

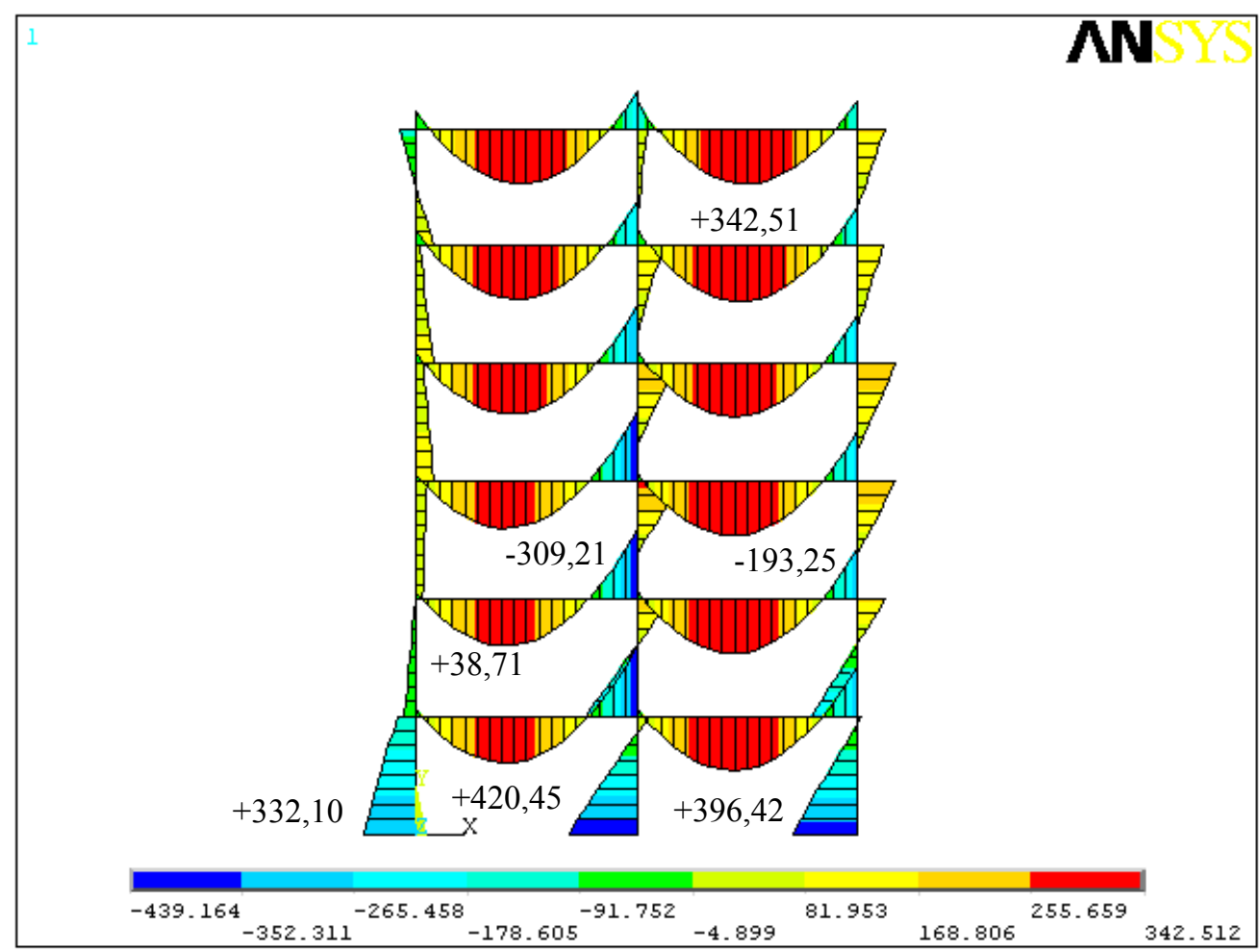

Figura 4.32: Diagrama de momento fletor obtido segundo a $1^{\text {a }}$ combinação de ações com ligação vigapilar semi-rígida de comportamento bi-linear 
Desta forma, obteve-se uma melhor distribuição de esforços de momento fletor viabilizando o arranjo pré-definido para a estrutura. A consideração da plastificação da ligação tornou a estrutura mais deslocável, no entanto este acréscimo de deslocamento não aumentou os efeitos de segunda ordem de forma significativa como apontado pelo valor obtido de $\gamma_{Z}$. A análise da estrutura com o modelo de ligação bi-linear provocou uma redistribuição de esforços da ordem de $10 \%$ nos pilares, houve um acréscimo de $0,5 \%$ no $\gamma_{z}$.

Embora a consideração do modelo elasto-plástico da ligação tenha possibilitado uma melhor distribuição de esforços na estrutura, existem outras formas de melhorar a capacidade de distribuição de esforços na estrutura como, por exemplo, aumentar a capacidade resistente das ligações.

De uma forma geral, adotam-se as seguintes ações no incremento da capacidade resistente das ligações:

Adotar extremidade da viga em apoio sem recorte, aumentando desta forma a seção, bem como a altura útil da armadura junto à ligação viga-pilar;

> Aumentar o espaço disponível para ancoragem da armadura negativa junto à ligação viga-pilar de extremidade com o auxílio de vigas com abas, conforme ilustra a Figura 4.33. Vigas com seção "I" também podem ser utilizadas para melhor acomodar o apoio da laje e a armadura negativa;

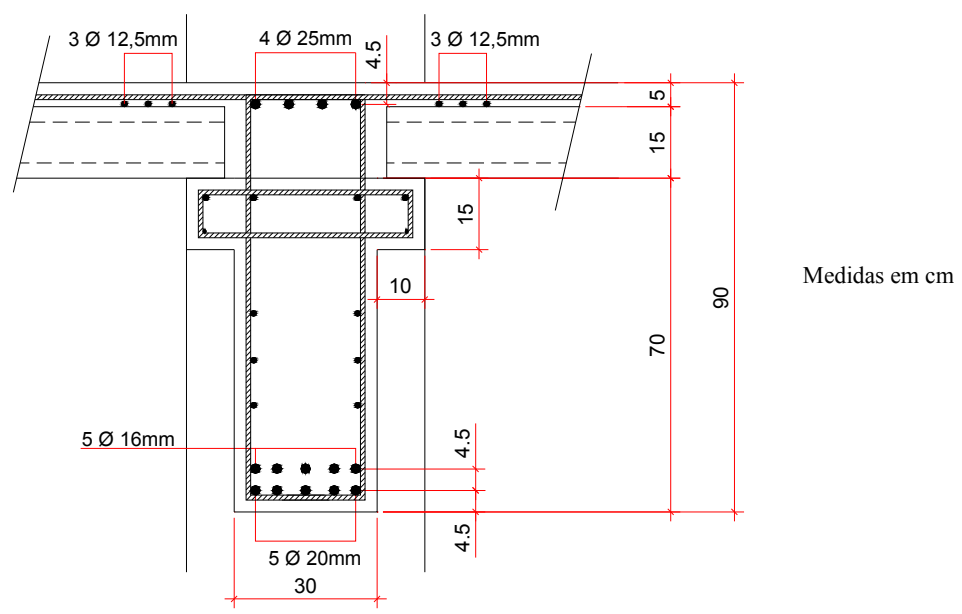

Figura 4.33: Seção de viga alterada pela adoção de abas

Inclinar o chumbador com intuito de aumentar a momento positivo resistente da ligação, conforme apresentado em BALDISSERA (2006);

Adotar aço com alta tensão de escoamento no chumbador; 
$>$ Adotar para a ligação viga-consolo chapa soldada, conforme apresentado em FERREIRA (1999).

\subsubsection{INFLUÊNCIA DA UTILIZAÇÃO DE SEÇÃO COMPOSTA ALTERNATIVA (CONCRETAGEM EM DUAS FASES)}

O momento positivo existente na ligação viga-pilar pode ter seu valor reduzido adotando-se uma seqüência executiva alternativa à usualmente empregada nas vigas em seção composta de concreto pré-moldado, onde o posicionamento e a concretagem da armadura negativa são feitos no nível da laje alveolar. A Figura 4.34 ilustra as diferentes fases da viga em seção composta.

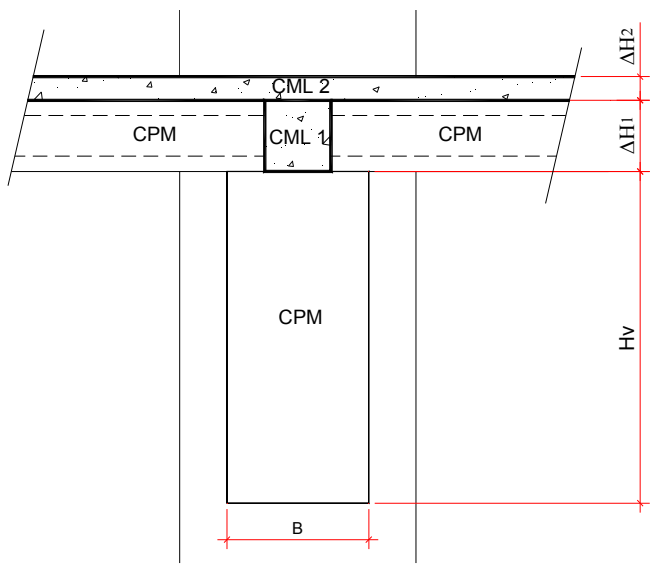

Figura 4.34: Seção de viga composta por duas fases de concreto moldado in loco (CML)

Na Tabela 4.30 é apresentada a nova configuração das situações de cálculo, nota-se que o acréscimo da altura na viga em concreto pré-moldado só deve estar associado à respectiva carga solicitante.

Tabela 4.30: Situações de cálculo de uma viga em seção composta com duas fases de CML

\begin{tabular}{|c|c|c|c|}
\hline SITUAÇÃO & ALTURA DA VIGA & CARREGAMENTO & ESQUEMA \\
\hline $1^{\mathrm{a}}$ & $\mathrm{H}_{\mathrm{v}}$ & $\mathrm{G}_{\mathrm{VIGA}}$ & ISOSTÁTICO \\
\hline $2^{\mathrm{a}}$ & $\mathrm{H}_{\mathrm{v}}$ & $\mathrm{G}_{\mathrm{VIGA}}+\mathrm{G}_{\mathrm{LAJE}}$ & ISOSTÁTICO \\
\hline $3^{\mathrm{a}}$ & $\mathrm{H}_{\mathrm{v}}+\Delta \mathrm{H}_{1}$ & $\mathrm{G}_{\mathrm{CAPA}}$ & HIPERESTÁTICO \\
\hline $4^{\mathrm{a}}$ & $\mathrm{H}_{\mathrm{v}}+\Delta \mathrm{H}_{1}+\Delta \mathrm{H}_{2}$ & $\mathrm{G}_{\text {REVEST. }}+\mathrm{Q}$ & HIPERESTÁTICO \\
\hline
\end{tabular}

Esta seqüência executiva exigiu a incorporação de uma nova situação de cálculo, além da necessidade de uma fase de concretagem adicional. Geralmente o acréscimo de fases de 
concretagem in loco torna o processo de execução mais lento, prejudicando a racionalização e a industrialização do uso das estruturas em concreto pré-moldado.

A estabilidade global e os esforços nos elementos estruturais e ligações foram analisados segundo as combinações de ações críticas para a nova configuração de viga em seção composta. A Tabela 4.31 apresenta os valores encontrados.

Tabela 4.31: Parâmetros de análise segundo combinação de ações para seção composta alternativa

\begin{tabular}{|c|c|c|c|c|c|c|c|c|}
\cline { 2 - 9 } \multicolumn{1}{c|}{} & \multicolumn{7}{c|}{ MOMENTO FLETOR(kN.m) } & \multicolumn{1}{c|}{} \\
\hline Combinação & $\mathrm{M}_{\mathrm{a}}$ & $\mathrm{M}_{\mathrm{b}}$ & $\mathrm{M}_{\mathrm{c}}$ & $\mathrm{M}_{\text {pos }}$ & $\mathrm{M}_{\text {neg,central }}$ & $\mathrm{M}_{\text {neg,lateral }}$ & $\mathrm{M}_{\mathrm{V}}$ & $\gamma_{\mathrm{Z}}$ \\
\hline $1^{\mathrm{a}}$ & 271,76 & 354,46 & 352,71 & 32,08 & 346,50 & 272,71 & 311,32 & 1,097 \\
\hline $2^{\mathrm{a}}$ & 311,37 & 373,07 & 359,74 & 62,11 & 295,81 & 235,82 & 228,15 & 1,085 \\
\hline $3^{\mathrm{a}}$ & 134,14 & 193,46 & 223,04 & --- & 284,46 & 208,98 & 340,21 & 1,096 \\
\hline
\end{tabular}

Analisando o momento positivo, obtido para a $2^{\text {a }}$ combinação de ações na Tabela 4.31, observa-se a diminuição de aproximadamente $23 \%$ no esforço solicitante quando comparado com a solução em que há apenas uma fase de concretagem. Na terceira combinação de ações, não há momento positivo nas ligações. Embora o momento positivo na ligação tenha diminuido, o mesmo não atendeu ao momento positivo resistente da ligação considerando o modelo de comportamento linear da mesma, sendo assim a ligação sofreria plastificação.

\subsubsection{INFLUÊNCIA DA PRESENÇA DA LIGAÇÃO SEMI-RÍGIDA PILAR- FUNDAÇÃO}

O projeto de uma estrutura em concreto pré-moldado de múltiplos pavimentos, geralmente, considera o comportamento semi-rígido das ligações viga-pilar. No entanto, costuma ser negligenciado o comportamento semi-rígido da ligação pilar-fundação. $\mathrm{O}$ comportamento semi-rígido pode ter origem na ligação entre o pilar e o elemento de fundação ou na interação solo-estrutura. No Brasil, usualmente, a ligação pilar-fundação ocorre por intermédio de um cálice, alternativamente esta ligação pode ser feita pelo uso de placas de base e chumbadores. Para a ligação pilar-fundação por meio de cálice o comportamento pode ser considerado rígido.

Neste trabalho é abordado o comportamento semi-rígido provocado pela interação solo-estrutura, mais precisamente enfatiza-se a deformação longitudinal das estacas sob os blocos. A Figura 4.35 ilustra o modelo discretizado por molas representando a deformabilidade das estacas em contato com o solo e o bloco. 


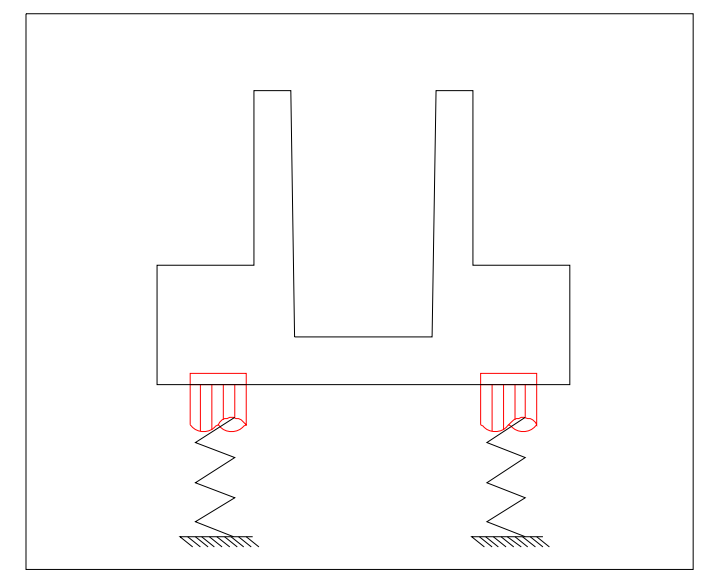

Figura 4.35: Interação solo-estrutura discretizada por molas

No modelo adotado considera-se que a resistência de ponta da estaca é responsável, exclusivamente, pela capacidade resistente da estaca, além disto, considera-se que o solo sob a ponta da estaca é indeformável. Portanto, neste modelo simplificado não está sendo contemplada a parcela de deformação elástica do solo.

O modelo ilustrado na Figura 4.35 pode ser transformado no modelo ilustrado na Figura 4.36.

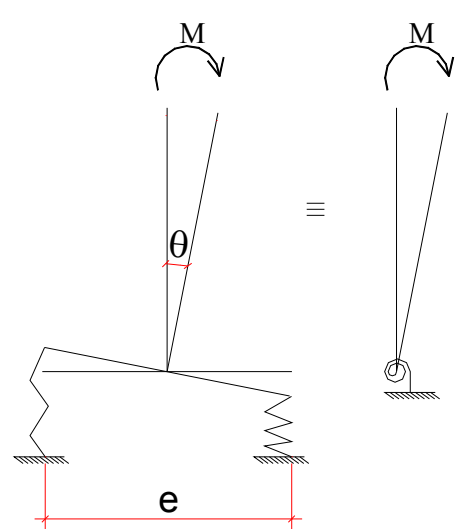

Figura 4.36: Modelos estruturais de comportamento equivalente

A formulação apresentada para consideração da deformabilidade das estacas teve como referência o trabalho de WALRAVEN \& STRAMAN (1997).

O deslocamento longitudinal das estacas é expresso em (4.7):

$$
\Delta l=\frac{M . l}{e . E A}
$$


Onde:

$\Delta l$ deslocamento longitudinal da estaca;

$M$ momento atuante no pilar;

$l$ comprimento da estaca;

$e$ excentricidade entre as estacas;

$E$ módulo de elasticidade do concreto da estaca;

$A$ área da seção transversal da estaca.

O deslocamento longitudinal da estaca pode ser relacionado com a rotação do sistema da seguinte forma:

$$
\Delta l=\theta \cdot \frac{e}{2}
$$

Uma vez definido o ângulo de rotação do sistema é possível definir a rigidez da ligação, conforme expresso em (4.9):

$$
K_{F}=\frac{M}{\theta}=\frac{E A e^{2}}{2 l}
$$

Analisando a expressão (4.9) é possível definir a rigidez de uma ligação pilarfundação para diferentes valores de $\mathrm{f}_{\mathrm{ck}}$, área de seção da estaca, excentricidade entre estacas e comprimento de estacas. Sendo assim foram construídos dois gráficos, relacionando as variáveis mencionadas. A Figura 4.37 e a Figura 4.38 ilustram o comportamento da ligação pilar-fundação para estacas com $\mathrm{f}_{\mathrm{ck}}$ de $20 \mathrm{MPa}$ e $40 \mathrm{MPa}$. Em relação ao tipo de estaca e suas particularidades, geralmente, as estacas pré-moldadas são especificadas com concreto de maior resistência, além disto, é comum a adoção de armadura ativa nestes elementos. A combinação destes dois fatores possibilita que a área das estacas e, conseqüentemente, a distância entre as mesmas diminua. Esta configuração permite que o bloco de fundação assuma um volume menor, no entanto, como pode ser visto na expressão (4.9), a rigidez da ligação é penalizada. 


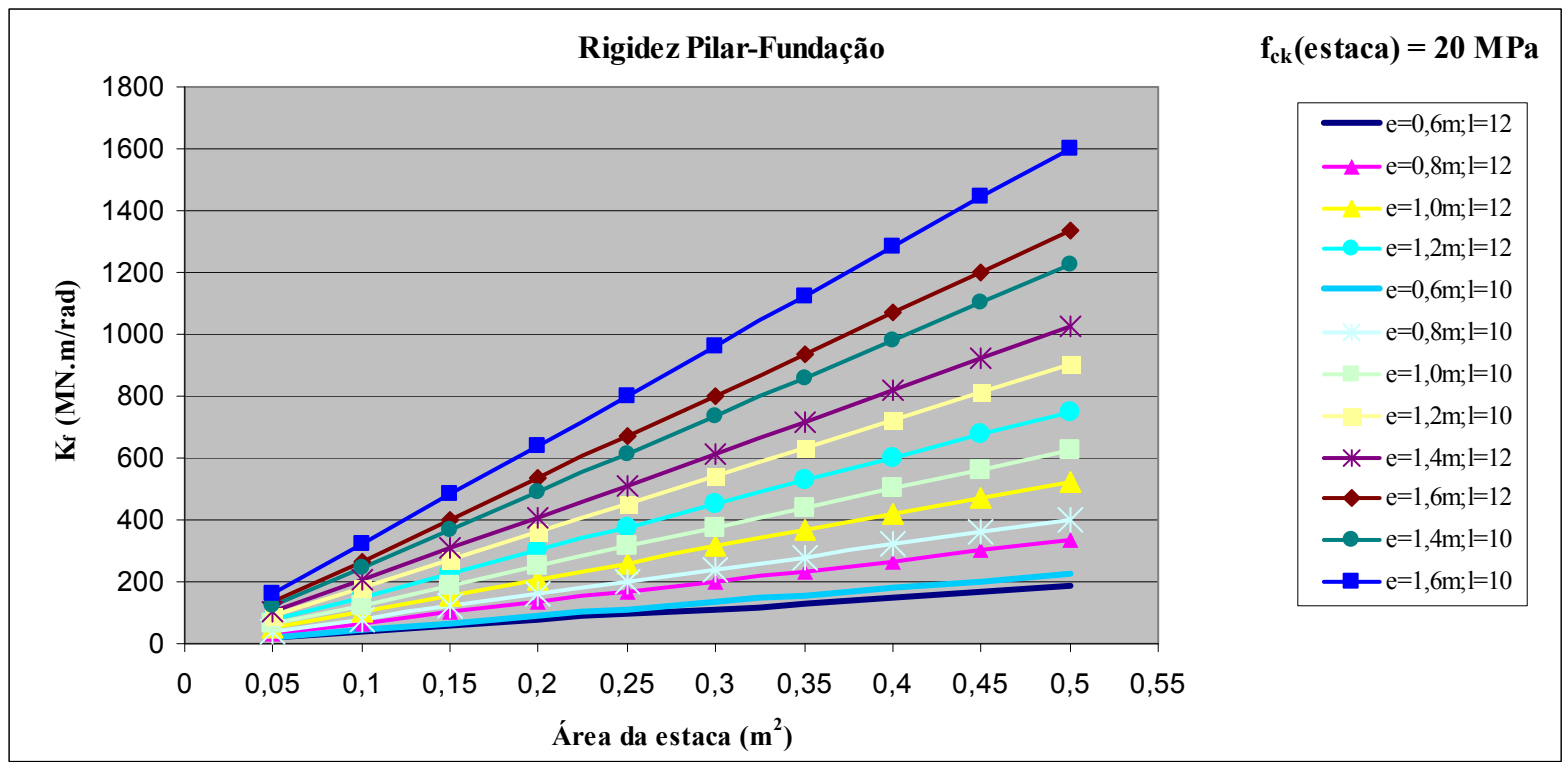

Figura 4.37: Rigidez da ligação pilar-fundação para estacas com $\mathrm{f}_{\mathrm{ck}}=20 \mathrm{MPa}$

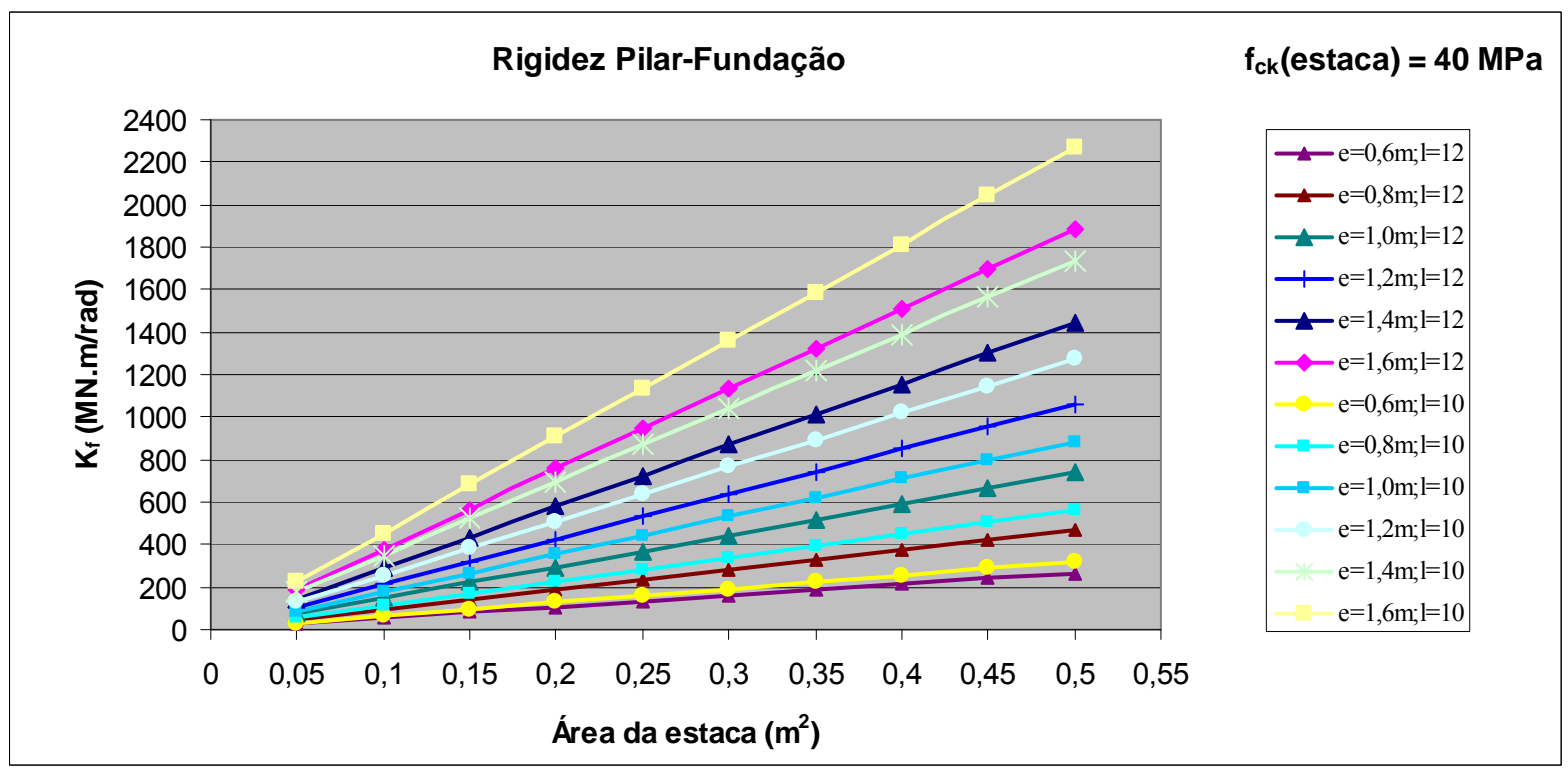

Figura 4.38: Rigidez da ligação pilar-fundação para estacas com $\mathrm{f}_{\mathrm{ck}}=40 \mathrm{MPa}$

A formulação apresentada no presente trabalho ilustra uma forma simplificada de consideração da semi-rigidez da ligação pilar-fundação.

A consideração da ligação pilar-fundação pode envolver outros fatores, como por exemplo, a presença do atrito lateral no mecanismo resistente das estacas ou a deformabilidade do solo. A solução abordada refere-se ao pilar apoiado em estacas constituindo um bloco de fundação, entretanto, é comum dependendo da ordem de grandeza dos esforços envolvidos a adoção de fundação constituída por pilar apoiado em estaca de grande diâmetro. Neste caso, deverá ser considerada na ligação pilar-fundação a rotação causada pelo esforço solicitante na extremidade superior da estaca. 
A influência na análise da estabilidade global da interação solo-estrutura na ligação pilar-fundação foi aferida considerando-se que os pilares da estrutura estão apoiados sobre blocos de quatro estacas, os dados estão apresentados na Tabela 4.32.

Tabela 4.32: Dados da fundação adotada para estrutura com modulação de 7,5m

\begin{tabular}{|c|c|c|c|c|}
\hline $\mathrm{CAP}(\mathrm{kN})$ & $1(\mathrm{~m})$ & $\mathrm{e}(\mathrm{m})$ & $\mathrm{A}\left(\mathrm{m}^{2}\right)$ & $\mathrm{E}(\mathrm{GPa})$ \\
\hline 800 & 12 & 0,65 & $0,055(0,235 \mathrm{x} 0,235)$ & 35,42 \\
\hline
\end{tabular}

CAP: Capacidade resistente nominal da estaca; 1: comprimento da estaca; e: excentricidade entre as estacas; A: área da estaca pré-moldada; E: módulo de elasticidade do concreto das estacas.

Efetuando as operações indicadas em (4.7), (4.8) e (4.9) obtém-se a rigidez $\mathrm{K}_{\mathrm{F}}=34,29$ MN.m/rad.

Os principais parâmetros de análise da estrutura, considerando a ligação pilarfundação semi-rígida, estão apresentados na Tabela 4.33 .

Tabela 4.33: Distribuição de momento fletor e $\gamma_{z}$ para $1^{\mathrm{a}}$ combinação de ações considerando a ligação semi-rígida pilar-fundação

\begin{tabular}{|c|c|c|c|c|c|c|c|}
\hline \multicolumn{7}{|c|}{ MOMENTO FLETOR(kN.m) } & \multirow{2}{*}{} \\
\hline $\mathrm{M}_{\mathrm{a}}$ & $\mathrm{M}_{\mathrm{b}}$ & $\mathrm{M}_{\mathrm{c}}$ & $\mathrm{M}_{\text {pos }}$ & $\mathrm{M}_{\text {neg,central }}$ & $\mathrm{M}_{\text {neg,lateral }}$ & $\mathrm{M}_{\mathrm{V}}$ & $\gamma_{\mathrm{Z}}$ \\
\hline 214,30 & 234,85 & 232,15 & 82,71 & 415,96 & 334,06 & 342,41 & 1,173 \\
\hline
\end{tabular}

A Figura 4.39 ilustra a mudança no diagrama de momento fletor da estrutura provocado pela consideração do comportamento semi-rígido presente na ligação pilarfundação. 


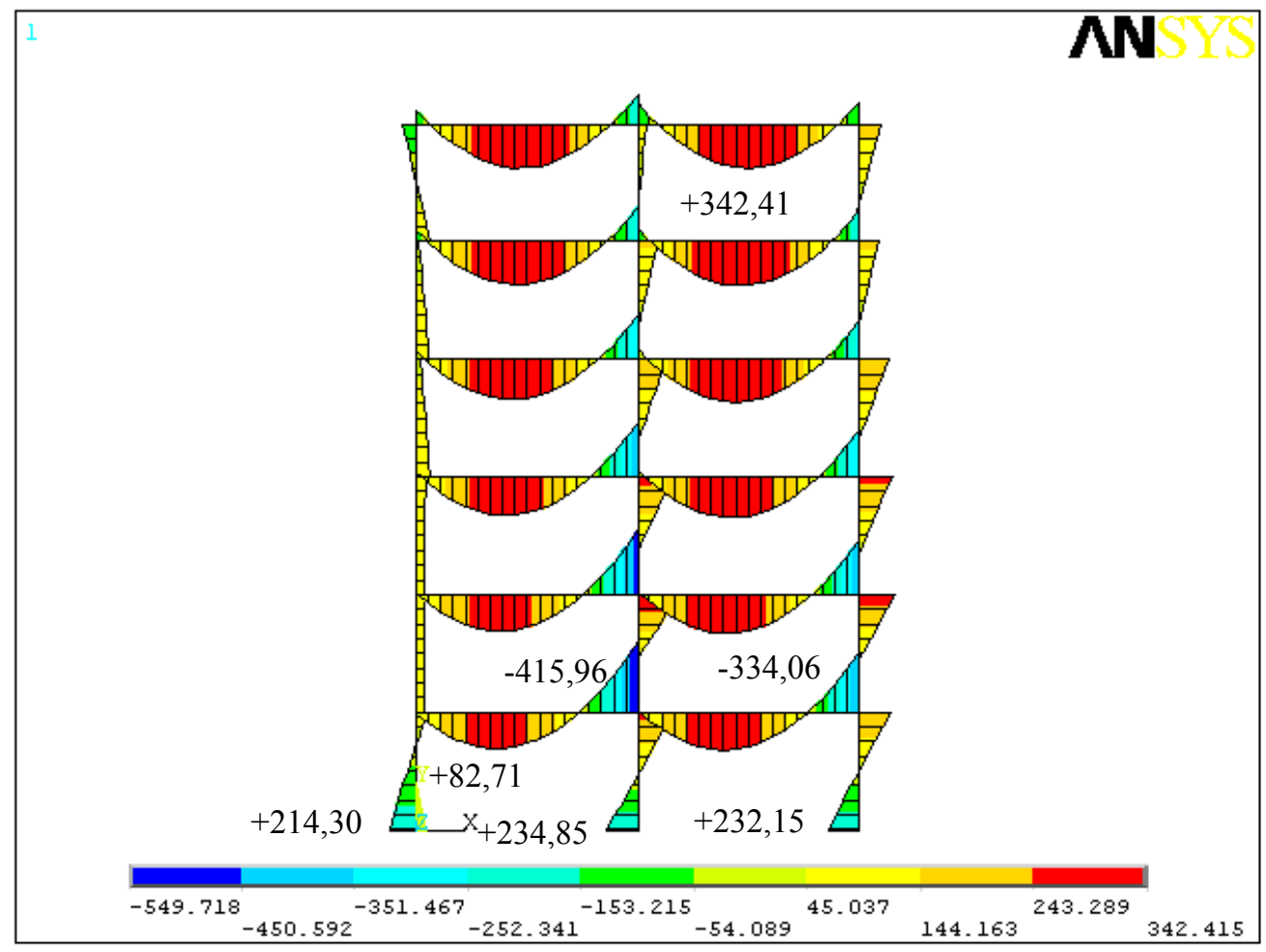

Figura 4.39: Diagrama de momento fletor obtido considerando a ligação semi-rígida pilar-fundação para a $1^{\text {a }}$ combinação de ações

Como já era esperado, a estrutura se tornou mais deslocável quando comparada com a estrutura com ligação pilar-fundação rígida, conforme indicado pelo aumento de $6 \%$ do valor do $\gamma_{Z}$ obtido. Quanto ao momento negativo absorvido pelas ligações houve um acréscimo de aproximadamente $31 \%$ nos esforços, para o momento positivo absorvido o acréscimo foi de aproximadamente $66 \%$. Nos pilares houve um decréscimo médio de, aproximadamente, $35 \%$ do momento fletor absorvido.

\subsubsection{INFLUÊNCIA DO TIPO DE ANÁLISE NLG}

As estruturas em concreto pré-moldado de múltiplos pavimentos estão sujeitas aos efeitos da não-linearidade geométrica, a avaliação destes efeitos sofre influência do método de análise. $\mathrm{Na}$ Tabela 4.34 é apresentado o processo do método da carga lateral fictícia na estrutura com ligação pilar-fundação semi-rígida. Para que os métodos de análise da nãolinearidade geométrica fossem comparados, foi adotado o mesmo critério de parada dos métodos iterativos já utilizados. 
Tabela 4.34: Processo (P- $\Delta)$

\begin{tabular}{|c|c|c|c|c|}
\hline \multicolumn{5}{|c|}{ ANÁLISE $1^{\mathrm{a}}$ ORDEM } \\
\hline Pavimento & $\mathrm{a}(\mathrm{m})$ & $\Delta(\mathrm{m})$ & $\mathrm{P}(\mathrm{kN})$ & $\mathrm{F}(\mathrm{kN})$ \\
\hline 6 & 0,09213 & 0,00385 & 1172,26 & 1,13 \\
\hline 5 & 0,08828 & 0,00822 & 2554,52 & 4,12 \\
\hline 4 & 0,08006 & 0,01360 & 3936,78 & 8,14 \\
\hline 3 & 0,06646 & 0,01886 & 5319,04 & 11,69 \\
\hline 2 & 0,04760 & 0,02309 & 6701,30 & 13,60 \\
\hline 1 & 0,02451 & 0,02451 & 8083,56 & 10,86 \\
\hline \multicolumn{5}{|c|}{ ANÁLISE $1^{\mathrm{a}}$ ITERAÇÃO } \\
\hline Pavimento & $\mathrm{a}(\mathrm{m})$ & $\Delta(\mathrm{m})$ & $\mathrm{P}(\mathrm{kN})$ & $\mathrm{F}(\mathrm{kN})$ \\
\hline 6 & 0,11929 & 0,00550 & 1172,26 & 1,61 \\
\hline 5 & 0,11379 & 0,01140 & 2554,52 & 5,67 \\
\hline 4 & 0,10239 & 0,01831 & 3936,78 & 10,74 \\
\hline 3 & 0,08408 & 0,02457 & 5319,04 & 14,65 \\
\hline 2 & 0,05951 & 0,02922 & 6701,30 & 16,28 \\
\hline 1 & 0,03029 & 0,03029 & 8083,56 & 12,25 \\
\hline \multicolumn{5}{|c|}{ ANÁLISE $2^{\mathrm{a}}$ ITERAÇÃO } \\
\hline Pavimento & $\mathrm{a}(\mathrm{m})$ & $\Delta(\mathrm{m})$ & $\mathrm{P}(\mathrm{kN})$ & $\mathrm{F}(\mathrm{kN})$ \\
\hline 6 & 0,12518 & 0,00580 & 1172,26 & 1,70 \\
\hline 5 & 0,11938 & 0,01203 & 2554,52 & 5,98 \\
\hline 4 & 0,10735 & 0,01929 & 3936,78 & 11,30 \\
\hline 3 & 0,08806 & 0,02582 & 5319,04 & 15,35 \\
\hline 2 & 0,06224 & 0,03062 & 6701,30 & 16,95 \\
\hline 1 & 0,03162 & 0,03162 & 8083,56 & 12,61 \\
\hline \multicolumn{5}{|c|}{ ANÁLISE $3^{\mathrm{a}}$ ITERAÇÃO } \\
\hline Pavimento & $\mathrm{a}(\mathrm{m})$ & $\Delta(\mathrm{m})$ & $\mathrm{P}(\mathrm{kN})$ & $\mathrm{F}(\mathrm{kN})$ \\
\hline 6 & 0,12658 & 0,00587 & 1172,26 & 1,72 \\
\hline 5 & 0,12071 & 0,01219 & 2554,52 & 6,06 \\
\hline 4 & 0,10852 & 0,01953 & 3936,78 & 11,43 \\
\hline 3 & 0,08900 & 0,02612 & 5319,04 & 15,52 \\
\hline 2 & 0,06288 & 0,03094 & 6701,30 & 17,11 \\
\hline 1 & 0,03193 & 0,03193 & 8083,56 & 12,69 \\
\hline \multicolumn{5}{|c|}{ ANÁLISE $4^{\mathrm{a}}$ ITERAÇÃO } \\
\hline Pavimento & $\mathrm{a}(\mathrm{m})$ & $\Delta(\mathrm{m})$ & $\mathrm{P}(\mathrm{kN})$ & $\mathrm{F}(\mathrm{kN})$ \\
\hline 6 & 0,12692 & 0,00590 & 1172,26 & 1,73 \\
\hline 5 & 0,12102 & 0,01222 & 2554,52 & 6,07 \\
\hline 4 & 0,1088 & 0,01958 & 3936,78 & 11,47 \\
\hline 3 & 0,08922 & 0,02619 & 5319,04 & 15,55 \\
\hline 2 & 0,06303 & 0,03102 & 6701,30 & 17,14 \\
\hline 1 & 0,03201 & 0,03201 & 8083,56 & 12,71 \\
\hline
\end{tabular}

A Tabela 4.35 apresenta a diferença percentual entre as iterações realizadas no processo (P- $\Delta$ ), nota-se que na terceira iteração a diferença percentual em deslocamentos é de, aproximadamente, $0,25 \%$. A Figura 4.40 ilustra a seqüência da análise do método (P- $\Delta$ ) em relação aos descolamentos nodais. Nota-se que os deslocamentos obtidos na $3^{\mathrm{a}}$ e $4^{\mathrm{a}}$ iterações convergem para valores muito próximos, o que representa que a estrutura assumiu a posição de equilíbrio. 
Tabela 4.35: Análise de convergência do processo (P- $\Delta$ )

\begin{tabular}{|c|c|c|c|}
\hline \multicolumn{4}{|c|}{ ANÁLISE DE CONVERGÊNCIA } \\
\hline Cota $(\mathrm{m})$ & $\mathrm{a}_{3^{\mathrm{a}}}$ iteração $(\mathrm{m})$ & $\mathrm{a}_{4^{\mathrm{a}}}$ iteracãão $(\mathrm{m})$ & $\%$ \\
\hline 24 & 0,12658 & 0,12692 & 0,27 \\
\hline 20 & 0,12071 & 0,12102 & 0,26 \\
\hline 16 & 0,10852 & 0,10880 & 0,26 \\
\hline 12 & 0,08900 & 0,08922 & 0,25 \\
\hline 8 & 0,06288 & 0,06303 & 0,24 \\
\hline 4 & 0,03193 & 0,03201 & 0,23 \\
\hline
\end{tabular}

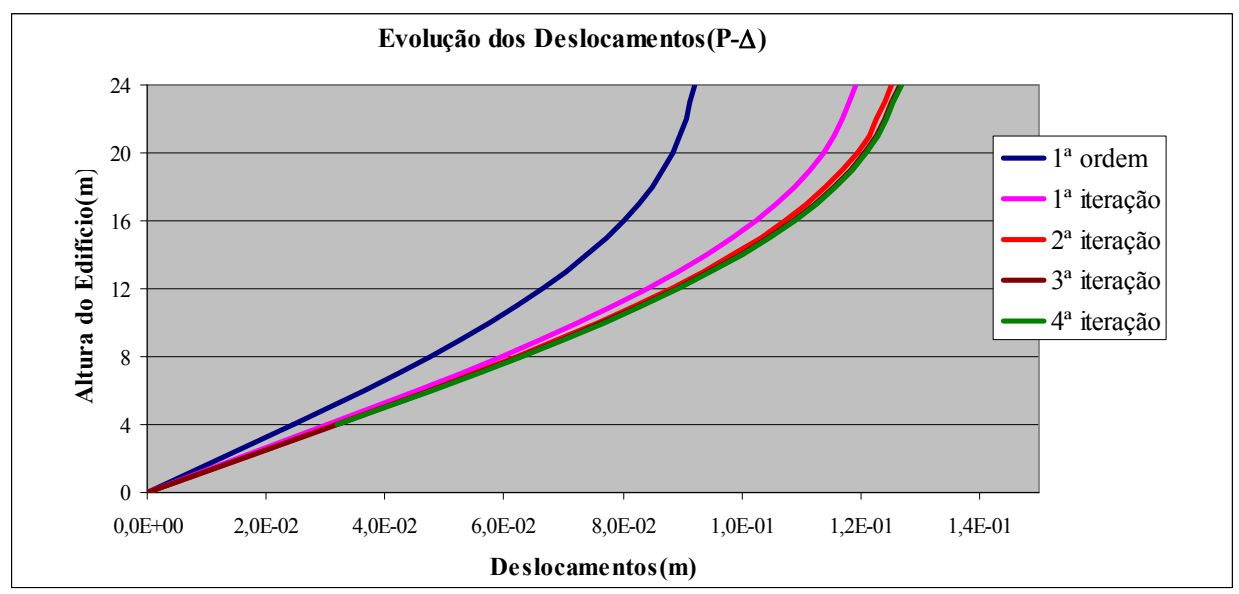

Figura 4.40: Evolução dos deslocamentos segundo o processo (P- $\Delta$ )

Na Tabela 4.36 são apresentados os principais parâmetros de análise segundo o método empregado.

Tabela 4.36: Análise da não-linearidade geométrica segundo diferentes métodos para $1^{\mathrm{a}}$ combinação de ações

\begin{tabular}{|c|c|c|c|c|c|c|c|}
\cline { 2 - 8 } \multicolumn{1}{c|}{} & \multicolumn{7}{c|}{ MOMENTO FLETOR(kN.m) } \\
\hline$\gamma_{\mathrm{Z}}=1,173$ & $\mathrm{M}_{\mathrm{a}}$ & $\mathrm{M}_{\mathrm{b}}$ & $\mathrm{M}_{\mathrm{c}}$ & $\mathrm{M}_{\text {pos }}$ & $\mathrm{M}_{\text {neg,central }}$ & $\mathrm{M}_{\text {neg,lateral }}$ & $\mathrm{M}_{\mathrm{V}}$ \\
\hline $\mathrm{M}_{1^{\mathrm{a}} \text { Ordem }}$ & 170,71 & 188,42 & 187,62 & 63,04 & 352,61 & 281,81 & 342,23 \\
\hline $\mathrm{M}_{\mathrm{T}}($ ANSYS $)$ & 214,30 & 234,85 & 232,15 & 82,71 & 415,96 & 334,06 & 342,41 \\
\hline $\mathrm{M}_{\mathrm{T}}\left(0,95 \cdot \gamma_{\mathrm{Z}}\right)$ & 193,13 & 212,30 & 210,71 & 73,61 & 386,85 & 310,03 & 342,35 \\
\hline $\mathrm{M}_{\mathrm{T}}\left(\gamma_{\mathrm{Z}}\right)$ & 204,58 & 224,57 & 222,52 & 79,05 & 404,42 & 324,53 & 343,16 \\
\hline $\mathrm{P}-\Delta$ & 222,34 & 243,77 & 240,97 & 88,42 & 434,74 & 349,45 & 342,58 \\
\hline$\frac{M_{T}(A N S Y S)}{M_{T}\left(0,95 \cdot \gamma_{Z}\right)} \cdot[\%]$ & 10,96 & 10,62 & 10,18 & 12,36 & 7,52 & 7,75 & 0,02 \\
\hline$\frac{M_{T}(A N S Y S)}{M_{T}\left(\gamma_{Z}\right)} \cdot[\%]$ & 4,75 & 4,58 & 4,33 & 4,63 & 2,85 & 2,94 & $-0,22$ \\
\hline$\frac{M_{T}(A N S Y S)}{M_{T}(\mathrm{P}-\Delta)} \cdot[\%]$ & $-3,61$ & $-3,66$ & $-3,66$ & $-6,46$ & $-4,32$ & $-4,40$ & $-0,05$ \\
\hline
\end{tabular}


$\mathrm{Na}$ Tabela 4.36 pode ser observado que os valores de momento obtidos na base do pilar pela teoria não simplificada de análise NLG fornecida pelo ANSYS concordam com os valores de momento obtidos pelo $\gamma_{Z}$ a menos de diferenças da ordem de $4 \%$. Para o exemplo escolhido, cujo $\gamma_{Z}$ assumiu o valor de 1,165 pode-se afirmar que o coeficiente $\gamma_{Z}$ apresentou resultados representativos quando comparado com a teoria não-aproximada da NLG tendo em vista que o método é direto. No entanto, quando comparados os valores fornecidos pelo ANSYS com os valores de momento obtidos por $0,95 . \gamma_{Z}$ as diferenças de momento encontradas aproximam-se de $10 \%$.

$\mathrm{O}$ método da carga lateral fictícia $(\mathrm{P}-\Delta)$ apresentou resultados próximos aos apresentados pelo $\gamma_{z}$ quando comparado com a teoria não-aproximada de não-linearidade geométrica. Embora o método (P- $\Delta$ ) tenha apresentado resultados próximos aos apresentados pelo uso do $\gamma_{\mathrm{Z}}$, o método $(\mathrm{P}-\Delta)$ requer uma análise iterativa.

Os métodos aproximados de análise NLG mostraram-se representativos para o grau de não-linearidade apresentado pelo problema.

\subsection{ANÁLISE DA VARIAÇÃo DE PARÂMETROS GEOMÉTRICOS E DE CARREGAMENTO DA ESTRUTURA TÍPICA}

Foi constatada na análise numérica da estrutura típica a necessidade de plastificação da ligação viga-pilar para se obter uma melhor distribuição dos esforços solicitantes. A questão que se coloca é o número de pavimentos limite para a utilização do modelo elástico linear de ligação considerando o chumbador retilíneo. São avaliadas estruturas com 6, 5 e 4 pavimentos com modulações de $7,5 \mathrm{~m}$ e $10 \mathrm{~m}$. As cargas acidentais avaliadas são de 3 e $5 \mathrm{kN} / \mathrm{m}^{2}$. Os coeficientes redutores de rigidez dos elementos de viga e pilar são definidos para cada modelo, os valores encontrados para o momento positivo e para o momento negativo nas ligações são comparados com os valores resistentes.

Primeiramente, é avaliado o arranjo com modulação de 7,5m e carregamento acidental de $3 \mathrm{kN} / \mathrm{m}^{2}$, a seção de pilar adotada para o modelo de 6 e 5 pavimentos está ilustrada na Figura 4.3. Para a estrutura de 4 pavimentos, a seção transversal com o arranjo de armadura está ilustrada na Figura 4.41, foi adotada a mesma taxa de armadura para todas as seções transversais do pilar, a taxa geométrica de armadura corresponde a 3,15\%. O concreto utilizado é especificado com $\mathrm{f}_{\mathrm{ck}}=35 \mathrm{MPa}$. 


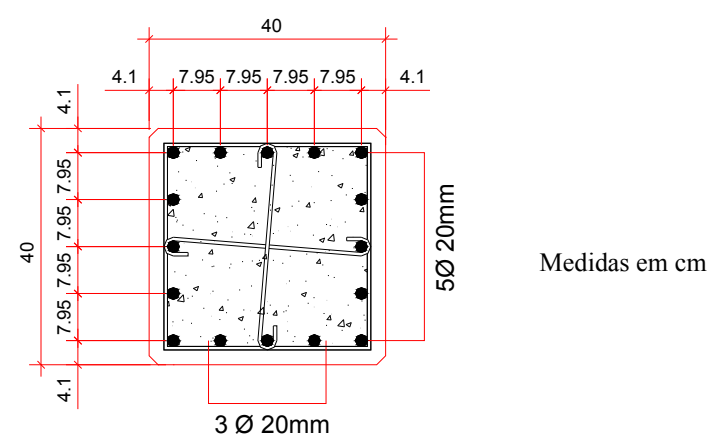

Figura 4.41: Seção transversal e disposição de armadura do pilar em concreto pré-moldado (P40x40)

A força normal adimensional obtida para a seção adotada na estrutura de 4 pavimentos está apresentada na Tabela 4.37 .

Tabela 4.37: Força normal adimensional atuante nos pilares (P40x40) para a estrutura com modulação de $7,5 \mathrm{~m}$ e carga acidental de $3 \mathrm{kN} / \mathrm{m}^{2}$

\begin{tabular}{|c|c|c|c|c|}
\cline { 2 - 5 } \multicolumn{1}{c|}{} & \multicolumn{2}{c|}{$v_{\mathrm{d}, 1}$} & \multicolumn{2}{c|}{$v_{\mathrm{d}, 2}$} \\
\hline PAVIMENTO & PC & PL & PC & PL \\
\hline 4 & 0,13 & 0,08 & 0,08 & 0,05 \\
\hline 3 & 0,27 & 0,19 & 0,17 & 0,13 \\
\hline 2 & 0,40 & 0,29 & 0,25 & 0,21 \\
\hline 1 & 0,53 & 0,40 & 0,33 & 0,30 \\
\hline
\end{tabular}

Sendo assim, foi possível definir os coeficientes redutores de rigidez para cada trecho de pilar segundo o pavimento, conforme apresenta a Tabela 4.38.

Tabela 4.38: Coeficientes redutores de rigidez dos pilares (P40x40) para a estrutura com modulação de $7,5 \mathrm{~m}$ e carga acidental de $3 \mathrm{kN} / \mathrm{m}^{2}$.

\begin{tabular}{|c|c|c|c|c|}
\cline { 2 - 5 } \multicolumn{1}{c|}{} & \multicolumn{2}{c|}{$\alpha, 1$} & \multicolumn{2}{c|}{$\alpha, 2$} \\
\hline PAVIMENTO & PC & PL & PC & PL \\
\hline 4 & 0,394 & 0,357 & 0,358 & 0,347 \\
\hline 3 & 0,481 & 0,435 & 0,419 & 0,394 \\
\hline 2 & 0,516 & 0,487 & 0,476 & 0,460 \\
\hline 1 & 0,578 & 0,515 & 0,497 & 0,488 \\
\hline
\end{tabular}

Os coeficientes redutores de rigidez apresentados na Tabela 4.38 possuem variações semelhantes aos apresentados para a seção de pilar com 50x50 cm na estrutura com 5 e 6 pavimentos.

As estruturas de 5 e 4 pavimentos foram processadas, sendo que os principais parâmetros de análise foram mapeados e apresentados na Tabela 4.39. 
Tabela 4.39: Parâmetros de análise segundo combinação de ações para modelo com 5 e 4 pavimentos, modulação de $7,5 \mathrm{~m}$ e carga acidental de $3 \mathrm{kN} / \mathrm{m}^{2}$.

\begin{tabular}{|c|c|c|c|c|c|c|c|c|c|}
\cline { 4 - 9 } & \multicolumn{7}{|c|}{ MOMENTO FLETOR(kN.m) } & \multicolumn{1}{c|}{} \\
\hline PAV & Combinação & $\mathrm{M}_{\mathrm{a}}$ & $\mathrm{M}_{\mathrm{b}}$ & $\mathrm{M}_{\mathrm{c}}$ & $\mathrm{M}_{\text {pos }}$ & $\mathrm{M}_{\text {neg,central }}$ & $\mathrm{M}_{\text {neg,lateral }}$ & $\mathrm{M}_{\mathrm{V}}$ & $\gamma_{\mathrm{Z}}$ \\
\hline 5 & $1^{\mathrm{a}}$ & 205,33 & 265,21 & 272,33 & 23,69 & 231,85 & 182,31 & 342,10 & 1,077 \\
\hline 5 & $2^{\mathrm{a}}$ & 244,56 & 288,92 & 283,53 & 54,24 & 182,18 & 147,00 & 233,95 & 1,074 \\
\hline 4 & $1^{\mathrm{a}}$ & 99,59 & 154,61 & 165,01 & 21,21 & 194,83 & 151,66 & 346,51 & 1,081 \\
\hline 4 & $2^{\mathrm{a}}$ & 126,26 & 164,96 & 163,86 & 45,77 & 138,14 & 118,02 & 238,32 & 1,076 \\
\hline
\end{tabular}

As verificações feitas para carga acidental de $3 \mathrm{kN} / \mathrm{m}^{2}$ foram feitas para carga acidental de $5 \mathrm{kN} / \mathrm{m}^{2}$. Desta forma, foram definidas as cargas normais adimensionais e os coeficientes redutores de rigidez para cada trecho de pilar, conforme apresenta a Tabela $4.40 \mathrm{e}$ a Tabela 4.41, respectivamente. Os valores obtidos referem-se às estruturas com 5 e 6 pavimentos, onde a seção adotada é de $50 \times 50 \mathrm{~cm}$.

Tabela 4.40: Força normal adimensional atuante nos pilares (P50x50) para a estrutura com modulação de $7,5 \mathrm{~m}$ e carga acidental de $5 \mathrm{kN} / \mathrm{m}^{2}$

\begin{tabular}{|c|c|c|c|c|c|c|}
\cline { 2 - 7 } \multicolumn{1}{c|}{} & \multicolumn{2}{c|}{$v_{\mathrm{d}, 1}$} & \multicolumn{2}{c|}{$v_{\mathrm{d}, 2}$} & \multicolumn{2}{c|}{$v_{\mathrm{d}, 3}$} \\
\hline PAVIMENTO & PC & PL & PC & PL & PC & PL \\
\hline 6 & 0,10 & 0,06 & 0,05 & 0,03 & 0,12 & 0,07 \\
\hline 5 & 0,21 & 0,14 & 0,11 & 0,09 & 0,24 & 0,16 \\
\hline 4 & 0,31 & 0,21 & 0,16 & 0,14 & 0,37 & 0,24 \\
\hline 3 & 0,41 & 0,29 & 0,21 & 0,19 & 0,49 & 0,33 \\
\hline 2 & 0,52 & 0,37 & 0,26 & 0,24 & 0,61 & 0,41 \\
\hline 1 & 0,62 & 0,44 & 0,32 & 0,29 & 0,73 & 0,50 \\
\hline
\end{tabular}

Tabela 4.41: Coeficientes redutores de rigidez dos pilares (P50x50) para a estrutura com modulação de $7,5 \mathrm{~m}$ e carga acidental de $5 \mathrm{kN} / \mathrm{m}^{2}$.

\begin{tabular}{|c|c|c|c|c|c|c|}
\cline { 2 - 7 } \multicolumn{1}{c|}{} & \multicolumn{2}{c|}{$\alpha_{1}$} & \multicolumn{2}{c|}{$\alpha_{, 2}$} & \multicolumn{2}{c|}{$\alpha_{, 3}$} \\
\hline PAVIMENTO & PC & PL & PC & PL & PC & PL \\
\hline 6 & 0,381 & 0,349 & 0,345 & 0,333 & 0,399 & 0,355 \\
\hline 5 & 0,454 & 0,408 & 0,384 & 0,366 & 0,490 & 0,420 \\
\hline 4 & 0,506 & 0,460 & 0,422 & 0,409 & 0,521 & 0,488 \\
\hline 3 & 0,535 & 0,501 & 0,459 & 0,443 & 0,568 & 0,510 \\
\hline 2 & 0,584 & 0,521 & 0,495 & 0,483 & 0,644 & 0,535 \\
\hline 1 & 0,649 & 0,544 & 0,507 & 0,501 & 0,722 & 0,575 \\
\hline
\end{tabular}

Na Figura 4.42 são apresentados os coeficientes redutores de rigidez segundo a força normal adimensional para os pilares de seção $50 \times 50 \mathrm{~cm}$ nas estruturas com variadas combinações de ações e carregamentos. Segundo a nuvem de pontos definida na Figura 4.42 pode ser constatada uma tendência de comportamento na variação dos coeficientes redutores de rigidez conforme a força normal adimensional. 


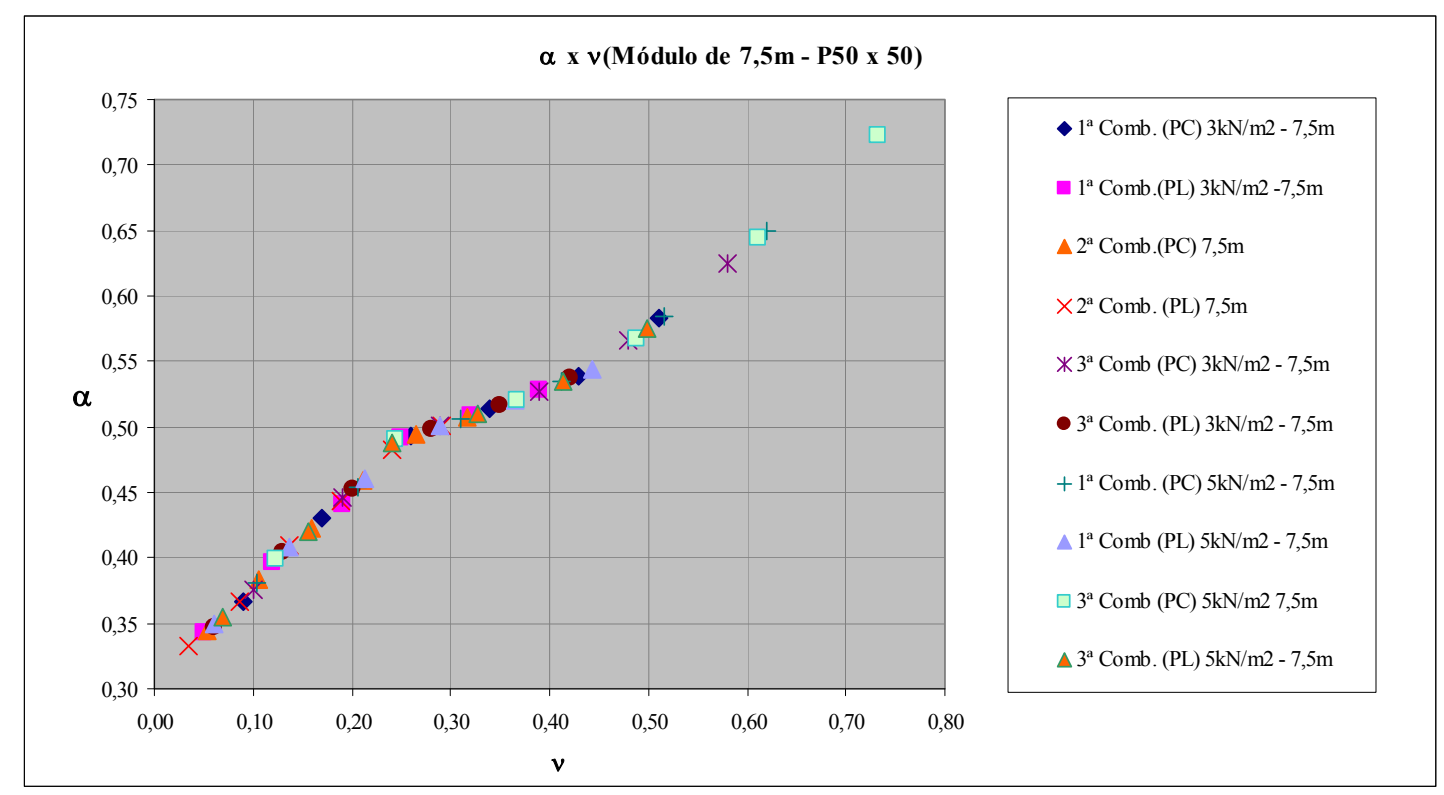

Figura 4.42: Diagrama dos coeficientes redutores de rigidez versus força normal adimensional para pilares (P50x50) em estruturas com modulação de 7,5m com carga acidental de $3 \mathrm{kN} / \mathrm{m}^{2}$ e $5 \mathrm{kN} / \mathrm{m}^{2}$

A Figura 4.43 ilustra duas aproximações com variação linear divididas em dois subdomínios de utilização.

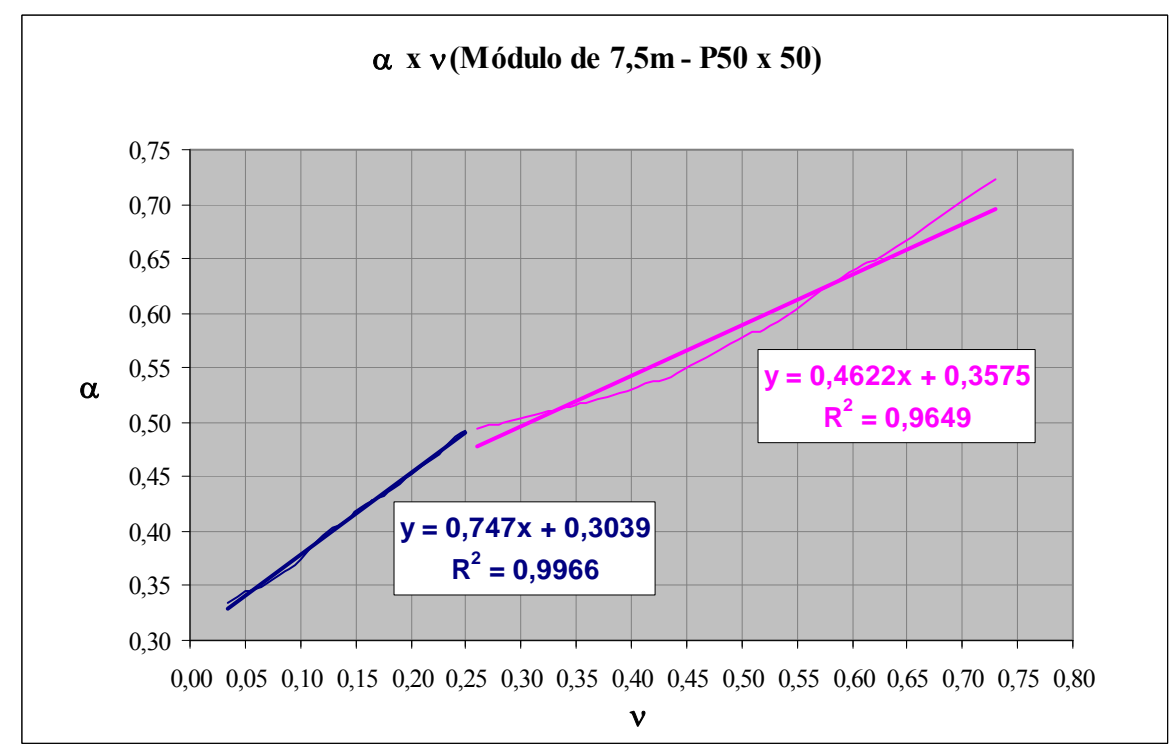

Figura 4.43: Funções aproximadoras dos coeficientes redutores de rigidez versus força normal adimensional para pilares (P50x50)

Sendo assim, propõem-se as seguintes funções de redução de rigidez segundo os respectivos subdomínios, conforme apresenta a Tabela 4.42: 
Tabela 4.42: Funções de redução de rigidez segundo subdomínios para pilar (P50x50)

\begin{tabular}{|c|c|}
\hline Função redução de rigidez( $\alpha)$ & Sub domínio(v) \\
\hline$\alpha=0,75 v+1,10\left(E_{s} I_{s}\right) / E I$ & $0 \leq v \leq 0,25$ \\
\hline$\alpha=0,46 v+1,32\left(E_{s} I_{s}\right) / E I$ & $0,25<v \leq 0,75$ \\
\hline
\end{tabular}

Para a estrutura com 4 pavimentos, cuja seção do pilar é de $40 \times 40 \mathrm{~cm}$, foi construída a Tabela 4.43 com a força adimensional e a Tabela 4.44 com os coeficientes redutores de rigidez.

Tabela 4.43: Força normal adimensional atuante nos pilares (P40x40) para a estrutura com modulação de $7,5 \mathrm{~m}$ e carga acidental de $5 \mathrm{kN} / \mathrm{m}^{2}$

\begin{tabular}{|c|c|c|}
\cline { 2 - 3 } \multicolumn{1}{c|}{} & \multicolumn{2}{c|}{$v_{\mathrm{d}, 1}$} \\
\hline PAVIMENTO & PC & PL \\
\hline 4 & 0,16 & 0,09 \\
\hline 3 & 0,32 & 0,21 \\
\hline 2 & 0,48 & 0,33 \\
\hline 1 & 0,65 & 0,45 \\
\hline
\end{tabular}

Tabela 4.44: Coeficientes redutores de rigidez dos pilares (P40x40) para a estrutura com modulação de $7,5 \mathrm{~m}$ e carga acidental de $5 \mathrm{kN} / \mathrm{m}^{2}$

\begin{tabular}{|c|c|c|}
\cline { 2 - 3 } \multicolumn{1}{c|}{} & \multicolumn{2}{c|}{$\alpha_{, 1}$} \\
\hline PAVIMENTO & PC & PL \\
\hline 4 & 0,416 & 0,365 \\
\hline 3 & 0,495 & 0,459 \\
\hline 2 & 0,550 & 0,498 \\
\hline 1 & 0,645 & 0,535 \\
\hline
\end{tabular}

Na Tabela 4.45 pode ser observado os valores dos principais parâmetros de análise para as estruturas com 4,5 e 6 pavimentos com carga acidental de $5 \mathrm{kN} / \mathrm{m}^{2}$.

Tabela 4.45: Parâmetros de análise segundo combinação de ações para modelo com 6, 5 e 4 pavimentos, modulação de $7,5 \mathrm{~m}$ e carga acidental de $5 \mathrm{kN} / \mathrm{m}^{2}$

\begin{tabular}{|c|c|c|c|c|c|c|c|c|c|}
\hline & \multicolumn{7}{|c|}{ MOMENTO FLETOR(kN.m) } & \\
\hline PAV & Combinação & $\mathrm{M}_{\mathrm{a}}$ & $\mathrm{M}_{\mathrm{b}}$ & $\mathrm{M}_{\mathrm{c}}$ & $\mathrm{M}_{\text {pos }}$ & $M_{\text {neg,central }}$ & $\mathrm{M}_{\text {neg,lateral }}$ & $\mathrm{M}_{\mathrm{V}}$ & $\gamma_{Z}$ \\
\hline 6 & $1^{\mathrm{a}}$ & 326,01 & 406,03 & 412,81 & 46,00 & 386,42 & 306,47 & 395,85 & 1,139 \\
\hline 5 & $1^{\mathrm{a}}$ & 184,00 & 250,03 & 267,95 & 9,52 & 264,89 & 206,98 & 396,84 & 1,081 \\
\hline 4 & $1^{\mathrm{a}}$ & 91,16 & 149,27 & 172,62 & 12,45 & 242,82 & 172,74 & 397,10 & 1,092 \\
\hline
\end{tabular}

Nas figuras 4.44, 4.45, 4.46 e 4.47 estão ilustrados gráficos comparativos de valores obtidos de momento positivo, negativo junto ao pilar central e negativo junto ao pilar lateral nas ligações para as estruturas com 4,5 e 6 pavimentos. As cargas acidentais avaliadas foram de $3 \mathrm{kN} / \mathrm{m}^{2}$ e $5 \mathrm{kN} / \mathrm{m}^{2}$. As combinações de ações envolvidas na avaliação do momento 
positivo, momento negativo junto ao pilar central e lateral foram a $1^{\mathrm{a}}$ e $2^{\mathrm{a}}$ combinações de ações.

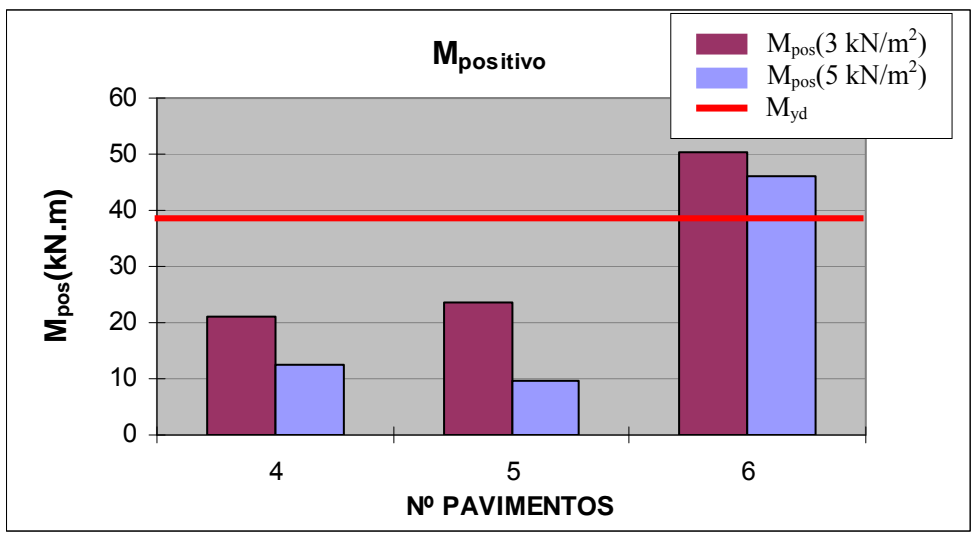

Figura 4.44: Análise comparativa para momento fletor positivo na ligação segundo a $1^{\mathrm{a}}$ combinação de ações nas estruturas com modulação de 7,5m

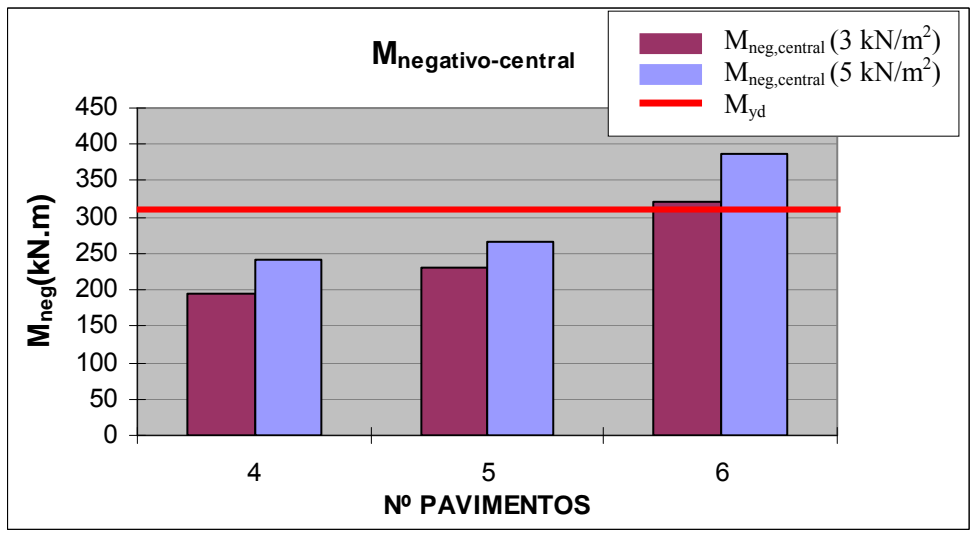

Figura 4.45: Análise comparativa para momento fletor negativo na ligação junto ao pilar central segundo a $1^{\mathrm{a}}$ combinação de ações nas estruturas com modulação de $7,5 \mathrm{~m}$

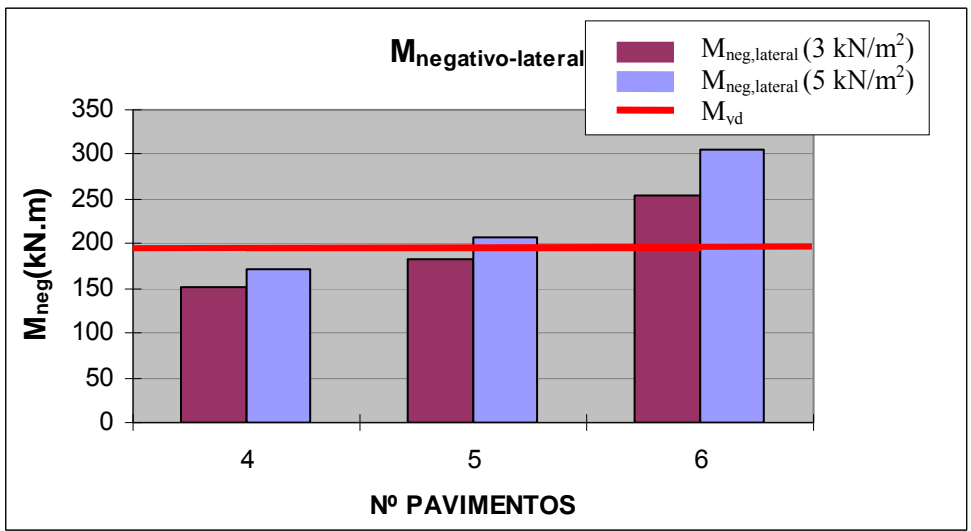

Figura 4.46: Análise comparativa para momento fletor negativo na ligação junto ao pilar lateral segundo a $1^{\mathrm{a}}$ combinação de ações nas estruturas com modulação de $7,5 \mathrm{~m}$ 


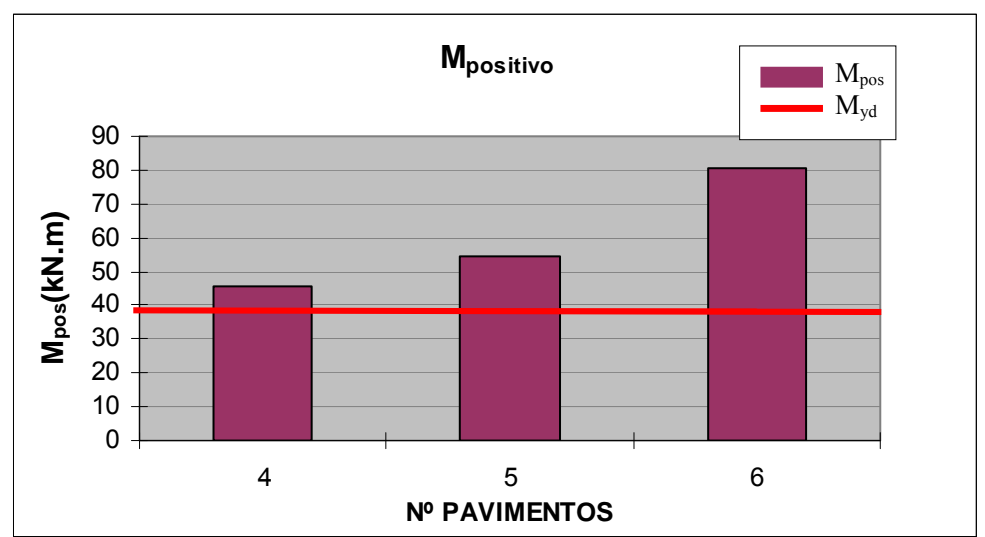

Figura 4.47: Análise comparativa para momento fletor positivo na ligação segundo a $2^{\mathrm{a}}$ combinação de ações nas estruturas com modulação de 7,5m

O parâmetro de estabilidade $\gamma_{\mathrm{z}}$ foi avaliado segundo as variações de carga acidental e número de pavimentos, conforme ilustra a Figura 4.48 .

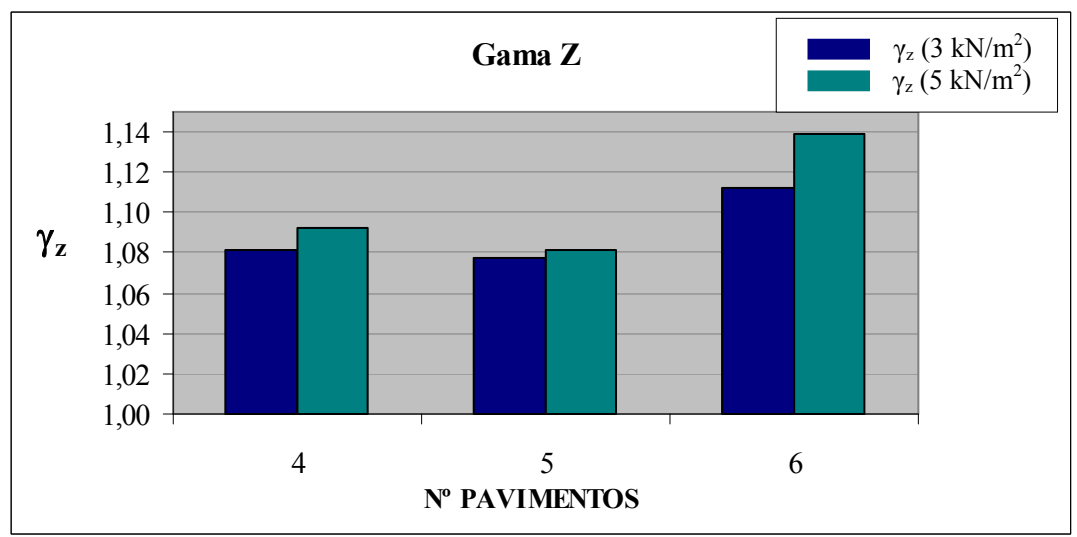

Figura 4.48: Parâmetro de estabilidade $\gamma_{\mathbf{z}}$ considerando comportamento linear assimétrico da ligação nas estruturas com modulação de $7,5 \mathrm{~m}$

Analisando os resultados apresentados, nota-se que não há proporcionalidade entre os valores encontrados para os esforços nas ligações e o $\gamma_{z}$ quando são comparados os valores entre as estruturas com 6, 5 e 4 pavimentos. Vale ressaltar que no modelo com 4 pavimentos a dimensão do pilar é de 40x40 cm, já nos modelos com 5 e 6 pavimentos a dimensão do pilar é de 50x50 cm. Portanto, em virtude desta diferença na dimensão dos pilares não há uma linearidade nos resultados apresentados.

Para ilustrar a não-proporcionalidade da rigidez relativa entre vigas e pilares, é apresentada na Tabela 4.46 a relação para rigidez secante e para a rigidez bruta das seções. 
Tabela 4.46: Relação entre a rigidez da viga e dos pilares para estrutura com modulação de 7,5m

\begin{tabular}{|l|c|c|}
\cline { 2 - 3 } \multicolumn{1}{c|}{} & Secante & Bruto \\
\hline $\mathrm{EI}_{\mathrm{VR}} / \mathrm{EI}_{\mathrm{P} 50 \times 50}$ & 1,47 & 2,65 \\
\hline $\mathrm{EI}_{\mathrm{VR}} / \mathrm{EI}_{\mathrm{P} 40 \times 40}$ & 3,70 & 6,46 \\
\hline
\end{tabular}

Segundo os resultados apresentados, para a $1^{\text {a }}$ combinação de ações apenas a estrutura com 4 pavimentos e a estrutura de 5 pavimentos com carga acidental de ocupação de $3 \mathrm{kN} / \mathrm{m}^{2}$ atenderam a capacidade resistente das ligações sem necessidade de consideração de plastificação. Nota-se que o $\gamma_{\mathrm{z}}$ obtido para a estrutura com 4 pavimentos assumiu um valor maior ao obtido para a estrutura com 5 pavimentos, isto ocorre, pois a seção transversal do pilar para a estrutura com 4 pavimentos é menor do que a seção utilizada na estrutura com 5 pavimentos. Para a $2^{\mathrm{a}}$ combinação de ações, nenhuma estrutura atendeu ao momento fletor positivo resistente da ligação considerando o modelo elástico linear.

Foi realizada uma nova simulação numérica considerando o modelo de comportamento elasto-plástico da ligação viga-pilar. A máxima rotação considerada ao momento negativo e ao momento positivo foi $0,01 \mathrm{rad}$, ou seja, $10 \%$.

A consideração do modelo de ligação elasto-plástico permitiu uma nova distribuição de esforços na estrutura, sendo assim respeitando-se a capacidade resistente das ligações. Em virtude da plastificação nas ligações as estruturas se tornaram mais deslocáveis, no entanto, este acréscimo de deslocabilidade não provocou efeitos de segunda ordem significativos.

Não houve convergência na obtenção dos resultados para a tolerância em deslocamentos definida apenas na estrutura com 6 pavimentos, sob carregamento acidental de $5 \mathrm{kN} / \mathrm{m}^{2}$. Portanto, a estrutura não foi capaz de redistribuir os esforços presentes nas ligações.

A Figura 4.49 ilustra os valores de $\gamma_{\mathbf{z}}$ obtidos para as diferentes combinações de ações considerando a plastificação da ligação.

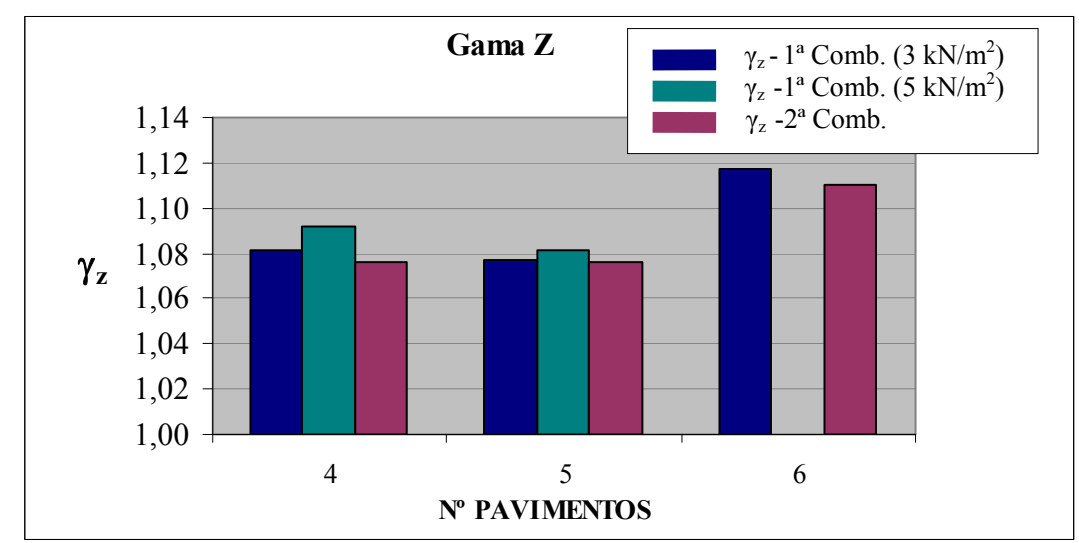

Figura 4.49: Parâmetro de estabilidade $\gamma_{\mathrm{z}}$ considerando o modelo elasto-plástico assimétrico da ligação na estrutura com modulação de $7,5 \mathrm{~m}$ 
As avaliações feitas quanto à capacidade de absorção de momento fletor pelas ligações viga-pilar para os arranjos estruturais com módulo de 7,5m foram feitas para arranjos com módulo de $10 \mathrm{~m}$.

A ação do vento para o arranjo selecionado está discriminada por pavimento na Tabela 4.47, os valores apresentados são característicos.

Tabela 4.47: Ação do vento na estrutura com modulação de 10,0 m

\begin{tabular}{|c|c|c|c|c|c|c|c|c|c|c|c|c|}
\hline \multicolumn{13}{|c|}{ Ação do vento- Direção Y } \\
\hline \multicolumn{4}{|c|}{ Modulo $10 \mathrm{~m}$} & \multicolumn{3}{|c|}{$6 \mathrm{PAV}$} & \multicolumn{3}{|c|}{$5 \mathrm{PAV}$} & \multicolumn{3}{|c|}{ 4 PAV } \\
\hline $\mathrm{h}(\mathrm{m})$ & $\mathrm{S}_{2}$ & $\mathrm{~V}_{\mathrm{k}}(\mathrm{m} / \mathrm{s})$ & $\mathrm{q}\left(\mathrm{kN} / \mathrm{m}^{2}\right)$ & $\mathrm{H} / \mathrm{L} 1$ & $\mathrm{C}_{\mathrm{a}}$ & $\mathrm{F}_{\mathrm{a}}(\mathrm{kN})$ & $\mathrm{H} / \mathrm{L} 1$ & $\mathrm{C}_{\mathrm{a}}$ & $\mathrm{F}_{\mathrm{a}}(\mathrm{kN})$ & $\mathrm{H} / \mathrm{L} 1$ & $\mathrm{C}_{\mathrm{a}}$ & $\mathrm{F}_{\mathrm{a}}(\mathrm{kN})$ \\
\hline 4 & 0,76 & 34,20 & 0,717 & 0,60 & 1,19 & 34,13 & 0,50 & 1,16 & 33,27 & 0,40 & 1,16 & 33,27 \\
\hline 8 & 0,80 & 36,00 & 0,794 & 0,60 & 1,19 & 37,82 & 0,50 & 1,16 & 36,86 & 0,40 & 1,16 & 36,86 \\
\hline 12 & 0,85 & 38,25 & 0,897 & 0,60 & 1,19 & 42,69 & 0,50 & 1,16 & 41,61 & 0,40 & 1,16 & 41,61 \\
\hline 16 & 0,89 & 40,05 & 0,983 & 0,60 & 1,19 & 46,80 & 0,50 & 1,16 & 45,62 & 0,40 & 1,16 & 22,81 \\
\hline 20 & 0,91 & 40,95 & 1,028 & 0,60 & 1,19 & 48,93 & 0,50 & 1,16 & 23,85 & & & \\
\hline 24 & 0,93 & 41,85 & 1,074 & 0,60 & 1,19 & 25,55 & & & & & & \\
\hline
\end{tabular}

A Figura 4.50 ilustra o arranjo de armadura adotado para os pilares da estrutura, foi adotada a mesma taxa de armadura para todas as seções transversais do pilar, a taxa geométrica de armadura corresponde a $3,3 \%$. O concreto utilizado é especificado com $\mathrm{f}_{\mathrm{ck}}=35$ MPa.

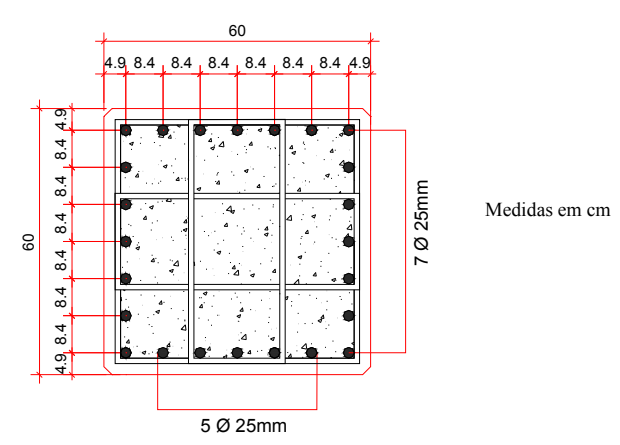

Figura 4.50: Seção transversal e disposição de armadura do pilar em concreto pré-moldado (P60x60)

A laje alveolar correspondente as estruturas com modulação de 10m é a LP20 com peso próprio de $2,6 \mathrm{kN} / \mathrm{m}^{2}$.

Desta forma foram definidas as cargas normais adimensionais e os coeficientes redutores de rigidez para cada trecho de pilar para carga acidental de $3 \mathrm{kN} / \mathrm{m}^{2}$ e $5 \mathrm{kN} / \mathrm{m}^{2}$, conforme apresenta a Tabela 4.48 e a Tabela 4.49 respectivamente. Os valores obtidos referem-se às estruturas com 5 e 6 pavimentos, onde a seção adotada é de $60 \times 60 \mathrm{~cm}$. Com intuito de avaliar o comportamento das ligações para os arranjos estruturais em questão, foram estudadas a $1^{\mathrm{a}}$ e a $2^{\mathrm{a}}$ combinações de ações. 
Tabela 4.48: Força normal adimensional atuante nos pilares (P60x60) para a estrutura com modulação de $10 \mathrm{~m}$ e carga acidental de $3 \mathrm{kN} / \mathrm{m}^{2}$ e $5 \mathrm{kN} / \mathrm{m}^{2}$

\begin{tabular}{|c|c|c|c|c|c|c|}
\cline { 2 - 7 } \multicolumn{1}{c|}{} & \multicolumn{2}{c|}{$v_{\mathrm{d}, 1}\left(3 \mathrm{kN} / \mathrm{m}^{2}\right)$} & \multicolumn{2}{c|}{$v_{\mathrm{d}, 1}\left(5 \mathrm{kN} / \mathrm{m}^{2}\right)$} & \multicolumn{2}{c|}{$v_{\mathrm{d}, 2}$} \\
\hline PAVIMENTO & $\mathrm{PC}$ & $\mathrm{PL}$ & $\mathrm{PC}$ & $\mathrm{PL}$ & $\mathrm{PC}$ & $\mathrm{PL}$ \\
\hline 6 & 0,11 & 0,07 & 0,13 & 0,08 & 0,07 & 0,05 \\
\hline 5 & 0,23 & 0,15 & 0,27 & 0,17 & 0,14 & 0,11 \\
\hline 4 & 0,34 & 0,24 & 0,40 & 0,27 & 0,22 & 0,17 \\
\hline 3 & 0,45 & 0,32 & 0,54 & 0,36 & 0,29 & 0,24 \\
\hline 2 & 0,56 & 0,40 & 0,67 & 0,46 & 0,36 & 0,30 \\
\hline 1 & 0,68 & 0,49 & 0,81 & 0,55 & 0,43 & 0,36 \\
\hline
\end{tabular}

Tabela 4.49: Coeficientes redutores de rigidez dos pilares (P60x60) para a estrutura com modulação de $10 \mathrm{~m}$ e carga acidental de $3 \mathrm{kN} / \mathrm{m}^{2}$ e $5 \mathrm{kN} / \mathrm{m}^{2}$

\begin{tabular}{|c|c|c|c|c|c|c|}
\cline { 2 - 7 } \multicolumn{1}{c|}{} & $\alpha, 1\left(3 \mathrm{kN} / \mathrm{m}^{2}\right)$ & \multicolumn{2}{|c|}{$\alpha, 1\left(5 \mathrm{kN} / \mathrm{m}^{2}\right)$} & \multicolumn{2}{|c|}{$\alpha_{, 2}$} \\
\hline PAVIMENTO & PC & PL & PC & PL & PC & PL \\
\hline 6 & 0,424 & 0,384 & 0,437 & 0,391 & 0,387 & 0,371 \\
\hline 5 & 0,503 & 0,447 & 0,525 & 0,461 & 0,443 & 0,422 \\
\hline 4 & 0,541 & 0,512 & 0,558 & 0,524 & 0,494 & 0,462 \\
\hline 3 & 0,572 & 0,535 & 0,615 & 0,547 & 0,529 & 0,514 \\
\hline 2 & 0,631 & 0,557 & 0,696 & 0,574 & 0,547 & 0,531 \\
\hline 1 & 0,699 & 0,588 & 0,771 & 0,623 & 0,567 & 0,547 \\
\hline
\end{tabular}

As cargas normais adimensionais e os coeficientes redutores de rigidez para os trechos de pilares para o arranjo com modulação de $10 \mathrm{~m}$ e estrutura com 4 pavimentos, cuja seção transversal do pilar é de 40x40 cm estão apresentadas na Tabela 4.50 e na Tabela 4.51, respectivamente.

Tabela 4.50: Força normal adimensional atuante nos pilares (P40x40) para a estrutura com modulação de $10 \mathrm{~m}$ e carga acidental de $3 \mathrm{kN} / \mathrm{m}^{2}$ e $5 \mathrm{kN} / \mathrm{m}^{2}$

\begin{tabular}{|c|c|c|c|c|c|c|}
\cline { 2 - 7 } \multicolumn{1}{c|}{} & \multicolumn{2}{c|}{$v_{\mathrm{d}, 1}\left(3 \mathrm{kN} / \mathrm{m}^{2}\right)$} & \multicolumn{2}{c|}{$v_{\mathrm{d}, 1}\left(5 \mathrm{kN} / \mathrm{m}^{2}\right)$} & \multicolumn{2}{c|}{$v_{\mathrm{d}, 2}$} \\
\hline PAVIMENTO & PC & PL & PC & PL & PC & PL \\
\hline 4 & 0,25 & 0,15 & 0,30 & 0,18 & 0,16 & 0,11 \\
\hline 3 & 0,51 & 0,34 & 0,61 & 0,39 & 0,33 & 0,25 \\
\hline 2 & 0,76 & 0,53 & 0,91 & 0,60 & 0,49 & 0,39 \\
\hline 1 & 1,02 & 0,72 & 1,21 & 0,82 & 0,65 & 0,54 \\
\hline
\end{tabular}

Tabela 4.51: Coeficientes redutores de rigidez dos pilares (P40x40) para a estrutura com modulação de $10 \mathrm{~m}$ e carga acidental de $3 \mathrm{kN} / \mathrm{m}^{2}$ e $5 \mathrm{kN} / \mathrm{m}^{2}$.

\begin{tabular}{|c|c|c|c|c|c|c|}
\cline { 2 - 7 } \multicolumn{1}{c|}{} & \multicolumn{2}{c|}{$\alpha_{, 1}\left(3 \mathrm{kN} / \mathrm{m}^{2}\right)$} & \multicolumn{2}{c|}{$\alpha, 1\left(5 \mathrm{kN} / \mathrm{m}^{2}\right)$} & \multicolumn{2}{c|}{$\alpha, 2$} \\
\hline PAVIMENTO & PC & PL & PC & PL & PC & PL \\
\hline 4 & 0,477 & 0,409 & 0,490 & 0,429 & 0,417 & 0,375 \\
\hline 3 & 0,563 & 0,500 & 0,621 & 0,513 & 0,496 & 0,476 \\
\hline 2 & 0,716 & 0,575 & 0,761 & 0,619 & 0,553 & 0,513 \\
\hline 1 & 0,732 & 0,690 & 0,661 & 0,742 & 0,650 & 0,578 \\
\hline
\end{tabular}


Na Figura 4.51 é apresentado um mapeamento da variação do coeficiente redutor da rigidez segundo a força normal adimensional para as diversas condições de modulação e carregamento aos quais os pilares de seção $40 \times 40 \mathrm{~cm}$ foram submetidos.

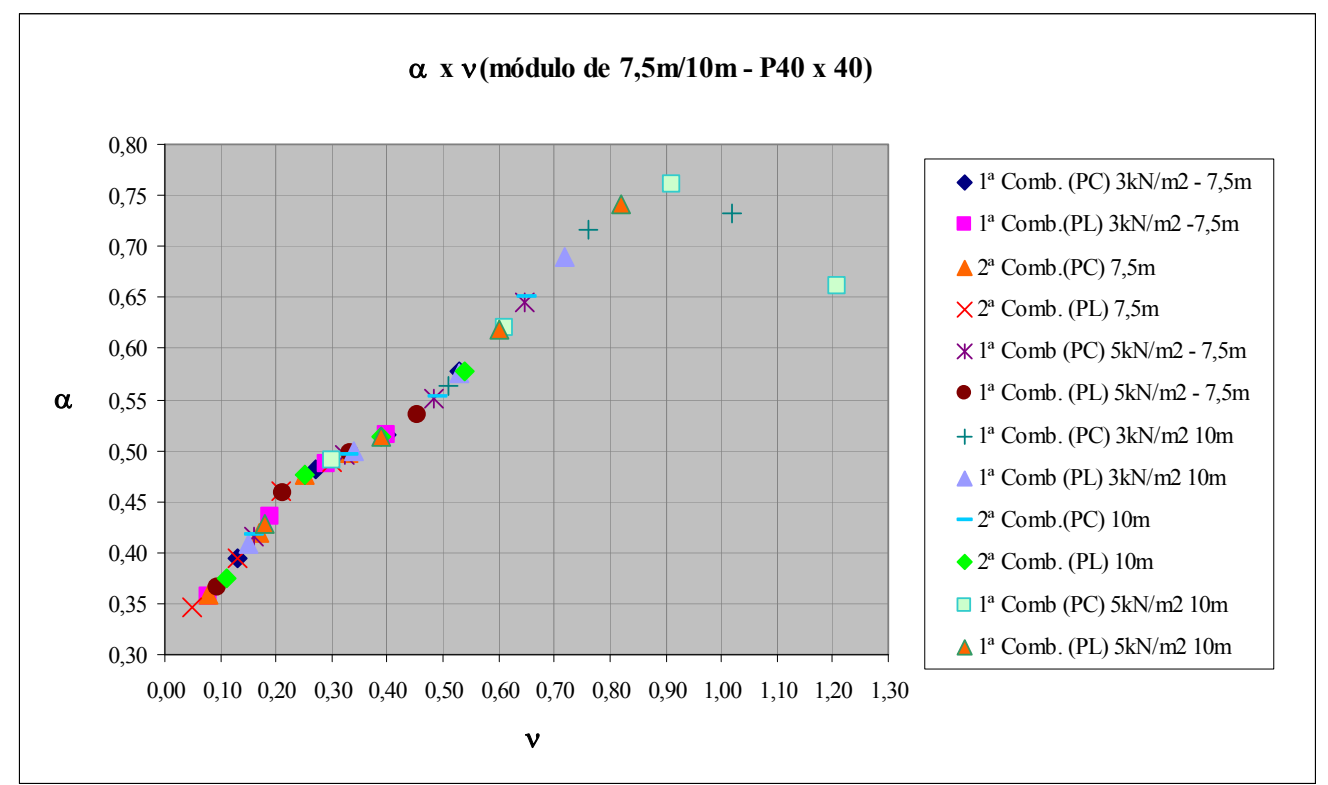

Figura 4.51: Diagrama dos coeficientes redutores de rigidez versus força normal adimensional para pilares (P40x40) em estruturas com modulação de $(7,5 \mathrm{~m} ; 10 \mathrm{~m})$ e carga acidental de $\left(3 \mathrm{kN} / \mathrm{m}^{2} ; 5 \mathrm{kN} / \mathrm{m}^{2}\right)$

Na Figura 4.52 é possível avaliar a variação dos coeficientes redutores de rigidez segundo três subdomínios e, respectivamente, três funções aproximadas.

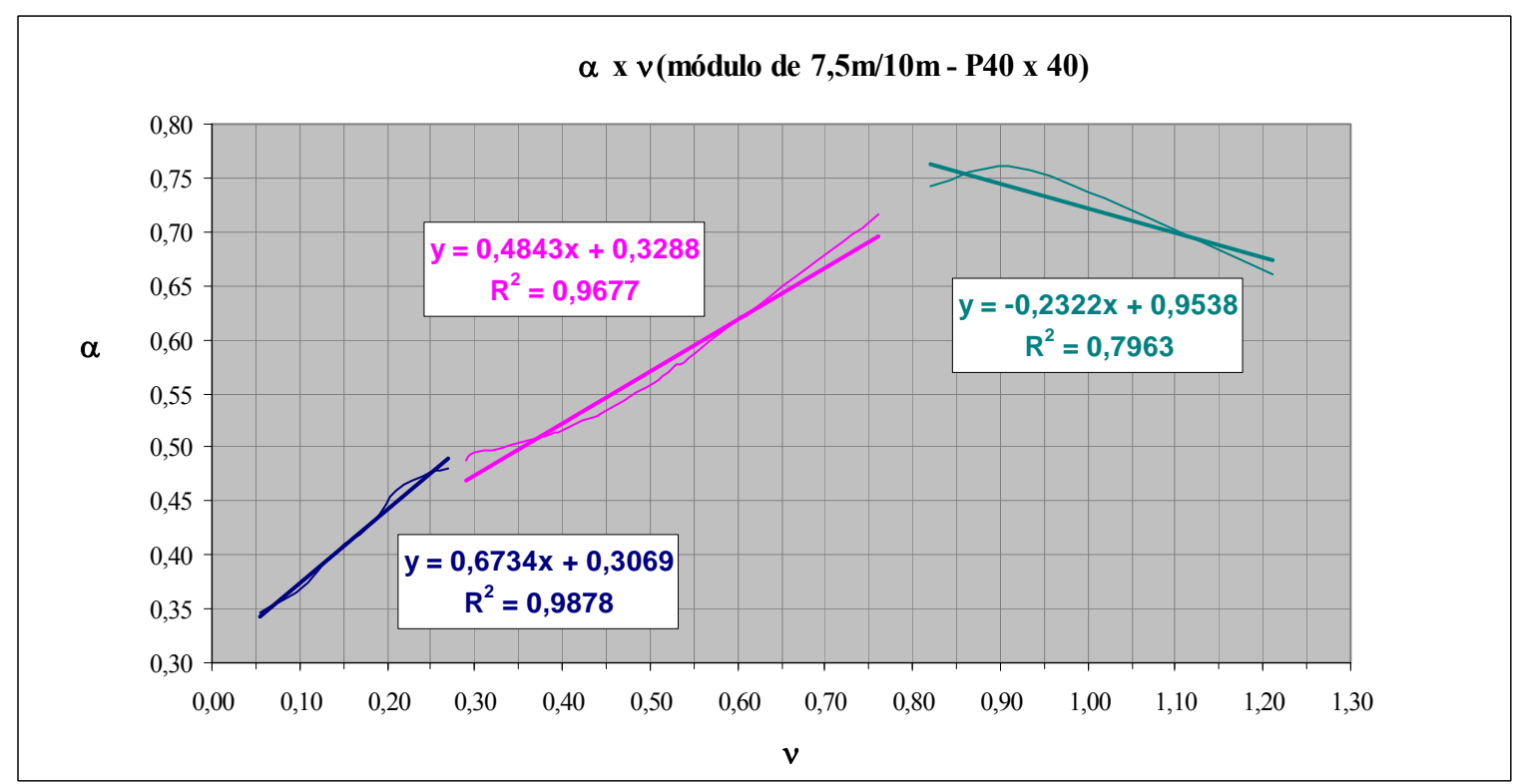

Figura 4.52: Funções aproximadoras dos coeficientes redutores de rigidez versus força normal adimensional para pilares (P40x40) 
A parcela associada a armadura do coeficiente redutor de rigidez assume o valor de 0,26 para o arranjo de armadura ilustrado na Figura 4.41. Segundo o diagrama M x N x 1/r o coeficiente redutor de rigidez associado a força normal adimensional nula é igual a 0,319.

Sendo assim, propõem-se as seguintes funções redução de rigidez segundo os respectivos subdomínios, conforme apresenta a Tabela 4.52 .

Tabela 4.52: Funções de redução de rigidez segundo subdomínios para pilar (P40x40)

\begin{tabular}{|c|c|}
\hline Função redução de rigidez $(\alpha)$ & Subdomínio $(v)$ \\
\hline$\alpha=0,67 v+1,15\left(E_{s} I_{s}\right) / E I$ & $0 \leq v \leq 0,25$ \\
\hline$\alpha=0,48 v+1,20\left(E_{s} I_{s}\right) / E I$ & $0,25<v \leq 0,85$ \\
\hline$\alpha=-0,24 v+3,50\left(E_{s} I_{s}\right) / E I$ & $0,85<v \leq 1,2$ \\
\hline
\end{tabular}

Com o auxílio da seção transversal ilustrada na Figura 4.53, da distribuição de armadura ativa com aderência ilustrada na Figura 4.54 e das inequações expressas na Tabela 4.53 são definidas as armaduras da viga em concreto pré-moldado. Foi considerado no concreto pré-moldado $\mathrm{f}_{\mathrm{ck}}=40 \mathrm{MPa}$ e $\mathrm{f}_{\mathrm{ckj}}=28 \mathrm{MPa}$. No concreto moldado in loco da capa o $\mathrm{f}_{\mathrm{ck}}=20 \mathrm{MPa}$. A armadura ativa presente na seção é composta por cordoalhas CP 190 RB 12,7, a armadura passiva é especificada em aço CA-50.

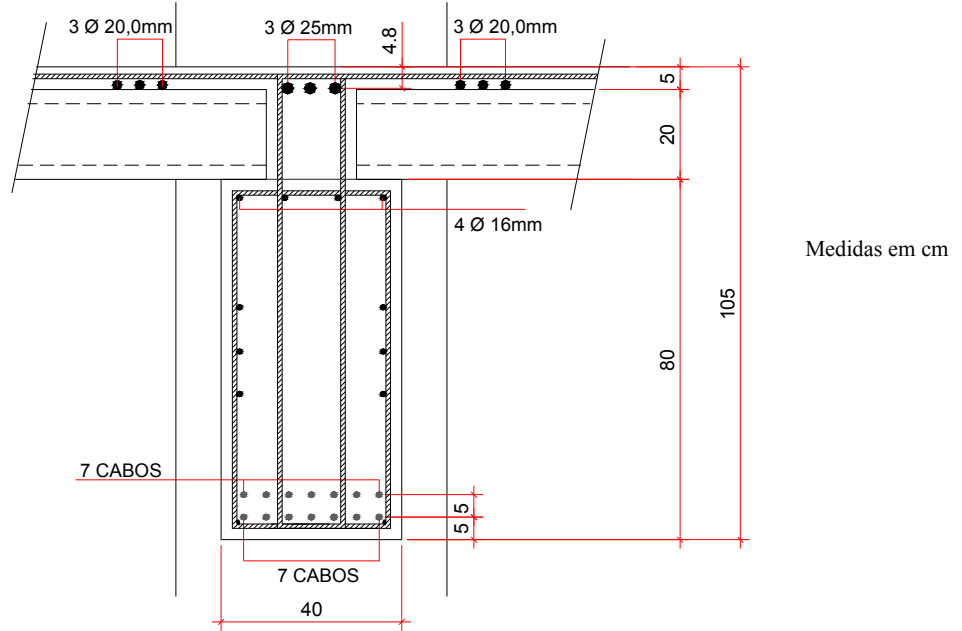

Figura 4.53: Seção transversal e disposição de armadura passiva e ativa da viga em concreto prémoldado em seção composta destinada a estrutura com modulação de $10 \mathrm{~m}$ 


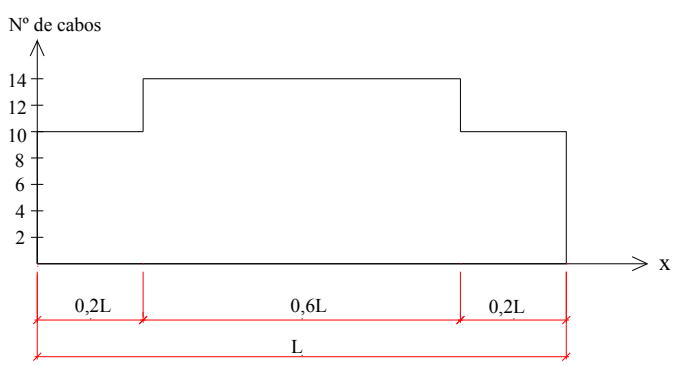

Figura 4.54: Distribuição da armadura ativa com aderência ao longo do eixo da viga para estrutura com modulação de $10 \mathrm{~m}$.

Para efeito de definição da armadura ativa e passiva na situação em vazio, foi considerado que a viga tem $9,4 \mathrm{~m}$ de comprimento. Foi considerada uma força por cabo no tempo 0 de $141,96 \mathrm{kN}$, o que equivale a uma deformação de $7 \%$ no cabo cuja área é de $101,4 \mathrm{~mm}^{2}$.

Tabela 4.53: Condições de verificação para o ELU na situação em vazio da viga para estrutura com modulação de $10 \mathrm{~m}$

\begin{tabular}{|c|c|c|}
\hline Borda & Condição de cálculo & Armadura \\
\hline inferior & $\frac{N_{p}}{0,32}+\frac{N_{p} \cdot 0,325}{0,01707} 0,4-\frac{88,36}{0,01707} 0,4<196 \cdot 10^{2} \mathrm{kN} / \mathrm{m}^{2}$ & 14 cabos de $12,7 \mathrm{~mm}$ \\
\hline superior & $\frac{N_{p}}{0,32}-\frac{N_{p} \cdot 0,325}{0,01707} 0,4+\frac{88,36}{0,01707} 0,4=-685,7.10 \mathrm{kN} / \mathrm{m}^{2}$ & 4 barras de $16 \mathrm{~mm}$ \\
\hline
\end{tabular}

$\mathrm{Na}$ verificação do ELS-F e ELS-D da viga considera-se em uma primeira aproximação que as ligações terão comportamento semi-rígido com absorção de $20 \%$ de momento fletor na ligação. Foi considerada uma perda de $20 \%$ na protensão para a $2^{\mathrm{a}}$ e $3^{\mathrm{a}}$ situações de cálculo. A Tabela 4.54 apresenta a distribuição de tensões nas bordas superior e inferior para cada situação de cálculo.

Tabela 4.54: Tensões atuantes na viga em concreto pré-moldado segundo as situações de cálculo para a estrutura com modulação de $10 \mathrm{~m}$

\begin{tabular}{|c|c|c|c|c|}
\hline \multirow{2}{*}{ Borda } & \multicolumn{4}{|c|}{ Tensão atuante(MPa) } \\
\cline { 2 - 5 } & $1^{\text {a }}$ Situação & $2^{\text {a }}$ Situação & \multicolumn{2}{|c|}{$3^{\text {a }}$ Situação } \\
\cline { 2 - 5 } Superior & $-6,86$ & 5,54 & $7,75^{(1)} / 6,99^{(2)} / 5,86^{(3)}$ & $7,51^{(1)} / 6,88^{(2)} / 5,94^{(3)}$ \\
\hline Inferior & 19,28 & 4,39 & $0,187^{(1)} / 1,63^{(2)} / 3,79^{(3)}$ & $0,095^{(1)} / 1,06^{(2)} / 2,50^{(3)}$ \\
\hline
\end{tabular}

(1) Carregamento acidental de ocupação igual a $5 \mathrm{kN} / \mathrm{m}^{2}$;

(2) Carregamento acidental de ocupação igual a $3 \mathrm{kN} / \mathrm{m}^{2}$;

(3) Carregamento acidental de ocupação igual a $0 \mathrm{kN} / \mathrm{m}^{2}$. 
A Figura 4.55 e a Figura 4.56 ilustram o diagrama $\mathrm{M}$ x N x 1/r junto ao meio do vão e na seção do apoio da viga, respectivamente. Os diagramas $\mathrm{M}$ x $\mathrm{N}$ x 1/r foram construídos considerando uma perda de $20 \%$ na protensão.

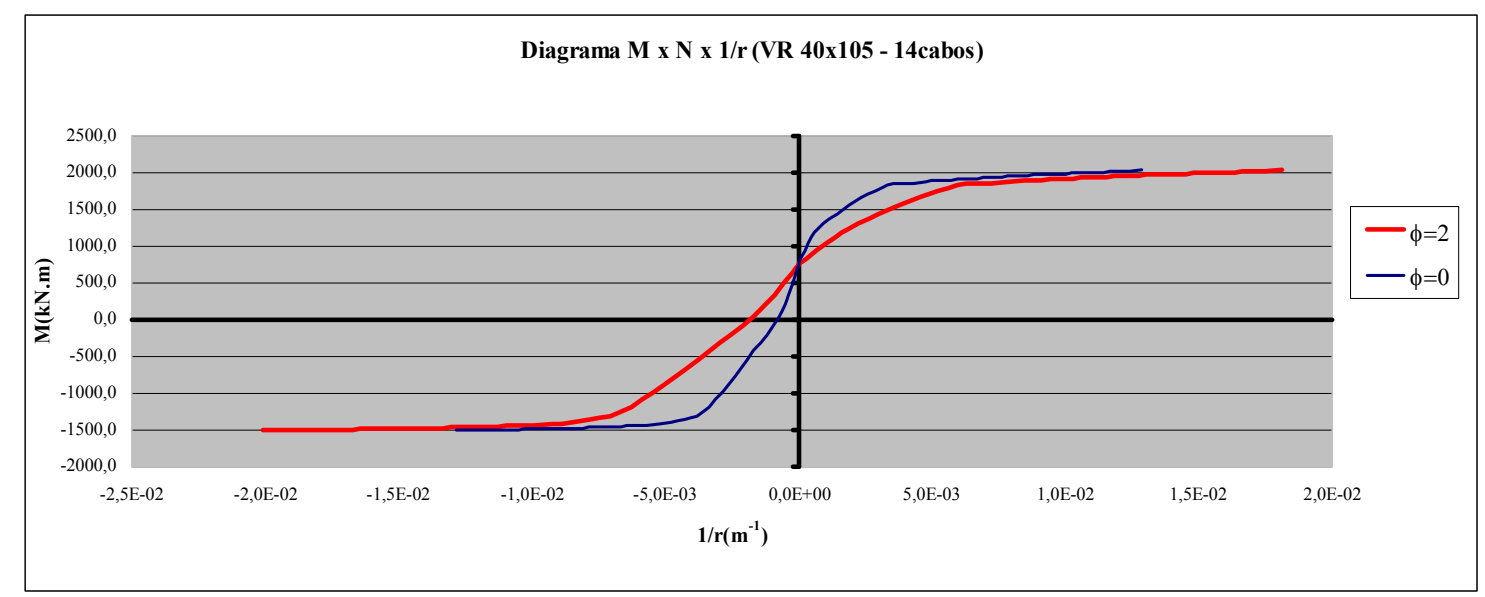

Figura 4.55: Diagrama M x N x 1/r sob efeito da protensão com 14 cabos

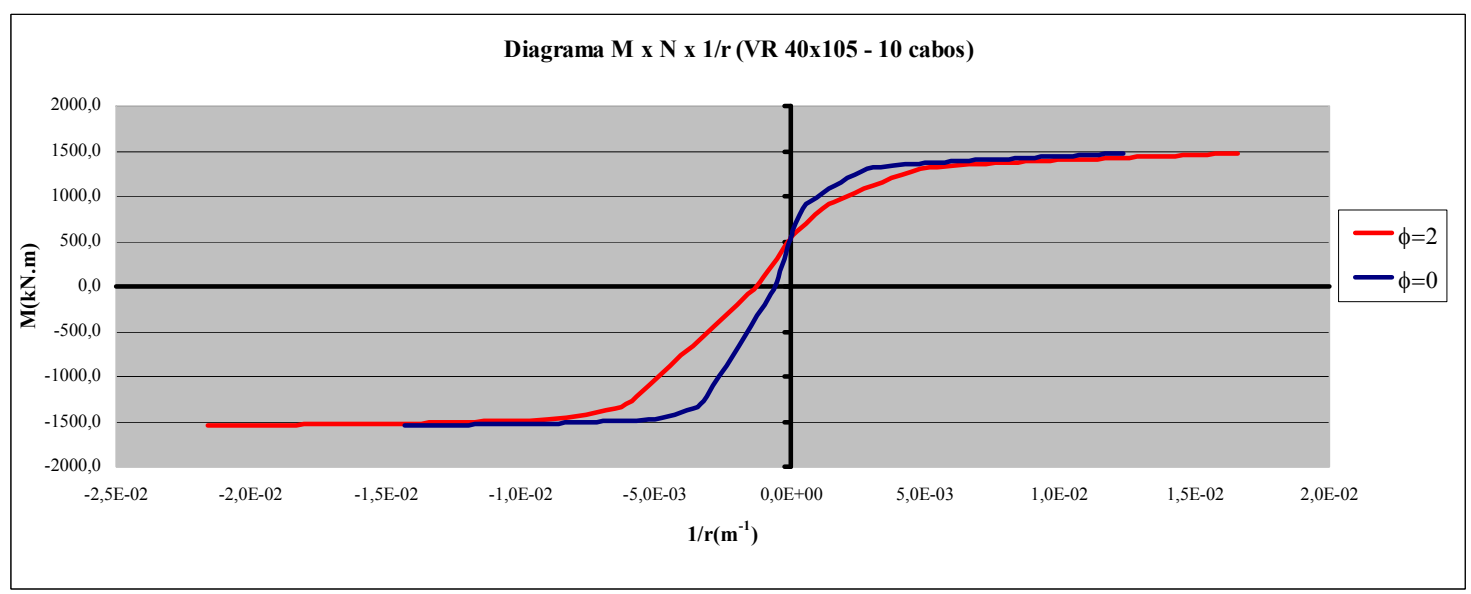

Figura 4.56: Diagrama M x N x 1/r sob efeito da protensão com 10 cabos

Os diagramas $\mathrm{M}$ x $\mathrm{N}$ x 1/r ilustrados na Figura 4.55 e na Figura 4.56 sofreram modificações em virtude da condição de contorno encontrada no programa ANSYS onde para curvatura nula tem-se momento nulo. Sendo assim os diagramas encontrados foram adaptados para os diagramas ilustrados na Figura 4.57. Os diagramas adaptados foram referenciados aos diagramas originais com coeficiente linear de fluência igual a 2. 


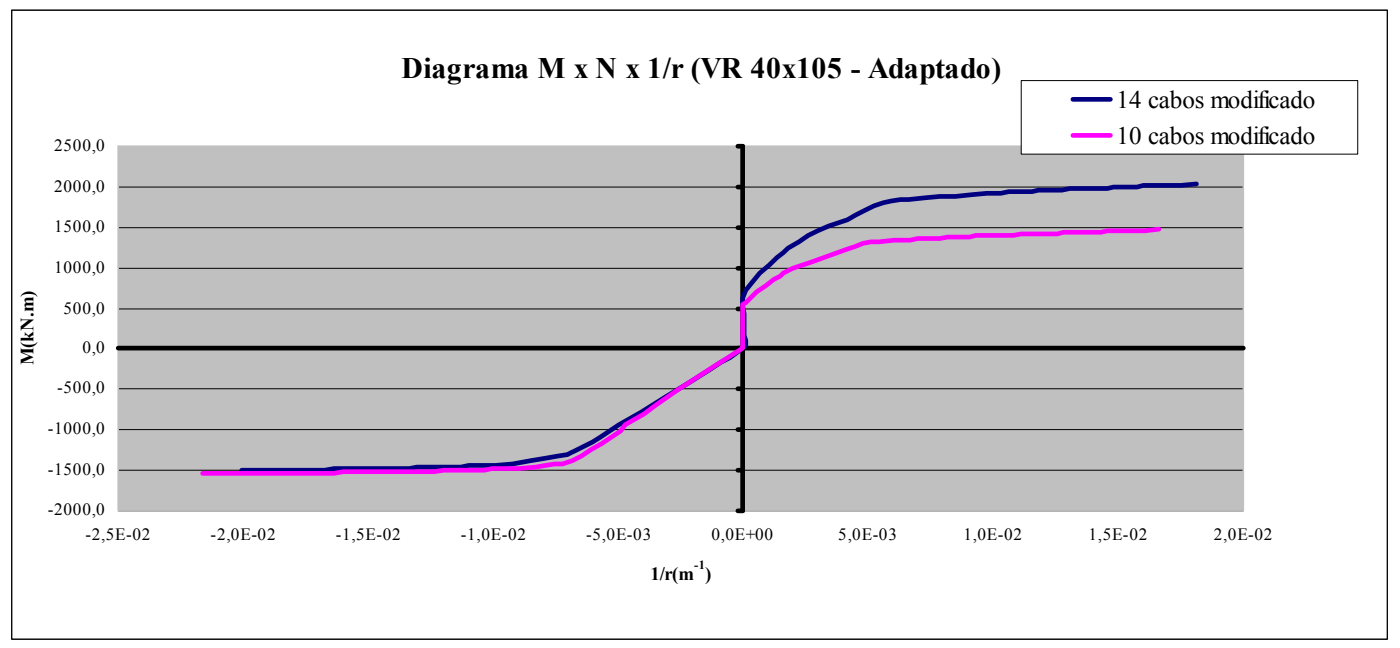

Figura 4.57: Diagrama M x N x 1/r adaptado sob efeito da protensão com 14 e 10 cabos

A Tabela 4.55 apresenta os coeficientes redutores de rigidez obtidos utilizando armadura ativa na face inferior e armadura passiva na face superior da viga.

Tabela 4.55: Coeficientes redutores de rigidez para a viga com armadura passiva e armadura ativa sob efeito da fluência na estrutura com modulação de $10 \mathrm{~m}$

\begin{tabular}{|c|c|c|c|c|c|c|c|c|}
\cline { 2 - 9 } \multicolumn{1}{c|}{} & \multicolumn{4}{c|}{10 cabos } & \multicolumn{4}{c|}{14 cabos } \\
\hline Fluência $(\varphi)$ & 0 & 1 & 2 & 3 & 0 & 1 & 2 & 3 \\
\hline $\mathrm{M}_{\text {pos }}(\alpha)$ & 0,384 & 0,294 & 0,239 & 0,200 & 0,554 & 0,400 & 0,313 & 0,257 \\
\hline $\mathrm{M}_{\text {neg }}(\alpha)$ & 0,287 & 0,203 & 0,157 & 0,128 & 0,254 & 0,178 & 0,137 & 0,111 \\
\hline
\end{tabular}

Os dados para caracterização da ligação junto ao pilar central para o momento negativo e positivo estão apresentados na Tabela 4.56 e na Tabela 4.57, respectivamente. Os dados da tabela referem-se à viga com extremidade em dente gerber.

Tabela 4.56: Dados de cálculo para caracterização da ligação ao momento negativo junto ao pilar central na estrutura com modulação de $10 \mathrm{~m}$

\begin{tabular}{|c|c|}
\hline$\varphi_{\text {armadura_médio }}(\mathrm{cm})$ & 2,25 \\
\hline $\mathrm{A}_{\mathrm{s} \text {,neg }}\left(\mathrm{cm}^{2}\right)$ & 33,9 \\
\hline $\mathrm{f}_{\text {yd,armadura }}(\mathrm{MPa})$ & 435 \\
\hline $\mathrm{d}_{\mathrm{e}}(\mathrm{cm})$ & 4,5 \\
\hline $\mathrm{h}_{\mathrm{e}}(\mathrm{cm})$ & 64 \\
\hline $\mathrm{b}_{\mathrm{w}}(\mathrm{cm})$ & 40 \\
\hline $\mathrm{f}_{\mathrm{cg}}(\mathrm{Mpa})$ & 20 \\
\hline $\mathrm{y}_{\mathrm{cn}}(\mathrm{cm})$ & 25,81 \\
\hline $\mathbf{M}_{\mathbf{y n}}(\mathbf{k N} \cdot \mathbf{m})$ & $\mathbf{6 8 7 , 1 4}$ \\
\hline $\mathrm{f}_{\mathrm{c}, \text { top }}(\mathrm{MPa})$ & 20 \\
\hline $\mathrm{E}_{\mathrm{c}, \text { top }}(\mathrm{MPa})$ & 25043,96 \\
\hline $\mathrm{E}_{\mathrm{s}}(\mathrm{MPa})$ & 210000 \\
\hline
\end{tabular}




\begin{tabular}{|c|c|}
\hline$\alpha_{\mathrm{e}}$ & 8,39 \\
\hline $\mathrm{A}_{\mathrm{c}, \mathrm{ef}}\left(\mathrm{cm}^{2}\right)$ & 550 \\
\hline$\rho_{\mathrm{s}, \mathrm{ef}}$ & 0,0616 \\
\hline$\tau_{\max }(\mathrm{MPa})$ & 9,45 \\
\hline $\mathrm{w}_{\mathrm{y}(\mathrm{m})}$ & 0,00092 \\
\hline $\mathrm{D}_{\mathrm{gj}}(\mathrm{m} / \mathrm{MPa})$ & $1,00 \mathrm{E}-05$ \\
\hline $\mathrm{y}_{\mathrm{cr}}(\mathrm{cm})$ & 19,14 \\
\hline $\mathrm{k}_{\mathrm{s}}(\mathrm{MN} / \mathrm{m})$ & 1595,09 \\
\hline $\mathrm{k}_{\mathrm{g}}(\mathrm{MN} / \mathrm{m})$ & 10322,55 \\
\hline $\mathbf{k}_{\mathbf{\varphi n}}(\mathbf{M N} . \mathbf{m} / \mathbf{r a d})$ & $\mathbf{2 9 9 , 9 8}$ \\
\hline
\end{tabular}

Tabela 4.57: Dados de cálculo para caracterização da ligação ao momento positivo junto ao pilar central na estrutura com modulação de $10 \mathrm{~m}$

\begin{tabular}{|c|c|}
\hline$\varphi_{\text {chumbador }}(\mathrm{cm})$ & 2 \\
\hline $\mathrm{f}_{\mathrm{cc}, \text { max }}(\mathrm{MPa})$ & 40 \\
\hline $\mathrm{f}_{\mathrm{yd}, \text { chumbador }}(\mathrm{MPa})$ & 209 \\
\hline $\mathrm{C}$ & 1,245 \\
\hline $\mathrm{F}_{\mathrm{sd}}(\mathrm{kN})$ & 76,97 \\
\hline $\mathrm{y}_{\mathrm{cp}}(\mathrm{cm})$ & 0,4898 \\
\hline $\mathrm{h}_{\mathrm{c}}(\mathrm{cm})$ & 64 \\
\hline $\mathbf{M}_{\mathbf{y p}}(\mathbf{k N . m})$ & $\mathbf{4 9 , 0 7}$ \\
\hline$\alpha_{\mathrm{vy}}(\mathrm{cm})$ & 0,2 \\
\hline $\mathrm{k}_{\mathrm{sd}}(\mathrm{MN} / \mathrm{m})$ & 38,48 \\
\hline $\mathbf{k}_{\mathbf{\varphi p}}(\mathbf{M N} . \mathbf{m} / \mathbf{r a d})$ & $\mathbf{1 5 , 6 4}$ \\
\hline
\end{tabular}

Na Tabela 4.58 é possível avaliar as possíveis variações das configurações de ligação e suas implicações na rigidez e no momento resistente.

Tabela 4.58: Rigidez e momentos resistentes nas ligações destinadas a estrutura com modulação de $10 \mathrm{~m}$

\begin{tabular}{|c|c|c|c|c|c|c|c|}
\cline { 2 - 8 } \multicolumn{1}{c|}{} & \multicolumn{2}{c|}{$\mathrm{PC}$} & \multicolumn{2}{c|}{$\mathrm{PL}$} & \multicolumn{3}{c|}{$\mathrm{PC} / \mathrm{PL}$} \\
\cline { 2 - 8 } \multicolumn{1}{c|}{} & $\mathrm{M}_{\text {neg }(1)}$ & $\mathrm{M}_{\text {neg }(2)}$ & $\mathrm{M}_{\text {neg }(1)}$ & $\mathrm{M}_{\text {neg }(2)}$ & $\mathrm{M}_{\operatorname{pos}(3)}$ & $\mathrm{M}_{\text {pos }(4)}$ & $\mathrm{M}_{\text {pos }(5)}$ \\
\hline $\mathrm{K}(\mathrm{MN} . \mathrm{m} / \mathrm{rad})$ & 299,98 & 1060,13 & 148,09 & 459,87 & 15,64 & 22,49 & 60,80 \\
\hline $\mathrm{M}_{\mathrm{y}}(\mathrm{Kn} . \mathrm{m})$ & 687,14 & 1291,75 & 350,98 & 618,51 & 49,07 & 70,67 & 116,20 \\
\hline
\end{tabular}

A Tabela 4.59 e a Tabela 4.60 apresentam os principais parâmetros de análise para a estrutura com modulação de $10 \mathrm{~m}$ e carga acidental de $3 \mathrm{kN} / \mathrm{m}^{2}$ e $5 \mathrm{kN} / \mathrm{m}^{2}$. 
Tabela 4.59: Parâmetros de análise segundo combinação de ações na estrutura com módulo de 10m e carga acidental de $3 \mathrm{kN} / \mathrm{m}^{2}$

\begin{tabular}{|c|c|c|c|c|c|c|c|c|c|}
\cline { 3 - 9 } \multicolumn{2}{c|}{} & \multicolumn{7}{c|}{ MOMENTO FLETOR(kN.m) } & \multicolumn{1}{c|}{} \\
\hline PAV & Combinação & $\mathrm{M}_{\mathrm{a}}$ & $\mathrm{M}_{\mathrm{b}}$ & $\mathrm{M}_{\mathrm{c}}$ & $\mathrm{M}_{\text {pos }}$ & $\mathrm{M}_{\text {neg,central }}$ & $\mathrm{M}_{\text {neg,lateral }}$ & $\mathrm{M}_{\mathrm{V}}$ & $\gamma_{\mathrm{Z}}$ \\
\hline 6 & $1^{\mathrm{a}}$ & 374,39 & 469,49 & 520,89 & 57,48 & 402,68 & 325,28 & 1030,00 & 1,104 \\
\hline 6 & $2^{\mathrm{a}}$ & 483,47 & 568,85 & 568,94 & 98,81 & 298,75 & 257,24 & 637,50 & 1,108 \\
\hline 5 & $1^{\mathrm{a}}$ & 251,75 & 341,40 & 386,93 & 34,14 & 290,50 & 217,45 & 1035,00 & 1,073 \\
\hline 5 & $2^{\mathrm{a}}$ & 352,21 & 412,49 & 432,16 & 66,10 & 199,95 & 172,19 & 640,95 & 1,079 \\
\hline 4 & $1^{\mathrm{a}}$ & 110,23 & 182,73 & 239,27 & 67,14 & 268,10 & 216,03 & 1043,00 & 1,138 \\
\hline 4 & $2^{\mathrm{a}}$ & 141,08 & 202,47 & 223,33 & 78,87 & 193,00 & 184,61 & 651,24 & 1,118 \\
\hline
\end{tabular}

Tabela 4.60: Parâmetros de análise segundo combinação de ações na estrutura com módulo de $10 \mathrm{~m}$ e carga acidental de $5 \mathrm{kN} / \mathrm{m}^{2}$

\begin{tabular}{|c|c|c|c|c|c|c|c|c|c|}
\hline \multicolumn{2}{|c|}{ 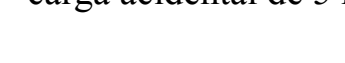 } & \multicolumn{7}{|c|}{ MOMENTO FLETOR(kN.m) } & \multirow[b]{2}{*}{$\gamma_{\mathrm{Z}}$} \\
\hline PAV & Combinação & $\mathrm{M}_{\mathrm{a}}$ & $\mathrm{M}_{\mathrm{b}}$ & $\mathrm{M}_{\mathrm{c}}$ & $\mathrm{M}_{\mathrm{pos}}$ & $\mathrm{M}_{\text {neg,central }}$ & $\mathrm{M}_{\text {neg,lateral }}$ & $\mathrm{M}_{\mathrm{V}}$ & \\
\hline 6 & $1^{\mathrm{a}}$ & 349,01 & 446,49 & 520,65 & 52,31 & 433,80 & 331,51 & 1241,00 & 1,111 \\
\hline 5 & $1^{\mathrm{a}}$ & 227,33 & 325,87 & 387,94 & 30,24 & 304,99 & 227,07 & 1239,00 & 1,077 \\
\hline 4 & $1^{\mathrm{a}}$ & 110,38 & 174,27 & 258,33 & 75,06 & 284,95 & 223,83 & 1252,00 & 1,169 \\
\hline
\end{tabular}

Nas figuras 4.58, 4.59, 4.60 e 4.61 estão ilustrados gráficos comparativos de valores obtidos de momento positivo, negativo junto ao pilar central e negativo junto ao pilar lateral nas ligações para as estruturas com 4, 5 e 6 pavimentos. As cargas acidentais avaliadas foram de $3 \mathrm{kN} / \mathrm{m}^{2}$ e $5 \mathrm{kN} / \mathrm{m}^{2}$. As combinações de ações envolvidas na avaliação do momento positivo, momento negativo junto ao pilar central e lateral foram a $1^{\mathrm{a}}$ e $2^{\mathrm{a}}$ combinações de ações.

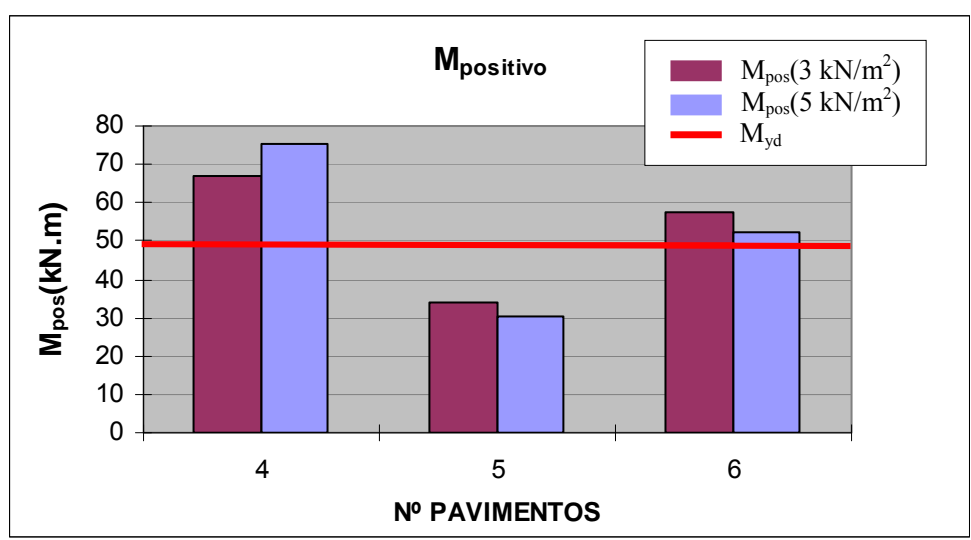

Figura 4.58: Análise comparativa para momento fletor positivo na ligação segundo a $1^{\mathrm{a}}$ combinação de ações nas estruturas com modulação de $10 \mathrm{~m}$ 


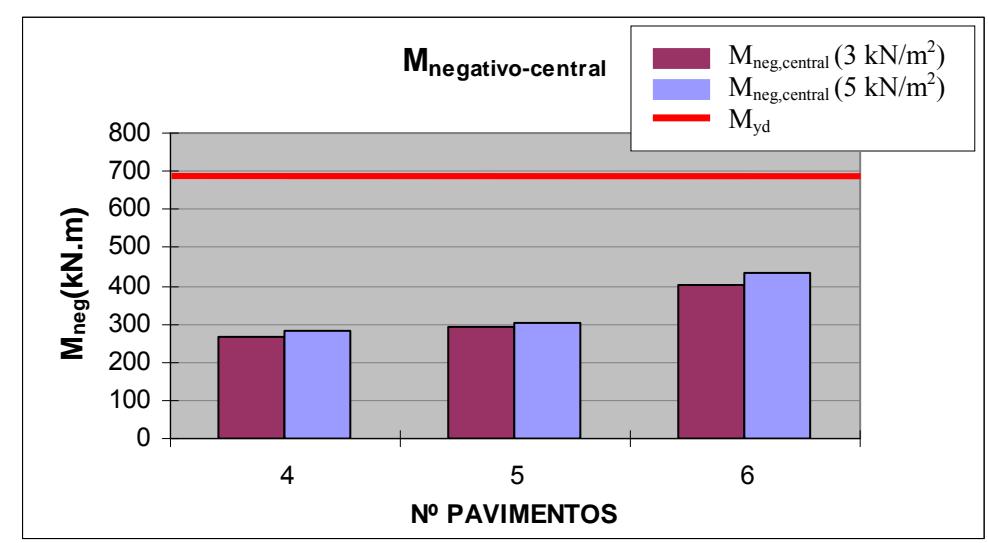

Figura 4.59: Análise comparativa para momento fletor negativo na ligação junto ao pilar central segundo a $1^{\mathrm{a}}$ combinação de ações nas estruturas com modulação de $10 \mathrm{~m}$

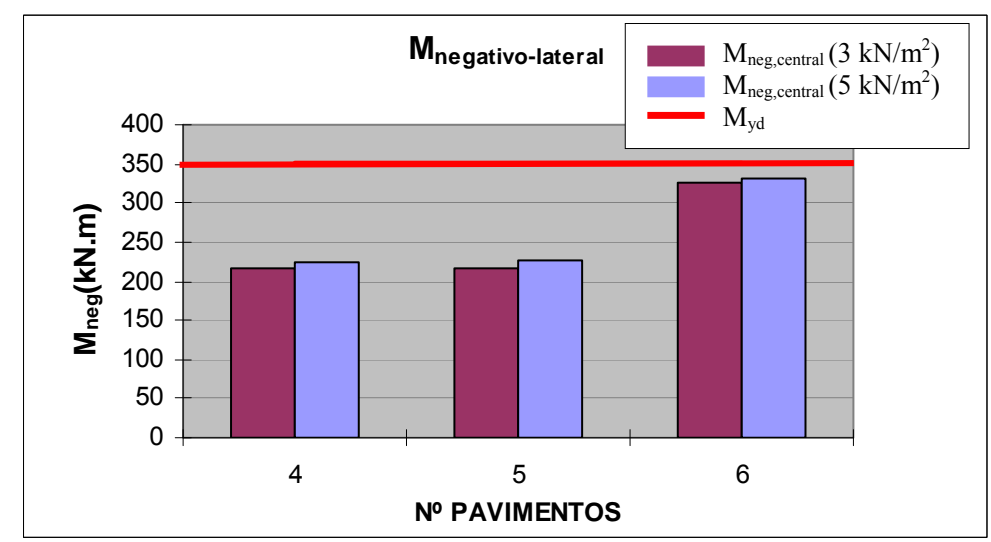

Figura 4.60: Análise comparativa para momento fletor negativo na ligação junto ao pilar lateral segundo a $1^{\text {a }}$ combinação de ações nas estruturas com modulação de $10 \mathrm{~m}$

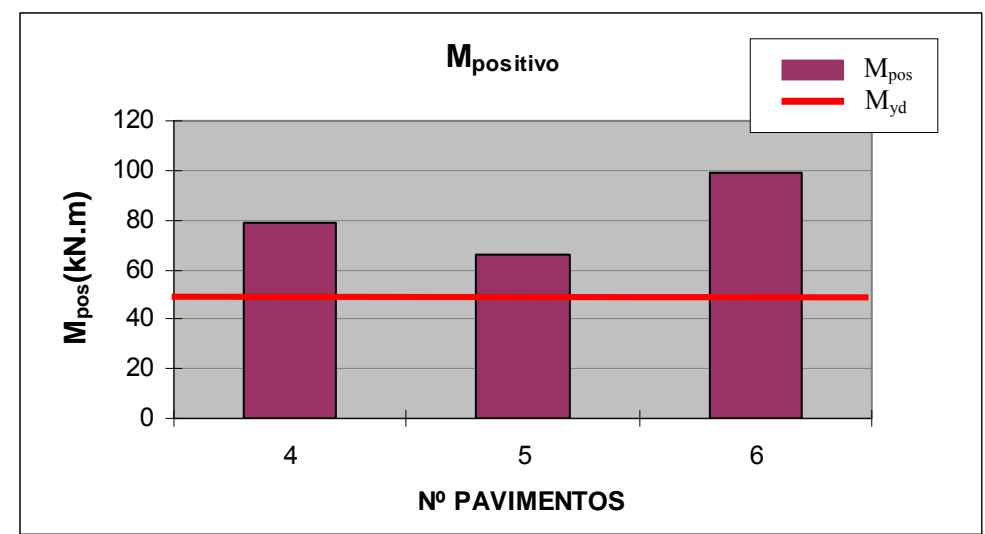

Figura 4.61: Análise comparativa para momento fletor positivo na ligação segundo a $2^{\mathrm{a}}$ combinação nas estruturas com modulação de $10 \mathrm{~m}$

O parâmetro de estabilidade $\gamma_{z}$ foi avaliado segundo as variações de carga acidental e número de pavimentos para a $1^{\mathrm{a}}$ combinação de ações, conforme ilustra a Figura 4.62. 


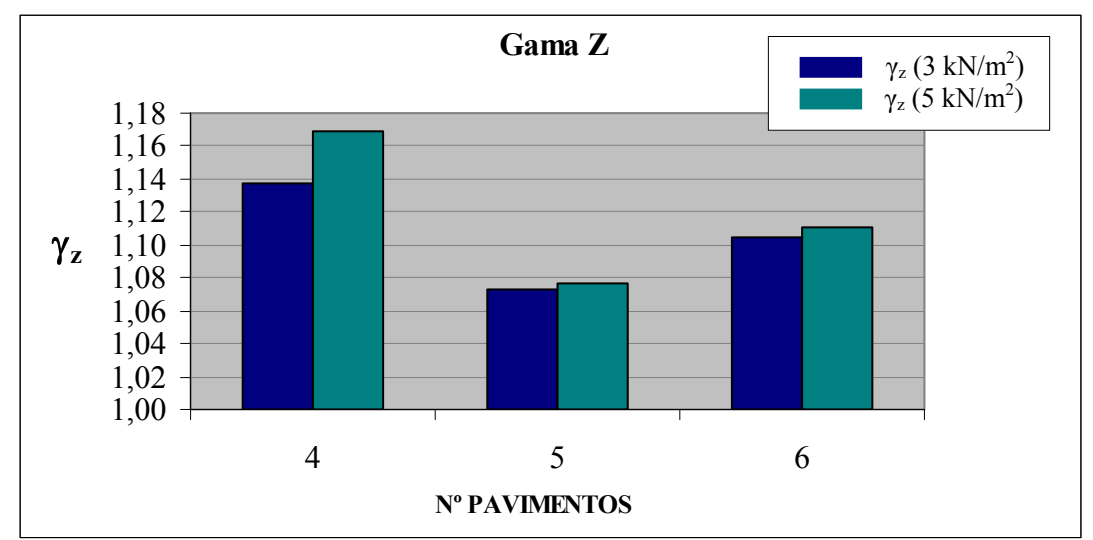

Figura 4.62: Parâmetro de estabilidade $\gamma_{\mathrm{z}}$ considerando comportamento linear assimétrico da ligação nas estruturas com modulação de $10 \mathrm{~m}$

Analisando os resultados apresentados para as estruturas com modulação de $10 \mathrm{~m}$, nota-se que não há proporcionalidade entre os valores encontrados para os esforços nas ligações e o $\gamma_{z}$ quando se comparam os valores obtidos para as estruturas com 6,5 e 4 pavimentos. Vale ressaltar que no modelo com 4 pavimentos a dimensão do pilar é de 40x40 $\mathrm{cm}$, já nos modelos com 5 e 6 pavimentos a dimensão do pilar é de $60 \times 60 \mathrm{~cm}$. Portanto, em virtude desta diferença na dimensão dos pilares não há uma proporcionalidade nos resultados apresentados.

Para ilustrar a não proporcionalidade da rigidez relativa entre vigas e pilares, é apresentada na Tabela 4.61 a relação para rigidez secante e para a rigidez bruta das seções.

Tabela 4.61: Relação entre a rigidez da viga e dos pilares para estrutura com modulação de 10m

\begin{tabular}{|l|c|c|}
\cline { 2 - 3 } \multicolumn{1}{c|}{} & Secante & Bruto \\
\hline $\mathrm{EI}_{\mathrm{VR}} / \mathrm{EI}_{\mathrm{P} 60 \times 60}$ & 1,59 & 2,70 \\
\hline $\mathrm{EI}_{\mathrm{VR}} / \mathrm{EI}_{\mathrm{P} 40 \times 40}$ & 7,57 & 13,67 \\
\hline
\end{tabular}

O comportamento apresentado no gráfico de momento positivo quando se comparam as estruturas com número de pavimentos diferente para a $1^{\mathrm{a}}$ combinação de ações pode ser elucidado com o auxílio do APÊNDICE A - Influência da rigidez dos elementos adjacentes no comportamento da ligação.

O comportamento não-linear da ligação semi-rígida assimétrica pode ser constatado com o auxílio do APÊNDICE B - Não-linearidade física presente em ligações semi-rígidas assimétricas. O comportamento assimétrico das ligações viga-pilar, bem como a rigidez relativa entre os elementos da estrutura influenciam de forma significativa nos resultados.

$\mathrm{Na}$ modelagem das estruturas com ligação em regime elástico linear foi possível identificar que as estruturas com 4 e 6 pavimentos apresentaram valores de momento positivo 
na ligação para a $1^{\mathrm{a}}$ combinação de ações maiores que os resistentes em regime elástico linear. Quanto ao momento negativo atuante nas ligações para a $1^{\mathrm{a}}$ combinação de ações, todas as estruturas atenderam aos valores resistentes. $\mathrm{Na} 2^{\mathrm{a}}$ combinação de ações onde o momento positivo na ligação é mais solicitado, todas as estruturas apresentaram valores maiores que os resistentes em regime elástico linear.

Foi realizada uma nova simulação numérica considerando o modelo elasto-plástico da ligação viga-pilar. A máxima rotação considerada ao momento negativo e ao momento positivo foi $0,01 \mathrm{rad}$, ou seja, $10 \%$.

A consideração do modelo de comportamento da ligação elasto-plástico permitiu uma nova distribuição de esforços na estrutura, sendo assim respeitou-se a capacidade resistente das ligações. Em virtude da plastificação nas ligações as estruturas se tornaram mais deslocáveis, no entanto, este acréscimo de deslocabilidade não provocou efeitos de segunda ordem significativos. A diferença entre os valores de $\gamma_{z}$ obtidos sem e com plastificação das ligações não excedeu $1 \%$.

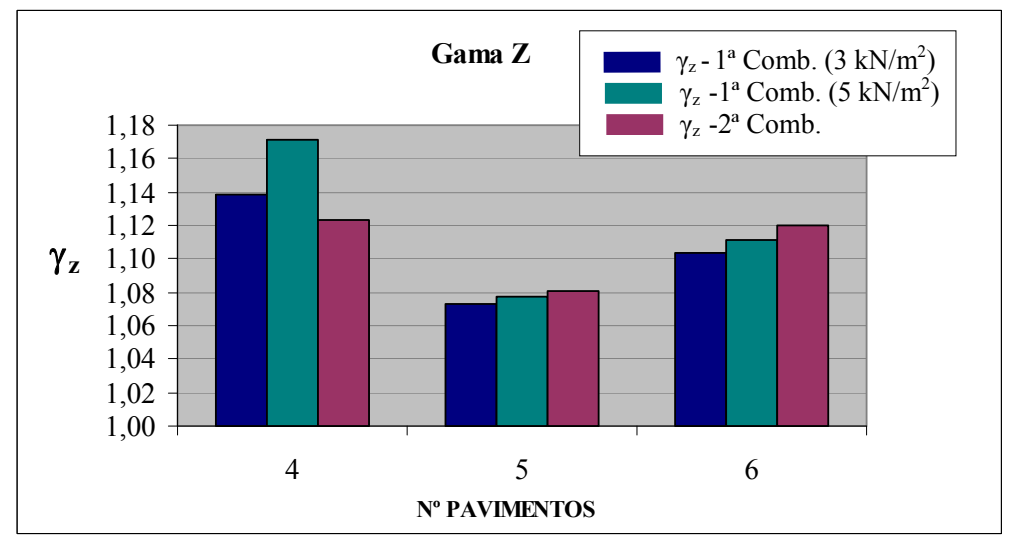

Figura 4.63: Parâmetro de estabilidade $\gamma_{\mathrm{z}}$ considerando o modelo elasto-plástico assimétrico da ligação na estrutura com modulação de $10 \mathrm{~m}$ 


\section{CONSIDERAÇÕES FINAIS E CONCLUSÕES}

O trabalho teve como principal objetivo analisar a influência dos principais parâmetros de projeto na estabilidade global de estruturas de concreto pré-moldado de múltiplos pavimentos considerando a não-linearidade física, não-linearidade geométrica e ligações semi-rígidas. Foram avaliadas estruturas com 6, 5 e 4 pavimentos com modulações de 7,5m e $10 \mathrm{~m}$. As cargas acidentais avaliadas foram de 3 e $5 \mathrm{kN} / \mathrm{m}^{2}$.

As conclusões do trabalho podem ser assim apresentadas:

a) A utilização do coeficiente $\gamma_{z}$ para efeito de consideração da NLG mostrou-se adequada para análise dos efeitos de segunda ordem nos elementos estruturais, havendo diferenças em torno de $4 \%$ da teoria não simplificada de análise NLG obtida com o auxílio do programa ANSYS. As diferenças de momento encontradas para $0,95 \cdot \gamma_{Z}$ aproximaram-se de $10 \%$. Além do coeficiente $\gamma_{\mathrm{z}}$ foram apresentados outros métodos simplificados de análise NLG, dentre os quais o do parâmetro $\alpha$ e o da carga lateral fictícia $(\mathrm{P}-\Delta)$. O método $(\mathrm{P}-\Delta)$ apresentou resultados próximos dos valores encontrados segundo a teoria da NLG, com diferenças de resultados da ordem de 4\%. Portanto, os resultados obtidos segundo o método $(\mathrm{P}-\Delta)$ foram próximos aos resultados obtidos com o coeficiente $\gamma_{\mathrm{z}}$. A vantagem da utilização do $\gamma_{\mathrm{z}}$ reside no fato do método de cálculo ser direto ao passo que no método (P- $\Delta)$ o processo de cálculo é iterativo. Para o exemplo numérico estudado a consideração simplificada da NLG por meio do coeficiente $\gamma_{\mathrm{z}}$ foi representativa quando comparado com a teoria não-aproximada da NLG. 
b) Os coeficientes redutores obtidos segundo o diagrama $\mathrm{M}$ x $\mathrm{N}$ x 1/r divergem das indicações normativas para consideração simplificada de NLF, principalmente sob efeito da fluência, força normal e armadura ativa. Os coeficientes redutores sofrem influência do nível de esforço normal, conseqüentemente variam de acordo com a combinação de ações utilizada. Os exemplos numéricos foram concebidos com diferentes seções de pilares, de acordo com o número de pavimentos e a modulação utilizada. Na Tabela 5.1 podem ser observados os intervalos de coeficientes redutores de rigidez obtidos para os pilares nos modelos analisados.

Tabela 5.1: Distribuição dos coeficientes redutores de rigidez dos pilares

\begin{tabular}{|c|c|c|c|}
\hline Modulação $(\mathrm{m})$ & Seção $(\mathrm{cm})$ & Carga acidental $\left(\mathrm{kN} / \mathrm{m}^{2}\right)$ & $\alpha$ \\
\hline 7,5 & $50 \times 50$ & 3 & $0,35-0,60$ \\
\hline 7,5 & $50 \times 50$ & 5 & $0,35-0,70$ \\
\hline 10,0 & $60 \times 60$ & 3 & $0,40-0,70$ \\
\hline 10,0 & $60 \times 60$ & 5 & $0,40-0,77$ \\
\hline 7,5 & $40 \times 40$ & $3 ; 5$ & $0,35-0,65$ \\
\hline 10,0 & $40 \times 40$ & $3 ; 5$ & $0,40-0,76$ \\
\hline
\end{tabular}

Segundo os estudos realizados, o aumento do nível de esforço normal incrementa a rigidez das seções, no entanto, a partir de um certo nível de esforço normal existe uma diminuição da rigidez da seção. No exemplo numérico avaliado obteve-se o valor de força normal adimensional de aproximadamente 0,9 , onde ocorreu uma inversão da tendência de incremento da rigidez.

c) A variação dos valores encontrados para os coeficientes redutores de rigidez nas vigas em concreto armado submetidos aos efeitos da fluência pelo coeficiente linear de 0 a 3 foi de 0,45 a 0,2 no combate ao momento positivo. No combate ao momento negativo os valores encontrados pertencem ao intervalo de 0,3 a 0,2. Nos elementos com armadura ativa os coeficientes redutores obtidos pertencem ao intervalo de 0,55 a 0,25 no combate ao momento positivo e ao momento negativo os valores encontrados pertencem ao intervalo de 0,25 a 0,1 .

d) A expressão de cálculo da rigidez equivalente indicada pela NBR 6118:2003 baseada na teoria de Branson apresentou resultados representativos quando comparado com os valores encontrados com o diagrama $\mathrm{M}$ x $\mathrm{N}$ x $1 / \mathrm{r}$ na análise de vigas com armadura 
passiva. Foi proposto um fator de correção igual a $C=1+\Phi / 3$, para análise contemplando a fluência.

e) A formulação e os indicadores prescritos nas normas nacionais a respeito da consideração simplificada da NLF são menos abrangentes que as formulações apresentadas em normas internacionais. As funções de redução de rigidez propostas no presente trabalho para o estudo de elementos em concreto pré-moldado são compostas, basicamente, pela contribuição de três parcelas: a armadura, o concreto e a força normal adimensional. A consideração da fluência pode ser introduzida pelo fator de correção $C=1+\Phi / 3$.

f) Foram comparados os resultados obtidos para representação na NLF segundo o diagrama $\mathrm{M} \times \mathrm{N}$ x 1/r e a rigidez secante, foi constatado que a modelagem das vigas com armadura passiva segundo a rigidez secante não provoca alterações significativas nos resultados. No entanto, a metodologia empregada ganha importância quando a análise envolve vigas com armadura ativa, havendo diferenças da ordem de $10 \%$ na distribuição de esforços obtida.

g) A influência do comportamento articulado, semi-rígido ou rígido ao momento fletor da ligação viga-pilar no valor do coeficiente redutor de rigidez dos elementos em concreto pré-moldado não foi representativa no exemplo numérico. Em estruturas compostas por ligações viga-pilar com comportamento articulado, o nível de esforço normal atuante nos pilares geralmente é baixo. Já em estruturas compostas por ligações viga-pilar com comportamento semi-rígido o nível de esforço normal atuante nos pilares, geralmente, é maior. Como pode ser visto no presente trabalho o aumento no nível de força normal adimensional nos elementos incrementa a rigidez dos mesmos. Portanto, a relação entre o comportamento da ligação viga-pilar com o coeficiente redutor de rigidez dos elementos é indireta. A influência da força normal, da taxa de armadura passiva e ativa, além dos efeitos reológicos do concreto preponderam na análise da rigidez.

h) Embora muitos projetistas de estruturas não levem em consideração o efeito do momento positivo nas ligações, as análises efetuadas nos exemplos numéricos comprovaram a importância de sua verificação e em alguns casos de adequação da ligação. 


\section{Considerações finais:}

No que se refere ao projeto de ligações semi-rígidas, o modelo proposto por EL DEBS et al (2009) para caracterização da ligação mostrou-se prático na resolução dos exemplos numéricos, uma vez que o modelo elasto-plástico é mais fácil de ser definido do que modelos tri-lineares.

A análise da estabilidade global da estrutura, dos elementos e ligações deve contemplar a envoltória dos esforços obtidos nas diferentes combinações de ações.

Existe a necessidade de compatibilização entre a rigidez das ligações e a rigidez dos elementos na estabilização da estrutura, portanto é necessário conhecer a rigidez de todos os componentes da estrutura para que seja efetuada uma análise representativa.

A consideração da não-linearidade física presente nas ligações semi-rígidas de comportamento assimétrico deve ser levada em conta na análise em virtude da influência nos resultados.

É de fundamental importância uma discretização adequada da estrutura via método dos elementos finitos em análise consistente da NLF e da NLG.

Não se pretende com o presente trabalho esgotar os estudos referentes à estabilidade global das estruturas em concreto pré-moldado de múltiplos pavimentos, os resultados obtidos na análise numérica podem servir como parâmetros de dimensionamento.

\section{Sugestões para trabalhos futuros:}

O escopo do trabalho abordou estruturas de múltiplos pavimentos, mais precisamente edifícios com 4, 5 e 6 pavimentos. Para que estruturas com um número maior de pavimentos pudessem ser analisadas numericamente, seria necessário avaliar o desempenho de sistemas de contraventamento alternativos ao de pórtico com ligações semi-rígidas. Sistemas de contraventamento em painéis, paredes ou núcleos de rigidez poderiam ser explorados tendo em vista o conceito de racionalização e industrialização das estruturas em concreto prémoldado.

Além de outros sistemas de contraventamento, as ligações de emenda de pilares poderiam ser investigadas quanto à rigidez, resistência e processo de execução.

As funções aproximadas que descrevem o comportamento da rigidez dos elementos segundo a presença da força normal, fluência, armadura passiva e armadura ativa poderiam 
ser exploradas em outros estudos tendo em vista a sua aplicabilidade. A criação de indicadores de projeto, principalmente no que se refere à rigidez dos elementos poderá auxiliar em uma melhor configuração da estrutura, além de estabelecer limites de utilização.

Os efeitos da interação solo-estrutura em edificações de múltiplos pavimentos em concreto pré-moldado poderiam ser investigados tendo em vista a criação de indicadores da mobilidade da estrutura.

Outros arranjos estruturais poderiam ser explorados em pesquisas futuras, principalmente estruturas de um e dois pavimentos com grandes dimensões em planta. Como por exemplo, estruturas destinadas para fins comerciais.

Por não possuirem altura elevada, estas estruturas normalmente apresentam deslocamentos pequenos frente aos esforços solicitantes. Em virtude da grande área destinada à ocupação em planta, a somatória da força normal atuante na estrutura assume valores significativos. Em geral o $\gamma_{z}$ calculado para estas estruturas assume valores altos para deslocamentos muito pequenos. Embora a NBR 6118:2003 limite a utilização do $\gamma_{z}$ a estruturas com mais de 4 pavimentos seria interessante a criação de um indicador de estabilidade ou magnitude dos esforços de segunda ordem destinados a este tipo de estrutura.

As situações transitórias que envolvem desmoldagem, transporte, armazenamento e montagem das estruturas em concreto pré-moldado poderiam ser investigadas quanto a sua influência na diminuição da rigidez dos elementos na situação final de utilização da estrutura. 



\section{REFERÊNCIAS BIBLIOGRÁFICAS}

AMERICAN CONCRETE INSTITUTE (2008). ACI 318-08: Building Code Requirements for Structural Concrete and Commentary. Farmington Hills

AMARAL, P.T. (2000). Análise dos efeitos de $\mathbf{2}^{\mathbf{a}}$ ordem em barras comprimidas de concreto armado. 98f. Dissertação (Mestrado) - Escola de Engenharia de São Carlos, Universidade de São Paulo, São Carlos, 2000.

ASSAN, A. E. (2003). Método dos elementos finitos: primeiros passos. Campinas: Editora da Unicamp.

ASSOCIAÇÃO BRASILEIRA DE NORMAS TÉCNICAS. NBR 9062 (2006). NBR 9062: Projeto e execução de estruturas de concreto pré-moldado. Rio de Janeiro. de Janeiro.

(1985). NBR 9062: Projeto e execução de estruturas de concreto pré-moldado. Rio . (2003). NBR 6118: Projeto de estruturas de concreto - Procedimento. Rio de $\overline{\text { Janeiro. }}$

. (1988). NBR 6123: Forças devidas ao vento em edificações. Rio de Janeiro. Janeiro.

(2003). NBR 8681: Ações e segurança nas estruturas - Procedimento. Rio de 
BALDISSERA, A. (2006). Estudo experimental de uma ligação viga-pilar de concreto pré-moldado resistente a momento fletor. 148f. Dissertação (Mestrado) - Escola de Engenharia de São Carlos, Universidade de São Paulo, São Carlos, 2006.

BARBOZA, A.S.R. (2002). Comportamento de juntas de argamassa solicitadas à compressão na ligação entre elementos pré-moldados. 154f. Tese (Doutorado) - Escola de Engenharia de São Carlos, Universidade de São Paulo, São Carlos, 2002.

BECK, H.; KONIG,G. (1966). Restraining forces in the analysis of tall buildings.In: SYMPOSIUM ON TALL BUILDINGS, WITH PARTICULAR REFERENCE TO SHEAR WALL STRUCTURES, 1., 1966, Southhampton. Proceedings... Oxford: Pergamon. P.513536.

BLJUGER, F. E. (1988). Design of precast concrete structures. Chichester, Ellis Horwood/New York, John Wiley. 279p

BRANSON, D.E. (1968). Procedures for computing deflections. ACI Journal, New York, v. 65 , n. 9 , p.730-742.

CAMADURO JUNIOR, I.S. (1997). Dimensionamento de pilares esbeltos de concreto armado com seção qualquer solicitados por flexão composta oblíqua. $123 \mathrm{f}$. Dissertação. (Mestrado) - Escola de Engenharia de São Carlos, Universidade de São Paulo, São Carlos, 1997.

CARMO, R. M. S. (1995). Efeitos de segunda ordem em edifícios usuais de concreto armado. 112f. Dissertação (Mestrado) - Escola de Engenharia de São Carlos, Universidade de São Paulo, São Carlos, 1995.

CARVALHO, R. C.; FIGUEIREDO, J. R. (2004). Cálculo e detalhamento de estruturas usuais de concreto armado. São Carlos. EdUFSCar.

CARVAlHO, R. C. (2005). Apostila do curso de concreto protendido da UFSCar. São Carlos: UFSCar. (Apostila).

CATOIA, B. (2007). Comportamento de vigas protendidas pré-moldadas com ligações semi-rígidas. 215f. Dissertação (Mestrado) - Universidade Federal de São Carlos, São Carlos, 2007.

CHAJES, A.; CHURCHILL, J.E. (1987). Nonlinear frame analysis by finite element methods. Journal of Structural Engineering, New York, v.113, n.6, p. 1221-1235.

CHAN. S.; GU. J. (2000). Exact tangent stiffness for imperfect beam-column members. Journal of Structural Engineering, New York, v.126, n.9, p. 1094-1102. 
CHANG, J. (2004). Derivation of the higher-order stiffness matrix of a space frame element. Finite Elements in analysis and Design, Amsterdam, v.41, n. 1, p. 15-30.

COMITEE EURO-INTERNACIONAL DU BETON (1993). CEB-FIP MODEL CODE 1990: design code. London: Telford.

COOK, R. D.; MALKUS, D.S.; PLESHA, M.E. (1989). Concepts and applications of finite element analysis. New York: Wiley. 3.ed.

CORREA, M. R. S. (1991). Aperfeiçoamento de modelos usualmente empregados no projeto de sistemas estruturais de edifícios. 342f. Tese (Doutorado) - Escola de Engenharia de São Carlos, Universidade de São Paulo, São Carlos, 1991.

EL DEBS, M. K. (2000). Concreto pré-moldado: fundamentos e aplicações. São Carlos, Editora da EESC-USP.

EL DEBS, M.K.; BALDISSERA, A. (2008). Estudo experimental de uma ligação viga-pilar de concreto pré-moldado parcialmente resistente a momento fletor. In: CONGRESSO NACIONAL DA PREFABRICAÇÃO EM BETÃO, 2., Lisboa, Portugal, Março, 2008. Proceedings... Lisboa, Portugal: ANIPB, 2008. p. 1-18. 1 CD-ROM.

EL DEBS, M.K.; MIOTTO, A.M.; EL DEBS, A.L.H.C. (2009). Analysis of a semi-rigid connection for precast concrete. Buildings \& Structures. [aceito para publicação]

ELliOTT, K.S. (1996). Multi-Storey Precast Concrete Framed Structures. Oxford: Cambridge: Blackwell Science.

ENGSTROM, B. (1992a). Combined effects of dowel action and friction in bolted connections. In: Workshop on semi-rigid behavior of civil engineering structural connections, 1., 1992, Strasbourg. Proceedings... Strasbourg, p.77-98.

ENGSTROM, B. (1992b). Anchorage of ribbed bars in the post yield stage. In: Workshop on semi-rigid behavior of civil engineering structural connections, 1., 1992, Strasbourg. Proceedings... Strasbourg, p.65-76.

FÉDÉRATION INTERNACIONALE DU BETON (1999). Structural concrete: textbook on behavour on design and performance update of the CEB/FIP model code 1990. Bulletin FIB. Lausanne, v.1-3.

FÉDÉRATION INTERNACIONALE DU BETON (2002). Design examples for FIP recommendations 'practical design of structural concrete', Bulletin FIB, Lausanne, v.16.

FÉDÉRATION INTERNACIONALE DU BETON (2008). Structural connections for precast concrete buildings, fib commission C6:Prefabrication. TG 6.2:Connections. 
FERREIRA, M.A. (1999). Deformabilidade de ligações viga-pilar de concreto prémoldado. 231f. Tese (Doutorado) - Escola de Engenharia de São Carlos, Universidade de São Paulo, São Carlos, 1999.

FRANÇA, R.L.S. (1991). Contribuição ao estudo dos efeitos de segunda ordem em pilares de concreto armado. 232f. Tese (Doutorado) - Escola Politécnica, Universidade de São Paulo, São Paulo, 1991.

FRANCO, M.; VASCONCELOS, A.C. (1991). Practical assessment of second order effects in tall buildings. In: Colloquium on the CEB-FIP MC 90. 1991, Rio de Janeiro. Proceedings... Rio de Janeiro: COPPE. p.307-323.

FUSCO, P.B. (1981). Estruturas de concreto: solicitações normais, estados limites, teoria e aplicações. Rio de Janeiro: Guanabara Dois.

GU, J.; CHAN, S. (2005). A refined finite element formulation for flexural and torsional buckling of beam-columns with finite rotations. Engineering Structures, Guildford, v.27, n.5, p. 749-759.

KATAOKA, M.N. (2007). Estudo da continuidade em ligações laje-viga-pilar em estruturas pré-moldadas de concreto. 134f. Dissertação (Mestrado) - Universidade Federal de São Carlos, São Carlos, 2007.

LEONHARDT. F. (1983). Construções de concreto: concreto protendido. Vol. 5. Rio de Janeiro: Interciência.

MACGREGOR, J.G. (1997). Reinforced concrete: mechanics and design. New Jersey: Prentice Hall

MIOTTO, A. M. (2002). Ligações viga-pilar de estruturas de concreto pré-moldado com ênfase ao estudo da deformação ao momento fletor. 263f. Tese (Doutorado) - Escola de Engenharia de São Carlos, Universidade de São Paulo, São Carlos, 2002.

MOTA, J. E. (2006). Contribuição ao projeto de estruturas de multi-piso reticuladas em concreto pré-moldado. São Carlos: EESC. Texto de Qualificação Doutorado.

OLIVEIRA, P.H.S. (2004). Processo aproximado para consideração da não-linearidade física de pilares em concreto armado. 208f. Dissertação (Mestrado) - Escola Politécnica, Universidade de São Paulo, São Paulo, 2004.

PAULA, J.A. (1988). Algoritmos para o estudo de pilares esbeltos de concreto armado solicitados a flexão normal composta. 201f. Dissertação (Mestrado) - Escola de Engenharia de São Carlos, Universidade de São Paulo, São Carlos, 1988. 
PINTO, R. S. (1997). Não-linearidade Física e Geométrica no Projeto de edifícios usuais de Concreto Armado. 201f. Dissertação (Mestrado) - Escola de Engenharia de São Carlos, Universidade de São Paulo, São Carlos, 1997.

PCI INDUSTRY HANDBOOK COMMITTEE (2004). PCI desing handbook: precast and prestressed concrete. 6 . ed. Chicago: PCI.

PCI CONNECTION DETAILS COMMITTEE (2008). PCI connections manual for precast and prestressed concrete construction. 1. ed. Chicago: PCI.

Recommended practice for the design of prestressed concrete columns and walls (1988). Journal of Presstressed Concrete Institute, Chicago, v.33, n. 4, p. 56-95.

REIS, A.; CAMOTIN, D. (2001). Estabilidade Estrutural. Lisboa: McGraw-Hill.

VENTURINI, W.S.; RODRIGUES, R. O. (1987). Dimensionamento de peças retangulares de concreto armado solicitadas a flexão reta. São Carlos: EESC-SET. (Apostila)

WALRAVEN, J.C.; STRAMAN, J. P. (1997). Gebouwen in Geprefabricerd Beton. Delft: Technishe Universiteit Delft.

WEN, R.K.; RAHIMZADEH, J. (1983). Nonlinear elastic frame analysis by finite element. Journal of Structural Engineering, New York, v.109, n.8, p. 1952-1971.

YANG, Y.; LEU, L. (1994). Non-linear stiffnesses in analysis of planar frames.Computer Methods in Applied Mechanics and Engineering, Amsterdam, v. 117, n. 3-4, p. 233-247. 



\section{APÊNDICE A - Influência da rigidez dos elementos adjacentes no comportamento da ligação}

A estrutura estudada está ilustrada na Figura A.1 e teve como referência geométrica de vão e altura a estrutura com módulo de $10 \mathrm{~m}$. São apresentados resultados de simulações numéricas onde a variação da relação entre a rigidez da viga e dos pilares provoca um mudança na distribuição dos esforços nas ligações.

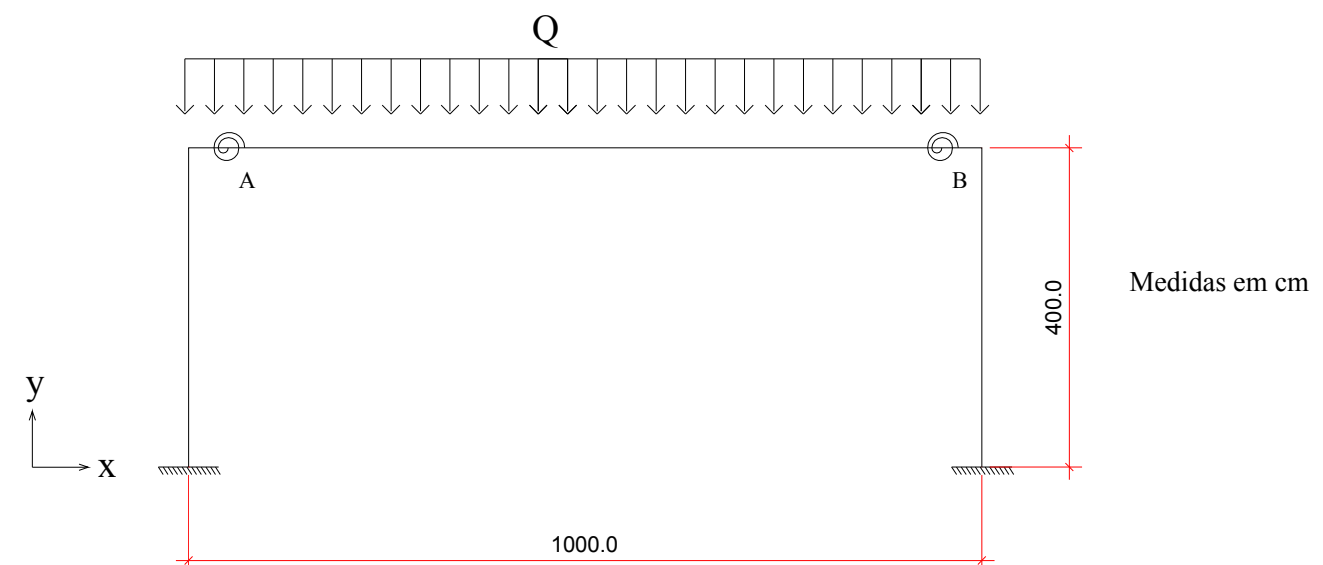

Figura A.1: Geometria, condição de vinculação e carregamento da estrutura

Segundo a convenção adotada, os valores positivos de momento provocam tração na fibra inferior e os valores de momento negativo provocam tração na fibra superior da seção da viga.

A Figura A.2 ilustra o modelo de ligação a ser estudado, as características de momento $\mathrm{x}$ rotação são as mesmas utilizadas na modelagem da ligação junto ao pilar central da estrutura com modulação de $10 \mathrm{~m}$. Note que a rigidez ao momento negativo é 19 vezes maior que a rigidez ao momento positivo. 


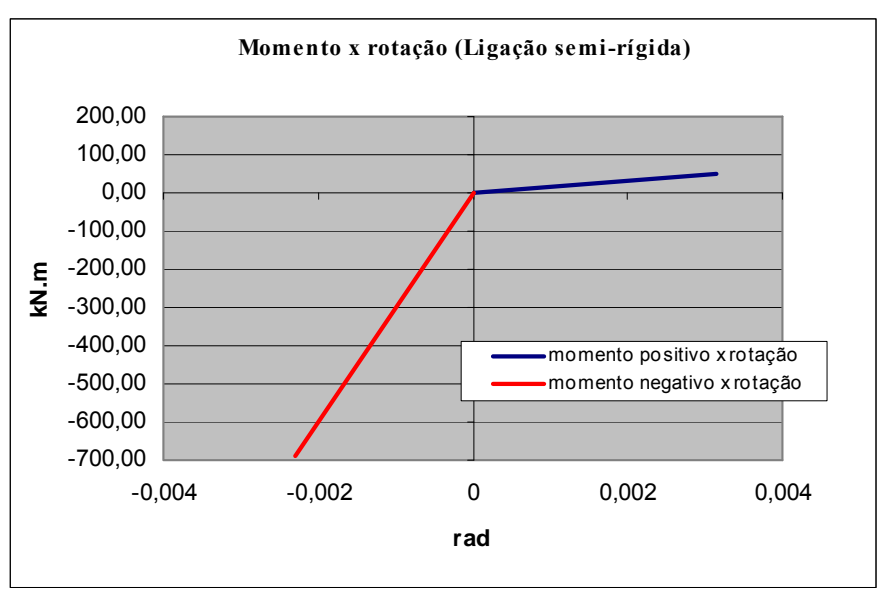

Figura A.2: Modelo de ligação semi-rígida assimétrica

A modelagem foi feita mantendo-se constante o carregamento $\mathrm{Q}=36,4 \mathrm{kN} / \mathrm{m}$, a rigidez da viga $\left(\mathrm{EI}_{\mathrm{viga}}\right)$ e a rigidez da ligação. Apenas a rigidez dos pilares foi alterada, desta forma após as simulações numéricas foi construída a Tabela A.1 que apresenta os momentos atuantes nas ligações segundo a variação da relação da rigidez das vigas pela rigidez dos pilares.

Tabela A.1: Distribuição de momento fletor na ligação segundo a rigidez dos elementos adjacentes

\begin{tabular}{|c|c|}
\hline $\mathrm{EI}_{\text {viga }} / \mathrm{EI}_{\text {pilares }}$ & $\mathrm{M}_{\mathrm{A}} ; \mathrm{M}_{\mathrm{B}}(\mathrm{kN} . \mathrm{m})$ \\
\hline 1 & $-119,85$ \\
\hline 2 & $-98,05$ \\
\hline 5 & $-53,66$ \\
\hline 10 & $-13,55$ \\
\hline 20 & $+7,80$ \\
\hline
\end{tabular}

De acordo com os resultados apresentados na Tabela A.1, quanto maior a relação entre a rigidez das vigas e dos pilares menor é o grau de engastamento das vigas nos pilares, a ponto desta elevada relação induzir ao surgimento de momento positivo na ligação.

Embora relações elevadas entre a rigidez de vigas e pilares não sejam tão comuns, existem situações práticas que podem causar o comportamento descrito. O comportamento pouco intuitivo apresentado pela ligação pode ser encontrado em estruturas com vãos de viga grandes o suficiente para exigir a utilização de armadura ativa. Além disto, associa-se a existência de estruturas com altura relativamente baixa frente ao vão da viga.

Desta forma, os pilares assumem dimensões menores comparativamente as dimensões das vigas, o que em parte define a relação entre a rigidez da viga e dos pilares. Outro aspecto importante a ser frisado refere-se ao fato da rigidez da ligação não contribuir de forma 
preponderante na distribuição dos esforços. Para efeito de projeto, neste caso, enrijecer os pilares da estrutura contribuiria para uma melhor distribuição dos esforços. 



\section{APÊNDICE B - Não-linearidade física presente em ligações semi-rígidas assimétricas}

No presente apêndice são apresentadas situações pouco intuitivas na distribuição de esforços atribuídas a existência de ligações semi-rígidas de comportamento assimétrico. A estrutura a ser estudada está ilustrada na Figura B.1 e teve como referência geométrica de vão e altura a estrutura com módulo de $10 \mathrm{~m}$. Os dados de carregamento são: Carregamento $\mathrm{Q}=36,4 \mathrm{kN} / \mathrm{m}$ e carga $\mathrm{P}^{*}$ variando segundo cada situação de carregamento. Os pilares foram modelados com rigidez (EI) e as vigas foram modeladas com rigidez (2.EI). A rigidez da ligação utilizada no modelo foi a mesma empregada na simulação feita no APÊNDICE A Influência da rigidez dos elementos adjacentes no comportamento da ligação.

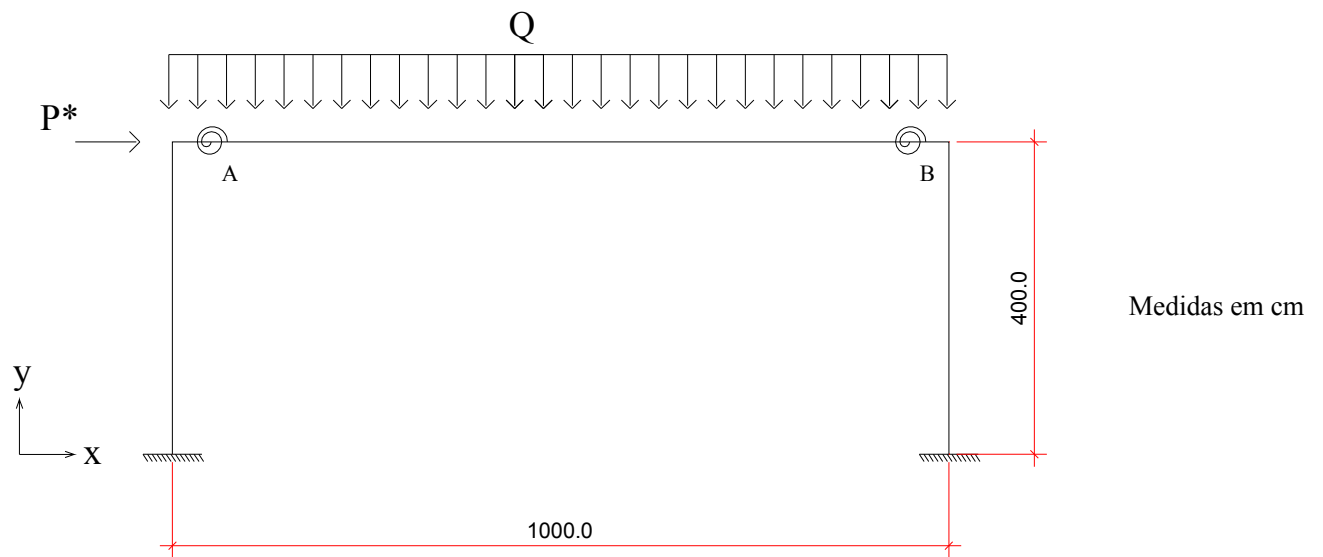

Figura B.1: Geometria, condição de vinculação e carregamento da estrutura

$\mathrm{Na}$ Tabela B.1 estão apresentadas as variações nos valores de momento nos pontos A e B segundo cada condição de carregamento, todas as situações de carregamento tiveram como referência variações da carga $\mathrm{P}^{*}$. Na primeira coluna de momento apenas a carga $\mathrm{Q}$ é 
aplicada, na segunda coluna apenas a carga $\mathrm{P}^{*}$ é aplicada e na terceira coluna a carga $\mathrm{Q}$ e $\mathrm{P}^{*}$ são aplicadas simultaneamente.

Tabela B.1: Distribuição de momento fletor nas ligações segundo carregamento atuante

\begin{tabular}{|c|c|c|c|c|c|c|}
\cline { 2 - 7 } \multicolumn{1}{c|}{} & \multicolumn{3}{c|}{$\mathrm{M}_{\mathrm{A}}(\mathrm{kN} . \mathrm{m})$} & \multicolumn{3}{c|}{$\mathrm{M}_{\mathrm{B}}(\mathrm{kN} . \mathrm{m})$} \\
\hline $\mathrm{P}^{*}(\mathrm{kN})$ & $\mathrm{Q}$ & $\mathrm{P}^{*}$ & $\mathrm{Q}^{+} \mathrm{P}^{*}$ & $\mathrm{Q}$ & $\mathrm{P}^{*}$ & $\mathrm{Q}^{+} \mathrm{P}^{*}$ \\
\hline 50,00 & $-98,05$ & 5,56 & $-66,64$ & $-98,05$ & $-35,97$ & $-128,76$ \\
\hline 100,00 & $-98,05$ & 11,11 & $-35,22$ & $-98,05$ & $-71,94$ & $-159,46$ \\
\hline 156,00 & $-98,05$ & 17,34 & $-0,04$ & $-98,05$ & $-112,22$ & $-193,84$ \\
\hline 200,00 & $-98,05$ & 22,23 & 4,88 & $-98,05$ & $-143,87$ & $-225,49$ \\
\hline 250,00 & $-98,05$ & 27,78 & 10,44 & $-98,05$ & $-179,84$ & $-261,46$ \\
\hline 300,00 & $-98,05$ & 33,34 & 16,00 & $-98,05$ & $-215,81$ & $-297,43$ \\
\hline
\end{tabular}

No ponto $\mathrm{A}$, a carga $\mathrm{Q}$ isolada mobiliza o momento negativo da ligação e a carga $\mathrm{P} *$ isolada mobiliza o momento positivo da ligação. Quando a estrutura é submetida a um carregamento simultâneo de $\mathrm{Q}$ e $\mathrm{P}^{*}$, não vale a superposição de efeitos das situações de carregamento isolado. A magnitude dos esforços apresentados para a situação de carregamento Q isolado é maior em comparação aos esforços apresentados para o carregamento $\mathrm{P}^{*}$ isolado. Analisando a Tabela B.1, observa-se que a partir da carga crítica $\mathrm{P} *$ o momento positivo prevalece na condição de carregamento simultâneo. Este comportamento é pouco intuitivo e é atribuído ao grau de não-linearidade da ligação semi-rígida assimétrica.

A carga crítica $\mathrm{P}^{*}$ associada à mudança na resposta da ligação é de, aproximadamente, $156 \mathrm{kN}$ conforme ilustra a Figura B.2 e apresenta a Tabela B.1.

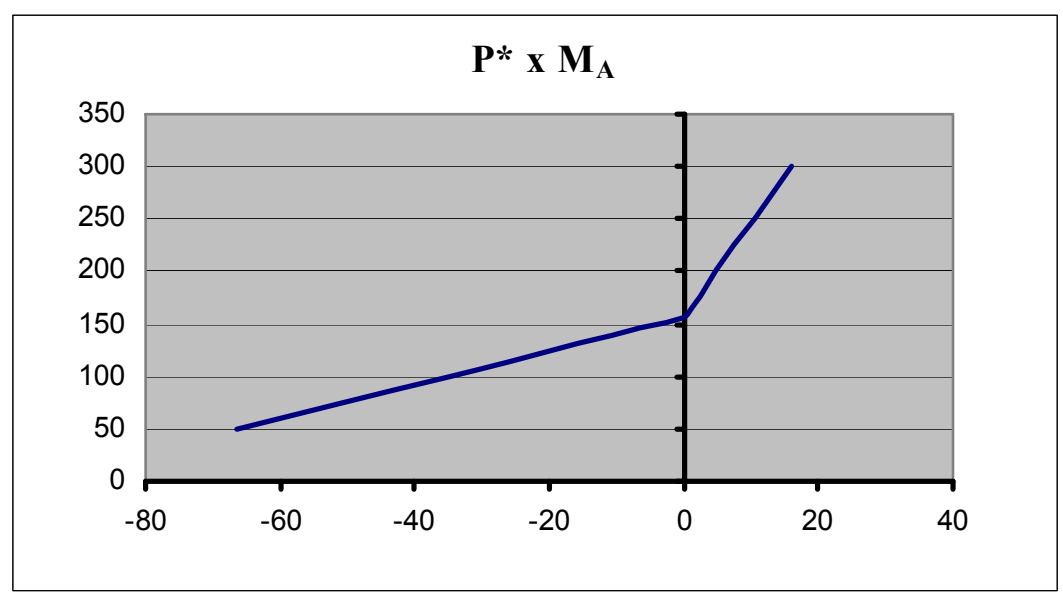

Figura B.2: Variação do momento fletor da ligação no ponto A 
A mudança da rigidez na ligação pode ser constatada construindo-se um gráfico de $\mathrm{P}^{*}$ versus o deslocamento nodal na direção x do nó de aplicação da carga $\mathrm{P}^{*}$, conforme ilustra a Figura B.3. Nota-se uma mudança no coeficiente angular da curva a partir do valor de $\mathrm{P}^{*}$ crítico.

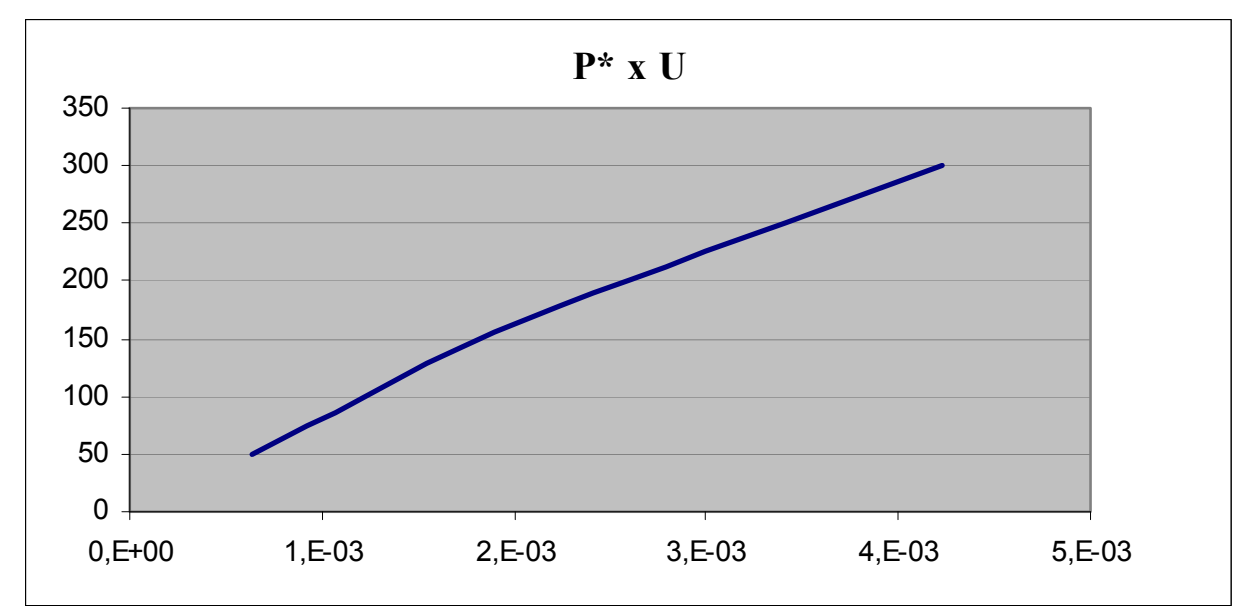

Figura B.3: Variação do deslocamento na direção x do nó de aplicação da carga $\mathrm{P}^{*}$

Na Tabela B.2 estão apresentados os deslocamentos nodais na direção x segundo a carga crítica $\mathrm{P}^{*}$.

Tabela B.2: Deslocamento na direção $\mathrm{x}$ do nó de aplicação da carga $\mathrm{P}^{*}$

\begin{tabular}{|c|c|}
\cline { 2 - 2 } \multicolumn{1}{c|}{} & $\mathrm{U}(\mathrm{m})$ \\
\hline 50 & $6,38 \mathrm{E}-04$ \\
\hline 100 & $1,23 \mathrm{E}-03$ \\
\hline 156 & $1,90 \mathrm{E}-03$ \\
\hline 200 & $2,61 \mathrm{E}-03$ \\
\hline 250 & $3,42 \mathrm{E}-03$ \\
\hline 300 & $4,23 \mathrm{E}-03$ \\
\hline
\end{tabular}





\section{APÊNDICE C - Estratégias de modelagem numérica das estruturas em concreto pré-moldado de múltiplos pavimentos}

Nos resultados apresentados a configuração final de esforços da estrutura foi obtida pela soma de efeitos decorrentes da situação em que as ligações não foram efetivadas, apresentando comportamento articulado e da situação em que as ligações após serem efetivadas apresentam comportamento semi-rígido.

$\mathrm{Na}$ situação em que as ligações apresentam comportamento semi-rígido foi considerada a somatória das cargas distribuídas provenientes do peso próprio da viga, da laje e da capa moldada in loco atuando de forma concentrada na ligação entre o consolo e o pilar.

Esta estratégia de modelagem foi motivada para que os efeitos NLG e NLF provocados pelo carregamento proveniente da primeira situação fossem contemplados na condição em que as ligações da estrutura apresentam comportamento semi-rígido.

Adotando uma estratégia diferente da primeira, foi realizada outra tentativa de representar a soma de efeitos da situação com ligação articulada e da situação com ligação semi-rígida. O sistema estrutural composto de viga em concreto pré-moldado solidarizada a capa moldada in loco da laje alveolar, onde ocorre à continuidade na ligação viga-pilar foi simulada no modelo por meio da criação de nós e de elementos adicionais de comprimento nulo no ponto de ligação entre o consolo e a viga pré-moldada. Estes elementos adicionais, que representam a ligação semi-rígida, foram desativados na primeira fase de processamento onde a ligação é considerada articulada para o carregamento proveniente do peso próprio das vigas, lajes e da capa, posteriormente os elementos de ligação criados foram ativados promovendo a continuidade da estrutura e desta forma foram somados a primeira análise os carregamentos de origem acidental e proveniente da vedação. 
A Figura C.1 ilustra o esquema de nós e elementos finitos criados, bem como os graus de liberdade associados aos mesmos. Nota-se que na primeira fase de processamento há compatibilização dos deslocamentos transversais e longitudinais, caracterizando a ligação articulada. Na segunda fase de processamento a ligação semi-rígida se faz presente pela presença de um elemento adicional de comprimento nulo onde os nós do elemento são compatibilizados segundo deslocamentos longitudinais, transversais e de rotação.

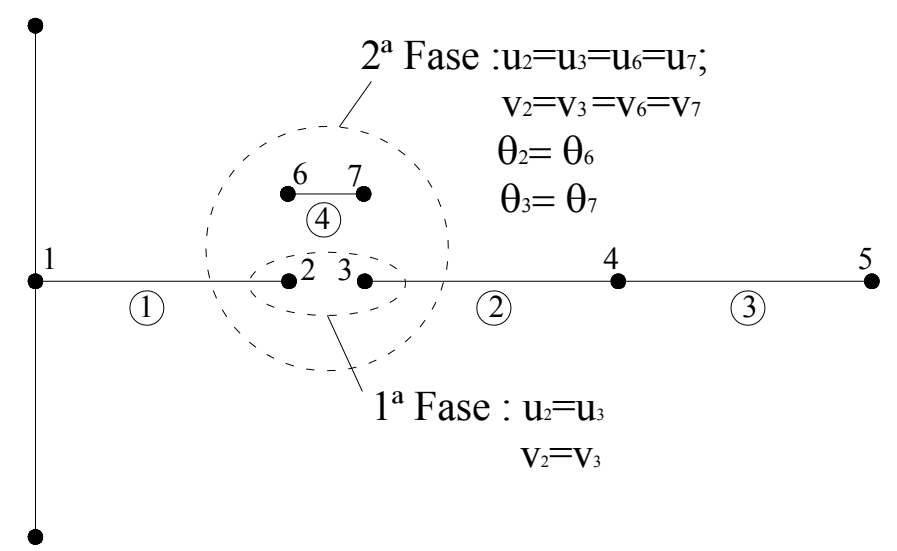

Figura C.1: Esquema de modelagem das fases de execução da estrutura em concreto pré-moldado

O recurso do ANSYS que permite que os elementos sejam ativados e desativados para uma determinada condição de processamento é o birth and death. Do ponto de vista matemático os elementos desativados não são excluídos da estrutura, pois estes elementos continuam tendo contribuição na matriz de rigidez da estrutura. No entanto o recurso birth and death permite que estes elementos quando desativados sejam multiplicados por coeficientes que diminuem de forma significativa a contribuição dos mesmos na matriz de rigidez. Em uma segunda fase de processamento quando os elementos são ativados estes coeficientes não são mais aplicados na matriz de rigidez. Atenção especial deve ser dada a magnitude do coeficiente utilizado, pois em alguns casos o coeficiente redutor especificado pode não ser suficiente para minimizar os efeitos da presença do elemento desativado. Após a realização de algumas simulações utilizando este recurso, notou-se que os elementos desativados ainda apresentavam uma contribuição significativa no modelo.

O único elemento finito de ligação que possui o recurso de ser desativado durante o processamento da estrutura é o elemento COMBIN14. No entanto este elemento finito possui a limitação de representar apenas comportamento simétrico da curva momento x rotação associado ao modelo elástico linear.

$\mathrm{Na}$ situação de modelagem ideal, o elemento de viga em seção não composta submetido ao peso próprio da laje e da capa moldada in loco apresenta um estado de 
deformação e tensão que deveria ser somado ao estado de tensão e deformação provocado pela ação da carga acidental na seção composta. Além disto, a mudança de configuração no estado de tensão do elemento em seção composta sob efeito da fluência deveria ser contemplada. As diferentes características de resistência e módulo de elasticidade do concreto que compõem a seção pré-moldada e a capa moldada in loco aumentam o grau de complexidade do estudo desta interação.

Outro ponto importante e de difícil análise refere-se à ponderação do efeito da fluência na análise da estabilidade global, dentre os fatores, podem ser citados o fato das ações serem majoradas, a história do carregamento da estrutura, a natureza das ações e o processo construtivo. 